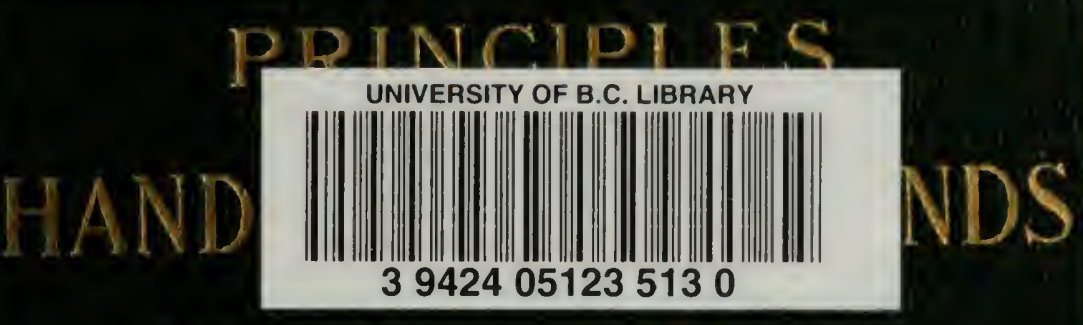

HENRY S. GRAVES

STCKAGE ITEA

PROCLES LNG-ONE

$L \neq 1-E 1 \geqslant D$ 


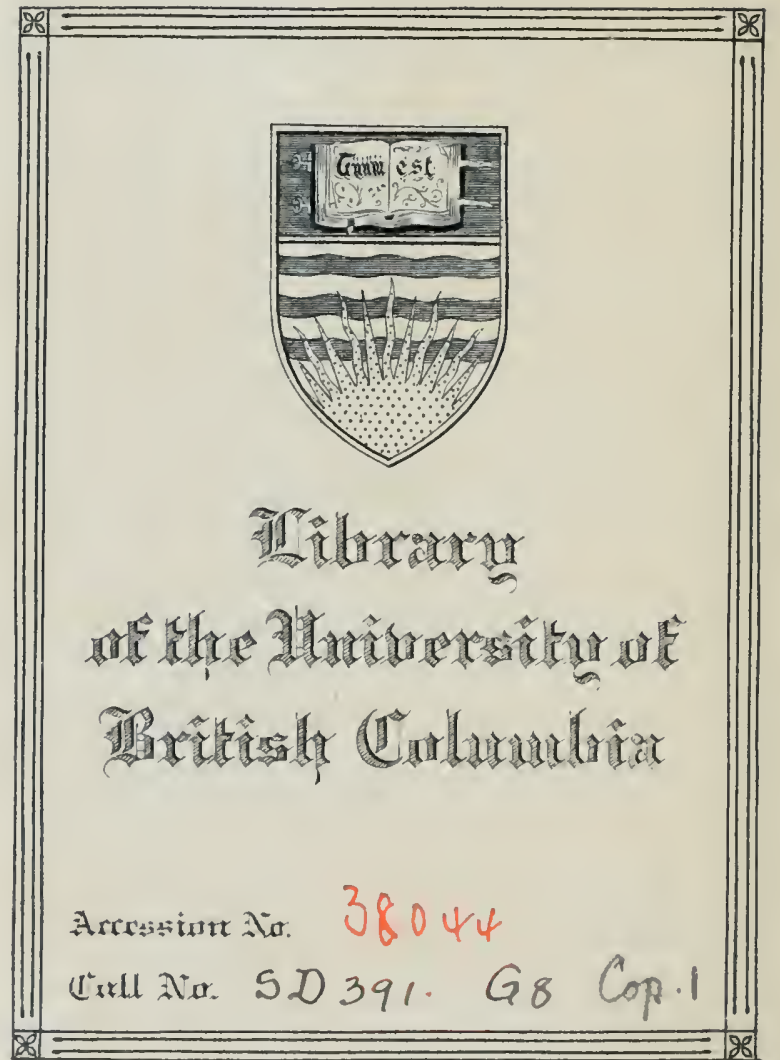





Digitized by the Internet Archive in 2010 with funding from University of British Columbia Library 


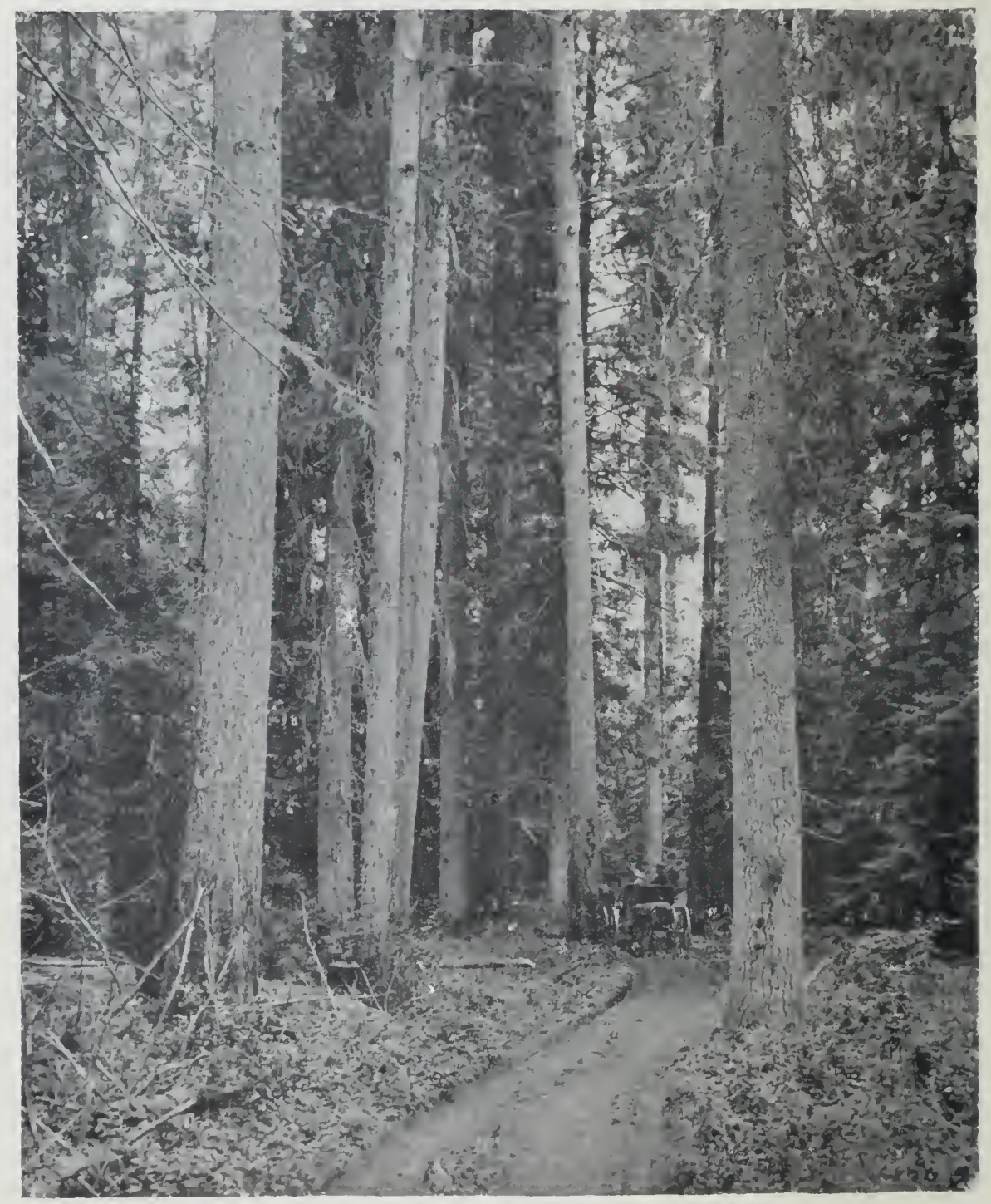

FIG. 1. - A Virgin Forest in Idaho. 


\section{THE PRINCIPLES}

\section{$\mathrm{OF}$ \\ HANDLING WOODLANDS}

BY

\section{HENRY SOLON GRAVES}

FORESTER, UNITED STATES DEPARTMENT OF AGRICULTURE

FIRST EDITION

FOURTH THOUSAND

NEW YORK:

JOHN WILEY \& SONS

London: CHAPMAN \& HALL, Limited

I 9 I 4 
COPYright, 1911, By HENRY SOLOON GRAVES

PRFSS (H THI PUBEISHEKS PRINTINC COMHANY, NEW YOKK, U.S. A. 
To My Father 



\section{PREFACE}

During the last few years there has been a rapid extension of the work of practical forestry in the United States. The Federal government has set aside as National Forests about 190 million acres, on which to-day all work is conducted under the principles of forestry. A number of States also have established reservations which have been placed under systematic forest administration. Forestry is being practised on a considerable number of private tracts, and there are many owners who are seeking information regarding forestry with a view of practising it if found to be commercially practicable.

The literature treating of forestry as applied in this country is still very meager. Much of it is fragmentary and scattered in various Government and State publications, and the information most desired by an owner or a forester is often not available. There is a great need of systematic works covering the different branches of forestry, for the use of owners of woodlands, for practising foresters, and students in the forest schools. As a contribution to this greatly needed literature of forestry, I have prepared the present volume covering the silvicultural treatment of woodlands. 
The book deals primarily with the principles of cutting mature stands of timber with a view to their replacement by new growth; cuttings in immature stands made for their improvement; and forest protection, with particular reference to forest fires. The book is not intended as a complete treatise on silviculture, but deals only with the treatment of woodlands. The methods of artificial seeding and planting are not included at all. This is an extensive subject in itself and is left to be handled by another author.

I have endeavored to present the subject primarily from the standpoint of conditions as they obtain to-day. The book is designed to serve a present purpose. In most parts of the country the methods of forestry first used are necessarily primitive in their application. We are using to-day methods in vogue in Europe many years ago, when market conditions were similar to those now common in this country. With the increasing value of timber and larger returns from forestry, better and more intensive methods will be used. In the long run the application of forestry in this country will resemble very closely that in Europe, with such modifications as are required by the peculiar characteristics of our species and our climate. I have laid special emphasis on some of the more primitive methods of forestry because these are often the only methods which can be applied under conditions of poor markets and difficult logging. Thus a prominent place is given to the selection system in its first application to virgin forests; some of the clear-cut- 
ting systems, which will necessarily later be replaced by better methods, are described in considerable detail; and more space is given to the primitive application of the shelterwood system than to its fully developed practise in Europe. A number of the European modifications of the various silvicultural systems have not been mentioned at all, as they would have at present only a very limited application in this country.

So far as possible I have endeavored to use such technical terms as have been already established. The terminology has been made to conform in most instances to that given by Mr. O. W. Price in Bulletin No. 61, U. S. Forest Service. There has, however, been some deviation from that list, and several new terms have been used where those in common usage seemed inadequate.

I am indebted to the Forest Service for the majority of photographs used in the book.

Henry Solon Graves. 



\section{CONTENTS}

Chapter I.-Introduction . . . . . . 1

The American forest . . . . . . . . 1

The march of forest destruction . . . . 2

Damage by fire . $\quad . \quad$. $\quad . \quad$. 3

Damage by insects . . . . . 3

Reduction of supplies . . . . . . 3

Unregulated cutting . . . . . 5

Disturbance of stream flow . . . . 5

Definition of forestry . . . . . . . 6

Definition of silviculture . . . . 7

Objects of silviculture $\quad . \quad$. $\quad . \quad$. 8

Quick reproduction .

Desirable species . . . . . . . 9

A full stand . . . . . . . 10

A valuable product $. \quad . \quad . \quad . \quad . \quad 10$

Rapid growth $\quad . \quad$. $\quad . \quad$. $\quad . \quad$. 12

Measure of production . $\quad$. $\quad$. 12

Purpose of the owner . . . . . 15

Objects of public forests . . 15

Objects of private forests . . . . 18

The cost of silviculture . . . . . . 18

Financial returns from forestry . . . . 19

Returns from public forests . . . 20

Problem of private owners . . . . 20

Profits of planting . . . . . 21

Investments in immature forests . . . 22 
Investments in natural reproduction . . 24

P'rogress of private forestry . . . . 25

Reproduction cuttings . . . . . . . 27

Classification of the trees in a forest . . . $\quad 27$

Age-class . . . . . . . 28

Size-class . . . . . . . . . 28

Crown-class . . . . . . . 28

The stand . . . . . . . 30

Origin of stands . . . . . . $\quad 30$

Form of the stand . . . . 30

The silvicultural systems . . . . . 32

Classification of silvicultural systems . . . 35

Systems depending on reproduction by seed . . 35

Systems depending on reproduction wholly or partly

from sprouts (coppice) . . . . . . . 38

Combination of silvicultural systems . . . . $\quad 38$

Application of silvicultural systems . . . 39

Choice of species . . . . . . . . 40 40

Pure and mixed stands contrasted . . . . 42

Chapter 11.-The Sflection System . . . 4 t

Origin of the selection system . . . . . 44

Theory of the selection system . . . . . 45

Principles of limiting the cut . . . . 48

'The diameter limit . . . . . . 53

Application of a diameter limit . . . 56

Marking . . . . . . 57

Defects of a rigid diameter limit . . . . 60

Provision for reproduction . . . . 62

Protection from windfall . . . . 64

Cutting small trees for improvement . . . 64

Influence of market conditions . . . . 65 
Cost of the system . . . . . . . . 67

Increased cost of logrging . . . . 67

Cost of protecting young growth . . . 68

Increased cost of construction work . . 68

Value of seed-trees . . . . . 69

Cost of improvement work . . . . 69

Intensive development of the selection system . . 69

Results of the selection system . . . . 71

Choice of the selection system . . . . 72

Example in the spruce forests of the Northeast . 74

Chapter III.-Systems of Clear-Cutting . . 83

Definition of clear-cutting . . . . $\quad 83$

Conditions requiring clear-cutting . . . 83

Disadvantages of a clear-cutting . . . . 86

Methods of reproduction . . . . . 87

Advantages of artificial reproduction . . 88

Advantages of natural reproduction . . 88

Clear-cutting with artificial reproduction . . 89

Use of the system in this country . . . 90

Use in Nationai forests . . . . $\quad 90$

Use in State forests . . . . . . . 93

Use in private forests . . . . . . 95

Clear-cutting the whole stand . . 96

Clear-cutting in strips . . . . . . 9 97

Clear-cutting in patches . . . . . 97

Clear-cutting with natural reproduction . . . 98

Conditions of success . . . . . . 9 98

Influence of market conditions . . . 100

Clear-cutting the whole stand . . . 101

Reserving blocks of trees . . . . 10.3

Reserving scattered seed-trees . . 107 
Reserving groups of seed-trees . . . 116

Reserving thrifty standards . . . . . 118

Clear-cutting in two or more operations. . 121

Alternate cleared strips . . . . . . 123

Irregular cleared strips . . . . . . 128

Progressive cleared strips _ . . . . 132

Use in this country . . . . . 134

Clear-cutting in patches . . . . 135

Chapter IV.-The Shelterwood System . . 137

Underlying principles of the shelterwood system . 137

Advantages of the system . . . . 137

Disadvantages of the system . . . . 140

Variation in application . . . . 140

Primitive application of the system . . . $1+1$

Application in the longleaf pine forests . . 142

The first or seed-cutting . . . . 144

The second cutting . . . . . 145

Results . . . . . . . 146

Application in the Black Hills . . . . 147

The first cutting . . . . . 149

The second cutting . . . . 150

Progress in the development of the shelterwood

system . . . . . . . 150

Intensive application of the shelterwood system . 152

Shelterwood system with uniform cuttings . . 153

The preparatory cuttings . . . . 153

The seed-cutting . . . . . . 150

The removal cuttings . . . . . 161

Shelterwood cuttings in strips . . . . 162

Shelterwood cuttings in groups . . . . . 164

The two-storied system . . . . . . 160 
Chapter I'- The Coppice: Systems.

Simple coppice . $\quad . \quad$. $\quad$. $\quad$. 170

Age of cutting . $\quad . \quad$. $\quad$. 172

Season of cutting . . . . . . . 17.3

Care in cutting . . . . . . . 173

The cutting . . . . . . . 174

Maintenance of density $\quad$. $\quad . \quad$. 174

Arrangement of cutting . . . . 175

Holding over reserves . • . . . • 177

Pole-wood coppice . . . . . . . 178

Use in the hardwood region of the East . . 179

The reproduction cuttings . . . . . 181

The second cutting . . . . . . 184

Coppice with standards $\quad . \quad$. . . . 184

Chapter I'I.-Impronement of the Forest • . 189

Improvement cuttings . . . . . . 189

Cleanings . . . . . . . . . 190

Liberation cuttings . . . . . . 194

Thinnings . . . . . . . 196

Need of thinnings $\quad . \quad$. $\quad . \quad$. $\quad$. 198

Results of thinnings . . . . . 200

Theory of thinnings . . . . . 201

Principles governing the severity of thinnings . 202

Time of first thinning . . . . . 204

Repetition of thinnings. . . . . 208

Application in Europe . . . . . 208

The French method . . . . 210

Practical application of thinnings in this

country . . . . . 212

Accretion cuttings . . . . . 210

Improvement work in irregular stands . . . 219 
Improvement work in selection forests . . . 220

1) amage cuttings . . . . . . . . . 221

Pruning . . . . . . . . 223

Chapter Vil.-Protection of Forests from Fire . 225

Character of forest fires . . . 226

Surface fires . $\quad$. . . . . . 226

Inflammable material . . . . . . . 227

Topography . • . • . • . 229

Character of the soil • . . . . . 230

Condition of the atmosphere . . . . . 230

Rapidity of surface fires . . . . . . 230

Grass fires . . . . . . . . 231

Brush fires . . . . . . . . 231

Ground fires . . . . . . . . 232

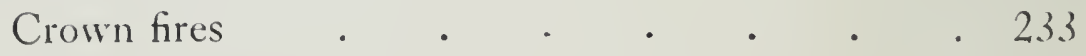

Damage by fires . . . . . . . 235

Death of standing trees. . . . . 235

Injury to trees . . . . . . . . 238

Injury to the soil . . . . . . 240

Reduction of density . . . . . . 241

Influence on reproduction . . . . 242

The prevention of fires . . . . . 244

Elimination of the causes of fires . . . 245

Organization of the forest . . . . 246

Disposal of slash . . . . . . 247

Disposal of brush and débris . . . 249

Piling and burning brush as logging proceeds 249

Piling and burning brush in separate operations 251

lopping the tops . . . . 260 
Broadcast burning

Annual or periodic burning of litter . . 265

Fire-lines . . . . . . 267

Roads . . . . . . . . . 268

Trails . . . . . . 270

Special fire-lines . . . . . 271

Location of fire-lines . . . . 281

Artificial fire obstructions . . . . 284

Supervision and patrol . . . . . 284

Aids to supervision and patrol . . . 285

Supervision of small tracts . . . . . 290

Supervision of large tracts . . . . . 291

Patrol along railroads . . . . . 294

The methods of fighting fires . . . . 297

Quick access to fires . . . . . 297

An adequate force of fighters . . . . 297

Proper equipment for fighting fires . . 299

Organization of the fighting crew . . . 300

Methods of fighting surface fires . . . . 301

Methods of fighting ground fires . . . 305

Methods of fighting crown fires . . . 305

Back-firing . . . . . 306

Patrol after a fire is extinguished . . . 308

Chapter VIII. - Protection from Other Injurious Agencies

Protection from Insects $\quad$. $\quad$. $\quad$. $\quad$. 309

Death of trees . $\quad . \quad . \quad . \quad . \quad 310$

Injury to trees . $\quad$. $\quad$. . 312

Injury to reproduction . . . . . . 314

Control of insects $\quad . \quad$. $\quad . \quad$. $\quad . \quad 314$

Protection from fungous diseases . . . . 318

Protection against other agrencies . . . . 319 



\section{LIST OF ILLUSTRATIONS}

FIG.

1. A Virgin Forest in Idaho............. Frontispiece

2. In the California Redwoods..............

3. The Devastating Effect of a Forest Fire in Minnesota ........................ 11

4. A Forest Destroyed by fire in the Cascade Mountains of Washington.............. 16

5. A Virgin Forest of Douglas Fir, Cedar, and Hemlock in Oregon.................. 23

6. A Forest of American White Pine in Germany..... 26

7. Natural Arrangement of Crown Classes in an Evenaged Stand... . . . . . . . . . . . . . 29

8. A Selection Stand. Spruce in the Mountains of Aus-

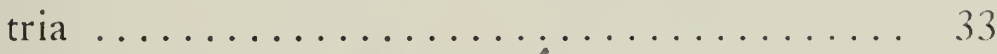

9. An Even-aged Stand. Mature Beech in Germany.. 33

10. Profile of an Ideal Selection Stand Before First Cutting ................... +6

11. Profile of an Ideal Selection Stand Twenty Years after Cutting................. +6

12. Trees Designated for Cutting under the Selection System. Engelmann Spruce, Arapahoe National Forest, Colorado ................ 51

13. After a Selection Cutting. Logs not yet Remored or Slash Disposed of. Missoula National Forest, Montana .................. 55

14. Marking Axe...................... 58

15. A Stand of Engelmann Spruce after a Selection Cutting. Arapahoe National Forest, Colorado.... 66 xvii 
FIG.

16. A Group of Balsam lirs Marked for Cutting in a Selection Forest. 'Their Removal will Favor the More Valuable Spruce. Arapahoe National Forest, Colorado.................. 66

17. Trees Designated for Cutting under the Selection System. Arapahoe National Forest, Colorado.. 73

18. A Stand in the Adirondacks in which there has been a Selection Cutting .............. 76

19. A Stand of Douglas Fir and Cedar of Great Size and Age. A System of Clear-Cutting is Required. Washington.................... 84

20. A Heavy Douglas Fir Stand in Washington, Calling for One of the Systems of Clear-Cutting.....

21. A Dense Stand of Tall Lodgepole Pines, Calling for some System of Clear-Cutting on Account of the

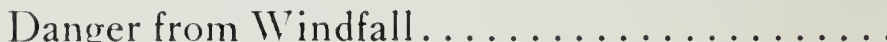

22. Application of a System of Clear-Cutting with Large Blocks of Timber Reserved for Seed. A Quarter Section in the Kaniksu National Forest, Idaho. .

23. Thrifty Standards Reserved to Grow through a Second Rotation. Scotch Pine in Europe........ 109

24. Reserving Scattered Trees to Distribute Seed after Lumbering. Minnesota National Forest..... 109

25. Groups of Trees left to Distribute Seed over Clearings. Lodgepole Pine. Deer Lodge National Forest, Montana .................. 117

26. A Stand of Western Yellow Pine, with Scattered Old Trees, Showing the Results which May be Obtained by Reserving the Thrifty Standards for Growth through a Second Rotation. Black Hills, South Dakota................. 122 
27. Clear Cutting as Applied in a Scotch Pine Forest in Germany. The Clearing will be Restocked by Planting. . . . . . . . . . . . . . . . 1.30

28. Clear-Cutting in Strips as Applied in Lodgepole Pine.

Deer Lodge National Forest, Montana...... . 130

29. Cutting Series................... 133

30. Reproduction of a Stand by the Shelterwood System.

The Sheltering Trees will be Removed in the

Next Ten Years, Black Forest, Germany......

31. Primitive Application of the Shelterwood System, after the First Cutting. Lodgepole Pine. Big Horn National Forest, Wyoming..........

32. After a Cutting under the Shelterwood System. Western Yellow Pine. South Dakota....... 148

33. Just Before the Removal of the Last Trees under the Shelterwood System. Young Growth has been Secured over the Whole Area. Austria...... 160

34. After the First Work in an Open Irregular Stand. The Cuttings Followed the Principles of the Shelterwood System. Western Yellow Pine. Black Hills National Forest, South Dakota.... 160

35. The First Cutting in an Irregular Open Stand of Western Yellow Pine. In Places it is Necessary to Make Small Clearings; Elsewhere the Shelterwood System is Followed.......... 167

36. Simple Coppice on a very Short Rotation, Illustrated by Willow Culture................ 171

37. 1)istribution of Annual Cutting Areas in a fiorest Managed under the Simple Coppice System on a Rotation of Twenty Years. A Communal liorest in Northern Germany. ......... 176 
FIG.

38. A Stand of Hardwoods, Composed of Trees of Sprout and Seedling Origin, after the First Cutting under the Polewood Coppice System. Southern New York ..................... 180

39. Coppice with Standards. Germany ........... 185

40. Another Example of Coppice with Standards. Germany ....................... 185

41. Inferior Trees which Should be Removed from over a Stand of Young Trees. A Liberation Cutting ...................... 192

42. A Spreading Tree which Should be Cut for the Benefit of the Younger Surrounding Trees. A Liberation Cutting. . . . . . . . . . . . 192

43. A Stand of Loblolly Pine after a Thinning. Maryland ........................ 197

44. A Stand of White Pine after a Thinning. New Hampshire . . . . . . . . . . . . . . . . 205

45. A Stand of Hardwoods after a Thinning. Massachusetts ........................ 213

46. A Thinning in Progress in a Shortleaf Pine Stand. Biltmore, North Carolina... . . . . . . . . 222

47. Example of a Damage-Cutting. Trees Removed Because Infected by Insects. Black Hills $\mathrm{Na}$ tional liorest, South Dakota........... 222

48. A lire Eurning in the Rocky Mountains......... 228

4?. A Surface Fire in a Longleaf Pine Forest in the South....................... 228

50. Brush Piled and Ready for Burning. Missoula National Forest, Montana.............. 248

51. Good Work in Piling Brush. Coconino National Forest, Arizona .................. 254 
FIG.

52. A Farorable Condition for Burning Piled Brush. Missoula National fiorest, Montana.... . . . . 259

53. A Spruce 'Top Improperly Lopped............ 263

54. The Same Spruce Top Properly Lopped.......... 263

55. A Well-Developed System of Roads and Trails, Used for Transportation and Fire Protection. Black

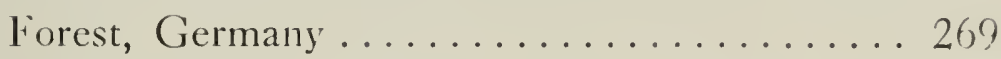

56. A Plowed lurrow that Stopped a Surface Fire.... . 274

57. A Fully Cleared Fire-Line in the San Gabriel Mountains, California.................... 274

58. A Fire-Line in the Chaparral. Angeles National Forest, California ............... 279

59. A Mountain Trail Built for Fire Patrol. Angeles National Forest, California ........... 283

60. Location of Fire-Lines in the Angeles National Forest, California................. 283

61. A Lookout Station. Cabinet National Forest, Montana ......................... 287

62. A Watch Tower in the Tusayan National Forest, Arizona... . . . . . . . . . . . . . . . . . 295

63. Fighting a Ground Fire by Trenching ......... $30 t$ 



\title{
THE PRINCIPLES OF HANDLING WOODLANDS
}

\author{
CHAPTER I \\ INTRODUCTION
}

\section{The American Forest}

A $\mathrm{T}$ the time of the first settlement of America the forests were unexcelled anywhere in the world. They stretched practically unbroken from the Atlantic Ocean half across the continent to about the ninetieth meridian. They covered a large portion of the Rocky Mountains and a broad strip on the Pacific coast. In the aggregate these forests comprised about 850,000,000 acres.

The original forests of this country were remarkable not only for their vast extent, but also for the great num. ber of valuable species composing them. The richness of our forest flora is due in part to the fact that the country includes several climatic zones, in part also to the fact that the climate and physiography have favored the development and continuance of tree life.

Another characteristic of the original forests in this country was the enormous yield in valuable material. The greater part of the country is comprised within the temperate zone, whose climate favors rapid growth and 
large development of trees. The original forest contained trees of great age and enormous size. Nature, working through centuries, had provided a vast storehouse of timber, fully grown and ready for use when required. It is on this supply that the American people have been drawing for four centuries. It has constituted a source of great wealth, and has been an important element in the internal development of the country and in the extension of its commerce.

\section{The March of Forest Destruction}

When the country was first settled, the effort was to clear the land for agriculture. With the increase of population there naturally arose a demand for forest products, and the timber was cut for use, and not merely destroyed. The first iumbering for use took only the choicest trees in the forest. 'Timber was so plentiful that the ordinary grades had no value. The selection of a tree here and there had little effect on the forest. In fact, the cutting was beneficial, for it removed the mature trees, and the openings which were made induced new growth, and thereby increased the increment of the forest. As the demand for timber increased for export and for local consumption, and the supply of the best grades became more remote, the forests near the settlements were cut over a second time; and this process went on until the modern systems of lumbering were introduced, which make very heavy inroads into the forests, in some cases removing practicallv every tree. 
Damage by Fire.- It was soon after lumbering for use began that forest fires became a common occurrence, and these increased in number and severity, burning over the majority of lumbered lands, and usually at the same time enormous areas which had not been cut, and destroying millions of dollars worth of timber. It is estimated that since 1870 an average of 50,000,000 acres has been burned and a damage of fully $\$ 50,000,000$ done each year, aside from the injury to young trees and to reproduction.

Damage by Insects.-The American forests have suffered, further, incalculable injury by insects. In some instances whole forests have been killed by bark-beetles. Sometimes the damage attributed to fire has been in the first instance due to beetles; and the dead trees and débris were later consumed, or practically consumed, by fire. In the Black Hills of South Dakota and Wyoming there has been a damage from beetles of $\$ 2,500,000$ within a decade.

Reduction of Supplies.-Taking together the various causes of destruction of forests, such inroads have been made into our resources that a conservative estimate shows that the bulk of our virgin supplies will be exhausted in less than a generation. The supply of forest products will then come entirely from what is now classed as second growth.

Heretofore, the only idea in the minds of the American people has been to utilize the great store of timber which they found already at hand. The Government and 


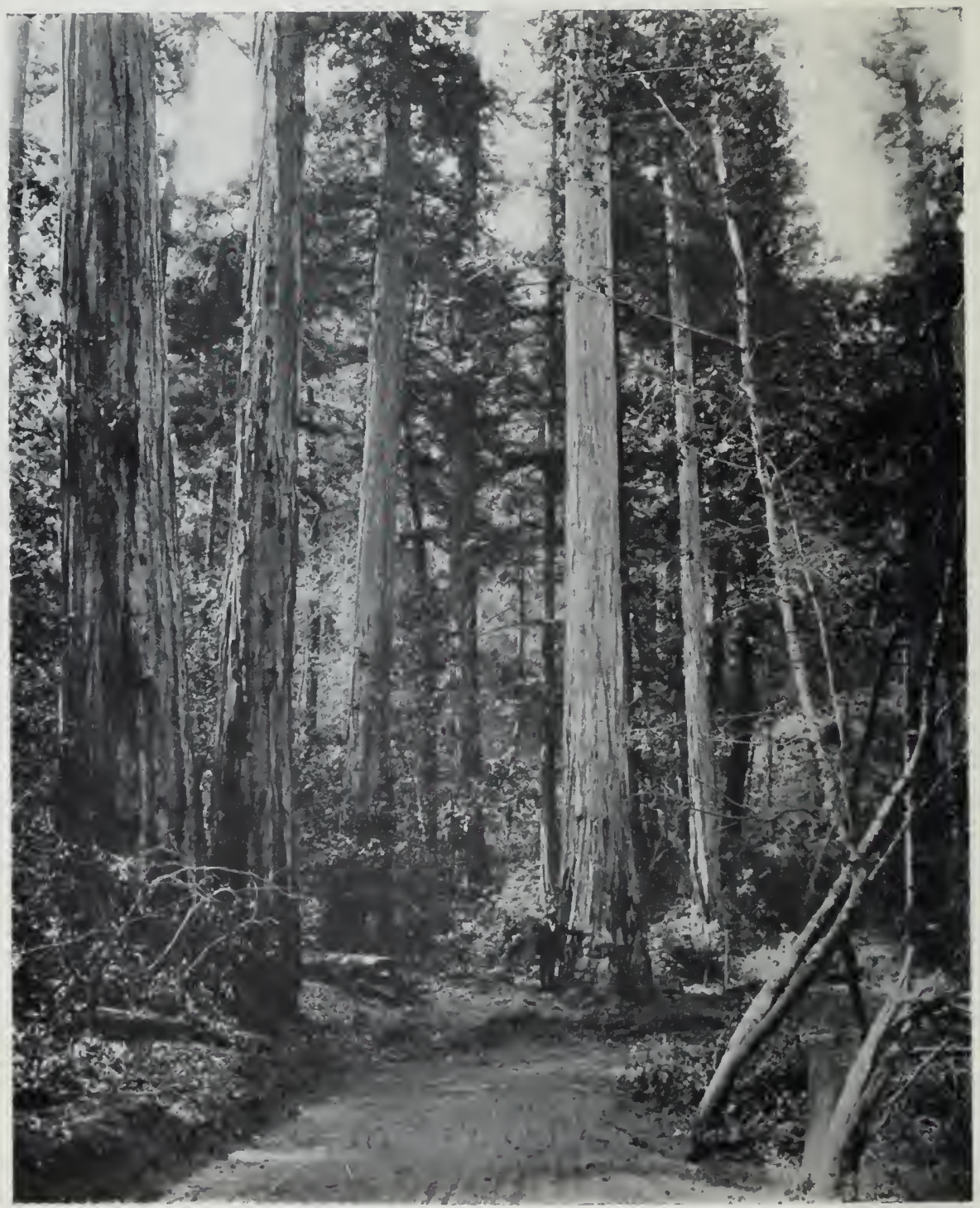

Fig. 2. - In the California Redwoods. 
States disposed of their lands as rapidly as possible to private owners and for private exploitation. Private owners, in handling their forest lands, had no other idea than to cut the accumulated stock without any regard whatever for future growth. While a few far-sighted lumbermen in Maine, and in some other sections, began 30 or 40 years ago to restrict their cuttings to the oldest timber, and to reserve the intermediate and young growth, and while a few individuals planted trees and otherwise practised forestry in a small way, it is only within a decade that there has been any wide-spread conception of the management of timberlands on a large scale with a view to perpetuating the forest.

Unregulated Cutting.-Ordinary lumbering, even when not accompanied by fire, results in a steady deterioration of the forest. The best individuals are taken out and the crooked and defective trees, which the lumbermen do not want, are left. In mixed forests, the poorer species are usually left, and these seed up the ground. 'The soil is often exposed, trees are blown over, and at best the production is very much lowered. So great has been the damage to our forests that the anmual growth upon them is less than one-third of what is actually used by the country. 'To meet the future demands of the country, with the ever-increasing population, waste and destruction must be stopped and the productive growth of the forests increased from 300 to 400 per cent.

Disturbance of Stream Flow.-One of the most serious effects of destructive lumbering, followed by fires, 
has been the disturbance of stream flow and the erosion of the soil. Forest destruction has already caused a damage of many millions of dollars, by silting up navigable rivers and reservoirs, by causing an increase of spring floods and a deficiency of water in the summer, by deposits of rocks, gravel, and sand on agricultural land, by the drying up of the sources of water used for irrigation and for domestic purposes, etc. This damage in the aggregate is so large as to constitute one of the principal causes of the present demand for forestry.

If the United States is to have an adequate supply of timber in the future, and if the headwaters of the rivers are to be properly protected, the practise of forestry is required not only on the public forests, but also on lands now in the hands of private owners.

\section{Definition of Forestry}

The underlying idea of forestry is continuity of use. Forestry aims to utilize the present product of the forest with the greatest possible economy, and with profit to the owner, and at the same time to provide for the continuance of the forest, and for the production of timber and other forest products in the future.

Heretofore, lumbering has been the exploitation of a ripe crop of timber, with no intentional provision for the future use of the land for forest growth. The forester regards a forest as a property capable of yielding repeated crops of timber. When a merchantable crop is cut, the forester aims to replace it by a new growth, to protect the 
young, middle-aged, and merchantable trees, which by the old methods would often be destroyed, and to secure from the forest the highest possible yield in the long run.

The highest possible utilization of the present product requires only the application of ordinary modern business principles. Forest production requires of the manager not only practical business capacity but also knowledge of the life and characteristics of the trees and forests, and the methods of carrying out the objects of forestry in a practical way. The forester, therefore, must be a man trained and experienced both in modern lumbering and also in the art of forest production, which, in technical language, is called silviculture.

\section{Definition of Silviculture}

Silviculture is the art of establishing, developing, and reproducing forests. It comprises:

1. The establishment of forest stands, by natural reproduction or by artificial seeding or planting.

2. The improvement of woodlands, including thinnings for the betterment of their composition and the enhancement of the quality and growth of the trees, pruning, and all other work of improvement.

The protection of woodlands from fire, insects, and other damage is not always dealt with in books on silviculture. The need of protection is so urgent in this country, however, and the successful handling of woodlands depends so much on securing their safety, that the subject is given a place in this volume. 


\section{Objects of Silviculture}

The ultimate goal of all silvicultural work is to secure on a given area a high production of valuable material, in order that the owner may secure the largest possible returns in the long run. More specifically the objects are:

1. 'To secure quick reproduction after the removal of timber.

2. To produce valuable species instead of those having little or no market value.

3. To secure a full stock, in contrast to stands of small yield.

t. To produce trees of good form and quality.

5. 'To accomplish the most rapid growth compatible with a full stand and good quality.

Quick Reproduction.-When forests are abused by unregulated cutting and by fire, reproduction is very slow, and sometimes, when the abuse continues, entirely prevented. 'Thus, for example, areas in Pennsylvania cleared by lumbering and repeated fires, are in many cases entirely covered with low brush and weeds, and years will be required for natural renroduction to take place. The great plains in the Lake States, which have been devastated by fire, are capable of producing as good timber as formerly, but the trees needed for seed have been destroyed. It will require a long period, amounting in some cases to many tree generations, for the reestablishment of the forest by natural means. There are, in this countrv. millions of acres of devastated forest land, on 
which it will be impossible to establish a stand by natural reproduction in less than a century. 'This represents the worst conditions of forest destruction. But even where fire has not played so important a part, but where lumbering has been conducted in the usual way, reproduction is generally slow and meager. 'This means loss of growth. 'To the owner it means that the soil is idle for a long time, and that the period between removing the timber and the maturing of the new crop is much longer than is necessary. To the country at large it means a great loss which, in the aggregate for a single State, may amount to millions of dollars each year.

Desirable Species.-Nature does not discriminate against the inferior species. In the struggle for existence between two species, the one which has the least market value often wins. In any forest left to nature a great deal of ground is occupied by trees which do not have as high technical value as some others. This is particularly true in a country like America, where the number of species is large. Thus, in southern New England the ground is often occupied by birch, soft maple, ironwood, or other species of relatively little value, where chestnut and oak might be growing. I umbering and fire are often followed by a deterioration of the soil and a growth of species inferior to those in the original stand. 'The purpose of silviculture is to improve the composition of the forest, so that a given area will be occupied by the most valuable species which are capable of growing under the given conditions. 
A Full Stand.-There are relatively few forests in America which are producing a maximum amount of timber. 'Thus, it is estimated that the second-growth woodlands of Connecticut do not yield much over 60 per cent of what is possible under good methods of forestry. 'This refers merely to the actual quantitative production, without regard to the quality of the product. The production from the standpoint of value is probably less than 60 per cent. of the possible. The reason for this small production is the fact that the stands are very irregular. Frequently the trees are straggling and spreading, and occupy a great deal of space to the exclusion of other trees, and there are many operings occupied by valueless shrubs or entirely bare, which might be growing trees. 'The loss to the country through this reduced productive power of the forests is very great. In Connecticut alone it probably amounts to at least $\$+00,000$ per annum. The purpose of silviculture is not only to produce the trees best adapted to the soil, but as many trees per acre as is compatible with good quality.

A Valuable Product.-In the American forests a large number of the trees are crooked or forked, or have low branches which destroy their otherwise high technical value. Frequently these trees are suitable only for fire-wood, though they are large enough, and of the right species, to furnish high-priced timber. 'Thus, frequently one sees a stand of oak, 75 years old, with trees of such poor form that the timber is worth only 1 cent per cubic foot, whereas within this period it would have been 
INTRODUCIION

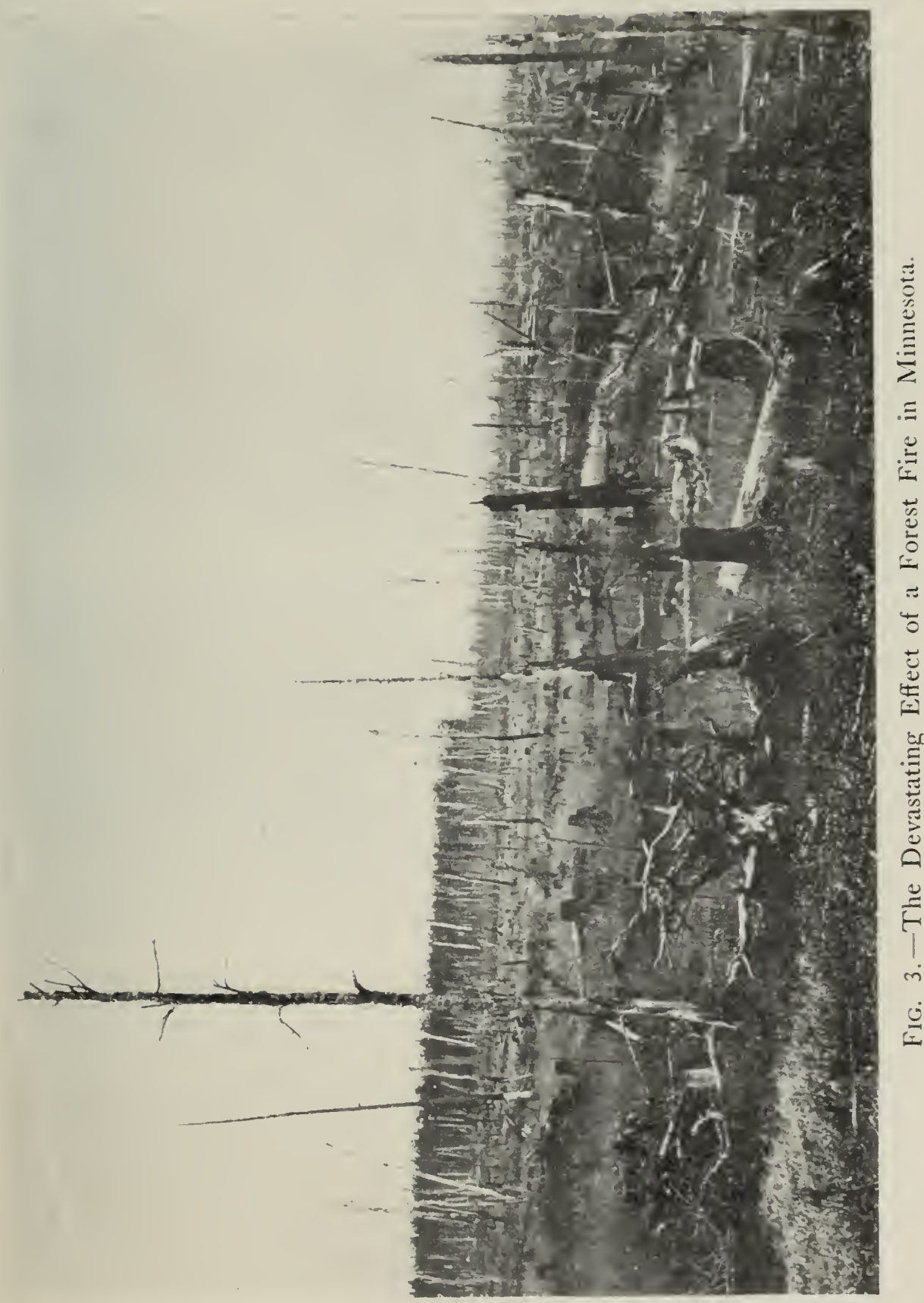


possible to produce a stand worth 3 cents per cubic foot. One purpose of silviculture is, therefore, to produce trees of high technical value.

Rapid Growth.--It is a proved fact that the growth in a natural forest is very much lower than in a cultivated forest. In the fierce struggle for existence trees are, in the majority of cases, retarded in growth, and those which live and come to maturity have usually grown relatively slowly. In the Adirondacks, for example, it requires on an average 180 years for a spruce to reach a diameter of 12 inches. Under favorable conditions, it is possible for spruce to reach 12 inches in from 80 to 100 years. One object of silviculture is to give each tree which is likely to come to maturity the requisite amount of light and growing space, in order that it may grow at its maximum rate. Trees standing in the open grow more rapidly than those in the forest, but this rapid growth is obtained at a sacrifice of form and quality of wood. A certain amount of crowding is necessary, in order to secure natural pruning and good form of trunk. 'The forester has, therefore, to sacrifice increment in a certain measure to form and quality, but by judicious silviculture he can secure the maximum rate of growth that is compatible with the production of valuable material.

\section{Measure of Production}

There is for every type of forest a maximum of production. By the expenditure of enough labor, it is possible in time to hring a forest to this high condition of 
productiveness. All open lands may be planted with good species of trees; ruined stands may be cleared and restocked artificially or naturally; stands containing weedtrees, or overcrowded, may be thinned and their composition and growth improved. 'The measures necessary to secure the maximum production may, however, involve a very large investment, and one which might not yield an interest return at all satisfactory to the owner. While the forester aims to secure a continued high production, he does not handle his forest with this alone in view, regardless of business considerations. His design is to make the forest serve the highest possible use to the owner as a piece of productive property. If any land is more valuable for agriculture or other purposes than for producing trees, it is put to its best use. If it is best suited to forest growth, the aim is to secure from it repeated crops of timber. Investments are made in forestry when it can be shown that there will be adequate returns in money or in some other desired form. It is a rule of silviculture that no investments are made unless there will be such returns. Under our present conditions it is usually not possible to secure the maximum productiveness of the forest and at the same time meet the financial requirements of the investment.

How much, then, must one produce from a forest in order to practise legitimate forestry? In other words, what is the minimum of forest production which may be established as the dividing line between forestry and destructive lumbering? The simplest principle is that 
those areas which are to be held permanently for forest use should be managed in such a way that the production by yearly growth will not be progressively reduced, but will at least be maintained. If by failure to provide for replacement, or through destructive fires, the productiveness of the forest is constantly decreasing, there will ultimately be little or no forest at all; and that is exactly what is happening in many places under the present methods. If, on the other hand, there is a provision for new growth and a conservative handling of growing timber, so that the growth equals that which produced the present stand, the forest's productiveness is not decreasing, even if it does not approximate what might be secured by a larger outlay of money.

This measure of production is a very easy matter to determine if it is based on the mean annual growth of the forest. If, for example, the first forest is 200 years old and yields 10,000 board feet to the acre, the annual growth is 50 board feet. In this case, if the forest is handled so that the mean annual growth of the next crop will be 50 feet, it falls within what may be called the dividing line between forestry, or a system of maintaining forest production, and exploitation, in which there would be al constint lowering of the yield. It may be said, however, that on account of the small yield of the virgin forest compared with what might be produced under forestry, such a return is exceedingly low. Any system that does not produce at least 100 feet per acre per annum is decidedly poor forestry. But between this 
minimum rate of growth and the possible maximum growth lies the range of timber production under legitimate forestry. Just what point will be reached within that range depends entirely on the object of the owner in handling his forest. 'The application of forestry to secure a high production, involving as it does a considerable outlay of labor, is called intensive forestry.

\section{Purpose of the Owner}

The management of a forest depends on what returns are sought by the owner. 'The object of management varies widely among different owners, and there is a corresponding variation in the application of forestry. 'The first consideration in organizing a forest is the purpose of management. Every investment is made to secure some definite return desired by the owner.

Objects of Public Forests.-In the case of public forests the financial returns, measured in actual interest on the invested capital, are ordinarily not the first consideration. National forests and State forests are set aside, to be managed for the permanent benefit of the public. In some cases these forests serve primarily to protect the slopes of mountains, to conserve moisture, and to control the run-off of water. The accomplishment of this object must be regarded as one of the returns from the forest. In case of some National Forests located in high mountains at the headwaters of important streams, the cost of administration and protection will exceed the returns which may be obtained from the sale of timber and from 


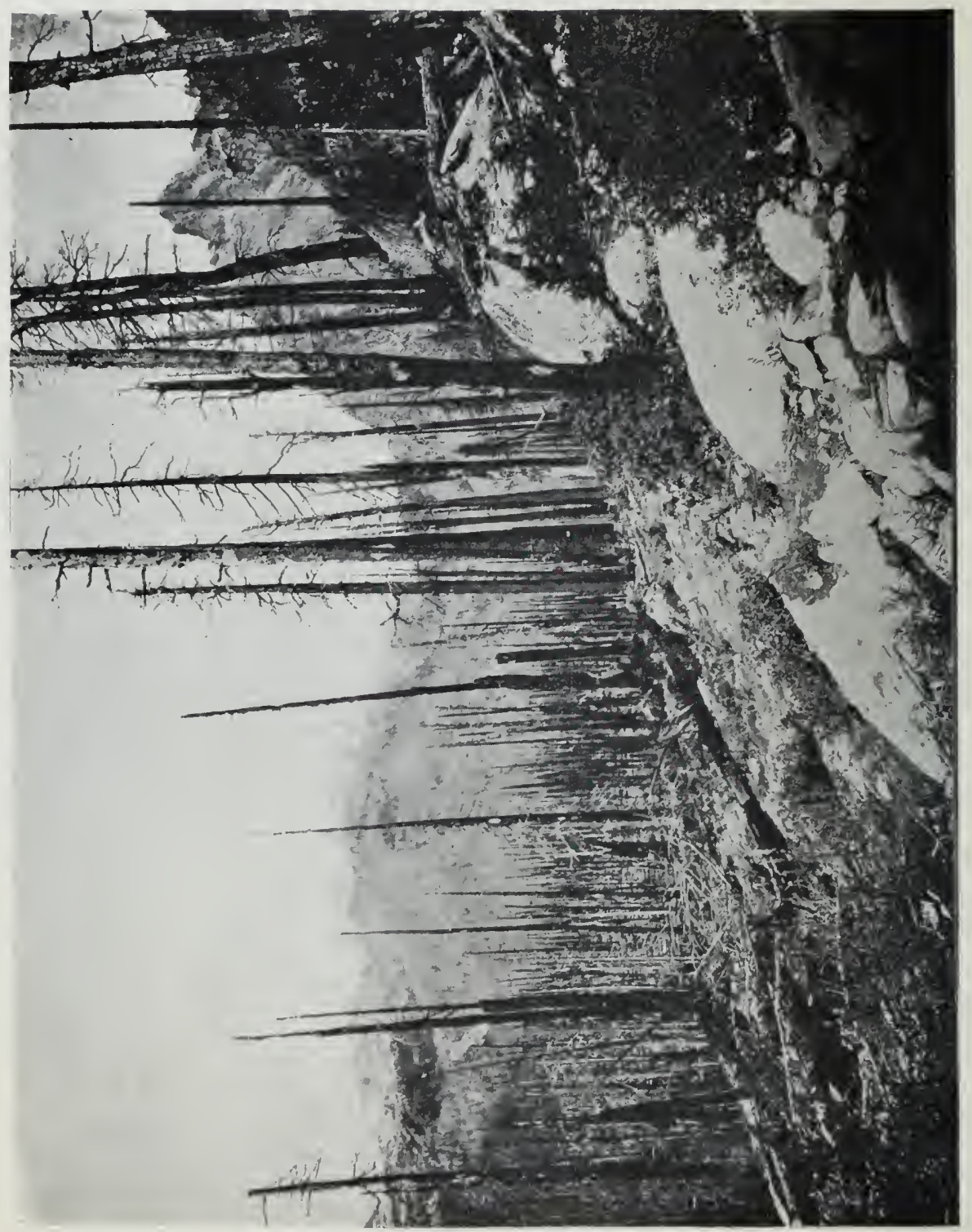

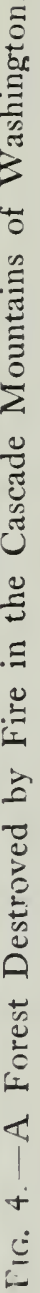


other sources. Public interest demands the protection of these forests, and this itself is an ample return on the investment necessary in forestry.

Some public forests serve as great recreation and health resorts. 'Thus the State forests in the Adirondack Mountains of New York are held primarily for these purposes, as well as for their value in protecting the headwaters of rivers. The constitution of the State prevents any cutting of timber whatever, and hence there are no returns in money at all. The public desires the forest to remain, at least at present, untouched. Large sums are spent each year for administration, protection, and improvement, and the indirect value to the public is regarded as a satisfactory return. In this particular case it would be possible to make the forests more than selfsupporting by judicious cuttings, and at the same time meet all the protective and esthetic purposes of management. Without doubt, such a policy of treatment will be introduced on these forests in a few years.

One of the greatest purposes of public forests is the continuous production of wood and timber for use. The object of management is not only the production of as large a quantity as possible, but also of the grades needed by the people dependent on the forests for their supplies. Oftentimes the public owner will aim to produce in its forests trees of large size and high quality, in order to secure grades of timber which private forests are not likely in the future to yield. The best grades of lumber can be obtained only from very old trees. Most privilte owners 
will cut their trees as soon as merchantable. The cost of producing very old trees is high because of the interest accumulating during a long period of years on the initial investment, and the annual expense of taxes, protection, and administration. 'The interest returns will be correspondingly lower than when there is a short rotation. ${ }^{1}$ The public owner alone can afford to produce timber of this character. The return will be in part the public advantage of having a certain amount of high-grade timber on the market.

Objects of Private Forests.-Private forests are, for the most part, managed for profit. On some large private estates of wealthy individuals and clubs, held as hunting and fishing preserves or pleasure parks, the questions of timber production and money returns are secondary. The protective principle enters strongly into the policy of the management by water companies of the forests about their reservoirs. Farmers frequently aim to produce timber of a certain class for local use. 'The essential object of most private owners in forestry is financial. Forestry with them is strictly a business problem.

\section{The Cost of Silviculture}

'The objects of silviculture cannot be secured without cost. 'There is always required an outlay in some form or other, an investment made for the purpose of securing greater returns in the long run. Sometimes the investment is in the form of actual expense for planting, protec'By rotation is meant the age at which it is plamned to cut the mature trees. 
tion from fire, inspection and supervision, or marking of trees; or it may be represented by increased cost of logging, and, hence, reduced profits of present cuttings; or it may be in the retention of seed trees and small timber left for growth, which might be utilized now; or perhaps, in the case of a farmer doing his own cutting, in the extra trouble necessitated by the application of farsighted, intelligent methods of treatment in his woodlot, as opposed to the thoughtless, haphazard methods usually employed. It is difficult to give any general average figures of cost of silviculture, because different measures are used under different conditions, and the cost of any given measure varies widely. In the discussion of the different methods of silviculture, the cost of the various operations is discussed. In general, it may be said that the extra cost of operating in the lumber woods by forestry methods, compared to the ordinary methods, is from 25 cents to $\$ 1$ per thousand board feet; that the cost of reproduction varies from $\$ 2$ to $\$ 10$ per acre; and the annual cost of protection, supervision, and administration varies from 2 to 10 cents per acre.

If a large lumber company were to practise forestry, the cost expressed in terms of the annual cut would be about from 50 cents to $\$ 1$ per thousand.

\section{Financial Returns from Forestry}

It is obvious that the practise of forestry in public forests is of great value. 'The indirect protective influences of the forest, the continued supply of a certain 
amount of useful products, the maintenance of certain industries which could not otherwise continue to exist in a given region, are all of great advantage to the people, and contribute largely to the actual creation of wealth and prosperity. They justify public forestry even if they involve a continued outlay of money.

Returns from Public Forests.-As a matter of fact, public forests pay financially in the long run, in addition to furnishing many indirect advantages. The forests of Prussia yield a net revenue of over $\$ 16,000,000$ a year, or about $\$ 2.50$ per acre. The forests of Saxony yield more than $\$ 5$ per acre per annum above all expenses of protection, administration, and operation.

Public forests in this country will also pay financially in the long run. In some cases the forests have been so badly damaged by destructive lumbering that there will be no revenue from them for a long time. 'Thus Pennsylvanial purchases cut-over forests. No timber can be cut on many of them for a long time. But ultimately there will be a large financial return to the State. A typical public forest in Europe yields about $2 \frac{1}{2}$ per cent. per annum compound interest on the value of the investment.

Problem of Private Owners. - The question asked by many private owners of forests is whether it will pay them from a business standpoint to practise forestry. Thus, for example, a lumber company owning 100,000 acres, has the problem of whether it shall cut everything from the tract that can be sold, or cut only the mature 
timber and handle the forest with a view to repeated crops.

It cannot be said that forestry will be a profitable investment for all private owners. There are a great many cases where the returns will not be satisfactory, compared to other investments. 'The reason why forestry frequently is not an attractive investment is on account of the danger from forest fires and burdensome taxation. Where a forest can be successfully protected from fire at reasonable cost, and where the annual taxes are not excessive, forestry will certainly pay, and in many cases yield a return fully equal to that which could be obtained in other lines of business.

Profits of Planting.-The question of the possible profit from forestry is usually based on the cost of producing timber from the seed. 'The value of the land, the cost of establishing the stand of trees, the annual expenses of taxes, protection, and administration are considered, the interest on all is compounded, and the aggregate costs are compared with the possible returns from the sale of the timber. When the land is cheap, the taxes are reasonable, the risk of damage by fire is not great, and the market is certain, a sure profit can be shown. Thus, in New Fingland forest planting has yielded over 6 per cent., and in the Prairie States, where small trees are valuable, an even higher return has been secured.

Under the present conditions confronting many timberland owners, forest planting is not an attractive 
investment, because of the risks from fire, possible burdensome taxes, and uncertainty of markets.

Investments in Immature Forests.-On the other hand, forests in such a condition that there are not only merchantable trees but younger trees which will reach merchantable size in a reasonable period, offer a splendid opportunity for profitable forestry. During the few years required for the young growth to reach merchantable size, there will be a very rapid increase in value. Thus, for example, a purchaser may in some sections secure secondgrowth chestnut and oak at $\$ 5$ per acre; in otner words, to obtain land well stocked with second growth up to 75 years old for the same amount as it would cost to buy a denuded land and plant a new crop, or even less.

A lumber company which has purchased a tract on the basis of the value of its mature timber, frequently acquires an enormous supply of young trees, for which it really pays nothing. The operation of the forest so as to protect and bring these to maturity will result in producing timber at exceedingly low cost, and with consequent high profits.

Those large producers who will require stumpage after the present abundant supply is depleted will find it very profitable to grow their own timber, purchasing young forests already well stocked and partly grown while these are relatively cheap. The virgin timber in the Fast will be largely cut in 25 or 30 years. The timber cut after that time will be that which is now called second growth. For example, after the old southern pine is cui, 


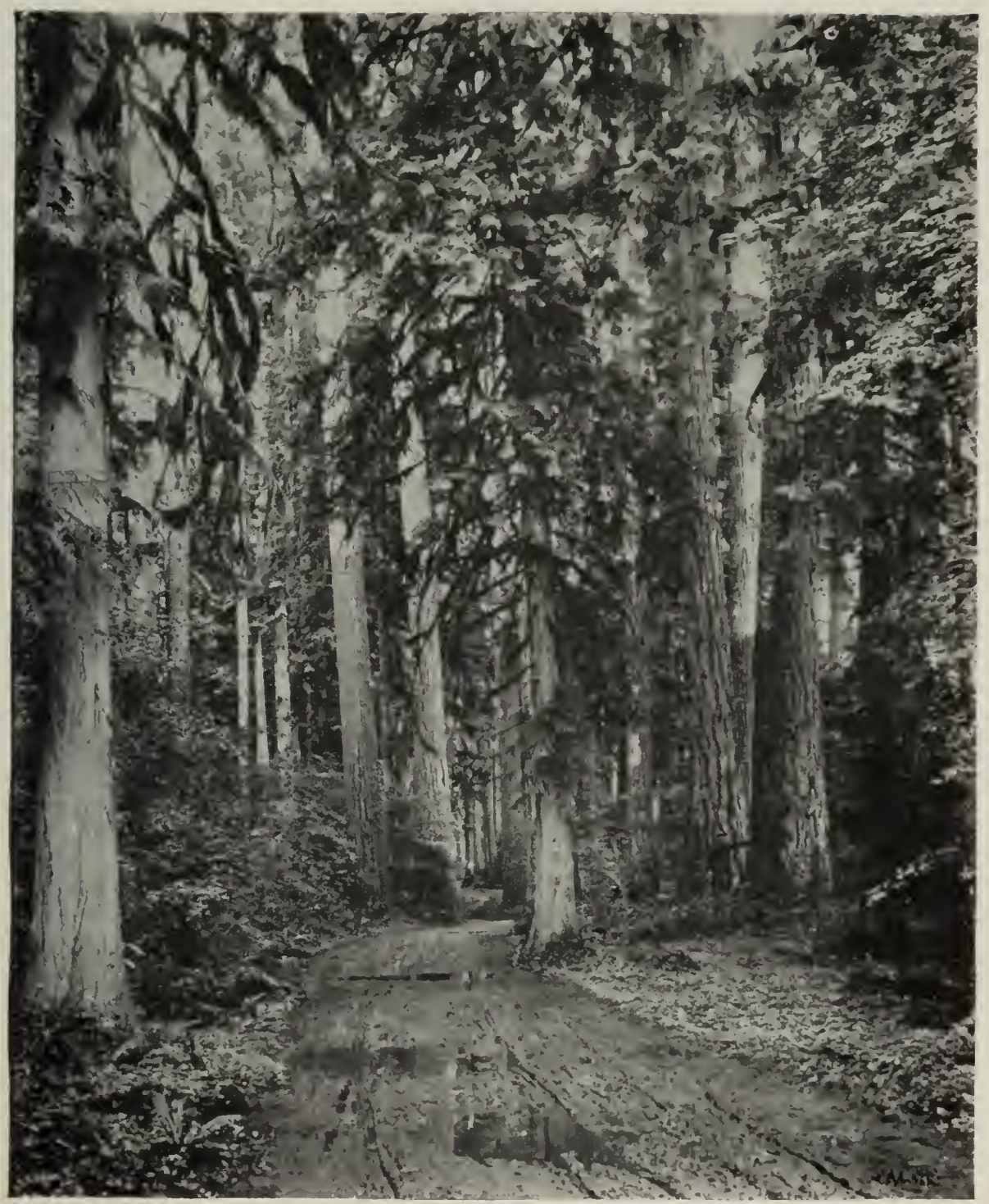

Fig. 5. - A Virgin Forest of Douglas Fir, Cedar, and Hemlock in Oregon. 
the lumbermen will use the stands which are now from 6 to 12 inches in diameter. Far-sighted owners who hold and protect these stands will furnish the stumpage of the immediate future. Their profit will be high, partly through the growth of the trees and partly through the increase in the stumpage value of trees of moderate size.

Investments of this sort should attract capital, even under our present conditions. The original investment called for is comparatively small, and both sure and early profits are clearly in sight. The forestry which will most generally appeal to private owners now is of this class, where thrifty and rapidly growing trees can be reserved as a basis for later cutting at the same time that renewal of the forest for an entirely new crop is provided for.

Investments in Natural Reproduction.-One serious objection which may be raised to the foregoing presentation of an opening for private forestry is that it is forestry with forestry left out; for earlier in this chapter it was shown that reproduction is necessary in order to have true forestry. The average American lumberman has not been much more interested in natural reproduction than in plantations. He is interested in a conservative forest policy, which will mean a return in 10,15 , or 25 years. It is hard for him to interest himself in returns one or two generations hence. Nevertheless, the question of reproduction is well worth his attention on practical grounds: even though he has not the interest of the 
owners who are plamning a heritage for their children and grandchildren, or of corporations organized on such a permanent basis that they can look far into the future.

Already in the best settled portions of the country land well stocker with young growth brings a higher price than denuded land. Even the land speculator who has no interest in permanent forestry may well take this into account. Reproduction can be secured naturally in most cases where a second cut is contemplated. If there is enough rapid-growing timber of medium size to make holding it for a second cut good business, natural reproduction can be secured from the reserved trees, provided fires are controlled. The holding of immature timber necessitates a certain amount of protection, which, with comparatively little additional outlay, will suffice to secure reproduction sufficient to maintain the required minimum of production.

Progress of Private Forestry.-In progressive States which have inaugurated a system of fire protection, the hazard from forest fires is already under way to be reduced to a minimum, making it worth while for forest owners to look beyond the cutting of trees now half-grown, and to replace the old stands by natural reproduction or planting. Farmers are beginning to practise forestry in order to produce wood and timber for their own use and for sale, and also in order to increase the sale value of their property. Large private owners are now considering this question from the standpoints of the actual returns from the increased value of the 


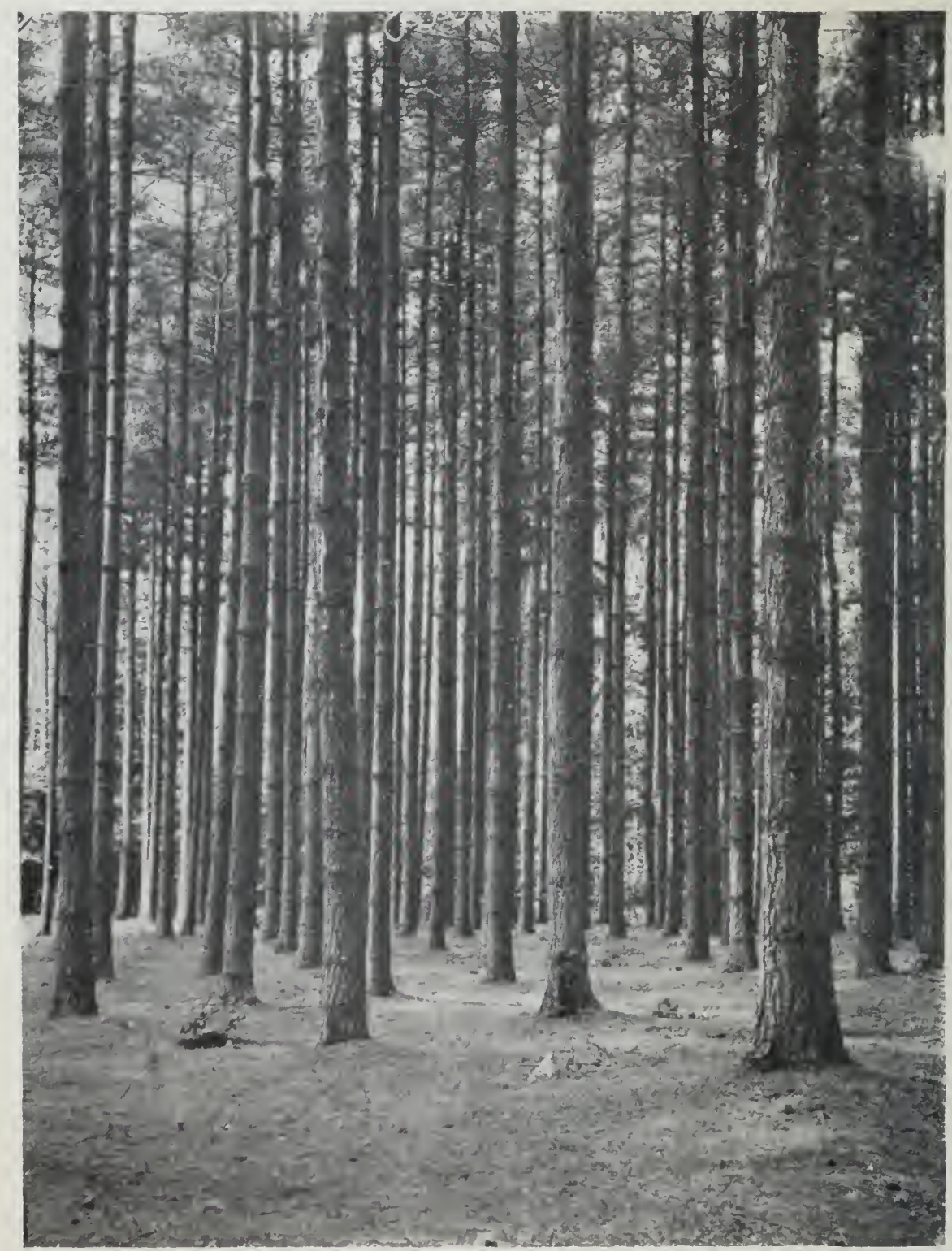

Fis, 6. - A forest of American White Pine in Germany. 
land, the continuance of the lumber trade, and their responsibilities to the public.

Already in a number of the States, as for example in Idaho and IVashington, large owners are forming partnership associations for fire protection and the practise of forestry. In the author's judgment, the time is not far distant when the States will fulfil their responsibilities in the matter of aid to the private owners in fire protection, taxes, and other ways, which will make it possible for private owners to practise forestry, and that there will then be carried out, on such private lands as are not better suited for agriculture or other purposes, a system of forestry which will at least maintain the minimum of production. This will be conducted roluntarily or under the guidance of the State.

\section{Reproduction Cuttings}

Prompt reproduction after cutting constitutes one of the important objects of forestry. IThenever a stand or portion of a mature stand is cut, the design is to establish new growth in its place, as soon as possible. Cuttings made with the expectation of replacement are called reproduction cuttings. They are in contrast to improvement cuttings, whose object is primarily to improve a growing stand and not to remove it and restock the area with new trees.

\section{Classification of the Trees in a Forest}

It is customary, for various purposes in forest work, to group the trees into classes. There are three different 
principles of classifying trees: First by age, second by size, and third by development of crown and position in the stand.

Age-Class.-It is customary to classify the trees in at forest in arbitrary age-classes. Usually the range of a single age-class is 20 years. Thus, if the oldest trees are 120 years, there would be 6 age-classes, 1-20, 21-40, $41-60,61-80,81-100,101-120$ years. Sometimes, in our forests, age-classes of 50 years are used. In Europe 10 -year age-classes may be used, but the 20-year age-class is most common, both here and abroad.

Size-Class. - In a great deal of forest work it is more convenient to classify the trees by size than by age. The simplest classification is by inch-diameter groups. Two-inch or 4-inch or other classes are used, according to convenience. In certain work in forest mensuration height-classes are also used.

Crown-Class. - Trees are classified also with reference to the development of the crowns and their position in the canopy of the forest. If the trees in an even-aged stand are examined, it will be seen that there is a wide variation in the development of the crowns. Some trees are distinctly the leaders, with crowns well developed, and occupy the principal position in the canopy. Other trees, crowded from the side by their more thrifty neighbors, lag behind in their growth, are shorter, and have a smaller crown and a smaller diameter than the leaders. Still other trees are entirely overtopped and after a time are killed. Five crown classes are recognized, as shown 


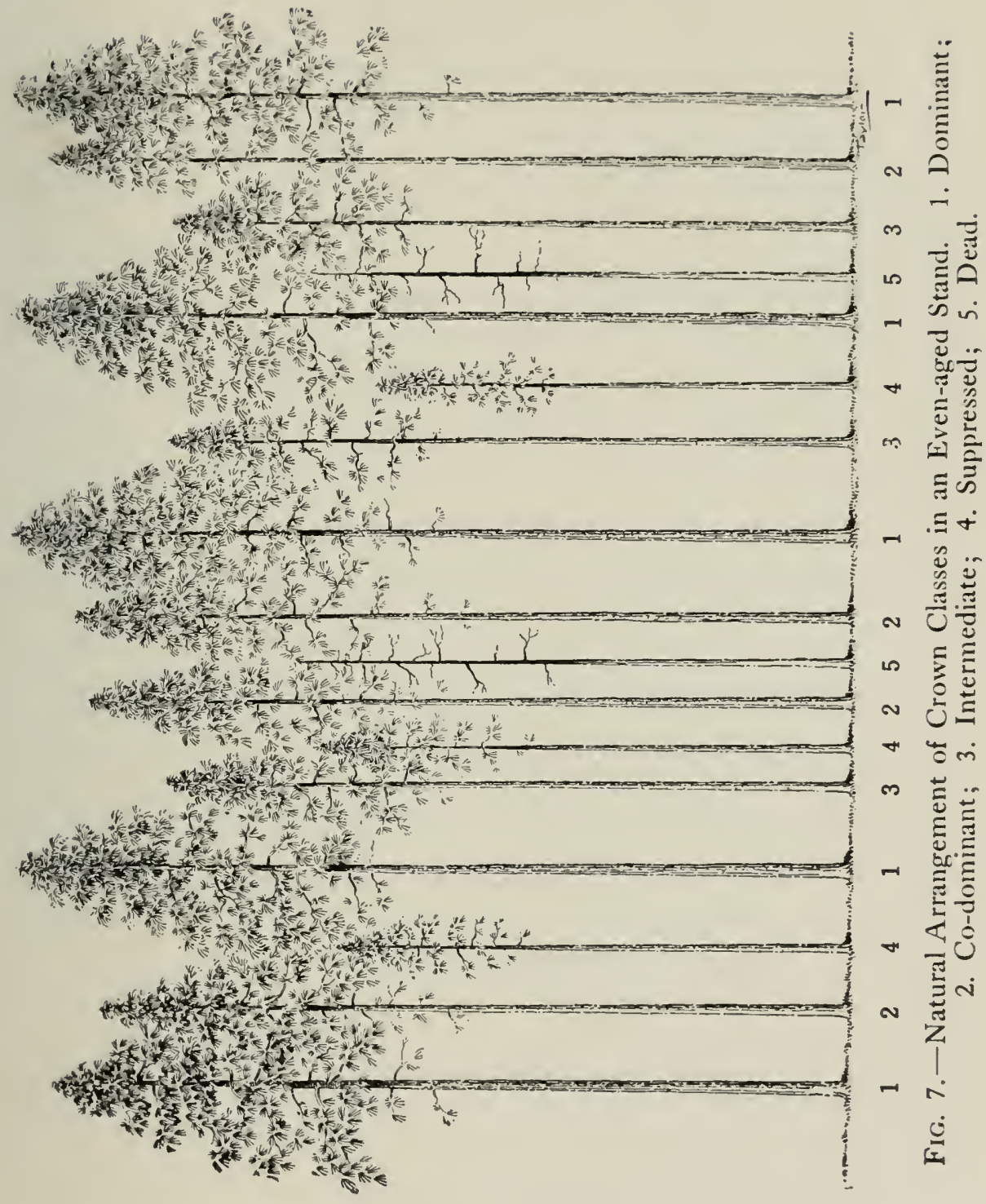


in the following list, and as illustrated in the sketch on page 29.

1. Dominant trees-the ordinary leading trees with full crown.

2. Co-dominant trees-those beginning to lag behind the dominant trees in height, crowded from the side, and having narrow crowns.

3. Intermediate trees-those with crowns retarded by crowding of the upper as well as of the lower part of crown, but still vigorous and usually capable of recovery if released.

4. Suppressed trees-those entirely overtopped.

5. Dead trees.

The Stand.-The term stand is a general expression applied to any given portion of a forest having a distinct character. The characteristics distinguishing a given stand may be age, form, density, quality, value, growth, yield, etc. Thus, such expressions are used as a 20year-old stand, a selection stand, a dense stand, a broken stand, etc. A forest is made up of a multitude of stands.

Origin of Stands. - Stands are distinguished according to whether the trees have originated from seed or from sprouts, or from both combined. The stand originating from the seed is usually called a high forest; that from sprouts a coppice or sprout forest; if both classes of trees are represented it is al composite forest.

Form of the Stand.- The result of the competition between trees in the forest under a given set of conditions 
is a stand of characteristic form. 'The form of a stand has reference to the arrangement among the different treeclasses. The form depends primarily on the distribution of the age-classes. Trees of different ages may mingle together promiscuously; the age-classes may be in groups; the trees may be all of about the same age; or there may be a more or less complete canopy of crowns, and underneath this a separate story of smaller trees, whose crowns form a secondary canopy. The forms most commonly recognized are the following:

\section{A. High Forest Forms.}

1. Selection Form. - Trees of different ages, from the seedling to maturity, are represented, mingled individually or in small groups.

2. Regular or Even-Aged Form.-The trees are approximately even-aged. 'The term is not confined to stands in which the trees are exactly even-aged. If the majority of the trees have nearly the same age and their crowns form a clearly defined, regular canopy, the stand is classed as regular. In a virgin forest a stand is regular if the majority of the trees are of merchantable size.

3. Irregular Form. - Through unregulated cuttings or accidental injuries the stand has been broken and there is an irregular representation of two or more ages. The age-classes are not all at hand, and therefore it is not of the selection form. 'I he irregular form necessarily varies enormousty.

t. 'Two-storied Form. - There alre two distinct stanc..; 
of regular form on the same area, one growing underneath the other.

5. The Reserve Form. - In a regular stand there are scattered older trees remaining over a second rotation.

B. Coppice Forms.

1. Regular Coppice Form.-The sprouts are approximately of the same age.

2. Irregular Coppice Form. - As a result of bad treatment, various ages are irregularly represented.

C. Composite Forms.

1. Regular Composite Frorm. - Sprouts and seedling trees of approximately the same age are growing together.

2. Irregular Composite Form. - Through abuse, an irregular mixture of ages occurs, with both sprouts and seedling trees represented.

3. Coppice with Standards.-Upon a given area there is a regular coppice stand, and also scattered trees, originating from the seed, which are allowed to grow over several sprout rotations.

\section{The Silvicultural Systems}

A silvicultural system is a broad plan of management under which a forest is reproduced and developed. In order to handle forests with a view to continued production of timber, ordinary lumbering must be modified or supplemented by special measures. 'To justify such investments as these measures involve the forester 


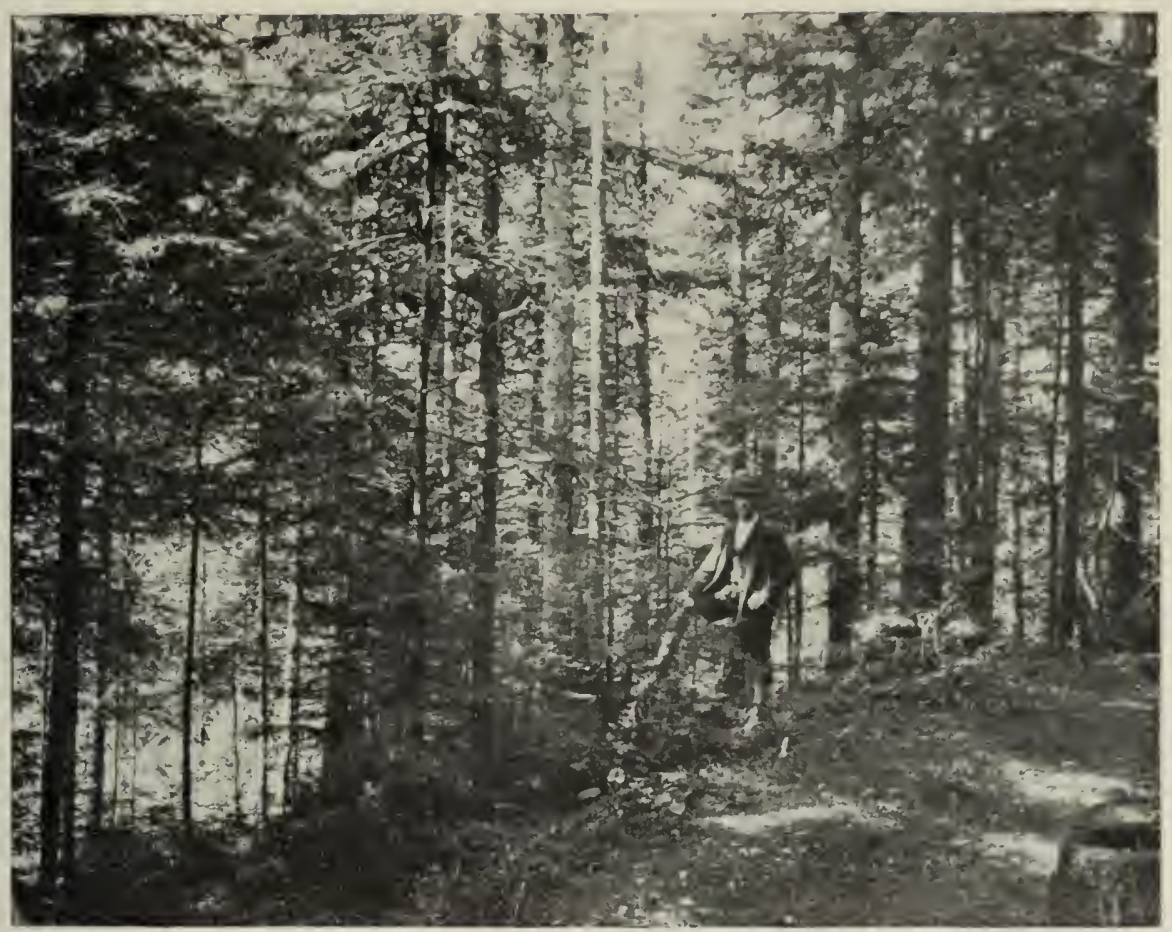

Fig. 8.-A Selection Stand. Spruce in the Mountains of Austria.

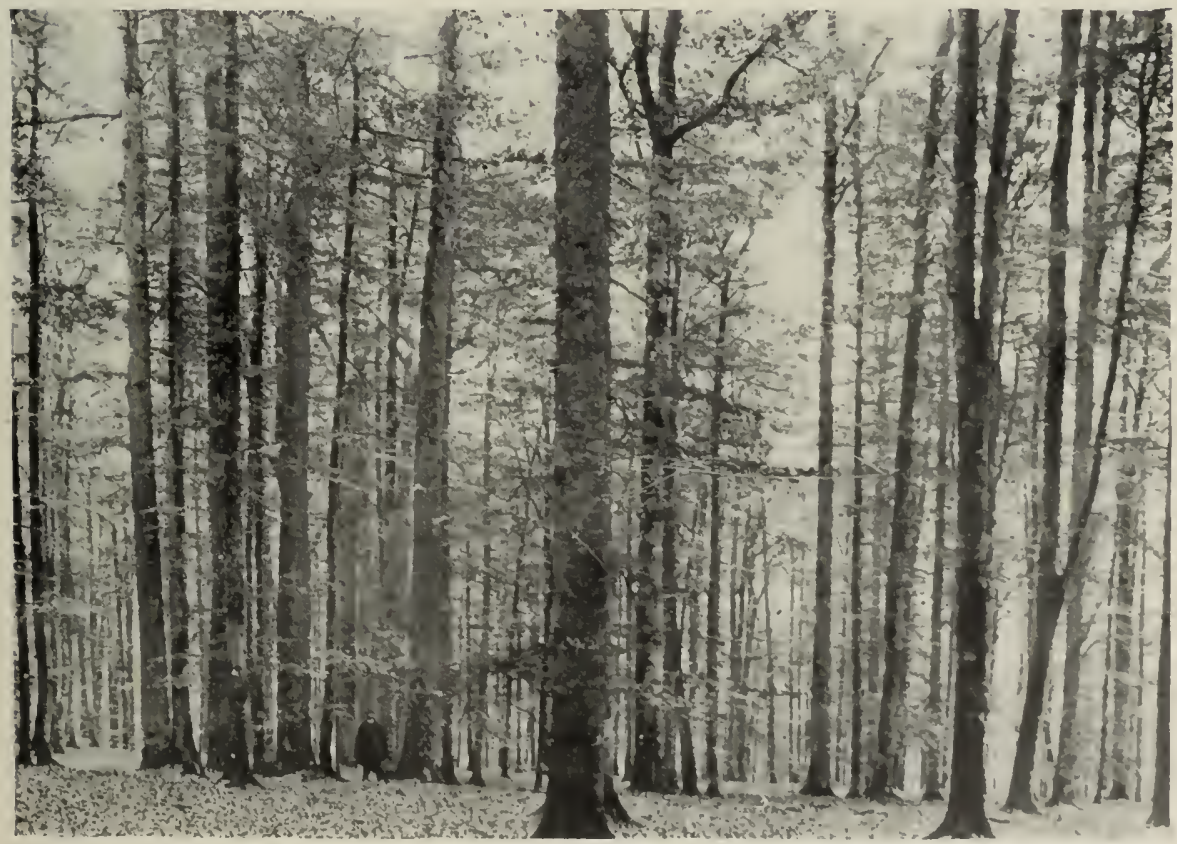

Fig. 9.-An Even-Aged Stand. Mature Beech in Germany. 
must have clearly in mind the results which may be secured, what kind of forest will be produced, what species will compose it, what form it will have, and the yield in salable products.

Definite results can only be secured under a systematic procedure. There have been developed by experience certain principles of handling forests of different character. These principles have been brought together and systematized, and are expressed as silvicultural systems. These systems do not, however, represent conventional rules for cutting, as often supposed, but rather are principles enabling the forester to systematize and control his work, and definitely to accomplish the purposes of management.

The silvicultural systems differ primarily in the manner of cutting and reproducing the stand. A given method of reproduction cutting results in a new stand, which has a characteristic form. Under systematic forestry, stands of a given form are given a specific treatment later. In forests thoroughly organized, therefore, the silvicultural system has a broader significance than merely a method of reproduction, and comprises also the development of the stand. In a new country, where the forests are irregular and the market conditions often poor or uncertain, it may be impossible to foresee the later handling of the forest. For American foresters the essential idea in a silricultural sy'stem is, therefore, the method of cutting and reproducing the stand. 


\section{Classification of Silvicultural Systems}

In the following pages are enumerated the silvicultural systems of most importance to the American forester. These are essentially the same as those used in other countries. In Europe, there are some systems representing modifications of those in this list, and adapted to the special conditions obtaining abroad. Some of those given prominence here are no longer considered of importance abroad, but were formerly used when the forest and market conditions were similar to those which are now found in this country. As the markets improve, the systems used in this country will, in their application, be more and more like those of Europe.

The list of systems differs in arrangement slightly from that found in most text-books. The present arrangement has been chosen as the one which has seemed to the author to be most helpful to the ordinary student, in view of the prevailing literature and the current ideas and practise of forestry in this country.

The silvicultural systems of chief importance to the American forester may be grouped under the following heads:

\section{Systems Depending on Reproduction by Sted.}

A. 'The Selliction Sistem.

Applicable to stands in which trees of all age are represented. The old trees, scattered or in groups, are selected for removal; the immature trees remain standing. 
B. The Clear-Cutting Systems.

1. Clear-Cutting with Artificial Reproduction.

a. Clear-Cutting the Whole Stand.-The whole stand is clear-cut in one operation, and the area restocked by artificial seeding or planting.

b. Clectr-Cutting in Strips.-The stand is removed gradually by a series of clear-cuttings in strips.

c. Clear-Cutting in Patches. - The stand is removed gradually by a series of clear-cutting operations, at least the first cuttings having the form of irregular patches cut in the stand.

2. Clear-Cutting with Natural Reproduction.

a. Clear-Cutting the Whole Stand.-The stand is clear-cut in one operation, and the surrounding stands are relied upon for reproduction.

b. Reserving Blocks of Trees. - The stand is cut clear, except for large blocks of trees left standing for seed, the latter usually constituting not over 15 to 25 per cent. of the area.

c. Reserving Scattered Seed-Trees.-The stand is cut clear, except for scattered individual trees left standing for seed.

d. Reserving Groups of Seed-Trees.-The stand is cut clear, except small groups left here and there for seed.

e. Reserving 'Thrifty Standards.-All trees are cut, except a limited number of thrifty individuals left to furnish seed, and to grow with the new 
stand over at second rotation. 'This differs from the scattered seed-tree system in that the trees left standing are much more numerous and are of a character to live through a second rotition.

f. Clear-Cutting in Strips. - The stand is removed in a series of strips, and reproduction secured from the uncut portions of the stand.

g. Clear-Cutting in Patches. - The stand is removed by a series of clear-cuttings in irregular patches of limited size, and reproduction secured from the side.

\section{C. 'The Shelterwool) Srstem.}

1. Cuttings Distributed Uniformly.-The stand is removed gradually by a series of thimnings; each thimning extends throughout the stand, and gives it a uniform character. The new stand starts under the shelter of the trees left standing, which act as a protection. The whole stand is usually removed within a period of twenty to thirty years.

2. Cutting in Groups. - The stand is removed gradually by a series of thimnings which are not uniform over the whole area, but concentrated on groups from which, as centers, the reproduction is progressively secured.

3. Cutting in Strips. - The stand is removed gradually by a series of thimnings, the work proceeding in progressive strips rather than uniformly over the whole stand. 
II. Systems Depending on Reproduction Wholly or Partly from Sprouts (Coppice).

a. Simple Coppice.-A stand of hardwoods is cut clear and reproduction from sprouts almost entirely relied upon. This system is usually managed on a very short rotation.

b. Coppice with Standards. - The bulk of the area is occupied by sprouts cut on a short rotation. Mingled with them are thrifty trees allowed to grow through one or more rotations of the coppice.

c. Pole-Wood Coppice.-An even-aged stand of sprouts and trees from the seed, combined, is allowed to grow to pole-wood size (40 to 70 years of age), and then reproduced in part bv sprouts, in part by natural seeding.

\section{Combination of Silvicultural Systems}

The various systems are very frequently combined. It is particularly common to combine systems of natural reproduction and systems of clear-cutting with artificial reproduction. Thus, a portion of the stand may' be reproduced naturally, and then the balance clearcut and replanted; or patches may be clear-cut and restocked with certain species, and then the rest reproduced naturally. The forester uses that method, or combination of methods, which will best meet the requirements of the forest and its management. 


\section{Application of Silvicultural Systems}

If the conditions of the forest and those alfecting lumbering are uniform, the forester may use a given system over the whole forest. Thus, for example, in the Minnesota National Forest the land is flat and the logging conditions are fairly uniform. The forest is also sufficiently uniform to enable the application of one system - the scattered seed-tree system-over most of the area.

Usually conditions are variable, and a system applicable in one place is not suitable on other areas. Even in the regular forests of Europe there are usually in each forest several different silvicultural systems in operation. In this country the forests are so irregular and the logging conditions so variable that often in a single logging operation more systems than one are used. For example, in a forest chiefly of the selection character and requiring the selection system, there may be patches of even-aged timber which must be handled under one of the other systems. In every case, the forester applies the system best adapted to meet the special conditions under which he works.

Not only does the choice of a system of cutting depend on local conditions, but the application of a given system is subject to great variation. The application of a given silvicultural system is dependent on the character and condition of the stand and on the market and logging conditions.

Every species has its peculiar requirements for repro- 
duction and growth, and these are subject to great variation under different conditions of soil and climate. Stands vary enormously in composition, form, density, and thriftiness. The forester must know the habits and requirements of the different species, and must be able to diagnose the needs of any given stand, in order to handle it in such a way as to secure the results desired.

Every measure of practical silviculture is, however, subject to local conditions of markets and logging. The owner desires as high a production as possible, but the question of cost will always shape the method of applying his operations. Not only may the market and logging conditions determine the system of silviculture; they will always be a great factor in determining the degree of intensity of the work, and govern the details of operation.

In the discussion of the various systems of silviculture, repeated references will be made to the different factors which modify the working out of details on the ground.

\section{Choice of Species}

In reproducing a forest, one aims to establish the species which will best meet the objects of management. In artificial reproduction there is, theoretically, a choice among all species adapted to the local climate and soil. In practise, it may be possible to secure trees or seed of only a limited number of species.

When natural reproduction is used, choice is restricted to the species already growing on the ground. In a mixed 
forest there are always some species more desirable than others. Poor forestry results in the decrease of the better species. In making cuttings for natural reproduction the better species are favored, with the aim of securing as large a proportion of them as possible in the new crop.

Successful forestry results, in the long run, in the gradual reduction in the proportion of the less valuable species, and their replacement by the more desirable ones.

In determining the most desirable species, the following points are considered:

1. The Intrinsic Value.-Ordinarily the tree whose wood is of the greatest intrinsic value is preferred.

2. The Rapidity of Growth. - Often a rapid growing tree is preferred, even if its wood is less valuable than that of some other species.

3. Suitability to Market. - The future market must be considered, as well as the present. Frequently, foresters regard certain species as undesirable because there is no present market for them, when their intrinsic qualities indicate that ultimately they will be valuable.

4. Logging Conditions. - The problem of handling and transporting the logs must be considered. In the mountains conifers are usually preferred to hardwoods, because they are more easily handled; and if there are streams, they can be driven. It is not merely the probable market which is considered, but also the cost of placing the product on the market. The profits, rather than the market value, may determine the desirability of a species. 
5. Cost of Reproduction.- -Some species cost more than others to reproduce, both artificially and naturally.

6. Resistance to Injury. - Species subject to damage by wind, insects, disease, or other damage may be rejected, even though otherwise desirable. A species may sometimes be favored primarily because of its ability to resist fire.

7. Silvicultural Value. - A species may be of special value in its influence on the growth of its neighbors or in conserving the factors of site. Thus, hemlock in mixture with pine helps the development of the latter, and furnishes an excellent soil cover.

8. Esthetic Value.-Sometimes a species is chosen because of its peculiar value from the esthetic or sentimental standpoint. This question becomes of importance on private estates, and those public forests which are used as recreation resorts.

\section{Pure and Mixed Stands Contrasted}

A pure stand is one composed of a single species. As the terms are used in this country, the stand is calied pure if 80 per cent. of the main crop is composed of one species. If there are two or more species, and no one of them comprises over 80 per cent., it is a mixed stand. The aim of forestry is to reduce the proportion of the less valuable species in the forest. Ultimately the un. desired species will be represented only as scattered, accidental specimens. 'The tendency in forestry is constantly toward pure stands. This is especially true 
where stands are established by artificial seeding, or planting. The forester is apt to choose the species which give promise of the highest returns, and to establish pure stands of it. Then again, the seeding or planting of a single species is simpler and often cheaper than if two or more species are in mixture.

There are, however, certain advantages in producing mixed forests, and these should be considered when a new stand is established. They are as follows:

1. Mixed crops form a denser leaf-canopy, and hence cast a heavier shade than pure stands. This is due to the overlapping of the crowns of trees whose natural crown development and ability to bear crowding differ.

2. In a judicious mixture of species there are a larger number of trees than in pure stands. This is the result of differences in ability to endure crowding, differences in crown development, and differences in root development.

3. It has been actually demonstrated that a larger volume of product can be obtained in mixed than in pure stands.

t. Many species are less subject to damage from fire, insects, disease, and windfall when in mixture than when grown pure.

5. By a judicious mixture certain trees develop a better form, and hence higher quality of wood, than in pure stand.

6. Mixed stands have a higher esthetic value than pure stands. 


\section{CHAPTER II}

\section{THE SELECTION SYSTEM}

\section{Origin of the Selection System}

As a rule, the original forest is composed of trees of all ages mingled together promiscuously, as individuals or in groups. In the early days in this country the smaller trees were not cut, because they could not be sold. The first lumbering, therefore, consisted in selecting here and there a tree or group of trees and leaving the remainder in the forest. No attempt was made to prevent damage to the younger trees, but so few trees were taken that comparatively little damage was done and the forest was left in fairly good condition. As the market improved and smaller trees became salable, the cuttings were progressively heavier. In the Adirondacks, for example, the first lumbering removed only the larger pine and the choicest spruce; later, spruce was taken down to 10 inches in diameter, and still later spruce down to 6 or 5 inches was cut, with any of the choicest hardwoods in addition. 'To-day, in sections where nearly all trees are merchantable, lumbering practically results in clear-cutting.

It is natural that the first conception of forestry under the primitive conditions in a new country is to cut only 
the largest trees and to reserve and protect the middlesized and young trees, which will reach merchantable size in a comparatively short time and will furnish the basis of the future cuts. This is the fundamental principle of the selection system. As far as the selection of the trees to be cut was concerned, the earliest lumbermen practised it as a matter of course. 'The forester takes the principle and applies it systematically, with the object of reproducing and so perpetuating the forest. By the system, as the forester uses it, the old trees and others which have passed their effective growth are cut, the immature trees are protected and encouraged, and reproduction is secured in the openings made by the cuttings. A given cutting never clears an entire stand, but makes only small openings.

\section{Theory of the Selection System}

The selection system is applicable to selection stands; that is, those in which trees of different ages are represented. An ideal selection stand is one in which trees of all ages, from the seedling to the mature tree, mingle together in full proportion. Even in the best selection forests, however, every year in the rotation would not be represented. If the rotation were 100 years, there would never be trees of every age, from 1 year up to 100 years, because seed is only produced at intervals. It is an ideal selection forest if all age-classes are proportionately represented. Thus if the rotation were 100 years and the age-classes comprise 20 years each, the oldest age-class should occupy in the aggregate about 20 per 


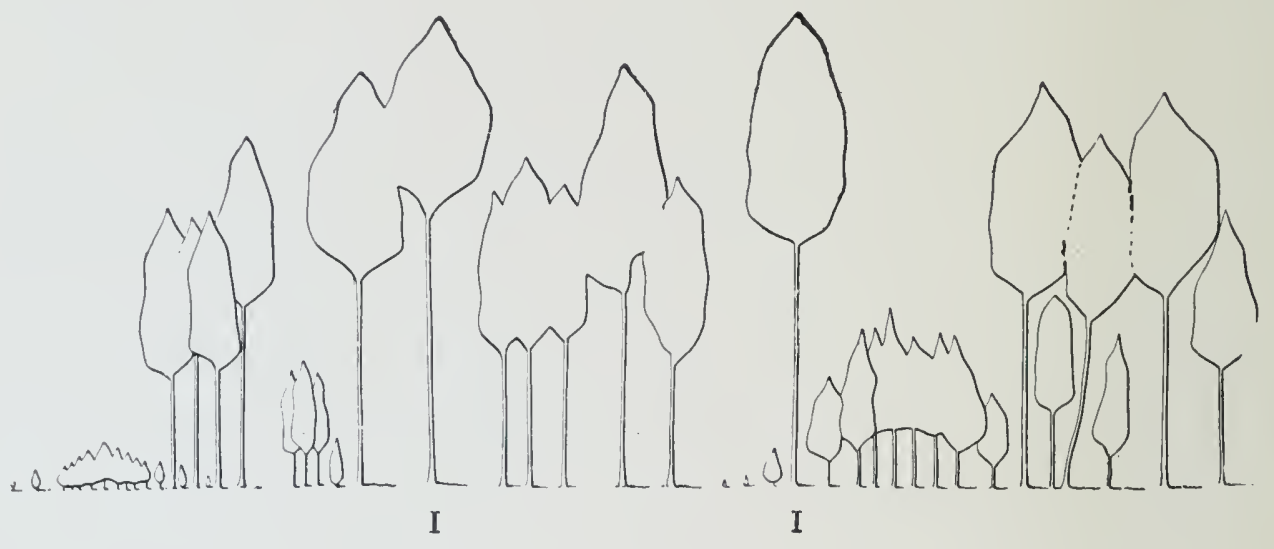

FIG. 10.

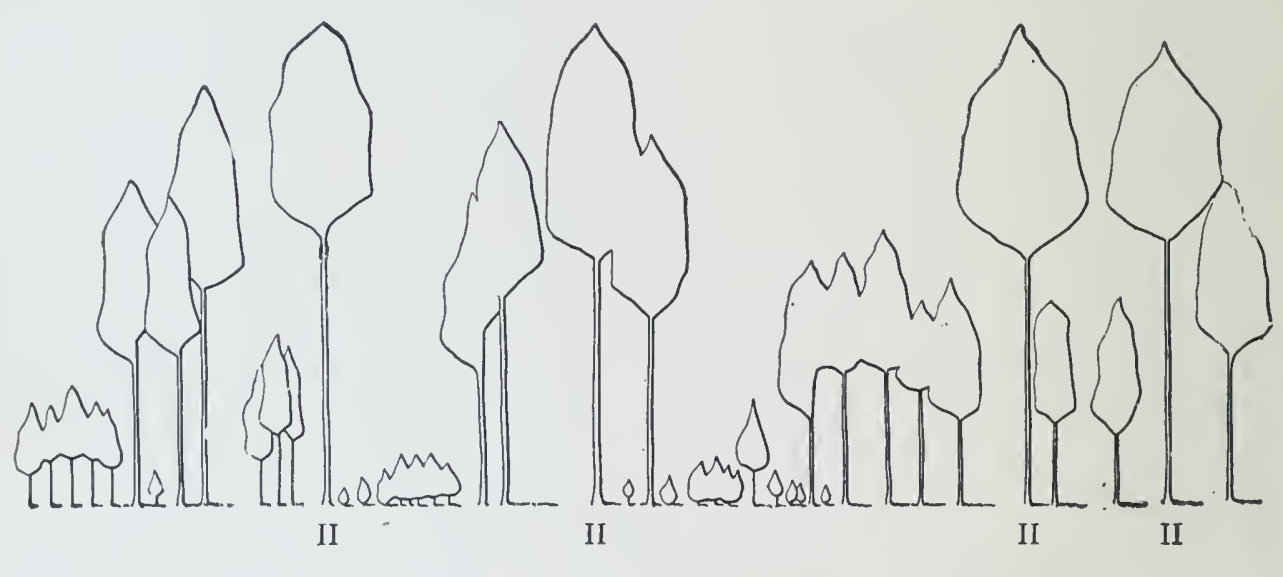

FIG. 11.

Profile of an Ideal Selection Stand. Fig. 10. Stand before First Cutting Fig. 11. Stand Twenty Years later, and ready for Second Cutting. 
cent. of the areal, and the other classes should have enough trees so that, as each comes to maturity, it will. occupy 20 per cent. of the area.

In making selection cuttings in this ideal forest, the oldest age-class would be removed during the first 20 years. Then the trees in the next age-class would begin to come to maturity, and would be cut during the following 20 years. If successful reproduction were secured, this process might be continued indefinitely.

The theory of the selection system is illustrated on page 46. Fig. 10 represents a fragment of a selection forest just before cutting. The trees designated as "I" are mature, and are therefore removed. Fig. 11 shows the same stand after 20 years. The trees marked "II" in Fig. 11 are now grown into the mature class, and are ready for cutting. All trees have grown both in height, diameter, and crown surface. Several trees have disappeared as a result of the mutua! crowding. Small groups of young seedlings are found growing in the openings made by cutting.

In some cases a stand is cut through every year. In the theoretical example this would mean cutting each year one-twentieth of the oldest age-class. Usually it is impracticable to make annual cuttings, and the stand is cut through periodically. The interval between cuts may be called the cutting cycle. In Europe, the cutting cycle is usually about 10 years. In this country the interval between cuts will more often be from 20 to 50 years. 


\section{Principles of Limiting the Cut}

In making selection cuttings the design is to remove primarily trees in the mature age-class. Even where all age-classes are well represented, they are usually not so clearly differentiated as in the theoretical example shown on page 46. When the market conditions are at all favorable, not only the trees in the oldest age-class, but also those in the younger classes are merchantable. The restriction of the cut to the oldest class would mean then that many trees for which there is a market are left standing as the basis of the next cut. There is always a temptation to increase the cut as much as possible, in order to show a large return and to reduce the cost of logging. It is obvious that therc must be some definite principle of restricting the cut to prevent the removal of such a large proportion of the tress of intermediate ages and sizes that succeeding returns will be greatly diminished, and to prevent disturbing the arrangement of the age-classes to such a degree that the continuance of the selection system is impossible.

There are two fundamental principles which must never be lost sight of: (1) The maintenance of the rate of growth of the stand, and (2) the continuance of a proper representation of age-classes.

If the age-classes are all represented in proper proportion, the problem is simple. The growth is determined in advance, and the cut limited to this amount. The trees removed are selected primarily among the 
oldest trees. If a given stand is cut through each year, there is removed an amount equal to the annual growth of the whole stand. If the stand is cut every 10 years, each cutting removes an equivalent of 10 years' growth. As all age-classes are at hand, there are continuously trees growing into the merchantable class as a basis for the next cut.

The theory may be illustrated by a concrete example. Suppose that the stand comprises 100 acres, the annual growth is found to be 250 board feet per acre, and the cutting cycle is 10 years; then 2,500 board feet per acre, or 250,000 feet on the whole tract, may be removed at each cutting, provided there are no special conditions to modify this amount. In a stand in which the age-classes are well represented, the proportion of the total area uncovered by a given cutting, that is, the aggregate of all openings taken together, is approximately equivalent to the rotation divided by the cutting cycle. Thus, if the rotation is 150 years, and the cutting cycle is 25 years, each cutting uncovers in aggregate of all small openings one-sixth of the area.

In the continued operation of a selection forest it is exceedingly desirable to have the different age-classes represented in their proper proportion. Obviously, if a given age-class is not represented or is deficient it is not possible to cut at regular intervals an amount of timber equivalent to the full growth of the stand. Suppose, for example, that in a selection forest handled on a rotation of 100 years the oldest age-class, namely from 80 to 100 years, is represented in full proportion, while there are 
no trees at all from 60 to 80 years of age, and the place which would normally be occupied by this age-class is covered with trees less than sixty years old. It is clear that after the expiration of 20 years and the oldest ageclass is removed, there would be no trees at all from 80 to 100 years old, and it would be necessary to wait another 20 years before cuttings could be made. Unless, therefore, all age-classes are normally represented the cuttings must be at irregular intervals.

The selection system is applied in this country chiefly in virgin forests. The normal form of a virgin forest is of a selection character; that is, it consists of trees of different ages mingled together promiscuously. 'The forests of the United States, however, have in the past been seriously damaged by destructive fires. It is common, therefore, to find in virgin forests stands of great age which have a regular or even-aged form. This occurs where past fires have cleared the ground and a new stand has come in on the clearing. Fiven in forests where there have been no destructive fires in the past, frequent small clearings have been made by windfall, insects, and other destructive agencies, and the distribution of age-classes is therefore irregular.

The range of age-classes in most virgin forests is very great. In northern Idaho, for example, the oldest trees may be over too years old. In such forests, if there have been no disturbances by fire or otherwise, all ages may be represented. But in classifying the trees with a view to practical management ail the mature trees would 


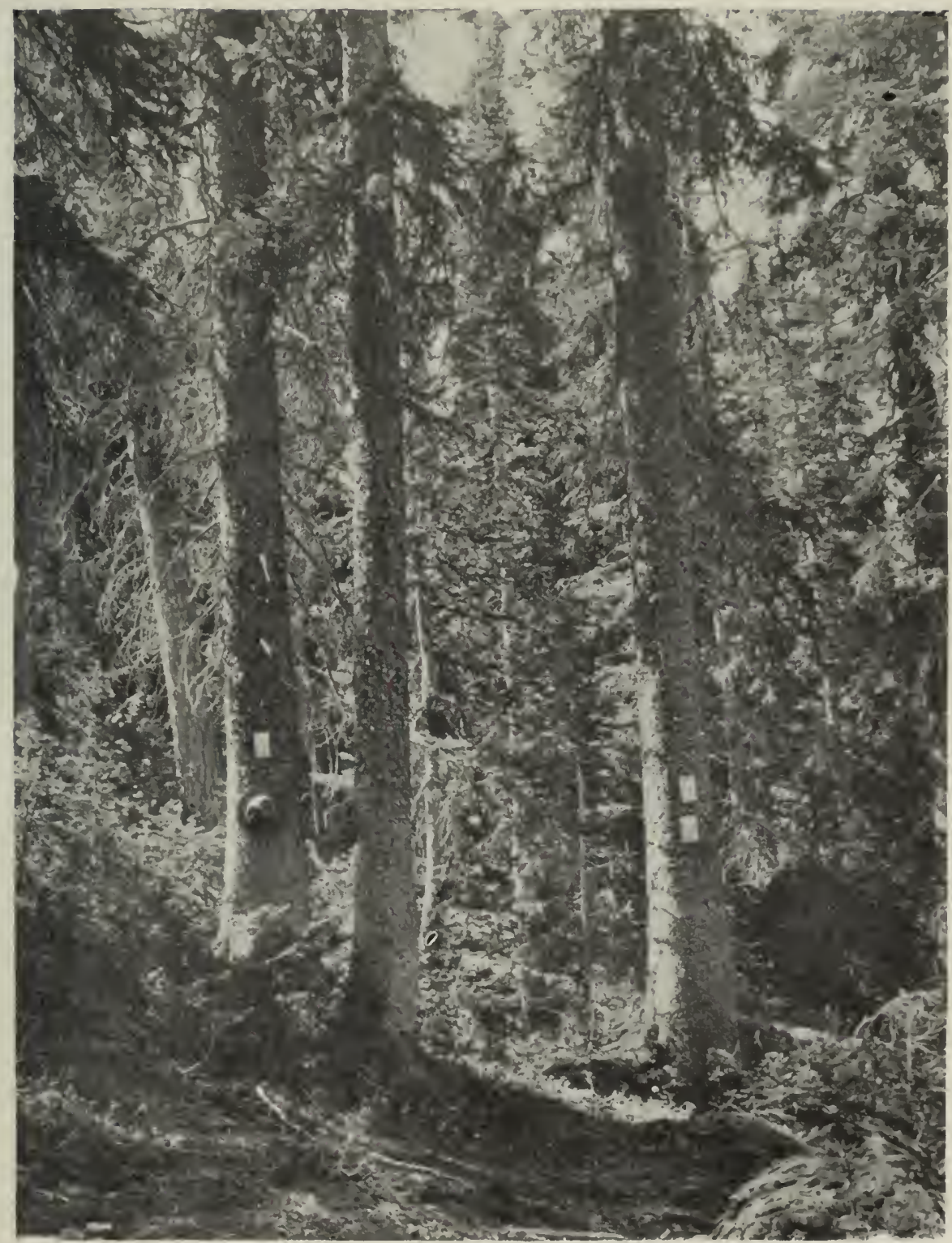

Fig. 12. - Trees Designated for Cutting under the Selection System. Engelmamn Spruce, Arapahoe National Forest, Colorado. 
be grouped together in the oldest age-class as trees which have ceased productive growth and ought to be cut. Thus, in northern Idaho this age-class might comprise all the trees over about 150 years of age. It is evident that under these conditions the oldest age-class would far exceed in number of trees any other age-class, and might occupy in the aggregate 50 per cent. or more of the area. The rest of the area would be occupied by trees belonging, in more or less varying proportion, to the age-classes below 150 years. In handling a virgin forest this undesirable representation of the age-classes cannot be helped. The mature trees should be cut and used, even if their removal disturbs the arrangement of ages. In the subsequent treatment of the forest, however, the gradual establishment of the proper proportion between the ageclasses is kept in view.

Very commonly in this country it is necessary to make cuttings before complete working plans have been developed, and it is not possible to determine what system of management will be best to use in the long run. The first cuttings are therefore made conservatively on the seiection system. In some cases without question the second cuttings will be comparatively heavy and will practically be shelter-wood cuttings, which transform the stand in a comparatively short time into an even-aged form. If, on the other hand, at the second cutting it seems desirable to continue the s lection system, cuttings are made with a view to bringing about a proper representation of different ages. 


\section{The Diameter Limit}

While theoretically one aims to select trees for cutting on a basis of age, in actual practise the decision whether a tree is to be cut or left standing for a later cut depends more on its size, condition, and capacity for growth than on its age. For this reason it is usually customary to restrict the cut on a basis of size rather than of age. The size set as a minimum for cutting is called the diameter limit.

The purpose of a diameter limit is to aid in restricting the cutting to those trees whose growth no longer represents a return satisfactory to the owner. The trees which are thrifty and growing rapidly are left standing, regardless of their age, as a basis for a later cut.

It is, of course, impossible to investigate the growth of each tree before cutting. It is, therefore, customary to determine in advance of cutting the average diameter at which trees cease to yield a satisfactory growth. Unless there are some special silvicultural reasons for modifying it, this limit is used in planning the work of cutting, and as a guide and check in selecting the trees.

When possible, the diameter limit of satisfactory growth is determined by a thorough local investigation. Such a study will show the rate of growth of stands cut to a number of different diameter limits, and will enable the owner to fix upon that limit which will result in a return most satisfactory to him. In making the study the forest is first analyzed, to determine the average num. 
ber of sound trees of different diameters. It is then assumed that all trees above a fixed diameter will be cut, and those below it left standing. In practice, the limit is somewhat elastic, but usually the trees left standing above a limit about equal in volume those cut below it. An inspection of the forest shows that the limit will fall within a comparatively narrow range. Thus in Maine it is readily seen that the average diameter limit of spruce will be somewhere between 8 and 14 inches. Accordingly, a computation of growth is made on the basis of cutting to $8,10,12$ and 14 inches. The limit which shows the most satisfactory returns in volume or in interest on the investment, according to the owner's wishes, is selected as the guide for the cutting.

This limit may be modified slightly by special silvicultural considerations, such as danger from windfall, reproduction, etc. These points have usually a greater bearing on the actual selection of the trees than on the fixing of the average limit. A limitation of cut, based on this method of study, maintains the rate of growth of the forest and guarantees succeeding cuts at short intervals.

Sometimes it is necessary to begin cuttings before an adequate study of growth can be made. This happens very conmonly in the National Forests when time, money, or men have been lacking to make the investigations, and the sales of timber cannot wait for possible later appropriations for such work. In this event the forester aims to cut only those mature trees which are 


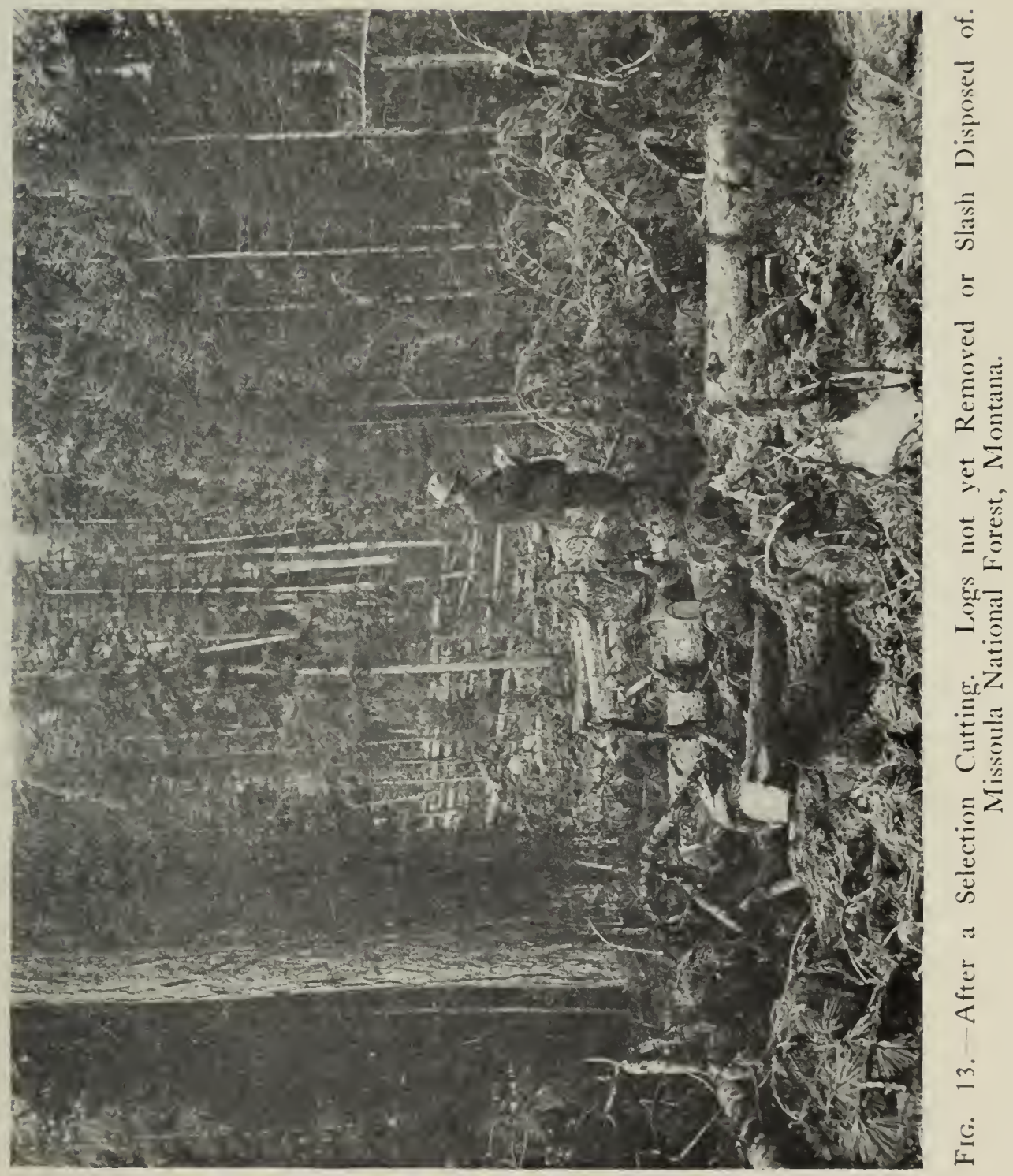


obviously no longer making a satisfactory growth, and he leaves the thrifty trees for a later cut. Thus, while no growth study is made, the limitation of cut is really based on growth.

\section{Application of a Diameter Limit}

In selecting the trees for cutting, one takes all trees above the diameter limit determined upon, unless there is some reason for leaving them, and leaves all trees below it, unless there is some reason for taking them. 'The reasons for leaving trees above a chosen diameter limit may be the following:

1. Where it is necessary to leave one or more trees for the distribution of seed in an opening.

2. Where the removal of a tree would expose a group of trees below the limit to damage by windfall.

3. Where a tree is very thrifty and increasing in volume and value very rapidly.

4. Where the removal of a tree, or group of trees, would result in erosion or serious damage to the soil from drying.

5. Where it is desirable to leave a tree, or trees, for esthetic reasons, as, for example, near roads of other public places.

6. Where the policy of management requires the leaving of a few prime trees for the production of exceptionally high grades.

The circumstances under which trees below the limit are cut are as follows: 
1. Where trees are defective.

2. Where trees are growing very slowly, and are unlikely to remain sound till the next cut.

3. Where trees are of poor development, and are retarding the growth of others of greater promise.

4. Where the removal of trees of poor promise will aid reproduction.

5. Where it is necessary to cut patches clear, because the trees, if left, would not withstand the wind.

6. Where trees will inevitably be injured by the felling of larger trees.

Marking.-The selection of the trees to be cut should not be left to the judgment of the loggers. It has usually been the custom of lumber companies cutting to a diameter limit to issue instructions to the sawyers to cut only trees above a certain diameter on the stump. Even when a diameter limit is the only basis for selecting the trees the best results are secured by marking in advance each tree which is to be cut. The ordinary logging crew cannot be expected to measure the trees with care and accuracy. The marking should be done by a special crew of men skilled in this work.

In selecting the trees the chosen diameter limit is used as a check. Accordingly, the marker carries a measuring rule of some sort. Some mark off rough graduations on the handle of the marking axe to measure diameters. Others carry calipers. Where only one limit is used, as when a single species is being marked, a set caliper or a simpie gage may be used. 
Diameters are best measured at breast-height, because the diameter limit is based on breast-high diameter classes. A diameter limit based on the stump measurements has no value, on account of the varying height of stumps.

The trees are marked with al special axe. A conspic-

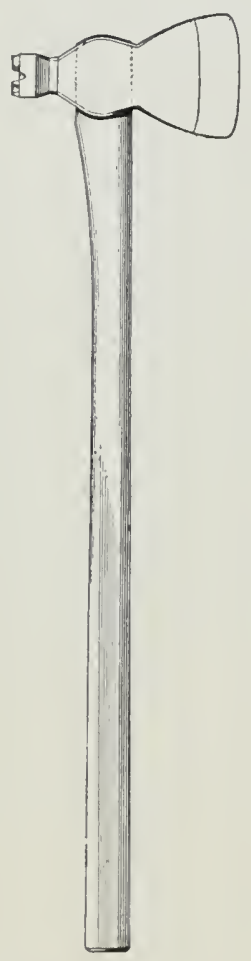

Fic. 14. - Marking Axe. uous blaze is made on the tree for the convenience of the sawyers, and a check-blaze and mark made at the butt, below where the stump-cut will be made. In making the check-blaze a chip of bark is removed and the blaze stamped with the "die" on the head of the marking axe. Means are thus afforded to determine whether any unmarked trees have been cut.

There are numerous types of marking axes. One type used by the U. S. Forest Service is shown in Fig. 14. The mark consists of the raised letters U. S. When a special axe is not available a substitute may be made from a shingle hatchet by cutting a letter or other mark on the hammer.

In marking timber one works over a given stand in progressive strips. 'The blazes are made on the side of the trees facing the outside edge of the strip. 'Thus, if the strips run north and south and progress east, the blazes are on the east side of the trees. This enables the 
marker to see the trees already blazed. Sometimes the trees are blazed on two sides.

A very rapid and convenient method of marking is to use a crew of three men, with one man to indicate the trees and the other two to make the marks. Frequently two or more men work together in a line, each selecting and marking trees. This method requires that each be a skilful marker, and is ordinarily more expensive than that of using one expert with one or more unskilled blazers.

The cost of marking varies enormously. The first work of marking in a forest is more expensive than later marking, done after the markers have been trained to the details of the work. At first the marking must be done by an experienced forester. Frequently, he can later turn the work over to a competent ranger and direct the work by occasional inspection, and thus reduce the cost.

In this country the cost of marking, in selection forests, has so far varied from 2.5 to 10 cents for each thousand board feet marked.

The cost of marking depends on the following factors:

1. Size of the Operation.-In general, the average cost per unit of volume of timber cut for marking is in inverse ratio to the size of the area marked.

2. Yield. - The larger the yield per acre and the larger the contents of the individual trees, the smaller the unit cost of marking.

3. Skill of the Marker.-An experienced marker can 
select the trees more rapidly and hence mark more cheaply than an unskilled man.

4. Simplicity of Silviculture.-The simpler the problem, the more rapid the selection of the trees.

5. Fase of Mechanical Work.-A marking crew can work faster when travel is easy, when the trees can be readily seen at some distance, and when the trees are easily blazed, than under the opposite conditions.

\section{Defects of a Rigid Diameter Limit}

In the northeastern woods it has been for a good many years customary for lumbermen to restrict their cuttings to the largest trees. They set a diameter limit, and instruct the cutting crews to take only trees above that size. All merchantable timber above the limit is cut, and none below, except such as may be required in the logging operations. It is assumed that there is a supply of medium-sized timber which will constitute the next cut. As a matter of fact, there is often a deficiency of thrifty trees just below the diameter limit capable of growth, and not uncommonly a large number of these are cut for skids, bridges, and other purposes in logging the mature timber.

Cutting to a fixed diameter limit disregards entirely the condition of the trees from the standpoint of health and possibilities of growth. 'The theory of the whole plan is that there are half-grown trees which will in a short time grow to full merchantable size. 'There are, however, in every virgin forest many trees below the 
diameter limit which are old, and will produce little growth, and may not live or remain sound till the next time the area is cut over. Naturally these trees ought to be cut and utilized. On the other hand, there are many trees just above the diameter limit which are growing very rapidly, and which it would be good business policy to leave standing.

Those practising this rigid method assume that reproduction will take care of itself. Under the scheme of cutting to a rigid diameter limit, this will not be the case. In a great many openings reproduction of the species desired will fail entirely, because of the removal from the neighborhood of all trees capable of bearing seed. As the work is usually conducted, a large amount of the small growth is injured through carelessness in logging. Some of this damage is necessary, but much of it is the result of thoughtlessness. The limitation of the cut, as the rigid limit is applied, itself is often a farce. Formerly, when only large trees were merchantable, there was little temptation to cut small timber. The stumps were ordinarily cut very high, and a rough rule was sufficient to prevent the choppers from taking trees below, say, 12 inches on the stump. Under present conditions a 12-inch limit measured on the stump is a different matter, because the trees are sawed and, with good logging methods, the stump-cut is well within the root swelling. A 12-inch limit now is equivalent to about a 10- or 11-inch limit under the old régime. It is seldom that the felling crew is required to measure 
the trees before cutting, while inspection is very lax, so that even when a company has the best intentions the plan fails to be properly carried out.

Another defect of the rigid diameter limit plan is that the limit itself is determined very largely by guesswork and tradition. A 12-inch limit under certain conditions may be conservative, from the standpoint of leaving the forest in a fairly productive state. In other conditions an owner may be deceiving himself as to the rate of production after cutting. As a matter of fact, this is exactly what is constantly happening. In many cases the owners have entirely overestimated the yield capacity of the forest under their method of treatment; and in the case of large corporations which are counting on an indefinite production this will be a serious matter. It would be wise business policy for such owners to determine what their forests can produce under a proper selection system, and then practise that system in the manner indicated in the foregoing section, so as actually to secure the production desired.

\section{Provision for Reproduction}

In the management of a selection forest the aim is to secure prompt reproduction of a suitable species in the openings made in lumbering. In some forests, trees of intermediate size, capable of bearing seed, are so well distributed that it may not be necessary to leave any large trees for this special purpose. In other cases the intermediate seed-bearing trees are scanty or not always prop- 
er!y located, so that some provision for seed distribution must be made from among the old timber.

Then, again, in mixed forests the intermediate trees near an opening may not be of the species most desired. 'The forester must endeavor to secure a distribution of seed by leaving seed-trees properly located. In leaving a seed-tree above the diameter limit, one must bear in mind that it involves an actual investment, for the tree might otherwise be taken out and sold. If the tree is salable now, but will not be so at the next cut, one invests its value in reproduction. If it is sound now, and likely to remain so till the next cut, it is merely a question of deferred profits. In any case, one must be certain that a special seed-tree is required, and that it will answer the purpose for which it is left.

Successful reproduction depends not only on a proper distribution of seed, but also on the conditions for germination, and for the development of seedlings. The problem is very simple with tolerant ${ }^{1}$ species, for these are able to grow in very small openings, and often a good reproduction is already established where the openings are to be made. With intolerant species, on the other hand, special measures often have to be taken if they are to be reproduced successfully. If such measures are not taken, other more tolerant species may occupy the opening to their exclusion. 'The opening must be large enough not only to give the trees a start, but also to allow them to make straight and thrifty growth. It is, therefore, some1 Tolerant species are those capable of enduring more or less neary shade. 
times desirable to enlarge an opening beyond what is necessary to remove a single mature tree. In such a case one would aim to cut several trees in a group; and in so doing it would often be necessary to cut trees under the diameter limit. Usually, however, this can be done without cutting medium trees of large promise.

\section{Protection from Windfall}

Very commonly a selection cutting would result in windfall among the trees left standing unless this point is regarded in the location of the trees to be cut. Sometimes it is necessary to cut whole groups clear, often as large as an acre, because they cannot be thinned without windfall. In many cases a tree, or group of trees, above the diameter limit must be left standing to protect the surrounding stand.

\section{Cutting Small Trees for Improvement}

The struggle for space in a selection forest is very great. The old trees overtop and crowd those coming up between and below them; the middie-aged trees crowd and suppress the younger ones, while all the competing trees are crowding one another. A poorly developed tree of small promise may often injure several trees of better form and species. The removal of such poor trees greatly increases the total growth of the stand. 


\section{Influence of Market Conditions}

The principles given in the foregoing are subject to restrictions in their practical application imposed by poor market conditions.

In the first place, it may happen that only a certain number of the species are merchantable. Thus, for example, in the Adirondacks there are certain areas where a number of the hardwood species cannot be marketed at all. Sometimes the best individuals of a species can be cut at a profit, but the crooked and defective trees are not merchantable. Ordinarily it is the merchantable species which the forester desires to reproduce. If he cannot cut the less desirable kinds, he is forced to leave the ground practically in their possession for reproduction. This will result in a reduction in the proportion of the best species. There is, however, no alternative except to wait for a market, and this is often, if not usually, impracticable. Whien such is the case the forester leaves the forest in the best condition for reproduction possible under the circumstances, but he must expect that there will be certain areas on which the poor species will gain the upper hand.

The larger trees which cannot be sold-because they are either of poor grade or of poor species-usually interfere with the growth of trees of better character. Their removal would increase the growth of the forest by releasing the trees which they crowd, and replacing them with reproduction of valuable species. But this would 


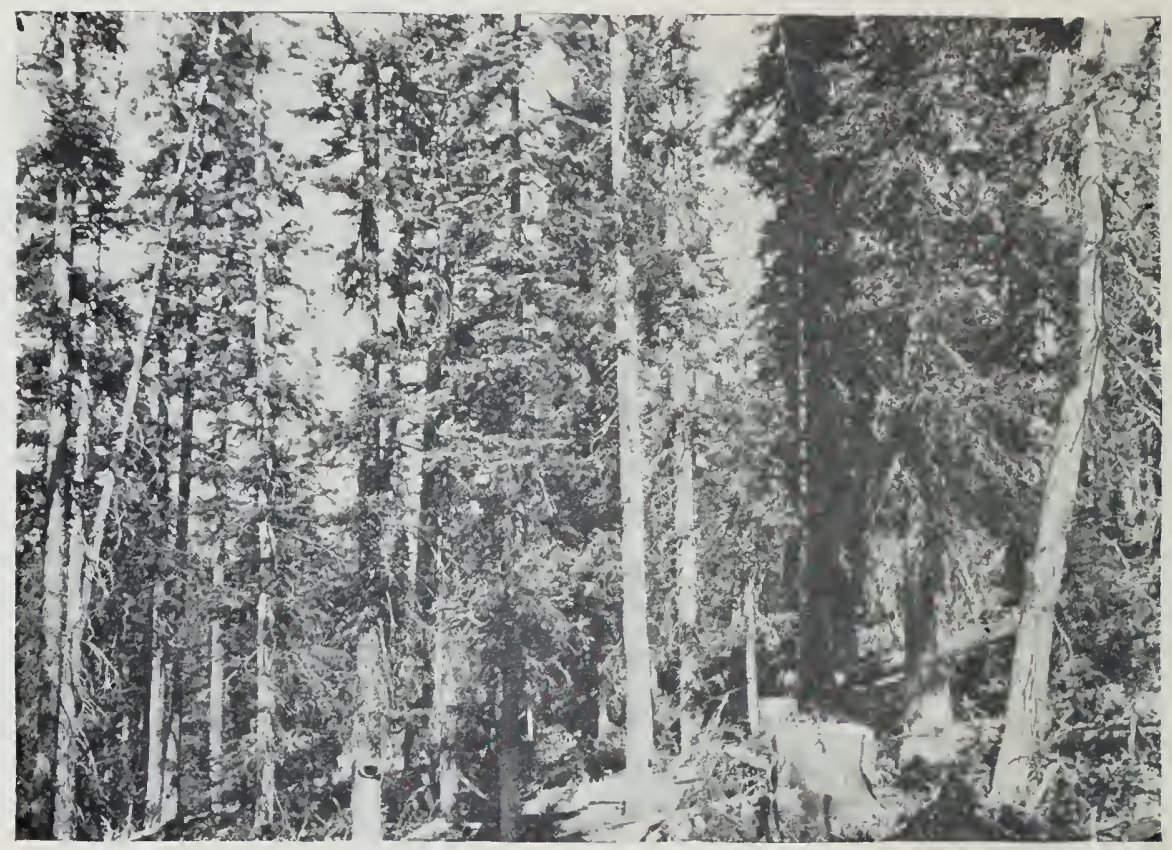

FIg. 15.-A Stand of Engelmann Spruce after a Selection Cutting. Arapahoe National Forest, Colorado.

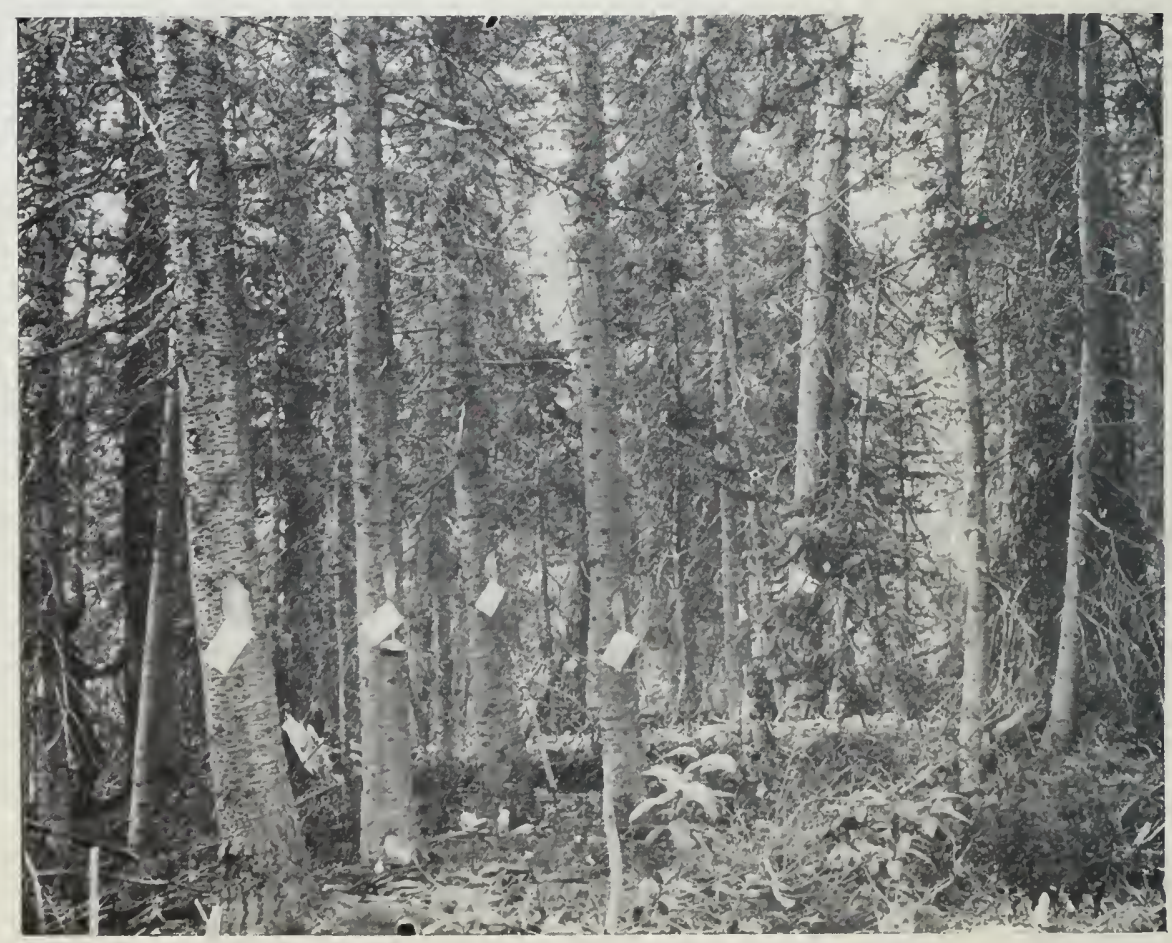

Fig. 16. A Group of Balsan Firs Marked for Cutting in a Selection Forest. Their Removal will Favor the more Valuable Spruce. Arapahoe National Forest, Co'so:ado 
be an actual outlay which often would not be justified. The experiment has sometimes been tried of girdling these trees. Doubtless this expedient would be practicable in certain instances in public forests, but there are usually more important cultural operations which demand the use of whatever money there is to devote to such purposes. Sometimes the danger of injury to young growth from the windfall of girdled trees would fully offset the advantages secured. As a rule, therefore, the cutting or girdling on a large scale of large, mature trees which cannot be sold is not advisable.

A poor market means that small individual trees cannot be sold. It would be impossible, with a poor market, except at considerable expense, to cut all the trees below a diameter limit which are defective, unpromising, or interfering with reproduction and with the growth of other better trees. The amount of money which can be spent on cutting small trees for these purposes depends on the returns which would result. The question must be worked out in the same way as any other proposed investment.

\section{Cost of the System}

The cost of forestry with the selection system depends on the following factors:

1. Increased Cost of Logging.-In any selection forest, like most of our virgin forests, the lumberman has to go over a good deal of ground for the timber. If there is a further restriction of the amount cut by limiting the size to only the largest trees, and by leaving seed-trees, 
the cost of logging per unit of volume is increased. As a matter of fact, most of the merchantable trees left standing are small, and the profit from them is insignificant. Often there is no profit from them at all, or there may even be actual loss in logging them. Thus the increase in cost of logging under the selection system is so slight that it may practically be disregarded.

Lumbermen usually contend that the trouble to the choppers in looking for marked trees adds to cost. As soon as the crews become accustomed to the work, there is no increased cost due to this cause.

2. Cost of Protecting Young Growth.-The felling crew has to be careful not to injure small trees in felling, and the skidding crew must avoid breaking down small trees and barking those of medium growth. A careful chopper does not in any case throw his tree into groups of young growth; and an intelligent swamper always avoids small trees, to save himself needless labor. An unintelligent crew will do a great deal of damage. A careful crew is able to hold down the damage to a minimum, without extra cost.

3. Increased Cost of Construction Work.-Ordinarily, a logger uses for skids, building bridges and skidding roads, etc., the straight, well-formed trees of medium growth which happen to be most convenient to his work. These are exactly the trees which the forester woukd save. If the logger must go to a greater distance to secure this material, and if it is less easily handled, there is a cost which adds to the total cost of lumbering. 
While this item is difficult to estimate, it is never large.

4. Value of Seed-Trees. - If seed-trees are left which have a value now, but will deteriorate before the next cut, there is an item of cost. Ordinarily, such trees are not left. Their total would be so small as to be insignificant in a large operation. If thrifty trees are left which will live till the next cut it is an investment comparable to that of leaving the small merchantable trees. The increase of stumpage price will often more than cover the investment, even if there should be no increase in volume by growth.

5. Cost of Improvement Work.-Under this head are comprised special measures to aid reproduction, and to improve the condition of the small trees. Usually this investment is not made at all. In case of valuable species, improvement work is often desirable and profitable.

\section{Intensive Development of the Selection System}

It has been shown that the selection system is usually the first development of forestry in a newly developed country. With a virgin forest of selection form and with a market only for the largest and best trees, the lumberman's first cutting resembles a conservative selection cutting, even though not designed by him to be such. With unfavorable market conditions, the system may thus be applied in a crude or primitive manner. On the other hand, with good market and logging conditions it may be developed into one of the most highly inten- 
sive of all systems, as illustrated in certain forests of Europe.

In the primitive application of the selection system, as described in the foregoing pages, the handicaps of markets and transportation prevent more than a rough protection and care of the young growth. If there is a market for all products and a system of permanent roads, the cutting cycle may be reduced even to a single year. The aim is then to make provision, as fast as the forest permits, for a proper representation of age-classes; reproduction of the right species is secured, if necessary, by planting; improvement work is done throughout the given stand, so as to give each tree the right amount of space for its best development; deteriorating trees, those of poor form, and injured trees are cut at the proper time. In other words, instead of handling the forest under long cutting cycles and large logging units, the management is intensified, the units are reduced in size, and each stand is cut over at frequent intervals.

This intensive development of the selection system finds its expression in a number of special forms of application in Europe. In general, the tendency is to transform the forest into the group-selection form, in which each age-class occurs in groups instead of in the singletree arrangement. The groups vary in size from fifty feet to severa: hundred feet across, are irregular in form and area, and their iocation in relation to each other is irregular; but the aim is to secure an equal aggregate area of each age-class in each stand. 'This develop- 
ment is really a series of even-aged groups, instead of larger, even-aged stands, which means a much more intensive management if each group is carefully handled for its best development. A prominent European forester, Dr. Ney, has carricd out this idea still further, and has merged the various groups of each age-class together in the form of regular or irregular strips.

\section{Results of the Selection System}

The selection system results in a many-aged form of forest which is well adapted to the protection of mountain slopes, because in the management of selection forests clearings are never made, and a permanent soil cover is maintained. It is a form most admired from an esthetic standpoint, and hence well adapted to public forests used as recreation grounds.

Comparing two forests, of which one has separate, even-aged stands of different ages, and the other is managed on the selection system, with trees of different ages mingling together singly or in groups, it is usually held that the growth of the latter is the less. In the former, trees grow in even competition with each other, and without cover overhead. In the selection forest the growth of individual trees is retarded, because of the shade either overhead or on the side during a large part of the tree's life. In the selection stand there are a very large number of trees, because the crowns overlap, but usually this advantage is not enough to equal the retarding of the growth by shading. There is no 
question that with intolerant species the growth is the greatest under one of the even-aged systems. With tolerant species and intensive management it is probable that as great an increment can be secured by the selection system as by any other.

The deveiopment of the individual trees in a selection stand is somewhat different than in an even-aged stand. They are apt to have larger crowns and larger diameters than those produced in even-aged stands. Because of the larger crowns, there is less clear bole and the knots are larger. The trees pass through periods of retarded and full growth, and hence the grain of the wood is less even.

\section{Choice of the Selection System}

The selection system is used in forests where the market conditions are such that only a limited class of trees can be cut at a profit. It is used in those all-aged forests in which the various sizes are represented, and the removal of the medium trees would be less profitable than saving them for growth and later cutting. It is an excellent method for the handling of a woodlot which is culled frequently for fuel, poles, posts, rails, and occasional sawlogs for home use and for sale. It is the ideal system for forests on ridges and slopes, where it is important to keep a continuous forest cover to control runoff or to prevent erosion. - It is particularly applicable to forests composed of tolerant species; it may, however, bé used successfully with intolerant species, provided that in making cuttings the openings are made large enough 


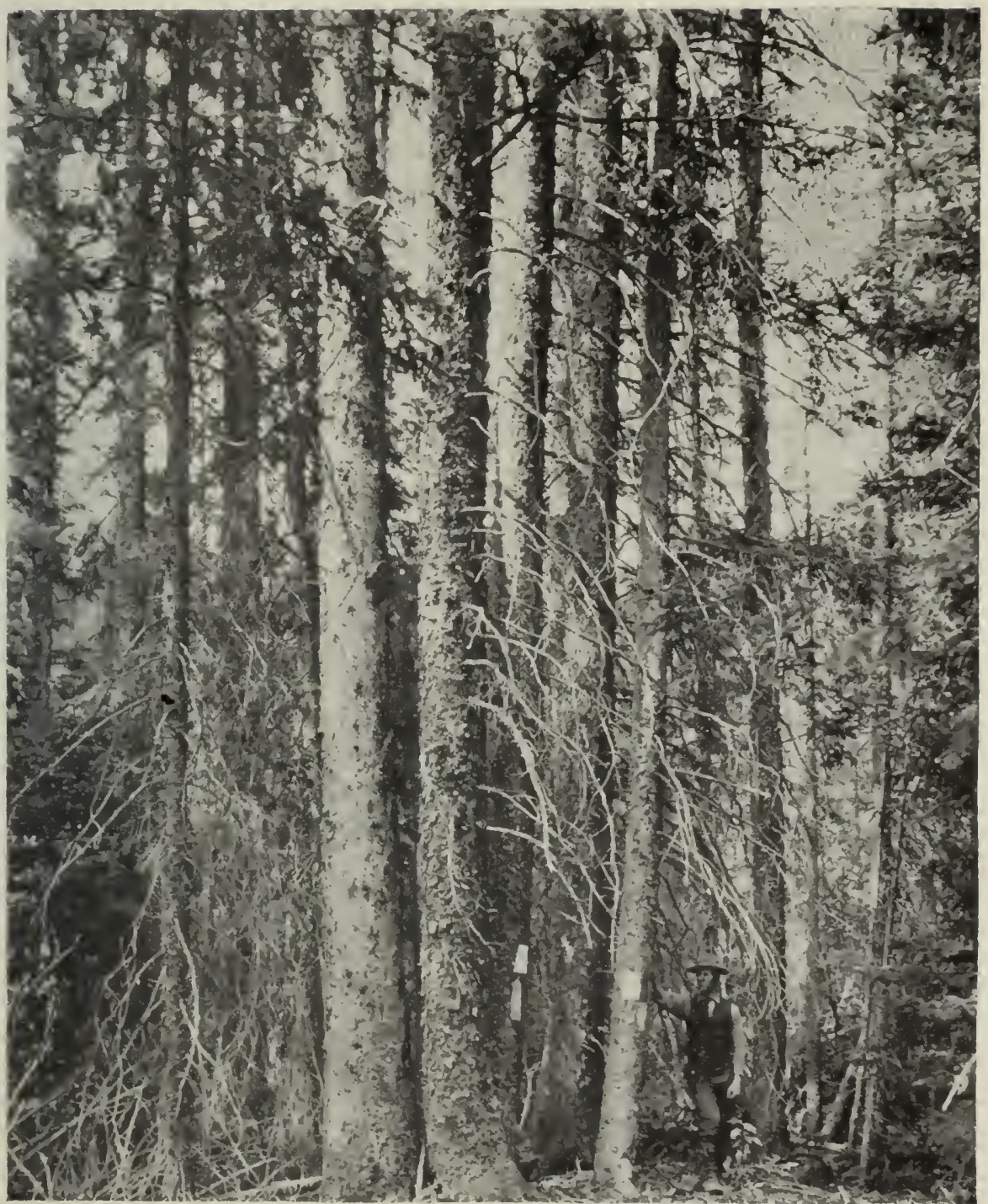

Fig. 17. - Trees Designated for Cutting under the Selection System. Arapahoe National Forest, Colorado. 
to secure reproduction and to permit the new stock to develop.

It is not applicable to even-aged stands. As the market in a given region improves, and as the smaller sizes of trees and those of inferior species become merchantable for fuel and other purposes, the tendency is away from the selection system. As intensive methods become practicable, the tendency is to use one of the systems resulting in a clearing and an even-aged new stand, rather than to use the intensive application of the selection system. This is well seen in continental Europe. There, the selection system is most widely used in the protection forests and the less accessible regions of the mountains, in which the market is still very poor. In regions in which all of the products have commercial value and the markets are good, it is the clear-cutting systems and the shelterwood system which are most used, and, as a result, the common form of forest is even-aged.

In this country the better-settled regions have an increasing proportion of even-aged stands on the cutover lands. This is partly because of the prevalent method of cutting, but partly because fires have followed cutting and made clearings. The second growth has more the character of an even-aged forest than otherwise, particularly among the conifers.

\section{Example in the Spruce Forests of the Northeast}

'The spruce forests of northern New Fingland and New York contain extensive areas to which the selection 
system is admirably adapted. 'This is particularly the case in the rolling plateau regions, such as most of northern Maine and the Adirondacks. In these regions the forest is almost altogether of a selection character, and trees of different ages are mingled together individually and in small groups. The natural form of the forest is due to the fact that the majority of species are tolerant of shade. These are spruce, hemlock, fir, beech, and hard and soft maple. The birches are very abundant species and, though less tolerant than the other trees, they can still hold their own in the selection forest. The intolerant species, like pine and larch, occur localized, and usually come up on new-made land, on the borders of lakes, and on clearings made by windfall and fire. On certain types of land where windfall has been extensive in the past, like swamps and steep slopes, there are groups and often whole stands of an even-aged character; but the forest is mainly all-aged.

Suppose that a privately owned tract in the western Adirondacks is to be managed under the selection system. In organizing it, the first step is to analyze the stand to determine for each species the representation and distribution of the different size-classes. This analysis shows the number of sound trees of different diameters, and makes it possible to determine what can be cut at a profit at once, and what will be left for the formation of a merchantable cut in the near future.

The next step is to determine the rate of growth or increment of the forest. It is not the present growth 


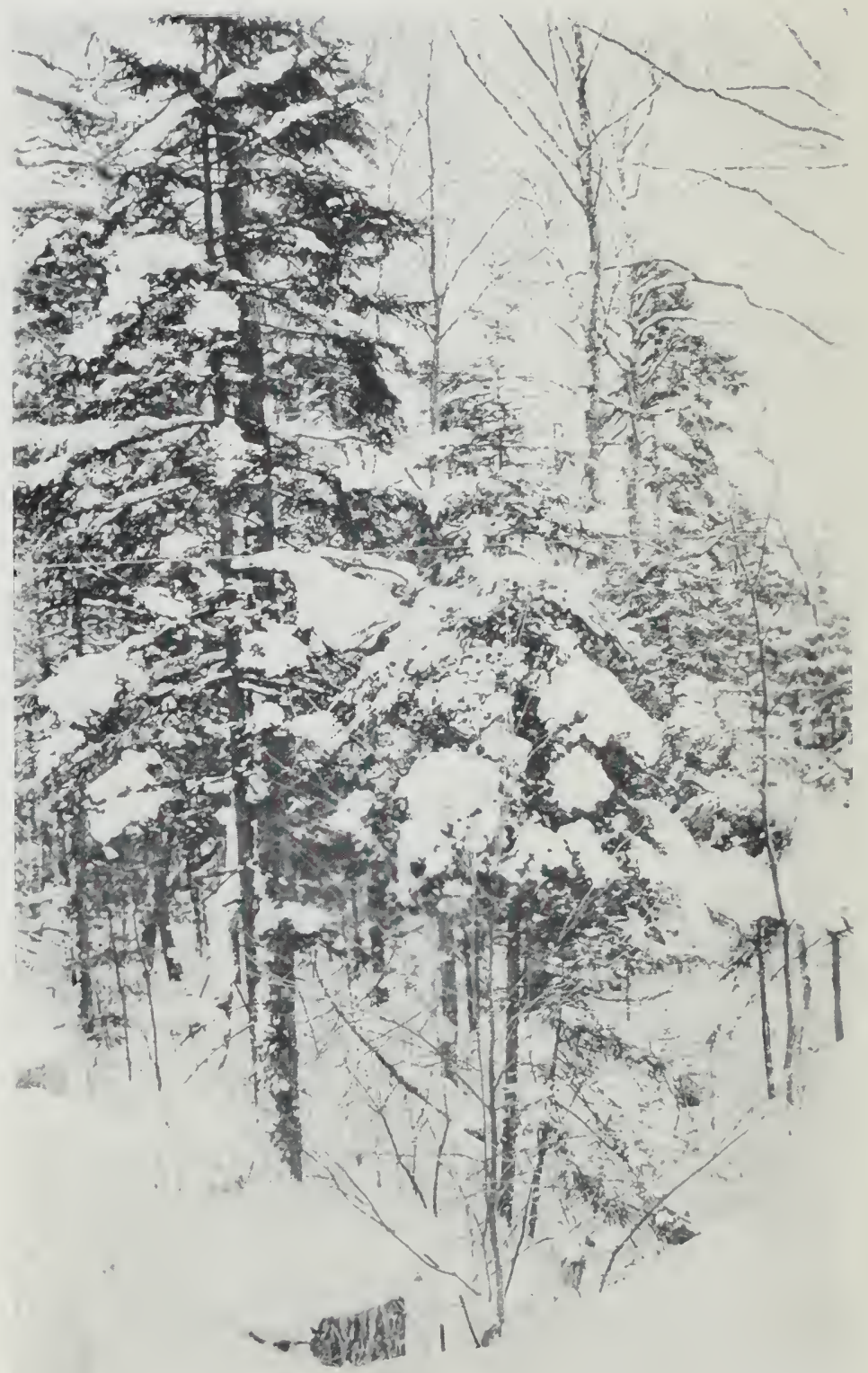

FIG. 18. - A Stand in the Adirondacks in which there has been a Selection Cutting. 
which is desired, but the growth of the stind after lumbering. The forester therefore makes a study of growth, which enables him to predict the rate of growth of the middle-sized trees; that is, those which will be the merchantable trees at the next cutting. In calculating the number of trees which will be standing after the lumbering, it is necessary to assume that the lumbering will take all trees above a diameter limit. Of course, the rigid diameter limit will not be used in the cutting, for the reasons already explained. The trees cut below the limit about offset in volume those left standing above the limit.

But it is not known in advance what general average limit is desirable. The forester therefore makes trial calculations of growth on the basis of several limits. Thus, in the case of spruce a superficial study shows that the limit may be below $1+$ inches, breast-high. The trees above this size are old and mature, and should be cut and utilized as soon as possible. Moreover, a higher limit would ordinarily not yield a profitable cut. One can readily see that a cut below 10 inches would deplete the pole-class so severely that the production of the forest would be reduced by an excessive amount. Hence the forcster makes trial computations of the rate of growth, assuming a cut first to 10 , then to 12 , and then to $1+$ inches.

A comparison of the various possible limits, and the possible present and future returns, together with a consideration of the problem of reproduction, enables the 
forester to fix the most desirable limit. In the supposed case in the Adirondacks, all conditions show that 12 inches is the desirable average limit for spruce. This corresponds to an average age limit of about 185 years. The growth after cutting will be approximately 110 board feet per acre per annum, compared with about 70 feet if 10 inches had been chosen as the diameter limit.

The other species are studied in the same way, and an average diameter limit is determined which will meet all requirements.

If all species are merchantable, one makes selections in accordance with the principles explained on page 56. Trees above the established diameter limit would be cut, except where needed for seed or some other special purpose. Trees below the limit would be left standing, except when they are defective, or interfere with better individuals, or have reached their limit of growth, or are of poor species likely to seed up openings, or for any other reason would benefit the stand by their removal.

Unfortunately, at the present time some species are not merchantable. In the Adirondacks it is often the case that only the spruce and the best individuals of hemlock, of fir, and of some of the hardwoods are merchantable. There is no market for the defective and crooked hardwoods, or for those small trees whose removal would benefit the stand.

The forester is therefore in the position of having to restrict his cuttings to the choicest trees in the forest. Many poor species are left which will distribute seed in 
the openings, and thereby compete in the next crop with the better species. Defective trees occupying the ground prevent reproduction by their shade, or they may be crowding and injuring valuable individuals. 'The result is that in some instances the poorer species will increase in the reproduction. In some types of forest the hardwoods will crowd out the spruce, while occasionally soft maple or beech replace the better birch and hard maple. Not only will the reproduction be of poorer quality than would be the case if the markets were favorable, but, on account of the impracticability of releasing crowded trees, the growth in the immediate future, as well as in the long run, will be less.

Under these conditions there are two alternatives: first, to defer cutting altogether and wait for better markets, when the cuttings under the selection system or some other one can be conducted in a better way than at present; second, to carry out the cuttings in the best manner possible under the present unfavorable conditions, with the full realization that the future returns will be somewhat less than would be obtained by more intensive work. In some cases it would be wise on State land to defer the cuttings for a better market. The State is not obliged to pay interest on investments, and can afford to hold the timber for 'ater realization.

Most private owners, however, cannot afford to hold their valuable timberlands without returns for a long time. They wish to realize something now, and to reduce the investment in the forest, which, cren under 
our best conditions, is exposed to considerable risk from fire. The policy is, then, to cut among the merchantable trees, with a view to leaving the forest in as good condition as possible for increment and for reproduction.

Under the conditions assumed, the forester has in mind the following general principles in marking the trees for cutting:

1. The following average diameter limits are used as a guide in the marking:

For spruce.............. 12 inches

For fir................. 10 "

For hemlock ............. 12 " "

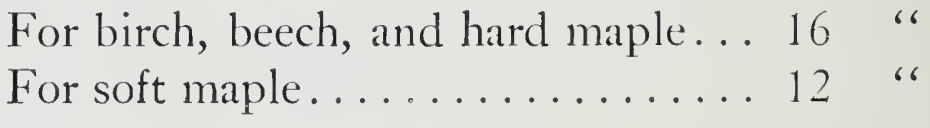

2. All trees above these respective limits are cut, except those needed for seed or for some other special purpose.

3. All trees below the limit are left standing, except such merchantable trees as are growing very slowly and will not live till the next cut.

4. Trees which are not over 3 inches larger than the diameter limit, and which are growing very rapidly and obviously increasing in value at a rapid rate, should not be marked.

5. Very old and slow-growing trees which are below the limit, but are incapal)!e of increasing their growth after release, should be marked, unless needed for some special purpose. 
6. All trees certain to be blown down should be marked.

7. Trees likely to be destroyed or seriously injured in lumbering should be marked.

8. It is occasionally necessary to leave trees above the limit, if their removal would result in serious windfall. This is particularly true of the hardwoods.

9. In leaving special trees for seed, spruce and white pine should be favored over all the other species, and hard maple and birch should be favored over hemlock, beech, fir, and soft maple.

10. A seed-tree should never be left where it will not serve its purpose. Thus, on hardwood land where abundant birch and maple seed-trees stand, there is little use in leaving for seed a spruce above the diameter limit.

11. In selecting seed-trees, only such as have a welldeveloped crown and are now capable of bearing seed should be left.

12. In choosing between trees for seed, each of which will serve the purpose equally well, the smallest should be chosen.

13. Do not leave seed-trees-

a. Which wili be blown down.

b. Which will be broken or destroyed in logging.

c. Which are likely to be cut for lumbering purposes.

d. Which must be cut to make way for a logging road or skidway. 
14. Seed-trees above the limit are left only where there are none below the limit to answer the purpose.

15. One or more trees of the species capable of bearing seed should be left on the border of every opening 15 feet or more in width.

16. In openings resulting from the cutting of a group of trees, and 50 feet or more wide, seed-trees should be located on the side toward the prevailing wind.

17. In case an opening is on a slope, the seed-trees should be located above rather than below the opening. 


\section{CHAPTER III \\ SYSTEMS OF CLEAR-CUTTING}

\section{Definition of Clear-Cutting}

A clear-cutting occurs on a given area when all of the trees are removed, or at least such a large proportion of them that those which remain do not materially affect the growth and development of the new stand. A clearcutting may be contrasted to those systems of cutting in which at any given time the stand is culled by the removal here and there of a tree or group of trees, and there remains after the cutting a sheltering cover which influences, advantageously or otherwise, the new stand.

A given stand may be cleared either in one operation or gradually in a series of operations, each of which has the character of a clear-cutting. In the latter case a short period usually elapses between the cuttings. The whole stand is, however, cleared within a limited time, usually not over 20 years. There are certain exceptions to this principle, which are described under the different methods of clear-cutting with natural reproduction.

\section{Conditions Requiring Clear-Cutting}

The popular impression is that the practise of forestry consists of thinning the forest in the manner described 


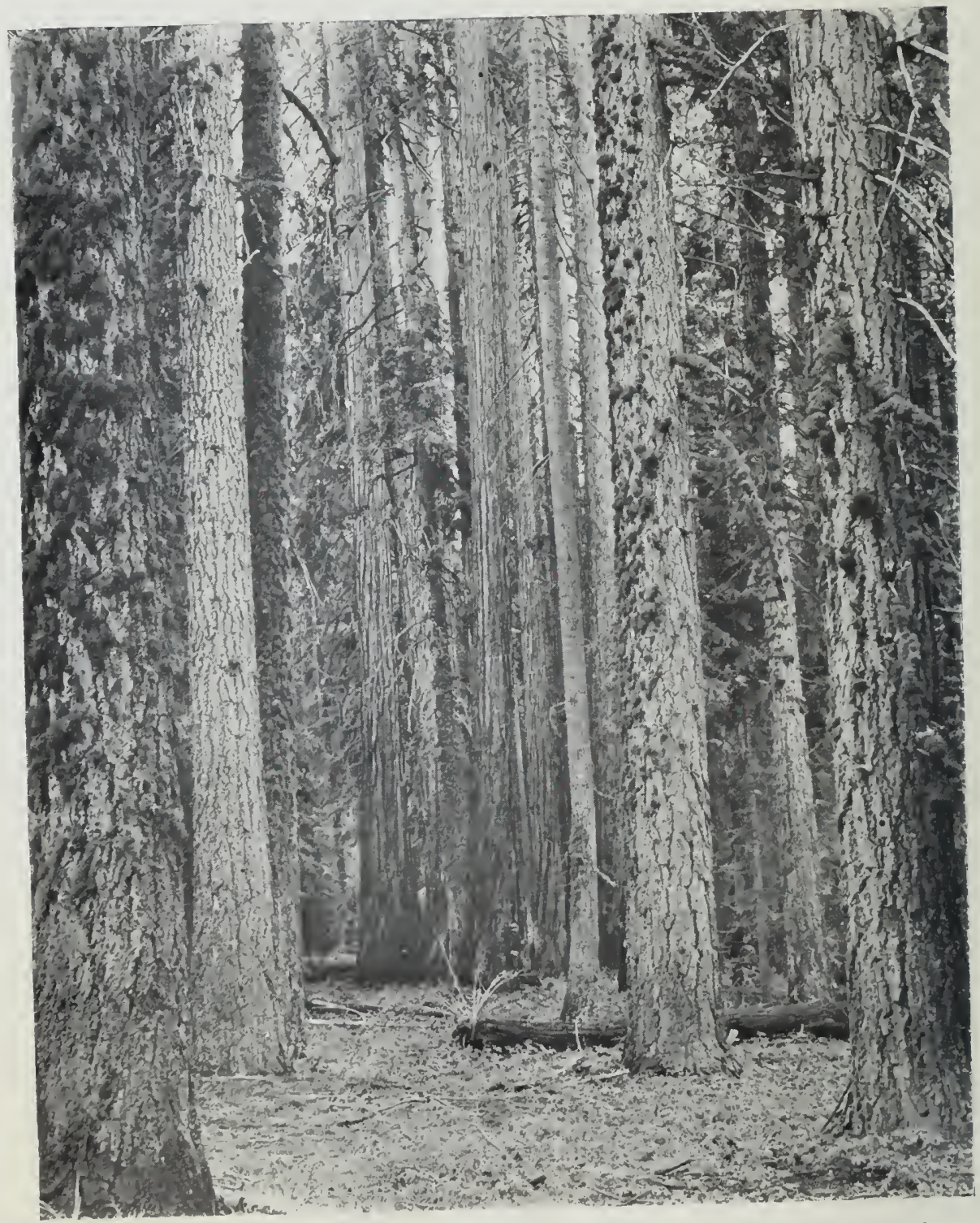

Fig. 19,-A Stand of Douglas Fir and Cedar of Great Size and Age. A System of Clear-Cutting is Required. Washington. 
for the selection system. The method of culling only the largest trees and leaving the smaller ones is, however, applicable only to stands having trees of different ages mingled together. In handling a stand in which all, or nearly all, the trees are mature, the design is to remove the whole stand, and replace it with new growth in as short a time as is feasible. This is accomplished either by one of the clear-cutting or one of the shelterwood systems.

The conditions requiring a clear-cutting are the following:

1. Where there is danger from windfall. Such a condition is found in mature coniferous forests which are growing on steep slopes and ridges in the mountains. For example, the spruce stands growing on the exposed slopes in the mountains of northern New England and New York cannot, as a rule, be heavily thinned, because the trees left standing would be almost certain to be uprooted by the wind. In most cases, however, a very light thinning, such as could safely be made, would not pay, so that some system of clear-cutting is necessary.

Conspicuous examples of the same principle are found in the mountains of the West. The lodgepole pine in the Rocky Mountains grows at high elevations in exposed situations. The stands are usually regular in form and the trees long and slender, with shallow lateral roots. Attempts to thin mature stands of lodgepole pine have, in many cases, resulted in heary windfall.

2. Where all the trees are large and mature, and prac- 
tical considerations of logging require a concentration of cutting.

3. Where the trees are so large that their removal after reproduction is established would result in destruction of the young growth.

t. Where the trees are so large and valuable that their retention for seed would involve a greater investment than artificial planting.

5. Where a clearing is necessary to remove trees of undesirable form or poor species, in order to establish artificially better species.

6. Where a clearing is necessary to secure good natural reproduction of some species which cannot thrive under shelter.

Frequently a clear-cutting is required by a combination of the conditions just enumerated. Thus, for example, in the Cascade Mountains of IVashington a stand of red fir, cedar, and hemlock from 400 to 800 years old, with trees from 4 to 10 feet in diameter, and from 200 to 250 feet high, presents the conditions of overmaturity of all trees, great expense of logging, and the impossibility of removing trees without injury to young growth. It is obvious that under such conditions a clear-cutting is necessary.

\section{Disadvantages of a Clear-Cutting}

'There are certain disadvantages attendant on the clearcutting system, as follows:

1. In any clear-cutting system there is necessarily al 
period in which the soil is exposed to the action of the elements. Even if the new stand is started at once after cutting, a number of years must elapse before the canopy is closed and the soil shaded. There may be a deterioration which influences, at least temporarily, the growth of the stand.

2. On slopes the exposure of the soil after the clearing may result in more or less serious erosion.

3. Grass, brush, and weeds spring up readily on clearings to a greater extent than under the shade of trees. This undesired vegetative cover interferes with reproduction, and competes with the young growth.

4. The young trees are exposed to drying by sun and wind.

5. In certain localities the young growth suffers from frost.

6. The young growth is apt to be more damaged by insects than when it starts under shelter.

The disadvantages of clear-cuttings are in direct ratio to the size of the clearings. Many of the evils of clearcutting can be obviated by reducing the size of the arear clear-cut. Intensive forestry avoids large clearings; and when a given stand of considerable size is to be removed under an intensive management, it is cut in a series of operations, each confined to only a portion of the stand.

\section{Methods of Reproduction}

Reproduction after clear-cutting may be accomplished artificially by planting young trees, or by sowing seed; or 
it may be accomplished by natural seeding from seedtrees, properly located for the purpose. Very commonly, natural and artificial reproduction are both used; a stand is reproduced as far as possible by natural means, and the areas incompletely stocked are filled by planting.

Advantages of Artificial Reproduction.-Contrasting the two methods, artificial reproduction has the following advantages:

1. The new stand is established at once. Natural reproduction often requires from 5 to 10 years to stock an area with young trees.

2. Artificial reproduction is more certain of success.

3. The forester is able to establish the species best adapted to the soil and best suited to the requirements of the market.

4. The trees may be given the right amount of growing space for their best development. Natural reproduction is often too dense or too open.

5. For the reasons already given, the yield of highgrade material is usually greater from artificial than from natural reproduction.

Advantages of Natural Reproduction.-On the other hand, natural reproduction has the following advantages:

1. It is usually cheaper than artificial reproduction.

2. With certain of the methods of natural reproduction there is a continuous partial shelter over the ground, and consequently less danger of soil deterioration.

3. Natural reproduction follows nature more closely, 
and is apt to produce a mixed forest, whereas the tondency of artificial reproduction is toward pure stands, which are less desirable over large areas than the former.

t. Natural reproduction is peculiarly adapted to rough conditions, like those in this country, where intensive methods are often not practicable.

Artificial reproduction is necessary when it is desired to establish a species different from any that occurs naturally on the ground. It is necessary where seed-trees are not present in proper location.

Artificial reproduction requires large initial outlay; often, therefore, it is impossible, even when it would obviously be the more profitable in the long run.

In general, natural reproduction will, for the present, be used chiefly in operating forests on a large scale in this country.

\section{Clear-Cutting with Artificial Reproduction}

Under this method a specified stand is cut clear, and the area is restocked by planting or by artificial seeding. Ordinarily the planting or seeding is done after the cutting, and not in advance of it. 'The logs and other material are removed as soon as possible, and the slash is disposed of by buming or otherwise. The ground is then clear, and may be restocked by setting out young trees or by sowing seed.

It is desirable to start the new stand as soon as possible, in order that there may be no loss of growth, and also in order that the new trees maly gain sufficient head- 
way to compete with the weeds and brush which inevitably spring up on clearings.

Use of the System in this Country.-The systems of forestry which will be practised in the United States in the immediate future will, for the most part, be those which depend on natural reproduction. The clear-cutting system with artificial reproduction will, however, be used under certain circumstances, and the use of the system will increase rapidly in the future, as the opportunities to practise intensive forestry become more common. The conditions under which it will be practised fall under the following groups:

Use in National Forests. - IVithout doubt, there will be in the immediate future many areas of public forests in which natural reproduction of a desired species will be exceedingly difficult. At the present time, planting on public lands is largely confined to barren areas. As the organization of the planting becomes more complete, and as the knowledge of the methods of planting is perfected, the system will undoubtedly be used in replacing mature stands where now natural reproduction is chiefly relied upon. It will find an extensive application in certain forests of the West, where the trees are very large and valuable, and where any system of natural reproduction involves an investment comparable to artificial reproduction. Already in certain instances this system is being used by the Forest Service in cutting the overmature forests of the Northwest.

Suppose, for example, that there is a block of over- 


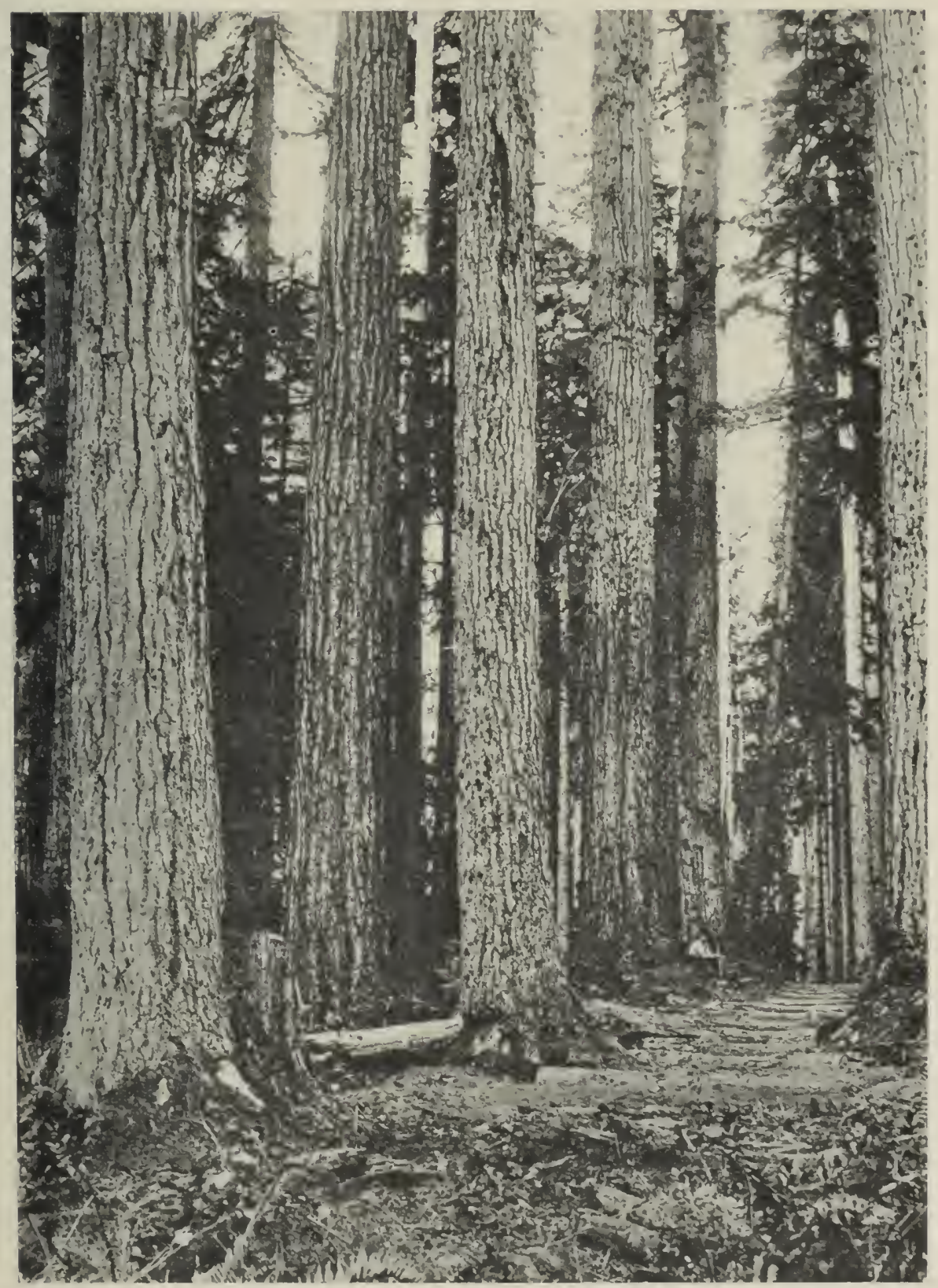

Fig. 20.-A Heavy Douglas Fir Stand in Washington, Calling for One of the Systems of Clear-Cutting. 
mature old fir, hemlock, or cedar corering an area half a mile wide. Suppose, further, that it would not pary to log in strips and patches, but only to cut clear the whole area; and suppose, further, that the only feasible way to secure natural reproduction were to leave as seedtrees large trees containing at least 2,500 feet each-very common conditions on the Coast. There is no question that the best method would be to cut clear and restock artificially. The Forest Service is using this method more and more. It has been frequently possible to rely on natural reproduction, but as the sales of timber increase and the areas cut orer become larger, the artificial restocking will be increasingly used.

It is probable that this system will be applied in certain portions of the semiarid region of the IVest. For example, in the Southwest there are certain types near and at the edge of the forest where reproduction comes exceedingly slowly. Frequently the present forest is mature, and it is desirable to make cuttings to utilize the timber while it is sound. 'There are, for instance, hundreds of acres of ITestern yellow pine in which the majority of trees are mature, with very little young timber, and where the conditions for reproduction are such that it is exceedingly doubtful whether the removal of the trees will be followed by young growth within any reasonable length of time. It may be that not less than from 50 to 75 years will have to be allowed for securing adequate reproduction. A period of 50 years amounts to fully one-half or two-thirds of a tree generation. 
We may well saly that under such circumstances forestry would be unsuccessful, and that it would be bet. ter policy in a public forest of this character to resort to artificial reproduction. It is probable, therefore, that under these difficult circumstances certain areas will be designated upon which natural reproduction is so difficult and hazardous that a system of restocking by artificial means will be adopted.

The actual conduct of the work would be governed by local conditions. Under the circumstances just described extensive clear-cuttings would be dangerous, for if it is difficult to secure matural reproduction it will also be difficult to protect the young trees from the drying influences. There has been little experience in planting such a tree as Western yellow pine under the conditions in question. The methods must be learned by experiments which will also determine how much shelter is required by the trees in youth. It may he necessary to restrict clear-cuttings to patches not over 10 or 15 acres in extent, or it may be found necessary to leave a portion of the stand as a shelter during the early life of the young trees. In the latter case the system of forestry would no longer be clear-cutting, but one of the methods of shelterwood cuttings described in a later chapter.

Use in State Forests. - There will be in the near future mans areals within State forests where an intensive system of forestry can be practised. In practically all States there will be dereloped State nurseries and an organization for planting. At first, just as in the Nil- 
tional Forests, the planting will be confined largely to waste areas. Cuttings will, however, be made in the mature portions of the forest, and in some instances a clear-cutting will be necessary or desirable. Suppose, for example, that there is a stand of 25 acres of mature pine of even age. This may be located so that a system of thinning and gradual removal of the trees can be used. It may happen, however, that much better results would be obtained by cutting the stand clear, and restocking the area by planting. Under the present conditions of the market such a system might be financially the best plan. Again, the timber might be so located that any system of thinning would be followed by windfall. In such a case it would be necessary to make the clear-cutting and restock the area either by a natural reproduction from seed-trees on the edge of the clearing or by planting.

It frequently happens that the areas acquired by the State have been badly damaged through unintelligent and reckless lumbering in the past, and are covered with undesirable species or an open stand. Under such conditions natural reproduction might result in a stand of a species which never would have much value. Thus, for example, the State forester might be operating on land suitable for white pine, and yet be unable to secure through natural reproduction anything but undesirable hardwoods. Fiactly this condition wals met in the Adirondacks on certain portions of the tract operated by Cornell University from 1899 to 1902 . The tract had been 
cut over and most of the softwoods removed, and the land was capable of producing pine and spruce; but natural reproduction would yield only hardwoods. A large part of the stand was of poor quality, and it was found that cuttings could be made profitable only by removing most of the stand. It was therefore decided that the best interests of the State lay in cutting clear and replacing the forest by a new one of softwoods. 'This system involved a large initial expenditure, with a view to large future returns in the form of a large yield of valuable timber. The experiment in the Adirondacks was the first instance of clear-cutting and planting on a large scale in this country, even in public forests.

Use in Private Forests. - It is probable that the system of clear-cutting with artificial reproduction will not be practised on a large scale by private owners in the United States for a long time. It is not unlikely that some owners may supplement the work of natural reproduction by planting, but this, like other intensive systems of forestry, will be chiefly confined to public owners and to small owners.

The system will, however, be used commonly on a small scale. Owners of small tracts who are interested enough to practise forestry at all, are impatient to see results. They are not willing to wait 10 or 20 years for natural reproduction to take place on a clearing. 'The area cleared is usually small, and the cost of restocking by planting not large. Not uncommonly the clearcut area would not be orer 5 or 10 acres. Ithen, for 
example, a private owner has patches of matured trees of a few acres each, much the simplest plan is to clear-cut and replant. An example of this condition is found in the lands owned by the New Haven Water Company, and operated by the Yale Forest School. An area of 2 acres of old hardwood timber was cut clear and restocked artificially with white pine. The total cost of planting was about $\$ 16$. The ground had run wild, and it would have been impossible to secure anything more than a meager stand of hardwoods through natural reproduction. In 40 years the resulting stand of hardwoods would have yielded about 20 cords per acre, with perhaps 10 per cent. of the material suitable for ties, and a money value of perhaps $\$ 30$ per acre. A pine plantation will yield in 40 years material worth at least $\$ 150$ per acre. Such an investment is worth while for a permanent concern like a water company.

In many woodlots there are stands composed of poor species, or of trees of poor form and quality. Where the material can be utilized, the best system of forestry is to clear-cut such stands and replace them artificially by a new growth of valuable species.

As the knowledge of tree planting progresses, and as private owners can secure seed and young trees at reasonable rates, clear-cutting with artificial reproduction will be used more and more.

Clear-Cutting the Whole Stand.-Under this method a whole stand is cut clear and the area restocked artificially. It is the method of clear-cutting which will be 
most commonly used in this country. In many cases the stand comprises a restricted area, which is cleared in one year's operation. In other cases there may be a very large stand of mature timber to be cleared, requiring severa! years' consecutive work to finish. In the latter case, the area cut in a single year is large, and is not comparable to the strips or patches described in the succeeding sections.

Clear-Cutting in Strips.-It has been explained (page 86) that extensive clearings are attended with certain dangers. In order to reduce these dangers, the strip clear-cutting was devised. This consists of removing a stand by a series of clearings in progressive strips, each relatively narrow. After cutting a given strip the new growth is established, and then several years are allowed to elapse before the next strip is cut. The new stand is in a measure protected by the neighboring trees, and at no time is there a very large clearing in any one place. This method is common in Europe. Its application in this country will for the present be confined to second-growth woodlots.

Clear-Cutting in Patches. - Under this method small clearings, more or less irregular in size and shape, are cut in the stand and restocked artificially. These patches are usually not over one-quarter to three acres in extent. After several years the clearings are enlarged by strips entirely surrounding them; and these are promptly restocked by planting. 'The process continues until the stand is entirely cleared. This is another 
European method which will not be used very much by us.

The principle of this method is used in combination with other systems. Thus, sometimes it is desired to introduce a valuable species which has some difficulty in competing with the species in mixture. Patches are clearcut as above described, and the valuable species planted. When the young growth has made a good start, the rest of the stand is then removed by some one of the systems, and reproduced to the other species. This modified plan is used in Europe in mixed oak and beech woods when oak has to be favored against the competing beech. The oak is introduced in the cleared patches and the beech reproduced naturally after the oak is well established.

\section{Clear-Cutting with Natural Reproduction}

Under this system a stand, or part of a stand, is cut clear, and the area is restocked by natural reproduction from trees standing on the border. The system is used where a clear-cutting is necessary, and where natural reproduction from the side is possible and can be accomplished cheaper than by artificial seeding or planting.

Conditions of Success. - The system under consideration depends, for reproduction, on natural seeding from the sides. It is, therefore, applicable to species having light seed that is distributed by the wind. Inasmuch as the new stand must be established in the open, reproduction can be secured only from species capable of germinating and developing without shelter. It may happen 


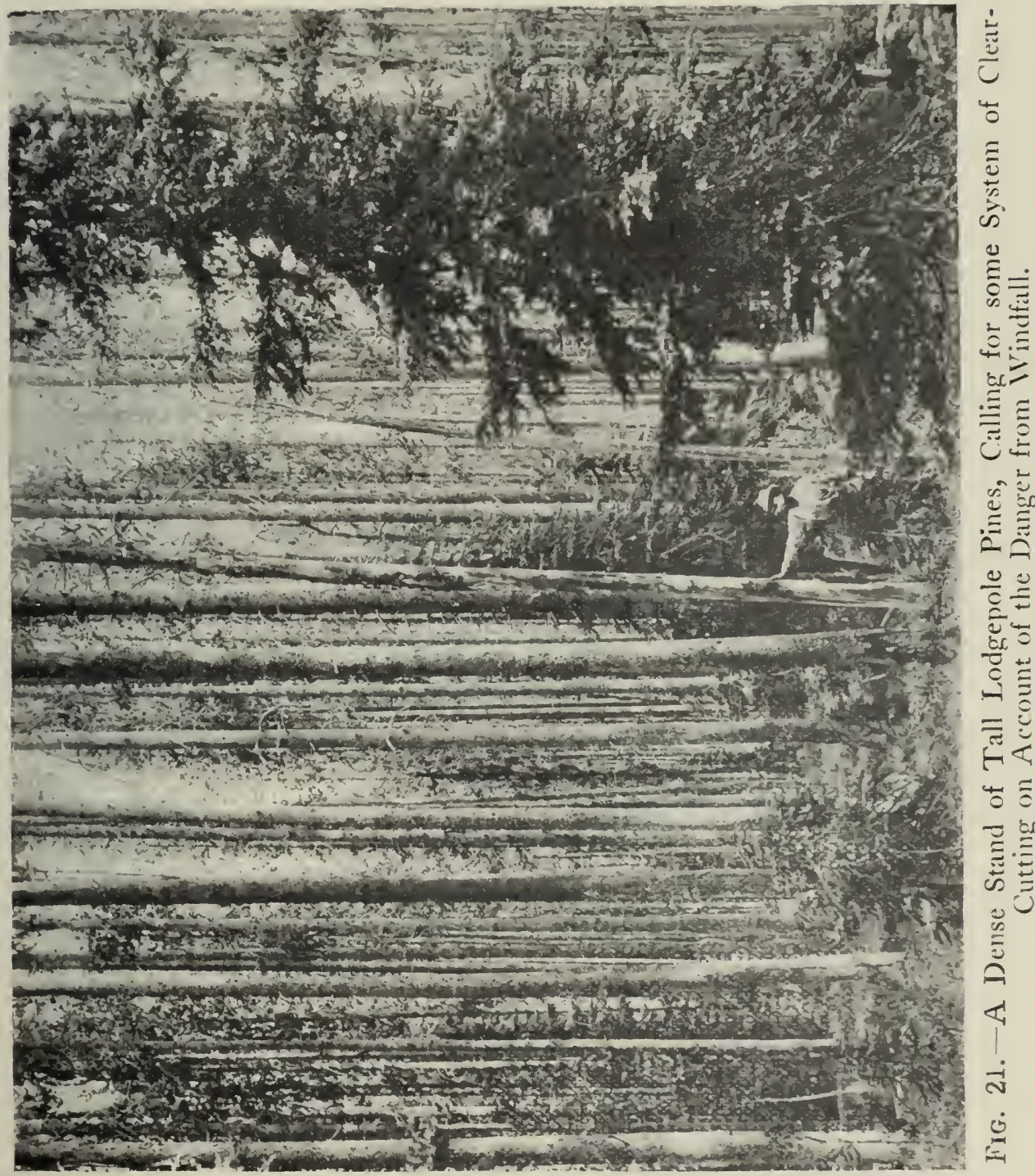


that a given species reproduces itself best on a clearing, but this is not by any means always the case. If a clearing is necessary, and a new stand of a desirable species cannot be secured upon it by natural reproduction, planting must be resorted to, or the area sacrificed to inferior and undesired species.

In the past, where the trees are all merchantable, lumbermen have usually cut clear, without regard to reproduction. It is a common opinion among them that reproduction will take care of itself, no matter how the stand is cut, provided the land is protected from fire. It is true that some large clearings made by haphazard cutting have been reproduced in a marvelous manner, even where fire has followed. These cases are, however, exceptional. Ordinarily, good reproduction will not take place unless there are seed-trees near at hand to provide the seed, and the conditions for germination are favorable. This means that where clearings are made and reproduction from the side is relied upon, there must be a restriction of the area cleared, based upon the distance to which seed may be carried in abundance. The location of the clearing, its form and size, and the work of preparing the ground for reproduction must necessarily vary enormously under different conditions.

Influence of Market Conditions. - I Th th is system a distinction may be made between its application in virgin forests having a large amount of overmature stock, with unfavorable market and logging conditions, and its application under such favorable economic conditions as exist 
in Furope and in the better-settled portions of this country. Applying this system is often the first step toward organized silviculture in a forest, and the methods used in the beginning may have to be very crude in comparison with the intensive work done in Europe.

The first factor determining the manner of using the system is whether the timber in a given stand can be taken off in a series of clear-cuttings, each taking unly a part of the stand, or whether the conditions are such that it is necessary to cut the bulk of the timber in one operation.

There are many areas on which the conditions of logging are such that, in order to make a profitable operation, a large part of the timber must be removed at one cutting. The cost of road construction, installing the logging equipment, and transporting the logs, may be so great that it would not pay to restrict the cutting in a given stand to only 50 or 60 per cent. of the timber.

Clear-Cutting the Whole Stand.-The principle of this system is to cut an entire stand clear, and rely for reproduction on seed which may be distributed from the trees in the surrounding stands. It is presupposed that the area of the stand to be cleared is small enough to enable a generous scattering of seed upon it. It very commonly happens that there are blocks of old, valuable timber, requiring a clear-cutting, which are surrounded by younger timber that should be left standing and that will furnish an abundance of seed. 'This is a rery common occurrence in the forests of the extreme Northwest. 
A specific illustration may be taken from northern Washington. A given area was swept by a fire about 50 years ago. Portions of the forest were destroyed, and natural reproduction filled them with excellent stands of Douglas fir. There are to-day blocks of the old forest, separated by the young stands. This old forest consists of Douglas fir, cedar, and hemlock. The trees are from 3 to 6 feet in diameter, and from 150 to over 200 feet high. There is a large amount of defect in all the species, the fir being especially unsound. A clear-cutting is demanded for the following reasons:

1. The trees are deteriorating, and public interests demand that they be utilized and the ground restocked with a new, growing stand.

2. The timber is so large that donkey and cable logging is required, necessitating a large yield per acre for a profitable operation, and making it impracticable to return a second time for a few trees per acre.

3. The trees are so large that their subsequent removal from among young growth would result in extensive destruction.

t. 'The old trees are so large and valuable that the leaving of over two trees per acre would equal the cost of artificial planting.

5. Natural reproduction of Douglas fir on the coast takes place best on openings where the mineral soil is exposed.

'The case is, therefore, simple. 'The blacks of old timber are restricted in size. About them are stands of 
Douglas fir already bearing seed. The merchantable old timber is, therefore, cut clear, and the ground burned over to prepare the soil for the reception of the seed.

If the area were so large that natural reproduction could not be relied upon, it would be necessary to rescrt to planting. Very often both natural and artificial reproduction are used. The old stand is cut clear, and a reasonable area near the edge of the clearing is left for natural reproduction, while the center-that part beyond the zone of good seed distribution-is planted. A good example of this method may be found in a Government cutting in Montana. The stand covers a valley bottom and the surrounding slopes. The timber on the bottom and the lower slopes is very heavy white pine, spruce, larch, Douglas fir, hemlock, white fir, and other species. On the main slopes there is a more or less irregular stand of the same species. The bottom and lower slopes must be clear-cut; the central and upper slopes may be culled, partly on the selection and partly on the shelterwood plan. For a distance of abou 250 feet from the seed-trees left on the central slopes, the lower slopes will be left to natural seeding. The bottoms will be planted.

Reserving Blocks of Trees.-Where extensive areas of very old timber require clear-cutting, and under conditions which at present make artificial reproduction impracticable, a portion of the stand must be left for the distribution of seed. Very frequently it impracticable to leave single trees, or even groups of trees, for seed, 
because they would be certain to be damaged by windfall.

The best methods are those of cleared strips described in later sections. But there are cases where, on account of the logging conditions, it is not feasible to leave standing 40 or 50 per cent. of the stand, as is required by those systems. In this event the stand is cut clear, except that solid blocks of timber, aggregating from 15 to 25 per cent. of the stand, and well located with reference to the distribution of seed, are left standing.

Where it is desirable to operate in this manner, it is usually the expectation that it will not be possible to return in a few years-after reproduction is establishedto cut the standing blocks. If this were possible, a better system of cuttings would usually be feasible.

In some instances no cutting will probably be made before the new stand is ready. By that time a portion of the timber left for reproduction will have died or become defective. In such a case the timber which cannot be used is a sacrifice to reproduction, and its original value represents the investment for that purpose.

I LOcation OF THE Blocks. - The blocks to be left standing are located with the care and skill that would be used in selecting single seed-trees in the other systems. In locating these areas the following considerations are kept in view:

1. 'They must be large enough to withstand the wind.

2. 'They are located so as to distribute seed as far as 


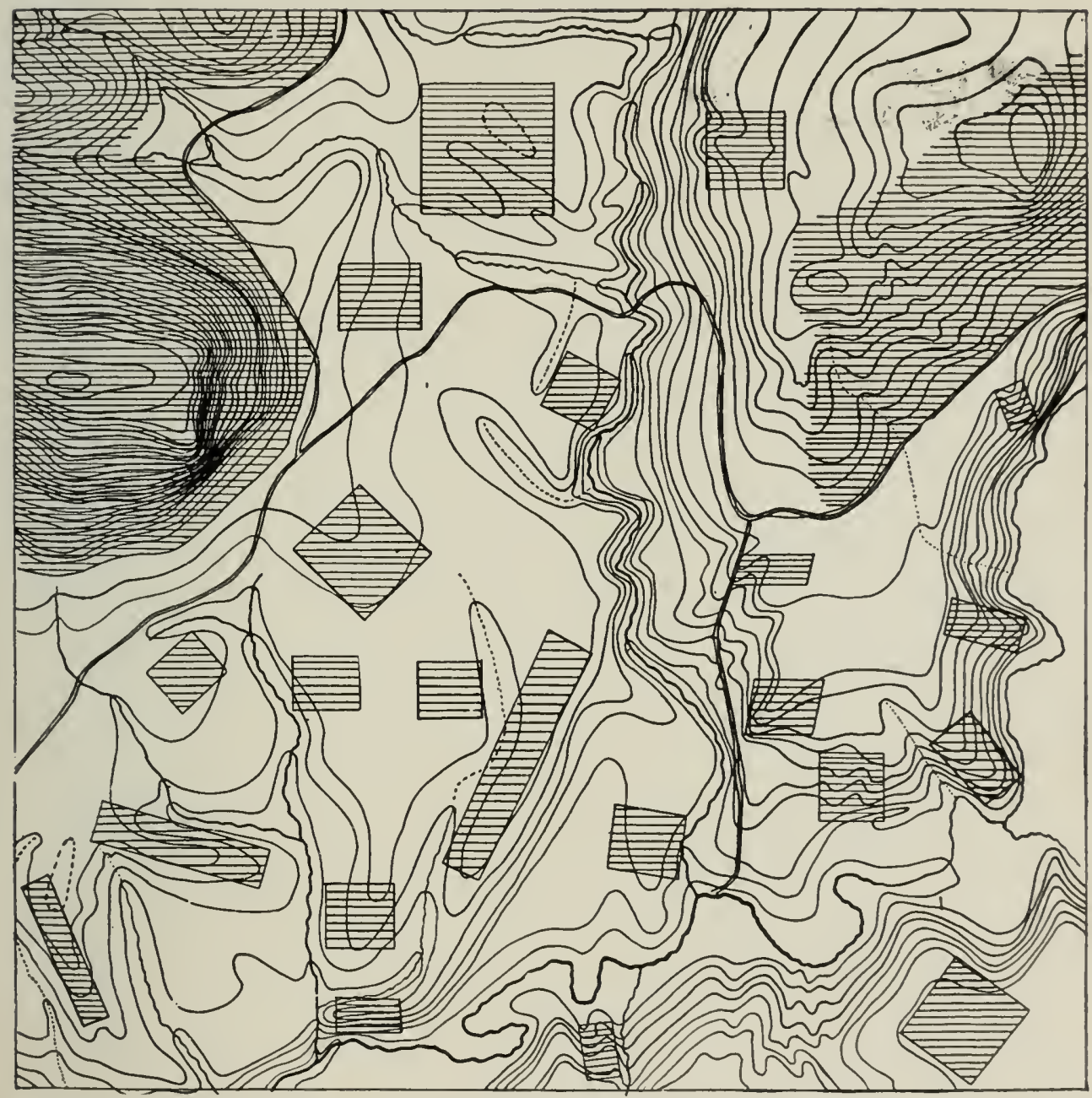

Fig. 22.-Application of a System of Clear-Cutting with Large Blocks of Timber Reserved for Seed. A Quarter Section in the Kaniksu National Forest, Idaho. 
possible. Usually they are located on ridges or upon slopes.

3. They are sufficiently close together to insure a distribution of seed between them. The intervals vary from 200 to 500 feet.

t. The youngest timber is selected which will answer the purpose from the standpoint of reproduction. The younger the trees the greater the proportion of living trees at the next cutting in the area.

5. One selects trees having as small a value as possible, but which will meet the needs of reproduction. The purpose is to reduce the investment to a minimum.

An Illustration from Idaho. - An illustration may be taken from the forests of northern Idaho. Here the forest is composed of white pine, larch, hemlock, Douglas fir, cedar, and white fir. An area of mature forest is to be cut, on which nearly all the trees are old and many are deteriorating. The stand is past maturity; there is loss of growth, and the timber should be utilized at an early date. It is believed that the pine, larch, and Douglas fir will reproduce themselves readily on the clearings, and that the cedar, hemlock, and white fir will come up underneath them. A clear-cutting is made, with carefully located blocks left untouched, where they will accomplish the most good. The arrangement of the clearings and the blocks is shown in Fig. 22. The blocks of timber are left chiefly on the upper slopes and ridges. Care is taken to select such areas as will be safe from windfall, and will distribute seed. There is also 
the aim to select, when possible, stands containing thrifty trees, which are likely to live for from 25 to 50 years. In the cutting it is clesired, as far as possible, to remove the declining trees and those attacked by fungus.

Characterization of the System. - The system just described is one of temporary expediency. As a measure of silviculture it has serious defects, and it should be used only where necessary. The chief defects are as follows:

1. A considerable amount of excellent timber is sacrificed to reproduction, with a loss in the plan of close utilization.

2. While reproduction will occur, it is problematical whether it will be in the amount and of the form desired. Thus, in the example cited another species might seize on areas planned for white pine. The area cleared is so large that in many cases the density will not reach the degree hoped for.

3. The system necessitates the clearing in one place of a very extensive area. An ordinary operation would cover two or three sections-from 70 to 85 per cent. clear. Such a clearing is not desirable.

Reserving Scattered Seed-Trees.- This system involves the removal of all trees in a merchantable stand, except a small number left scattered on the clearing for the distribution of seed. The essential characteristics which distinguish the method are:

1. There are only a very limited number of trees.

2. The trees are isolated and scattered. 
3. The trees are left primarily to provide seed.

Required Conditions. - The conditions under which this method is applicable in practise are:

1. In mature stands, where a clear-cutting is desirable.

2. With species whose seed is distributed by the wind.

3. Where seed-trees may be found which will not be overturned by the wind after lumbering.

4. Where the ground may be left in such a condition that the seed will germinate, and a new stand become established.

The system cannot be used, therefore, with hardwoods which have heavy seed-like oak, beech, hickory, chestnut, walnut, etc. It cannot be used in very dense regular stands of trees growing in exposed situations, like many areas of lodgepole pine, of spruce, and of Douglas fir.

Future of the Seed-Trees. - In projecting a cutting under this plan, one must consider whether it will be possible to cut and utilize the seed-trees after reproduction has been secured, or whether the conditions are such that it would be impossible to make a second cutting for them. The character of trees selected would depend very largely on this point. The leaving of merchantable seed-trees represents an investment. If they can be cut at a second operation, after they have performed their function in furnishing reproduction, the investment is represented in a higher cost of logging at the second 


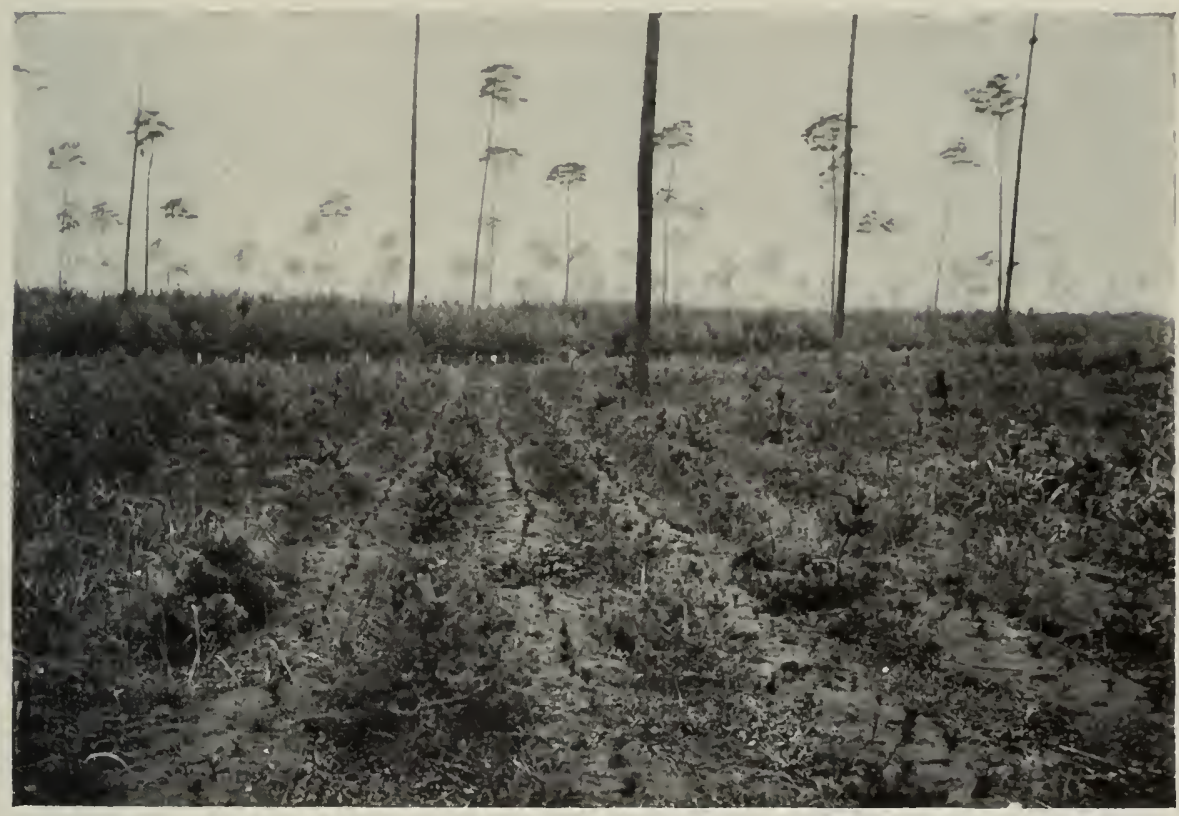

FIG. 23. - Thrifty Standards Reserved to Grow through a Second Rotation. Scotch Pine in Europe.

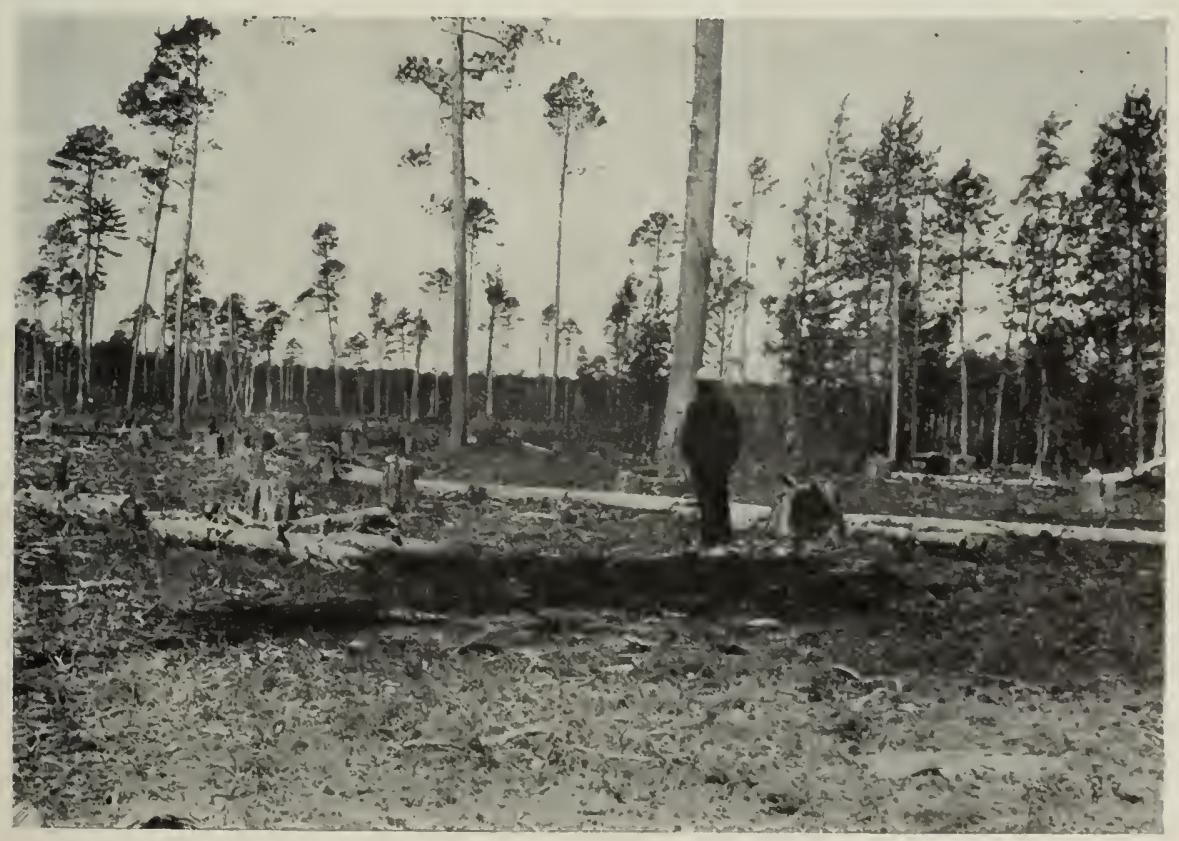

F1G. 24.-Reserving Scattered Trees to Distribute Seed after Lumbering. Minnesota National Forest. 
operation, and a loss of interest on their value during the period of reproduction. This may be compensated by increase in market value, and in some cases by the growth. If one cannot return for the seed-trees after reproduction is secured, and if the seed-trees are necessarily old and mature, it is probable that they will not live until the new stand is ready for cutting. The trees are then sacrificed for reproduction, and their value represents the principal item of investment for that purpose. It is obvious that one may leave better trees, and more of them, in the first than in the second case.

Number of Seed-Trees. - This depends on a variety of conditions. There must, in the first place, be enough trees to secure an abundant distribution of seed. Ordinarily the principle is to leave just as few trees as possible. This is especially important when it is likely that the trees will not be utilized by a second cutting. The forester determines the required number by a local study of reproduction. He determines how far abundant seeding will take place from individual trees of the species in question, taking into consideration their height and crown development, as well as the conditions of site and exposure to wind. The conditions of germination must also be considered; for, where these are not favorable, a larger number of seed-trees should be left than under the better conditions.

In general, the seed-trees should stand not farther apart than their average height. Under the best conditions, they may sometimes be reduced to an average of 
from 3 to 5 trees per acre. More often, from 5 to 10 trees per acre are necessary for good reproduction.

Character of Seed-Trees. - Seed-trees are chosen for reproduction, and they must be capable of performing that function. A satisfactory seed-tree is a wind-firm tree, with a full, thrifty crown. Generally the tree with a full, thrifty crown is the most wind-firm of the stand, since root and crown develop in harmony. A good working rule is to select, when possible, trees whose crowns take up at least 50 per cent. of the full height of the tree.

In selecting seed-trees one must consider constantly the question of the investment. If the trees are to be sacrificed to reproduction, and probably will not be utilized later, one chooses the least valuable trees which will serve the purpose. The forester, therefore, selects the smallest trees which will be satisfactory distributers of seed. They must, however, have full, thrifty crowns. Suppressed trees, trees with long boles and short crowns, or dominant trees with dying crowns, will not answer the purpose. If small seed-trees are wanting, larger and more valuable ones must be left in proper locations.

There are certain defects which unfit a tree for highgrade lumber, but do not affect its reproductive power. A knotty or a crooked tree may be fully as good a seedtree as a straight one. In fact, a knotty tree may be the best possible seed-tree, because it usually has a full crown. Other defects, like cat-face, seams, sun-scald, etc., do not injure a tree for reproduction. 
It may be safe in some cases to leave trees affected with rot. Sometimes those trees will be left anyhow, as there is no practical method of disposing of them. If the crowns are still thrifty, they will be good seed-trees. It may be dangerous, however, to leave seed-trees affected with diseases that are likely to spread. In some forests, for example, a disease may have become so prevalent that the majority of trees of certain species are infected. An illustration is the diseased condition of the fir, hemlock, and pine in some areas of northern Idaho. It is certain that diseased seed-trees will be liable to infect the new growth, through rapid propagation. Where possible, therefore, one avoids leaving trees inflicted with a disease which is likely to spread to the new crop.

Distribution of the Seed-Trees. - The design is to have the trees distributed regularly over the cutting area. The more regularly spaced the trees, the less the required number. It is not always possible, however, to find a suitable tree in the precise location most desired. It is much more important to have suitable trees than a regular distribution.

The Cutting. - The whole stand is cut clear, except for the reserved trees. The slashings are disposed of as described in Chapter VII-either piled and burned, or, where the conditions demana it, cut up and scattered. Any individuals or groups of small trees which have started as advance growth are carefully protected in the operation.

Preparation of 'THE Soll. - It is essential that the 
soil be in a condition for the ready germination of the seed and for the growth of the seedlings. Frequently there is a heavy layer of litter which retards germination, or a dense growth of weeds and brush which interferes with the development of the young seedlings. Ordinarily the best plan is to destroy this material by surface burning. The ground is burned over preferably during a seed year. This gives an opportunity for the seed to germinate, and for the young seedlings to gain headway and compete successfully with other vegetation.

Results. - The scattered seed-tree method produces excellent results in reproduction where there is little competition for the occupancy of the ground by other species, where there is little injury to young growth by competing brush and weeds, and where the soil conditions are favorable for the germination and continued life of the young seedlings. There is no difficulty in securing an adequate distribution of seed over the cleared ground, for that is merely a matter of properly locating a sufficient number of seed-trees. The difficulty is entirely in securing the germination of the seed and the protection of the seedlings. Where the conditions are unfavorable for the germination and growth of the seedlings, the system inevitably yields poor results. In some situations a heavy opening in the forest is followed by a drying out of the soil. This is particularly true in the semiarid regions of the West. In the same way, reproduction under this system is apt to be a failure where there is danger of damage by frost. In a mixed forest other 
species are apt to compete in the new growth, and retard, or in some cases entirely prevent, reproduction of the desired species. 'Thus, in a mixed forest of white pine and hardwoods, hardwood trees very commonly form the bulk of the second growth after a clearing, even where abundant seed-trees of white pine have been left standing.

If good reproduction is secured, the new stand is essentially even-aged. If the seed-trees are not cut after reproduction, they are so scattered that they do not interfere in a material way with the development of the new stand.

The investment is usually small. 'The value of the trees left standing is under most circumstances not over $\$ 2$ to $\$ 5$ per acre. Sometimes, however, the system is used in a virgin forest where the only adequate seed-trees have considerable merchantable value. If the trees are very valuable, the probabilities are that it will pay to come back for them in a second cutting after they have accomplished their reproductive function. If it is impossible to return for them, and they are very valuable, it would not pay to use the system at all. In general, the results in reproduction are so uncertain that it would not pay to use this system where the investment in securing reproduction would be over $\$ 3$ to $\$ 5$ per acre.

Practical Application.-The system has already been used in this country in a number of instances. 'The work conducted on the largest scale is that on the Minnesota National Forest. 'This area formerly belonged to the Chippewa Indians. When the land was relinquished 
by them and ceded to the United States, provision was made by statute that in cutting the pine timber 5 per cent. was to be left standing as seed-trees. A later statute required that the amount left for seed be 10 per cent. The forest was by no means regular, and in some places the cutting has left several seed-trees to the acre, and in others only one seed-tree to from three to five acres. There was no special preparation of the soil and the cuttings were made without regard to seed years.

The results have not been very satisfactory, first, because there are not enough seed-trees, and second, because the ground has been covered with a growth of brush which interferes with reproduction. A clearing of the brush by carefully regulated burning just before a seed year would enormously aid reproduction.

The value of the seed-trees would probably not be over one or two dollars per acre.

This system has also been used in the white pine forests of the Northeast. Where it has been applied, the forest has been usually a second growth from 50 to 100 years old. From 2 to 5 seed-trees have been left per acre, and these have been of comparatively small vilue, averaging ordinarily not over $\$ 3$ per acre. In certain sections, as, for example, in southern New Hampshire, very good reproduction follows this method, for there is very little competition with other species in mixture, and the conditions for germination are excellent. In Massachusetts, on the other hand, there is a distinct tendency toward the replacement of white pine, after 
cutting, with oak, maple, and other hardwoods. If the original stand was a mixture of white pine and hardwoods, many of the latter send up vigorous sprouts, which practically maintain the proportion of hardwoods in the future stand, and it becomes difficult to increase the proportion of pine. In pure white-pine stands there is also a tendency toward a replacement by hardwoods because of the great abundance of seed on the ground, and of young seedlings already started under the pines. This tendency can partly be overcome by burning over the ground. Where, however, the hardwoods are established as the principal growth, pine creeps in underneath them in a few years, provided there are trees to furnish the seed.

The system of scattered seed-trees is applicable also to the second-growth stands of loblolly and other yellow pines in the South; in certain instances to secondgrowth Douglas fir stands on the Pacific Coast; and, where the conditions of moisture are favorable, to certain stands of pure IVestern yellow pine.

It is a system more commonly applicable in second growth than in a virgin forest, because in the former the investment in securing reproduction may be brought within a reasonable amount, while in the virgin forest it is difficult to find seed-trees of the right character which do not represent so great an investment as to make the system impracticable.

Reserving Groups of Seed-Trees.-In exposed sites it is often not practicable to leave isolated seed-trees, because 


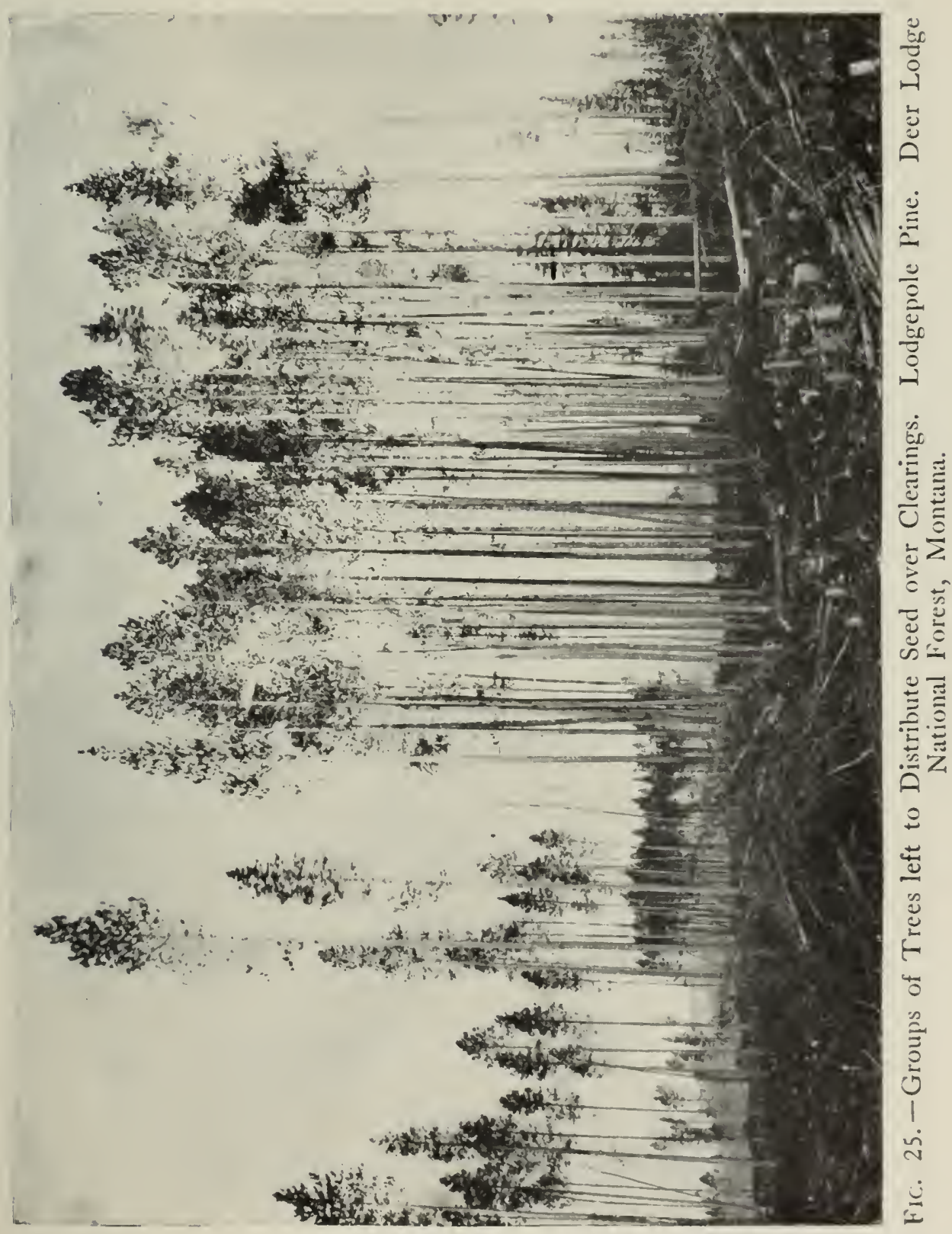


of the danger from windfall. In many instances a clump of trees will resist the wind where single trees will not. This is particularly the case when one or two fairly windfirm trees are in the clump. Suppose, for example, that a forest is composed of two species, one subject to windfall and the other fairly wind-firm; and suppose that it is desired to reproduce the former. It might often be the case that a clump of trees composed of both species would resist the wind and accomplish the reproduction, even if only a few of the trees in the clump were of the windfirm species.

The clumps would ordinarily comprise from three to thirty trees, and would be located and spaced on the same principles as under the system of scattered seedtrees. The only difference between the two systems is that in the latter a group of several trees would usually be left instead of single isolated trees.

Reserving Thrifty Standards.-In the two systems described in the foregoing pages, the purpose of leaving reserves is for reproduction, and for that only. Under the method now to be described, trees are left standing for two reasons, reproduction and growth.

The system is applied in regular, relatively even-aged stands of moderate age; that is, to stands in which there are many trees still capable of living a long time, and capable of rapid growth. It is not applicable in very old stands in which the trees have ail reached their limit of profitable growth. Usually the system is not applicable to stands over about 100 years old. 
The design is to leave scattered over the cutting areal trees which are thrifty, calpable of producing abundant seed, and capable of living through a second rotation. Suppose that a stand is cut when 100 years old. Selected reserves are left standing, and these restock the ground. The reserves, then, are designed to stand during the entire rotation of the new crop. If this new stind is cut at 100 years of age, there will be scattered throughout it a certain number of trees about 200 years old. The reserves will have stood for fully half a century practically isolated, and for another half century as the leaders in the stand. With the advantage of full light they will have made a maximum growth. With a rotation for the stand of only 100 years, a certain amount of timber of large size and high grade will be produced.

Selection of the Standards. - The trees selected to remain standing are from among the dominant trees of moderate development. The aim is to select trees of as little present commercial value as will meet the requirements of reserves. The trees must, however, be from the dominant class. Suppressed trees and ordinary intermediate trees would not be suitable for purposes of reproduction or growth. The trees must be wind-firm, since they will stand isolated for many years. They must have thrifty crowns capable of responding to the new conditions of light and space, and capable of producing rapid growth. They must be likeiy to develop into good seed producers, even if they are not so at present. Ordinarily, their crowns should take up at least 35 
or 40 per cent. of the tree's length. They should be thoroughly sound, and as straight as can be found. In a stand having trees from 6 to 16 inches in diameter, they would usually have a diameter of from 9 to 12 inches. Trees with large, spreading crowns are avoided, in order that there may be as little interference with the new crop as possible.

Number of Standards. - In determining the number of reserves, it must be borne in mind that they must stand far enough apart for a new stand to develop among them. It is necessary, therefore, to consider the size of the crowns of the reserves. The reserves are evenly distributed, so far as this is compatible with the selection of proper trees. Since the method is most commonly applied with intolerant trees, the number of reserves must be comparatively restricted. A good rule is to aim to have an average interval between the crowns of fully 30 to 40 feet. This would usually mean about from 15 to 25 reserves per acre.

Results. - This system yields better reproduction than the scattered seed-tree system. There are from 15 to 25 seed-trees, and though they are not so large as those left under the other system, and each would not yield so much seed, they are so much more numerous and so much nearer together that the results are better. The trees are near enough together to give a certain amount of shade that is very beneficial in checking excessive drying of the soil, and in reducing damage to the seedlings by frost. The presence of 15 or 25 reserves 
cannot help interfering to some extent with the development of some of the young trees. About 10 or 20 per cent. of the area will be shaded from above, and this proportion of the new crop will be prevented from making normal growth. In case of loblolly pine, this would result in reducing the yield from the new crop by about from 1,000 to 2,000 board feet. On the other hand, if 20 of the reserves lived through the second rotation successfully, they alone would yield at least from 5,000 to 10,000 feet of lumber of the highest grade.

Application. - There are no instances in this country of the systematic use of this system. In Europe, the plan of reserving certain trees for growth over a second rotation has long been in practise. The purpose of these reserves has, however, been chiefly for growth. Reproduction has generally been accomplished by planting.

The system may well be applied to many even-aged, comparatively young stands in this country, such as loblolly and other yellow pines in the South, white pine occasionally, Western yellow pine, and Douglas fir.

Clear-Cutting in Two or More Operations.-The condition requiring the clear-cutting of an area in one operation is temporary. The advance in values will before long permit the cutting in a single operation of a smaller amount in a given logging unit than is now practicable. Already in many stands that require clear-cutting, it is possible to restrict the first cuttings to strips or patches occupying not over 40 or 50 per cent. of the area, and 
122 THE PRINCIPLES OF HANDLING WOODLANDS

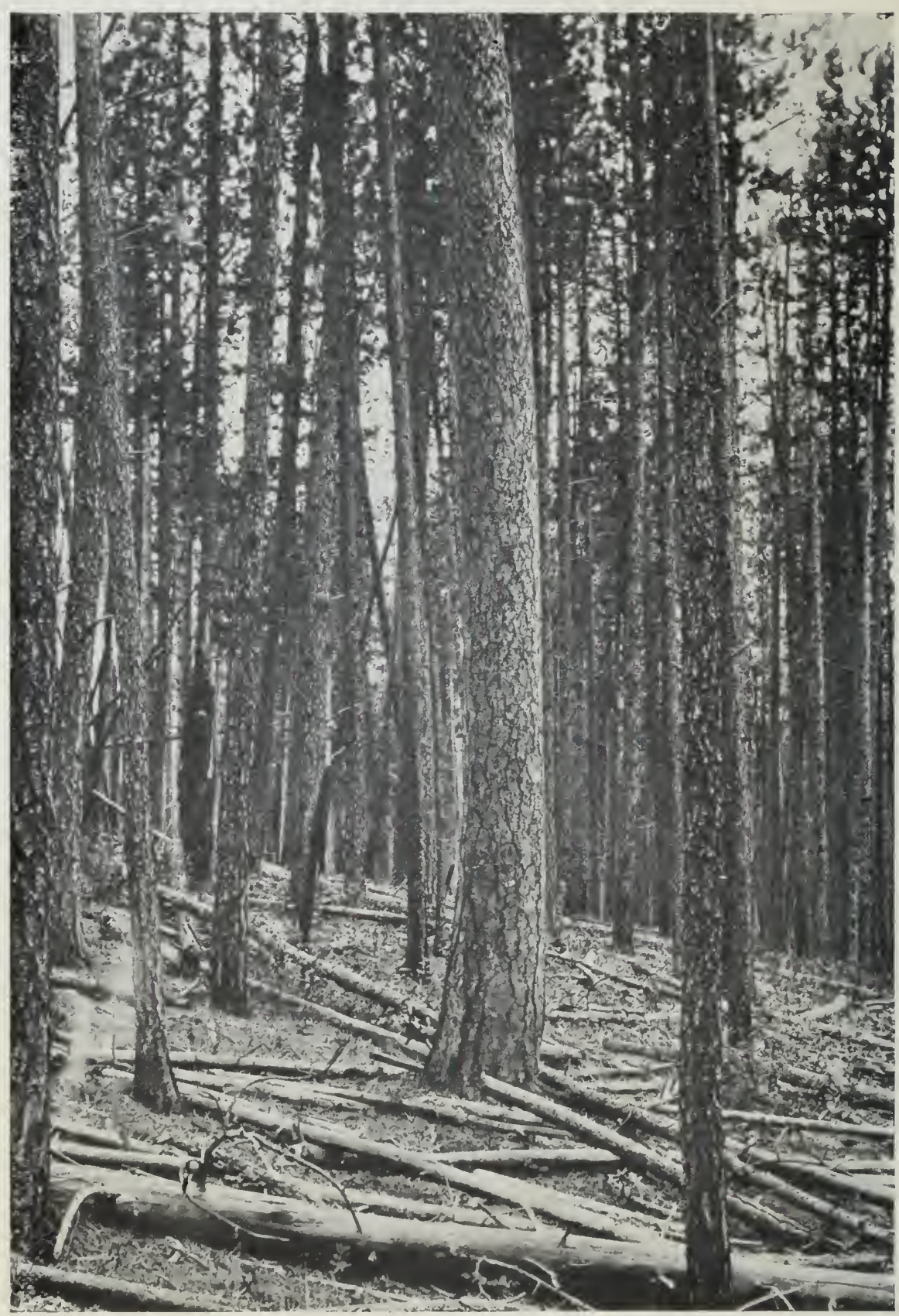

Fig. 26. - A Stand of Western Yellow Pine, with Scattered Old Trees, Showing the Results which May be Obtained by Reserving the Thrifty Standards for Growth through a Second Rotation. Black Hills, South Dakota. 
then return and cut the remainder in one or several operations.

The clear-cutting systems which involve more than one operation may be classed under three heads:

1. Alternate Cleared Strips.

2. Irregular Cleared Strips.

3. Progressive Cleared Strips.

Alternate Cleared Strips.-In the first operation, the strips are cut at more or less regular distances, leaving alternating bands of standing timber between them. The design is to cut from to to 60 per cent. of the area clear at the first cutting. It is expected that the clearings will become restocked by seed from the standing timber. When reproduction has taken place on the cleared strips, a second operation is made for the timbered strips between them.

Location of the Strips. - A regular arrangement of alternate strips is possible wherever the topography permits it. In general, the conditions must be such that the logs may be conveniently taken out of the strips to the road. The simplest conditions are where the ground is level or gently sloping. Logging is then easy, and the strips may be laid off uniformly, and with main reference to reproduction.

Under these conditions the strips are laid off at right angles or diagonally to the prevailing winds, unless some special considerations require a different arrangement. This manner of cutting insures the best possible distribution of seed over the clearings. It may happen that the 
area is so situated that the necessary location of the roads will not permit the laying off of the strips at right angles to the direction of the prevailing wind. It is usually possible, however, to make them run in such a way that seed will blow across them. This may necessitate making the strips narrower than would be proper if their location were the best.

If the timber is situated on a long, even slope, the method of alternate strips can be used, provided that a profitable logging operation can be conducted. Ordinarily under such circumstances, the strips are run up and down the slopes. On broken, rugged topography the method of regular alternating strips cannot be used at all. The clearings are then located according to the topography, and are arranged very irregularly in the manner described on page 128 .

IVIDTh of STRIPS. - The width of the strips depends on the distance to which seed will be distributed in sufficient quantity to insure reproduction. It depends also on the conditions for germination. If these are good, the strips may be wider than when they are poor, for in the latter case more seed is necessary to insure reproduction. No rule can be given, because every case must be judged on the ground with a knowledge of the reproductive habits of the species in question. In general, the best results are secured when the strips are not wider than the height of the bordering trees. Seed is carried to considerably greater distances, but usually not in quantities sufficient for a full reproduction. In 
this country, logging conditions may often require strips wider than the standard. The wide strips are cut with full knowledge that the reproduction will not be so good as on narrow strips.

In most forests where this method is likely to be used, and with species growing in their optimum region of development, fair reproduction can be secured at a distance of about three times the height of the seed-trees. Under especially favorable conditions even a greater distance can be safely used. Thus, it is believed that in Douglas fir stands in the foothills of the Cascade Mountains, where the trees are from 150 to 175 feet or more in height, strips may be cut from 500 to 600 feet wide.

In this country, the general rule has been to make the strips as wide as possible. In Europe, the rule has been to make them as narrow as possible. The effort to make a wide strip is designed to cheapen the cost of lumbering; the aim is to reduce the present investment, even at a sacrifice of future returns. The advantages of a narrow over a wide strip are as follows:

1. A quicker, surer, and denser reproduction is secured.

2. A smaller, continuous area is exposed, and there is less damage by drying of the soil.

3. The newly established trees have a measure of side shade, and suffer less from drought.

4. On steep slopes the danger from erosion is less.

5. The damage to small growth by insects is in the long run less. 
The distance between the strips is ordinarily about the same as the width of the clearings. This is determined on a basis of the percentage of timber to be removed at the first cutting. If 50 per cent. is to be cut, then the strips and bands of standing timber are the same in width. If more than 50 per cent. is to be cut, the intervening bands of timber are correspondingly narrower than the areas cleared. Ordinarily, the strips are of uniform width. There will, however, be many spots where a strip will run through a site with an exceptionally shallow or soft soil, and danger of windfall would be great. In that case, a widening of the strip is made, to comprise the endangered area. In the same way other special conditions will often require a departure from uniformity in the width of the strips.

The Second Cutting. - I When the cleared strips have become stocked with young growth, the bands of standing timber may be removed. Sometimes reproduction takes place promptly in the first seed-year succeeding the cutting. More often several seed-years are required. This is particularly true when wide strips are cut. Ordinarily, with wide strips the second cutting may be made within 10 or 15 years; with narrow strips in from 5 to 6 years.

The second cutting camnot, like the first, be a clearing, for there would then remain no seed-trees for natural reproduction. The simplest silviculture would be to clear-cut and plant, but that is often out of the question. If these second strips must be practically all taken off 
in one operation, and single trees and groups cannot be left because of danger from windfall, blocks must be left comprising as large a percentage of the stand as the conditions permit-say from 15 to 25 per cent. These blocks would not insure very good reproduction when they could not be properly located. Under poor market conditions at the time of the second cutting, there is, therefore, no method of securing adequate natural reproduction.

Frequently, in this country, the question of how the second strips of timber are to be removed is not decided when the first strips are cut. The forester has usually located the first cuttings, and, knowing that some 10 years or more will elapse before the second cutting, has left the problem of how to reproduce the balance for some one else to solve. This is not good practise, and is justified only under the stress of being obliged to cut in a given stand when a clear-cutting system is necessary, and when a clearing of over about 50 per cent. would be a misfortune. Good reproduction on half the area is better than very poor reproduction on the whole.

Operation. - The strips are cut clear. Theoretically this means the removal of every tree. In practise, even with the good market conditions, there are some small individuals which it is too expensive to remove. Such trees would not, however, interfere in any serious way with reproduction or with the development of the stand. Yet it is desirable not to have any such trees if it can be helped, unless they are likely to live and constitute legiti- 
mate reserves. If any groups of young growth occur, they are carefully protected, unless they are so small and scattered that this would involve an unwarranted expense. The logs are removed just as soon as practicable, and the slash is destroyed. In some cases it is desirable to burn over the surface of the ground to prepare for the reception of the seed.

Irregular Cleared Strips.-Where the topography is uneven and rugged, a regular arrangement of alternating strips is impracticable. Such cuttings would usually increase the difficulties and cost of logging; the regular strips would result in windfall on many exposed points; the location of the strips with reference to the bordering seed-trees would often be unfavorable for good reproduction; the bands of standing timber would in many cases be poorly located with reference to reproduction at the time of the second cut; and one could not take full advantage of the condition of the timber to locate the cuttings where most needed.

On rough topography the clearings may be irregularly arranged, and be irregular in size and form. Just as in the case of the regular cleared strips, the design is to remove the stand in two or more operations. The first cuttings comprise from 40 to 60 per cent. of the area, and take the form of clearings restricted sufficiently to permit a distribution of seed from the bordering trees.

The forester determines in advance the proportion of the area which will be cleared. 'This is based on considerations of logging, reproduction, windfall, protection 
from fire, the condition of the timber, and the succeeding operations which will remove the balance of the stand. The clearings are located with reference to the same considerations. 'Their location is a matter of careful and skilful selection in contrast to a conventional arrangement of cleared strips of uniform width at regular intervals.

Location of Strips. - In locating on the ground the areas to be cut, the forester should keep in mind the following considerations:

1. Logging.-The question of practical logging must be considered first of all. The location of the cutting areas, which would be most advantageous from the silvicultural standpoint, might, under some circumstances, be entirely impracticable on account of the difficulties and cost of logging. Under a given set of conditions of forest and topography, the required method of logging is pretty clearly defined. The method of logging, the location of roads, and the cost of constructing them, the cost of installing the appliances, the cost of cutting the logs and transporting them to market, and their market value, must determine the general arrangement of the clearings and their approximate size. Their precise location depends, in addition, on the considerations discussed below.

2. Reproduction.-The clearings are sufficiently narrow to enable the distribution of seed over them from the seed-trees standing on the border. The form of the cleared areas is a matter of no importance as far as reproduction is concerned. For the reasons explained on page 


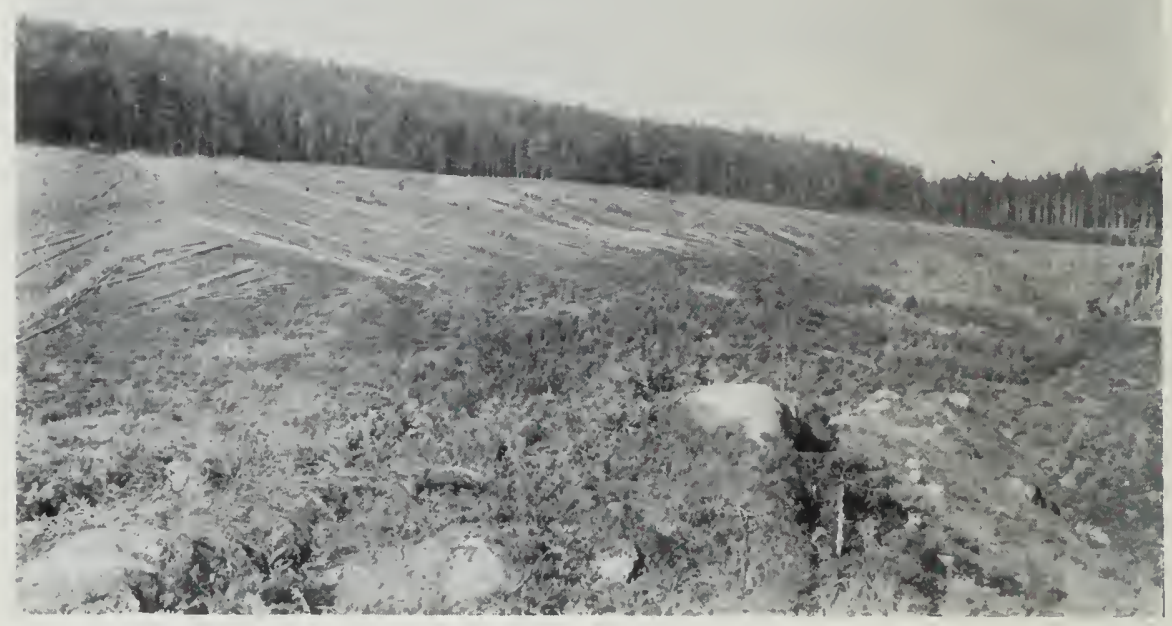

Fig. 27. - Clear-Cutting as Applied in a Scotch Pine Forest in Germany. The Clearing will be Restocked by Planting.

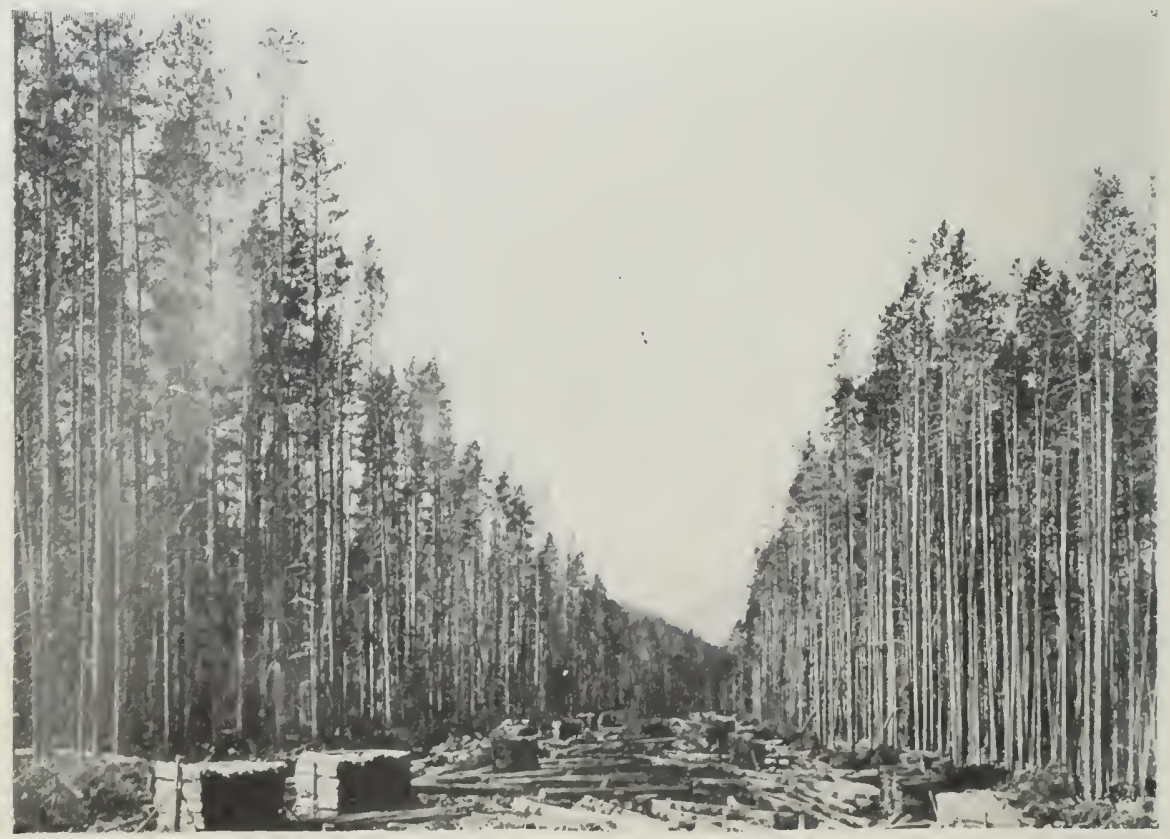

FIg. 28. - Clear-Cuttilig in Strips as applied in Lodgepole Pine. Deer Lodge National Forest, Montana 
125 the clearings should be as narrow as is compatible with practical requirements of logging. They must not be wider than the distance of abundant seed distribution.

The clearings are so located that there will be numerous seed-trees on the border, especially on the side toward the prevailing wind. Where there is danger of injury to the soil and to the reproduction by drying winds, the cuttings are as far as possible located so that the remaining stands act as shelter belts and reduce the winds' unfavorable influence.

In general, the cutting areas are located more on the lower than on the upper slopes, when this is compatible with the proper operation of the second cutting. There are several advantages, as follows:

a. The present logging is facilitated-at the time of poorest market conditions.

b. The location of seed-trees above a clearing is better than below it, and such a location enables a larger opening to be made.

c. The steepest part of the slopes are kept under forest at a time when market conditions only permit a clear cutting.

d. Very commonly, as a result of old clearings by fire, the trees on the upper slopes are younger than those below; and the greatest amount of unsound timber is usually on the lower ground.

3. Condition of the Forest. - The irregular arrangement of clearings enables the forester to cut just those stands which are most in need of attention, namely, the patches 
which are mature, deteriorating, diseased, insect-infested, or damaged by fire or other agency.

4. Windfall.-The cuttings may be made so as to reduce to a minimum the damage to the remaining stand by windfall. In a broken topography the irregular location of cuttings is the best method of making clearings so as to avoid this danger.

The Second Cutting. - The problem of reproduction at the time of the second cut is taken into account in locating the first clearings. In some instances the location of a clearing may be determined entirely by this consideration. Suppose, for example, that there is a choice between locating the cutting on a site exposed to windfall and on a sheltered site. This might occur where a strip is to be cut on one side of a ravine and not the other. The exposed side is cut at the first operation, and the sheltered side left for the second cut. When the second cut is made, reproduction may be accomplished by leaving seed-trees, or by some other system applicable where the danger from windfall is removed.

On the other hand, there are many instances in every operation where the problems of logging and present reproduction do not permit locating the cutting primarily with reference to the second operation. In this event the situation is precisely that of the conventional alternate strips.

Progressive Cleared Strips. - This method provides for the gradual clearing off of a stand of mature timber 
by a series of strips beginning on one side and progressing across the area until the whole is cleared.

It is a method which requires a number of separate operations in the same stand. After the first strip is cut, an interval is allowed to elapse until the clearing is restocked by natural reproduction. Then a second strip, bordering on the first, is cut, and this in turn is reproduced, and then successive other strips are cut at intervals until the timber is cut off.

It is at once obvious that if this method were applied

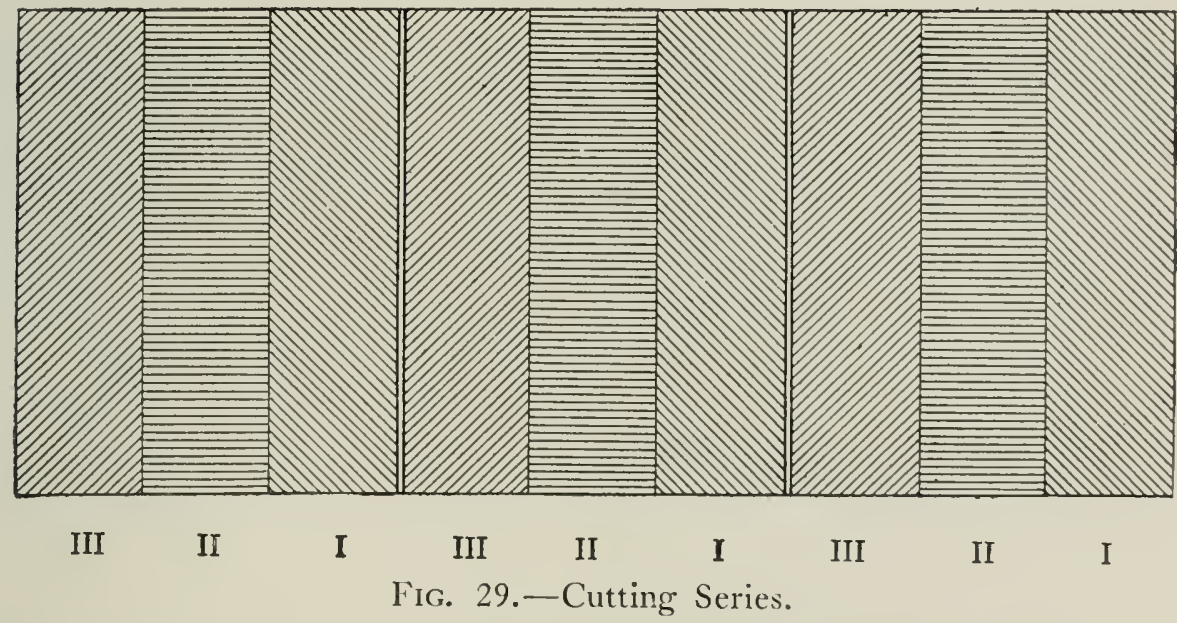

to a large block of timber and the strips cut even moderately wide, it would take a long period to cover the area, and that a very small yield would be obtained at a single operation.

Cutting Series. - To meet this difficulty, it is customary to constitute in a single block several cutting series. Instead of beginning at one side and progressing across the area in a single series of strips, the stand is divided into several approximately equal divisions, and a series 
of strips established in each. Suppose, for example, that a tract 900 feet long, such as that represented in Fig. 29, is to be cut, and it is desired to remove the timber in 12 years. Suppose, further, that reproduction of the cleared strips can be secured in about + years. The aim should then be to cut over a single division in three operations indicated in the figure as I, II and III. The first cutting then removes 3 strips, each 100 feet wide, separated by a distance of 200 feet. After about + years, the second operation removes the second strips bordering on the first. At the end of the next period of + years, the final strips are ready for reproduction. This last strip cannot be cut clear and reproduced naturally, for there would be no seed-trees left standing. It is, therefore, either reproduced naturally by some other system, or cut clear and restocked artificially.

Use in this Country.-This system is not used very commonly, even in Europe. It has not been used in this country in a systematic way, as far as the author is informed. It is probable that it will occasionally be used in a small way in cutting woodlots under certain conditions. 'Thus, it is sometimes customary to cut off the even-aged stands of white cedar in New Jersey by strips. The owner cuts a strip each year and gradually works over the swamp. He does not cut in this way in order to secure reproduction, but because it is the most convenient way for him to operate. 'The result, however, is a series of strip reproduction cuttings. Probably the 
plan would work very well in the small holdings of second-growth loblolly pine in the central Atlantic Coast region, and in other coniferous stands where reproduction is simple.

Clear-Cutting in Patches.-This system ordinarily involves the gradual removal of a given stand by a series of clearings, each covering only a restricted part of the area. In the first operation, patches of irregular form and limited size are cut. These patches, which are usually not over 100 to 200 feet across, are located here and there through the stand at points requiring the most immediate attention. As a rule, they do not aggregate over $t 0$ per cent. of the area. They are skilfully located with reference to reproduction. When a new growth has been established, each patch is enlarged by a second cutting in the form of a cleared strip running entirely around it. After this strip is reproduced, another cutting is made, still further enlarging the opening. This is continued until the clearings merge together. The last cutting will leave no seedtrees standing, so that natural reproduction cannot be secured. Unless there has been natural reproduction under the trees as advance growth, the final clearing must therefore be planted artificially.

'This plan of successive enlargements of patches is seldom carried through to its logical completion. In practise, the patch system is applied only in making the first cuttings, and some other method is used for the reproduction of the balance. Thus, the first cuttings may be 
in the form of patches cut clear, while reproduction is secured naturally from the bordering trees. The portion of the stand left standing may be cut under the shelterwood system, or it may be cut clear and the area planted. An illustration may be taken from a case in southern Europe that once came under the author's observation. The forest was composed of beech and spruce. It so happened that the natural reproduction of beech in that district was better than that of the spruce. The use of the shelterwood system would have resulted in an increase of beech in the new stand. Accordingly, the first cuttings were in the form of patches, made about as wide as the tree-height. Care was taken to leave abundant seedtrees of spruce on the border. The light seed was readily distributed over the area, while beech-seed is scarcely carried beyond the periphery of the crowns. Good reproduction was secured on the plots, and a certain proportion of spruce in the new crop was thus guaranteed. The balance was then reproduced by the shelterwood method, the beech predominating in the new reproduction. 


\section{CHAPTER IV}

\section{THE SHELTERWOOD SYSTEM}

\section{Underlying Principles of the Shelterwood System}

Experifnce has shown that the systems of clear-cuttings with natural reproduction have certain disadvantages which in many cases render their results uncertain and unsatisfactory. The exposure of the soil often results in retarding reproduction through drought or frost, or through competition with brush and weeds, which spring up in abundance on clearings. A disadvantage of the clear-cutting systems with natural reproduction is that they cannot be used with trees having heary seed. All of these difficulties are in a measure overcome by the application of the shelterwood system.

The principle underlying this system is to remove a given stand gradually by a series of thinnings. The opening of the canopy results in reproduction over the ground under the protective shelter of the trees left standing. These trees are then removed at one cutting, or gradually, in accordance with the needs of the new crop and the special requirements of market and logging.

Advantages of the System.-The special advantages of the system are the following:

1. The cuttings for reproduction leave a large num- 
ber of seed-trees, evenly distributed and comparatively close together. In consequence, a relatively large amount of seed is produced, and is regularly distributed over the area.

2. The system may be used with trees having heavy seed, for the distribution of seed may be entirely controlled by the number of seed-trees and their distance apart.

3. The shade of the remaining trees retards the growth of grass, weeds, and brush, which would interfere with the young growth of trees.

4. The shelter acts as a protection to the soil, preventing excessive drying and baking.

5. The shelter protects the seedlings from drought and frost.

6. During the period of reproduction the trees left standing are more or less isolated, and grow at a maximum rate, adding substantially to the final aggregate yield and value.

7. The new stand is established in advance of clearing. As a result, there is not only a gain of several years' growth, but the interval between removing the cover of old trees and the formation of a close canopy by the new trees is much shorter than in the clear-cutting operations. The soil is, therefore, exposed for a minimum length of time.

8. The gradual clearing of a forest by successive thinnings is always less objectionable from an esthetic standpoint than a clear-cutting. 


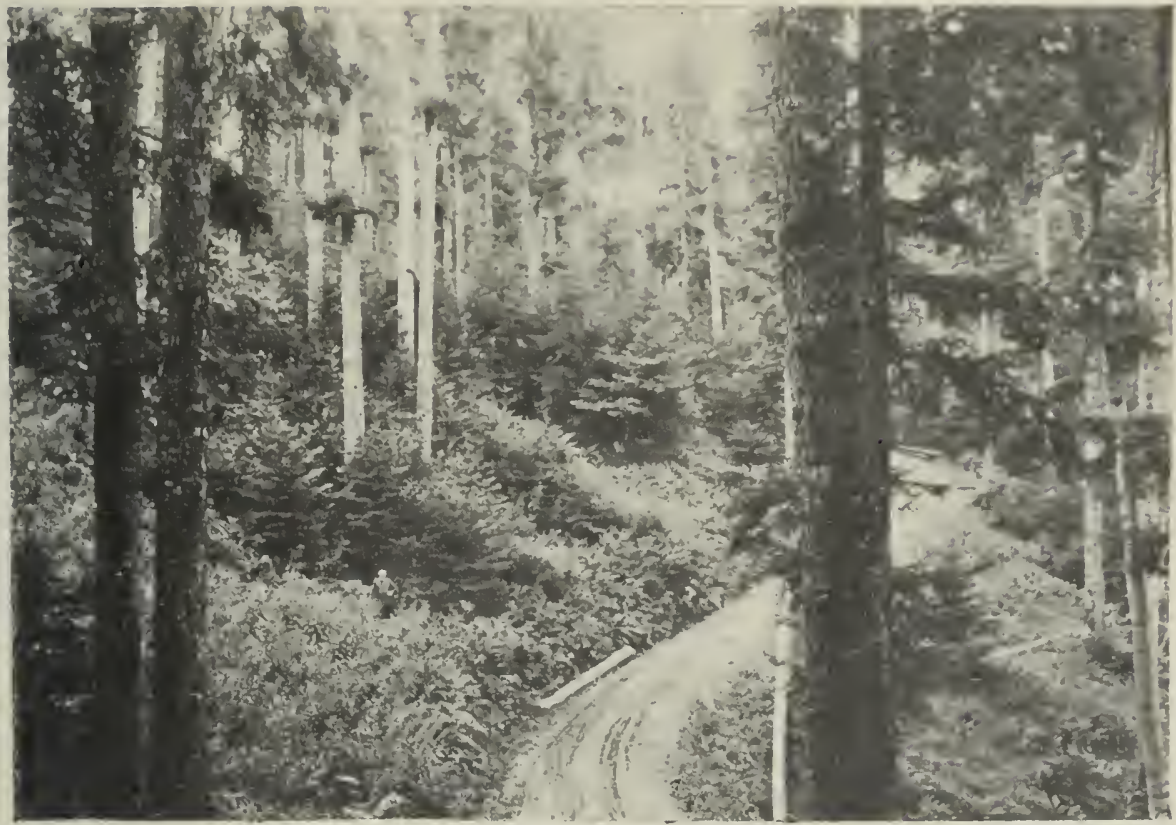

FIG. 30.-Reproduction of a Stand by the Shelterwood System. The Sheltering Trees will be Removed in the Next Ten Years. Black Forest, Germany.

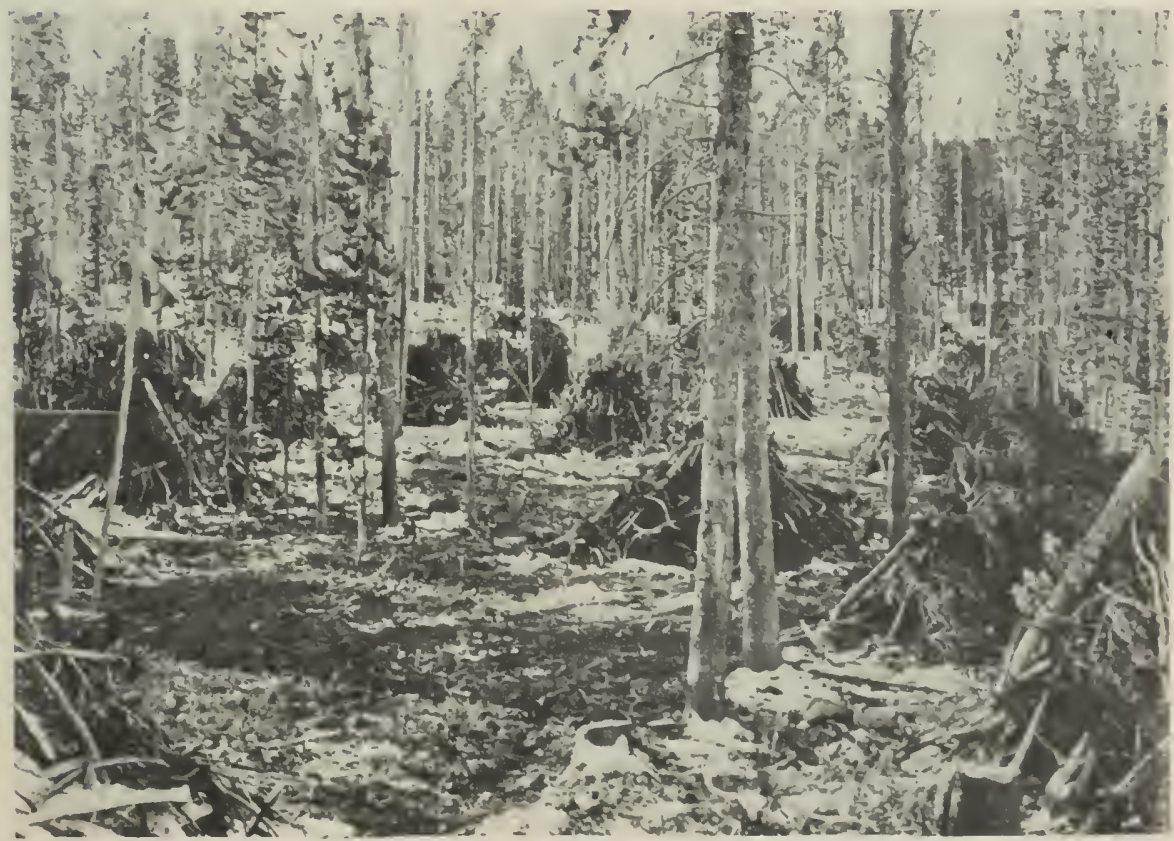

FIg. 31.- Primitive Application of the Shelterwood System, after the First Cutting. Lodgepole Pine. Big Horn National Forest, Wyoming. 
Disadvantages of the System.-As compared with the clear-cutting systems, the shelterwood system, therefore, gives to the forester means of better controlling reproduction, protecting young growth, and conserving the quality of soil, as well as the appearance of the forest.

The chief disadvantage, from a silvicultural standpoint, is that the system cannot be applied when there is great danger from windfall. During the period of cuttings the trees are isolated, and, therefore, exposed to danger from windfall. This disadvantage is partly overcome in European practise by opening up the forest in the first instance by a series of light thinnings, and thus gradually rendering more windfirm the trees that are chosen to stand. Even this measure is of no avail where the danger from windfall is extreme. In this country a series of light thinnings is often not feasible, and this fact excludes the system not only from the more exposed sites, but also from many areas where it would be practicable if it could be intensively applied.

A second disadvantage touches the problem of logging. The conditions must be such as to permit the restriction of the first cutting and the removal of only a part of the stand in the form of a thinning; then a return for one or more subsequent cuttings.

Variation in Application.-This system, like all others, must be applied with wide variations in different forest types, according as the forests vary in age, density, and reproductive capacity. But the application of the system is mainly affected by the market and logging 
factor. Upon this factor depends the number of thin nings which may be made during the process of removing the given stand. The best work is done where it is possible to dispose of any and all products of the forestcordwood as well as logs-and where there are permanent roads. Under these conditions one may make a thinning in the forest whenever needed, and may cut just those trees whose removal is required in each given case.

The other extreme is found where the market and logging conditions permit only two cuttings; one thinning to open the stand for reproduction, and a final cutting after reproduction is secured. The better the conditions of market and transportation the more thinnings will it be feasible to make. The greater the number of thinnings, the more intensive will be the application and the better will be the final results. The most intensive application is found in Germany; the most primitive, in America and in other countries just inaugurating the practise of forestry.

\section{Primitive Application of the System}

The simplest use of the system is when it is designed to remove a given mature stand in two cuttings. The first is a thinning intended to secure the conditions required for reproduction. This is called the seed-cutting. 'The next cuting is made after the reproduction is secured, and removes the trees left after the first cutting. This is called the funal cutting. Usually the final cutting is made from 10 to 20 years after the seed-cutting. 
The method is applicable to stands in which the timber is all, or nearly all, mature, where the trees are fairly windfirm, and where the market permits the cutting of a part of a stand in the form of a thinning. Precisely these conditions are found in many of our original forests which have an even-aged form of stand. The best illustrations are the old yellow pine stands in the South, and many stands of Western yellow pine in the West.

The application differs so widely in different forests that the principles are best illustrated by a discussion of several practical examples.

\section{Application in the Longleaf Pine Forests}

The ordinary longleaf pine forest is composed of stands and groups of regular form. The old stands and groups are composed chiefly of mature trees. These asually are not continuous, but are broken by stands, patches, and groups of younger trees, each of which is also of regular form. The average forest in which the lumberman to-day is operating is composed chiefly of old, mature stands. Usually about 75 per cent. is mature. A cutting of all mature trees would, therefore, constitute a series of clear-cuttings. The younger trees would remain as stands, patches, and groups standing by themselves. The reason why the forests are in this condition must be sought in the effect of the forest fires which have doubtless occurred for countless years, and in the destructive tornadoes which periodically sweep certain sections of the longleaf pine region. 
The mature stands require a system of silviculture which will remove the timber in a restricted period, and replace it with a new even-aged stand. The selection system is out of the question. Heretofore, it has been the custom to clear-cut without reference to reproduction. Nany foresters and lumbermen agree that the best method is to remove the timber in two cuttings, separated by a period of from 10 to 20 years. This is in reality the shelterwood system, though a very primitive example in comparison with the practise in Furope. It is the best, and indeed often the only, method which can be used under the given conditions.

The advantages to the owner in using this system are as follows:

1. The forest is cut over rather rapidly, and the mature, deteriorating timber is utilized.

2. The trees left standing are thrifty. They will grow rapidly and add materially to the amount which may be taken out at the second cut, thus prolonging the supply on the tract.

3. Since the trees left standing are the smaller diameters, the average grade of the present cut is raised.

t. The increase of stumpage, and particularly the increase for the lower grades, should result in a much greater return from the trees left standing than could be realized from them if cut now.

5. A good reproduction may be secured, which will undoubtedly increase the value of the land for future sale, at least that portion not designed for cultivation. 
The First or Seed-Cutting. - In making the first cutting, the forester has in mind present utilization, a profitable logging operation, the securing of a maximum growth between cuts, a profitable second cut, and reproduction before the time of the second cut. The special points considered in selecting the trees for removal are as follows:

1. Cut all deteriorating trees, such as those infected with red rot and those with burned butts, cat-face, or similar defects likely to affect their value before the next cut.

2. Cut mature trees which have reached their limit of effective growth, except where absolutely needed for seed.

3. Cut trees with suppressed and broken crowns.

4. Cut all trees liable to be blown over before the second cut, such as certain leaning trees, tall, slim trees with small crowns, and those weakened by boxing.

5. The trees left standing must be:

a. Windfirm.

b. Sound.

c. With well-developed and thrifty crowns.

d. Capable not only of living till the second cut, but of adding substantial growth.

6. Provision is made for the distribution of seedbearing trees, so that seed will be scattered in abundance over the entire area.

7. If the trees which should be left for growth are not sufficient in quantity, or not properly located, special seed-trees from the mature class are left standing. 
8. In leaving special seed-trees, the ones of least present commercial value are selected.

9. Defective trees may sometimes be left as special seed-trees, but only if they will produce seed in abundance, and will stand long enough to secure reproduction.

10. All groups and patches of immature timber and young growth are carefully protected.

11. Of no matter what size, trees attacked by insects should be cut, even at extra expense, since this is the only way to prevent the spread of insects to the rest of the forest.

In operating on these principles, care must be taken not to injure the trees left standing. This applies to the work of felling and of skidding out the logs. The forest is usually so open that there is no excuse for damage in felling trees. Nor is there any reason for injuring the standing trees and the young growth, especially if logs are taken out by horse power.

The Second Cutting.-After reproduction has been successfully secured, the forest is cut over a second time, and the timber left from the first cut is removed. Theoretically, this cutting should take place as soon as the young growth is thoroughly established. In actual practise, however, the second cutting cannot be accurately timed with reference to the needs of the new growth. This is particularly the case in extensive forests operated on a large scale. Usually the second cutting will not be made until the first cuttings have been completed through the whole forest. Then the operations will 
commence all over again, beginning at the same point as the first cuttings. Frequently, however, the second cuttings will not follow precisely the same cutting areas, and they may progress at a different rate. Often, therefore, the interval between the cuts must depend on the length of time it takes to work over the forest the first time. This will ordinarily vary from 10 to 20 years.

When the second cut is made, the ground will presumably be covered with young growth. A certain amount of damage to the new growth will be inevitable. If reproduction has been successful, the new growth will be very dense; there will be so many trees that a certain amount of loss by breakage will not materially affect the final crop. The small openings made in getting out the logs will be covered by the closing together of the neighboring trees as they grow older. If the reproduction is not complete, but in patches, the logs can be taken out with very little damage to such young growth as has been secured. In any case, the loggers must exercise a great deal of care not to injure this growth. At that cutting it is probable that the use of a steam skidder would have to be discontinued.

Results.-It is estimated that, on an average, about 65 per cent. of the merchantable trees are taken out at the first cutting, and that this amounts approximately to 70 or 80 per cent. of the volume and 60 or 70 per cent. of the crown cover. The trees left standing are capable of fair growth, and this materially increases the yield of the second cut. 
If fires are kept out, reproduction may be secured in large amounts. It may happen, however, that a full stand cannot be obtained. The necessity of confining the operations to only two cuttings, the heavy openings and rather extensive exposure of the soil, the competition of weeds which cannot be controlled, and the damage at the second cut, are factors likely to reduce the reproduction below what could be secured under an intensive system of management. If, however, the work is carried out as indicated, there is no reason why a stocking of 60 per cent. of the maximum should not be secured. Under the circumstances, this should be considered very good; it is enough most amply to repay the expense and trouble incurred.

\section{Application in the Black Hills}

The forest of the Black Hills of South Dakota and Wyoming is chiefly composed of one species- Western yellow pine. From time immemorial the area has been swept by forest fires, which have made clearings of greater or less size. On these clearings stands of relatively even-aged pine have come up, so that to-day the forest is composed of stands, patches, and groups, each of regular form: There are, to be sure, many very broken and irregular stands with individuals and clumps of trees of different ages intermingling; but the prevailing form is regular. The mature stands of this regular character are very well handled by the shelterwood method, and the Government is now adopting this plan of cuttings. 


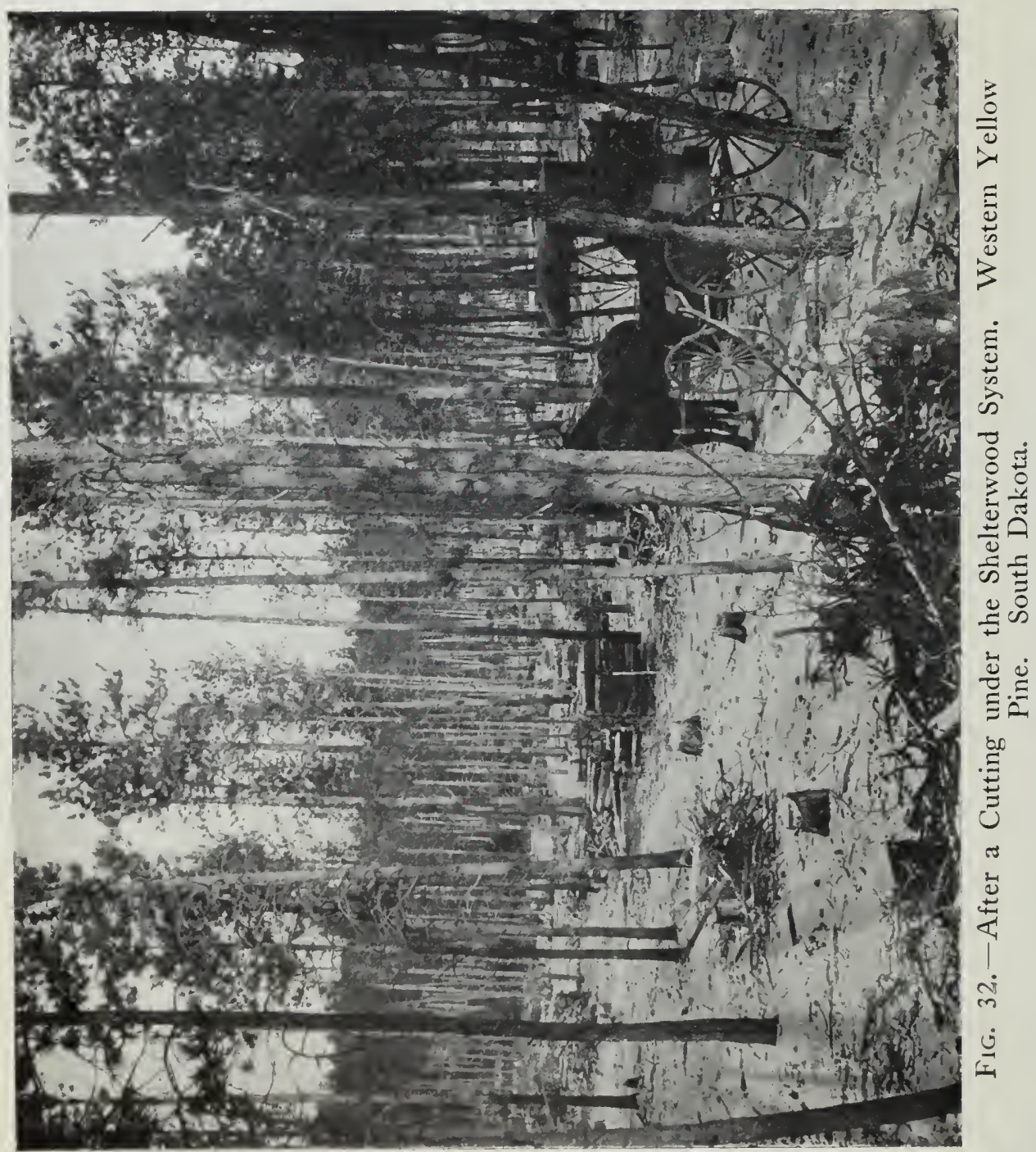


The First Cutting.-Suppose, for example, that at stand has an age of 100 to 150 years, a range of diameters from 8 to 16 inches, and a yicld of 12,000 feet per acre. The trees for the first cutting are selected with the following considerations in mind:

1. The cutting is restricted to about 60 per cent. of the present merchantable stand.

2. The trees selected for cutting are primarily:

a. The largest trees.

b. Defective trees which will not live till the next cut.

c. Trees with suppressed, badly broken, or unhealthy crowns.

d. Insect-infested trees.

e. Trees likely to be blown over or otherwise dam. aged before the next cut.

f. Trees with the long slender boles and small taper.

g. Fire-scarred and otherwise injured trees which are in danger of becoming defective before the next cut.

3. The trees left standing are primarily dominant trees of moderate diameter, with crowns of moderate size.

t. The trees left standing should be sound, thrifty, and capable of responding to the new conditions of light and space, and of producing an effective growth. They should be windfirm, and capable of bearing seed now or in the near future.

5. When the stand is dense and regular, the trees left standing can usually be spaced at fairly regular intervals. 
When the stand is broken and irregular, this is impossible. Care is taken to leave trees capable of bearing seed, at least every 50 feet. If there are no trees of the moderate diameters which will serve as seed-trees, larger trees, properly located, must be left.

6. All thrifty individuals and groups of immature and young trees are left standing.

7. The trees standing over good reproduction are cut freely.

The Second Cutting.-The second cutting will probably take place in from 10 to 20 years. By that time there should be ample reproduction over the whole area and in fairly uniform distribution, under the trees as well as between them. The damage to this growth in taking out the trees in the final cutting will be considerable. But the trees left standing are those with moderate crowns, which will do less damage than large veterans with sprawling crowns. The damage should not reduce the real density of stocking in the new stand over 10 per cent., because the young growth will usually be denser than is necessary, and the loss of a few small trees will not materially impair the develcpment of the new stand.

\section{Progress in the Development of the Shelterwood System}

'The removal of a stand in two successive cuttings represents the most primitive application of the shelterwood system. As was said, the time of making a given cutting is dependent more on the conditions of 
market and logging than on the requirements for reproduction.

The next step in the development of the system is the removal of the trees left after the first or seed-cutting in two cuttings instead of one cutting. The additional cutting is a thinning made after reproduction has been started, in order to admit more light for development of the seedling growth. It is made when the condition of the new crop requires it; and the amount of timber to be removed and the selection of the trees depend on the needs of the young growth. It is a thinning, and therefore leaves standing a certain number of trees which still act as a partial shelter and seed up blanks not reproduced after the first thinning. This second thinning is called the Removal Cutting.

The two-cutting plan was used in Europe as early as 1720. In the early part of the 19th century the idea of three cuttings was fully developed. With the improvement of market conditions, still greater attention was given to reproduction and the development of the new stand. It became more and more possible for the forester, from first to last, to direct all cuttings so as to secure a full and thrifty new crop, and at the same time to meet the requirements of logging. The result of experience in reproduction and of the development of a good market is the modern shelterwood system, as applied in Furope, which consists of al series of cuttings, from three to ten or more, according to the needs of a given case. 
In this country we are passing through the same process of development. 'The two-cutting plan is used in certain virgin forests under difficult market conditions. With improved conditions the stand left after the first cut may be taken off in two cuttings. It is probable that this is about as far as we shall go in operating old forests from 150 to 300 years old.

The further development and more intensive application will come with the second-growth regular stands, which do not exceed 100 years of age. Already in many parts of the East the market is such that the system can be applied in much the same way as in Europe. This condition is reached when there is a market for all wood products, including cordwood, and when there is a permanent road system-conditions which enable the forester to make a thinning just when it is needed, and to cut just what is required for the good of the forest.

\section{Intensive Application of the Shelterwood System}

It is necessary to look to Europe for the best illustrations of the shelterwood system intensively applied. The description which follows is drawn entirely from European practise. It holds equally good, however, in the intensive application of the shelterwood system in this country.

The use of the shelterwood system varies to some extent. The individual cuttings may be made uniformly over the whole stand, or they may be concentrated in 
strips or groups; and in the latter case a given cutting affects only a part of the stand. There are recognized in Europe three methods of application:

Cuttings distributed uniformly.

Cutting in strips.

Cutting in groups.

\section{Shelterwood System with Uniform Cuttings}

This is called the uniform system because the various operations extend over the whole stand, and the thinnings are designed to secure a regular and uniform reproduction over the area, rather than in groups or in strips.

In order to make the description concrete, let us suppose that the stand in question is pure spruce, even-aged, about 100 years old, and fully stocked. The design is to cut and reproduce the stand within a period of 20 years. This is done by a series of thinnings which fall into the following groups:

1. The Preparatory Cuttings, designed to prepare for reproduction.

2. A Seed Cutting, which accomplishes the reproduction.

3. The Removal Cuttings, which are made to help the seedling growth and which include the Final Cutting.

The Preparatory Cuttings.-The objects of the preparatory cuttings are:

1. To prepare the soil for the reception and germination of the seed. A dense spruce forest is characterized 
by little or no undergrowth, and by a deep layer of litter and humus. This forest floor is a very poor germinating bed, and the first requisite for reproduction is to hasten the decomposition of the vegetable material. This is accomplished by the preparatory cutting, which admits a free circulation of the air. The object is to open up the forest enough to bring about this rapid disintegration of the humus, but not enough to allow the soil to run wild with weeds and brush.

2. A second object is to stimulate seed production. The first thinnings admit more light to the crowns and stimulate assimilation, and hence seed reproduction.

3. Still another object is gradually to accustom the trees to isolation, and make them more windfirm.

These purposes may sometimes be accomplished by making a single thinning. If, however, the forest is very dense, it may be necessary, on account of danger from windfall, to open up the forest gradually by two or, in some cases, three thinnings.

The preparatory cuttings are thinnings which open the canopy uniformly throughout the stand. The trees taken out in the preparatory cutting are primarily of the following character:

1. Trees infected with disease.

2. Trees with suppressed, broken, or otherwise defective crowns.

3. Trees with overdeveloped, spreading crowns.

4. Very tall, slender trees likely to be overthrown by the wind. 


\section{Species not desired in the next crop.}

The aim is to leave thrifty dominant trees of moderate size regularly distributed over the area. It is often necessary to leave standing trees with overdeveloped crowns, as well as undesired species, when their removal would open the canopy so much as to induce a growth of weeds and brush before the stand is ready for the seedcutting.

The preparatory cutting removes from 25 to 40 per cent. of the trees, which amounts to from 20 to 30 per cent. of the volume. The crown canopy is reduced 20 or 25 per cent. The aim is to isolate the trees very moderately, leaving them spaced from 3 to 5 feet between the peripheries of their crowns.

The number of cuttings needed, the severity of each, and the aggregate opening made, depend on the following factors:

1. Danger from Windfall. - The greater the danger, the more gradual must be the opening.

2. Character of the Forest Floor.-The thicker the vegetable cover, the heavier the cuttings. The slower the natural processes of decomposition, the heavier the cuttings.

3. The Character of Canopy.-The thicker the canopy, the denser is the shade, and, consequently, the heavier are the openings required.

4. Height of Canopy.-The higher the canopy, the denser is the shade cast, and hence the larger are the openings required. 
5. Soil.- The richer the soil, the greater the tendency to growth of weeds.

The preparatory cuttings are successful when the soil is in good condition for the reception of the seed about the time when it is designed to make the seed cutting. When the humus and litter are so far decomposed that here and there mineral soil appears, the ground is in receptive condition. Usually there is at the same time a light growth of grass and tolerant annuals.

In a forest in which there is a deep humus to begin with, the time required to bring about the desired condition of the forest floor varies greatly with different soils, and with humus derived from different species. Roughly, from three to ten years may be required.

The Seed-Cutting.-As soon as the soil is ready to receive the seed, the seed-cutting may be made. This is a heavy thinning, made through the stand, and designed to establish the conditions necessary for the start of reproduction and for the life of the seedlings during the first few years. It is the aim to make this cutting during a seed year, in order that these new conditions may immediately follow the fall of seed. If the soil has duly benefited from the preparatory cuttings, and the seed-cutting is made during a good seed-year, one cutting for seed is all that is necessary. The seed-cutting removes from 25 to 50 per cent. of the volume of the stand. It reduces the density of cover to 30 or 50 per cent.

The principles of selecting the trees for cutting are similar to those governing the preparatory thinning, 
except that the seed-cutting is a much heavier thinning. The aim is to cut such defective, malformed, and suppressed trees as are left from the preparatory cuttings. The larger trees with spreading crowns are taken, because of their possible danger to the reproduction if left for later cutting. Trees of undesirable species, likely to reproduce themselves in competition with the good species, are also cut. Just as in the preparatory cuttings, the trees to be left are of moderate size, and chosen from the dominant class. They should be thrifty and capable of rapid growth during the remainder of the period of reproduction. They should also be capable of producing seed, since they not only must produce the greater part of the seed for the first reproduction, but are also counted on to seed up any gaps that may occur.

In general character, the thinning is uniform-that is, it extends over the whole stand. Usually, however, it is not necessary to be very precise in spacing the trees at a uniform distance. It may happen that a given site is subject to danger from frost, and that protection of the small trees in the earliest period requires a uniform cover. Even if the trees are not regularly spaced, a uniform distribution of seed may usually be secured. If the seed is distributed by the wind, smal! openings here and there would be readily covered with seed, as well as the ground under the trees. With trees having heavy seed, a good distribution is obtained if the seed-cutting is made after the ripening of the fruit in a seed-year. There is then a production by all seed-trees left from the preparatory cut- 
tings, and the ground should be amply covered in a uniform manner. A slightly irregular thinning would not be unfavorable to the young growth from the standpoint of protection from drought, for there would usually be enough side shade to meet the requirements of the seedlings. With trees of only moderate tolerance an irregular thinning might often be better than a uniform one, because it would admit a certain measure of side light to young growth standing under slightly too heavy shade. The best rule is to make the thinning uniform so far as the conditions permit, but not to make undue sacrifice to uniformity where, for one reason or another, certain trees ought to be removed.

In judging how heavy to make the seed-cutting, the forester has in mind the distribution of seed, and the maintenance of such a degree of shade as is necessary to protect the new crop from drought and frost, and to hold in check the growth of weeds. The usual rule is to leave only as much as is necessary to accomplish this purpose, in order that the uncovering of the crop later on will be attended by the least possible danger.

If the preparatory cutting has been successful and reproduction is pretty certain, a heavier cutting would be made than when reproduction is uncertain. Just how extensive an opening of the canopy is best for establishing and for protecting reproduction must depend in each case on the species, the site, and the condition of the ground.

In Europe, it is often customary to aid the reproduction by artificial measures. Thus, if there is a growth of 
grass and weeds which will interfere with germination and the establishment of the reproduction, the soil is sometimes broken up to expose the mineral soil. One method is to break the ground cover with mattocks at intervals of 5 or 6 feet, exposing about a square foot of soil in each place. Another method, used when the soil and topography permit, is to plow furrows among the trees; and yet another in common use is to turn hogs into the woods before the seed-year, to work up the soil.

In some instances a certain amount of planting is done after the seed-cutting. This would be done when natural seeding is uncertain, and the species requires shelter during youth. If no shelter were needed, the stand would be cut and the trees planted on the clearing. The planting in advance of cutting usually has for its object the maintenance of a certain species in mixture. It is a common measure in mixed beech and spruce forests, where the natural reproduction of beech is better than that of spruce. The young spruce-trees are planted near stumps and rocks, where there will be the least possible damage by the later logging.

When a seed-cutting fails to yield good reproduction, and the ground is begimning to be covered with weeds and brush likely to retard reproduction from later seedyears, planting is commonly used to complete the new stand. If the young growth requires shelter, the planting is done as soon as the fail-spots are located; otherwise the stand is cleared rapidly, and the planting done after the final cutting. 


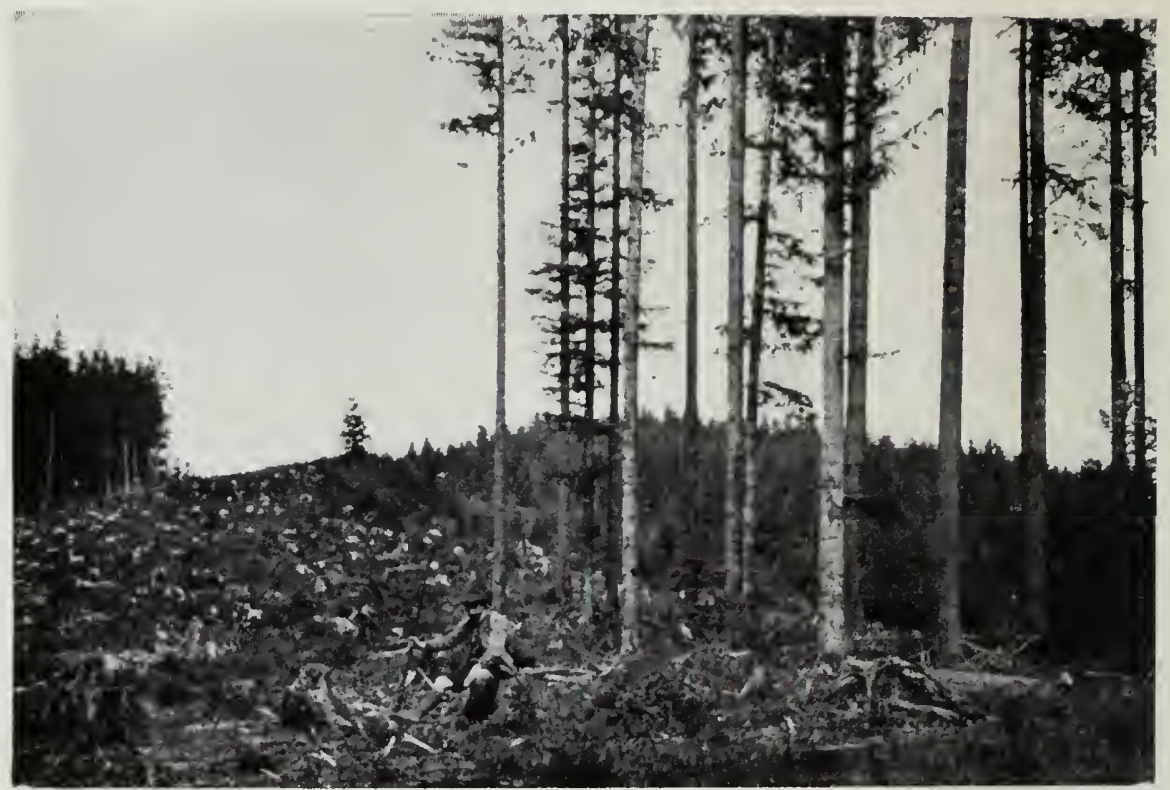

FIG. 33. - Just before the Removal of the Last Trees under the Shelterwood System. Young Growth has been Secured over the Whole Area. Austria.

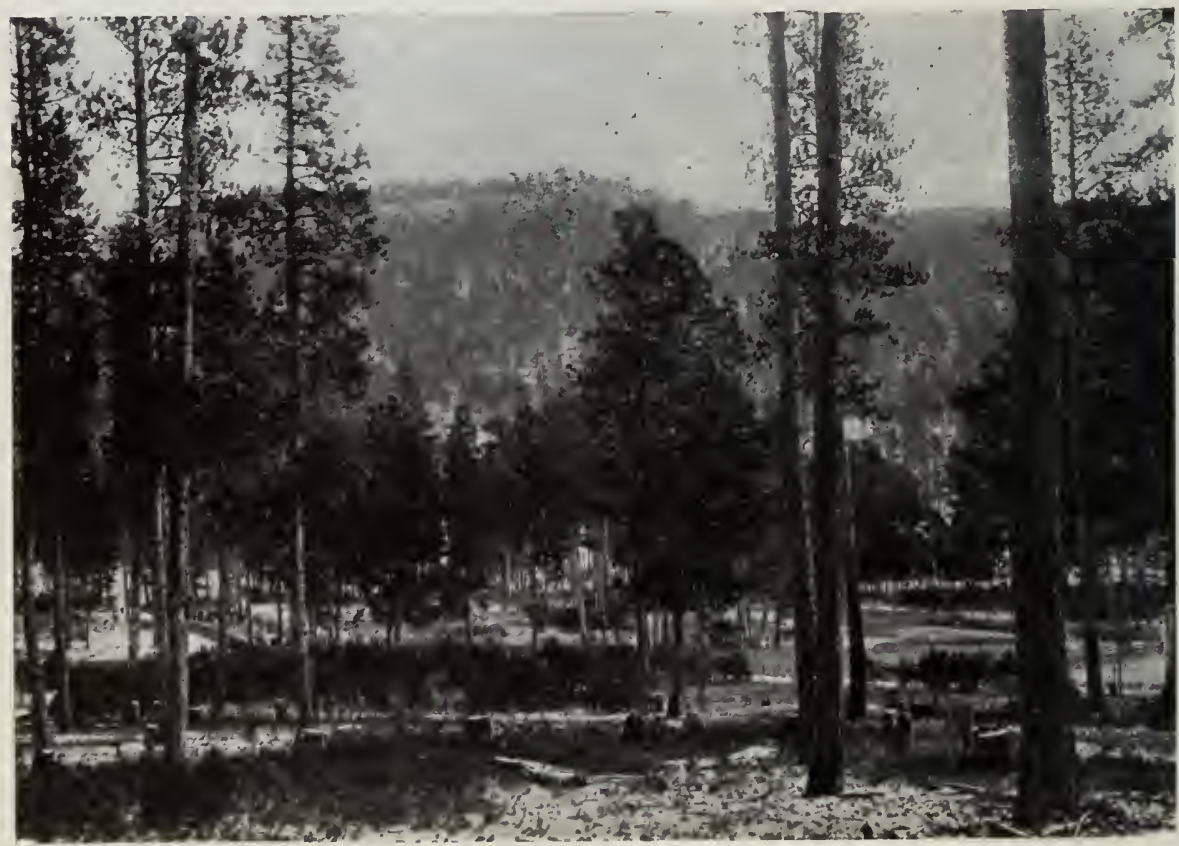

FIG. 34.-After the First Work in an Open Irregular Stand. The Cut tings Followed the Principles of the Shelterwood System. Western Yellow Pine. Black Hills National Forest, South Dakota. 
Very frequently there are at the time of the seedcutting groups of advance growth. Any such groups as are thrifty and will develop well after releasing, are carefully protected. The shading trees are cut, so far as there is need of more light; and, if desirable, a group is entirely uncovered. Useless advance growth which is likely to interfere with the new crop is cut out. Such useless advance growth consists of poor species, poorly formed and unsound trees, and trees so much suppressed that they cannot recover and become of value.

The Removal Cuttings.-Just as soon as the young growth is well established and no longer needs protection from drought and frost, the shelter-trees are removed. Sometimes this can be done in one cutting without danger to the seedlings from the sudden exposure; but it is usually better to remove the shelterwood by a series of cuttings.

The first removal cutting is made as soon as the seedlings begin to need a greater amount of light. As a rule, this is within three or four years after the seed-cutting. The forester must watch the young growth to see if it is suffering from shading. If the seedlings are stunted, weak-looking, and unhealthy of color, and have a sparse foliage, or if they are found to be bending to one side in their search for light, this is an indication that a thinning must be made.

The removal cuttings are not made uniformly over the whole stand, but are necessarily irregular, because some portions of the new crop require more light than 
others, or some are in a position to stand a greater amount of exposure. Ordinarily three or four removal cuttings are required in the best practise. These are made at intervals of from 2 to 4 years.

Just as soon as the young trees have entered the stage of rapid growth and are out of danger from exposure, the final cutting is made. The last trees are usually taken off in about ten years after the seed-cutting.

The rapidity of the removal of the shelterwood necessarily depends on the species and on the site conditions. The operation progresses more rapidly with intolerant than with tolerant species, with drought-enduring than with moisture-loving species, with frost-hardy than with frost-sensitive species, and more rapidly on favorable than unfavorable sites.

The most serious problem in the removal cuttings is the damage to the young growth. With hardwoods, this is very small, because the young trees bend over under the weight of the falling trees, and many of them recover when released. The damage is greatest with conifers. If the reproduction is abundant and the logging done with care, this damage may be kept down to an amount so small as not to materially affect the final crop. In Europe, it is customary to plant up the blanks made by damage in the final cuttings or by other causes.

\section{Shelterwood Cuttings in Strips}

'This is a modification of the method just described, used principally when the uniform opening of a large 
stand endangers the trees from windfall. The cuttings at a given time are made in narrow strips, instead of over the whole stand. Beginning on the lee side and progressing against the wind, successive strips are worked over and reproduced until the whole stand is covered. The first operations are the preparatory cuttings in the first strip. After a few years the second strip is taken in hand, and preparatory cuttings are made about the time the first strip is ready for the seed-cutting. When the first strip is ready for the removal cuttings and the second for the seed-cutting, a preparatory cutting is made in the third strip, and so on.

The conduct of the cuttings in this manner has certain advantages, as follows:

1. Since each operation is in a narrow strip in the lee of an uncut block of timber, the danger from windfall is less than when the whole stand is opened at one time. This permits the use of the shelterwood system under conditions which would otherwise prohibit its use.

2. The protection from the wind gives a freer hand in conducting the cuttings; in many cases, fewer operattions in the series are required, and heavier individual cuttings may be made.

3. The side shade is beneficial, while the protection from the wind lessens danger from drought.

4. When used with species having light seed, as is usually the case, there is an abundant distribution of seed over a given strip from the bordering trees. This is 
particularly valuable in filling gaps, especially after the final cutting.

The width of the strips varies with conditions, and depends chiefly on the danger from windfall. The greater this danger is, the narrower must be the strips. They usually range in width from 100 to 600 feet. The period of reproduction with a given stand is the same as in the uniform system, namely, from 20 to 30 years, usually the former. If a stand is so long that a series will not be complete within the assigned period of reproduction, two or more cutting series are made in the same manner as described on page 133. The result is an approximately even-aged stand, with the trees at the side where cutting began somewhat older than at the other side. The difference in age would be hardly noticeable when the stand reaches maturity.

\section{Shelterwood Cuttings in Groups}

This is a further modification of the principles of the shelterwood system, by which the cuttings are concentrated at special points in the stand, and reproduction is secured in groups, instead of in strips.

The system is used in mountain forests where breaks have occurred and groups of advance growth have been established. These groups are used as centers of reproduction. The cuttings begin about them and progress radially from them. Ultimately, all groups are merged together.

'To illustrate concretely, suppose that in a given ma- 
ture stand of spruce and fir, there are a number of groups of advance growth, from 20 to 50 feet in width, of the character shown in Fig. 30. The center of a given group stands under an open or broken canopy, and there the trees are the tallest. The group extends under the denser portion of the canopy, obtaining enough side light from the central opening for life.

The first cutting, which may be called the primary cutting, is designed to uncover the larger of the young growth, to give more light to the less vigorous trees near the edge of the group, and to induce an extension of the group in all directions.

It might happen that an actual clearing would be made over the center of the group, while over the border trees there would be a heavy thinning, and still beyond there would be a lighter thinning. In fact, one would actually be making a final cutting over the center of the group and a removal cutting over the remainder of it, while immediately beyond the edge of the group the thinning would resemble in severity a seed-cutting. One could go farther, and if the forest were dense immediately beyond this point, a thinning resembling a preparatory cutting could be made in a still wider circle.

All the groups are thinned as just described. Suppose that the thinnings have been successful, and that reproduction has taken place beyond and around the several groups. They will then be extended a distance of from 50 to 100 feet. A secondary cutting is then re- 
quired to continue the operation which has already been started. In the secondary cutting more trees are taken from over the existing groups, according to their need, and the newly reproduced circle is opened up by a heavy removal thinning. The portion which was included in the previous preparatory cutting is thinned for seed, and if necessary a preparatory cutting is made still farther into the woods. These secondary cuttings are made not necessarily in all groups at the same time, but in any groups whose condition requires treatment. The result of the gradual extension of these groups is that they ultimately are merged together, and the whole stand is reproduced.

As a rule, a long period of reproduction is used to work over a whole stand-usually from 30 to 40 years. The result is a stand much less even-aged than that obtained by the other methods. The advance growth is often from 20 to 30 years old, thus making a total variation in age in the new stand of from 50 to 60 years. In spite of the wide difference in the age of the trees, the new stand is essentially regular in character, and is in no sense a selection forest.

\section{The Two-Storied System}

This is an intensive system used in Europe, having for its object the isolation of the best trees during the last half of the rotation in order to secure a maximum growth in diameter and volume. It is applied to even-aged stands of species which are windfirm and which have 


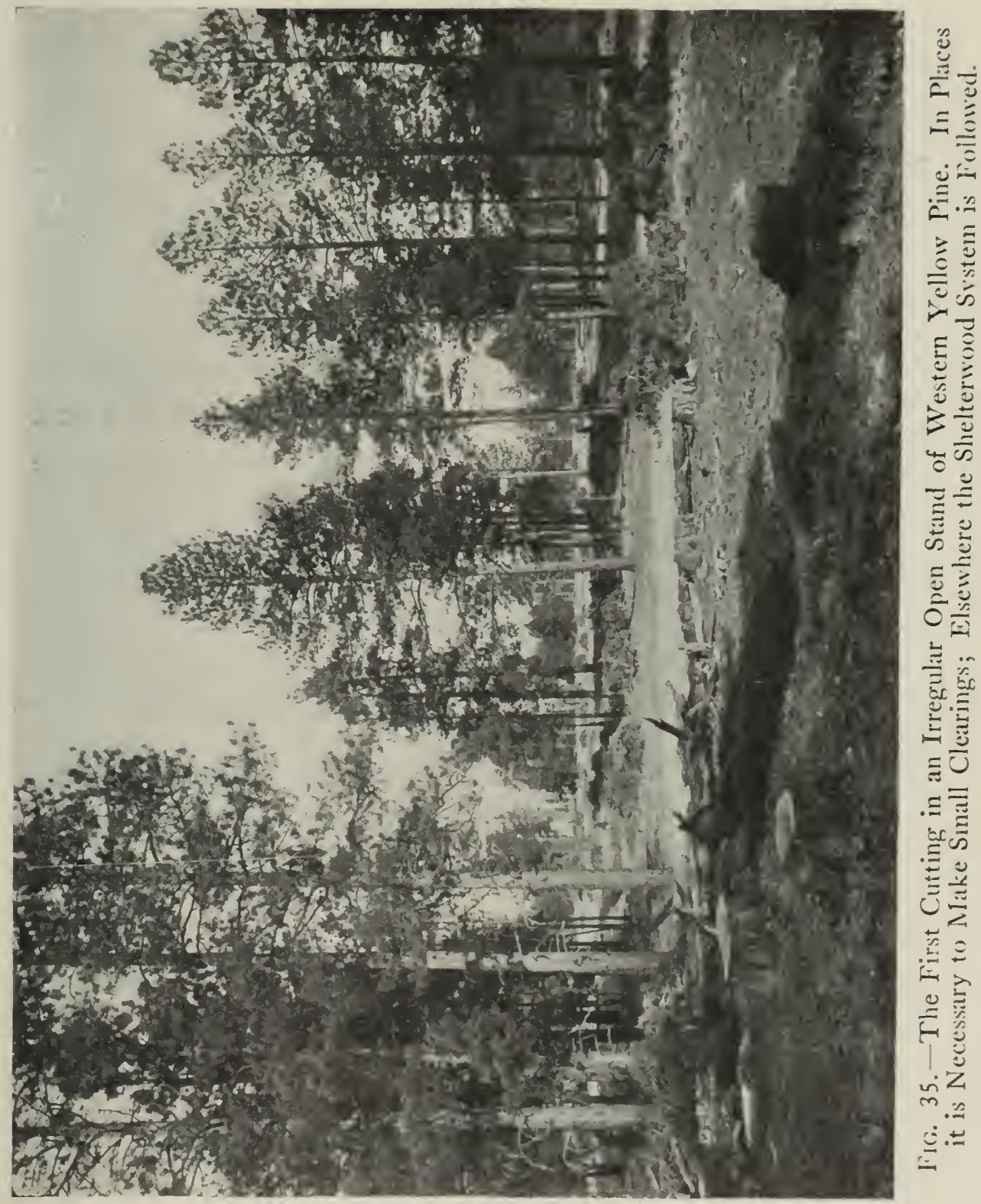


light or moderately light foliage, such as pine, oak, and larch. When a given stand has reached its main heightgrowth and the boles are well cleared by natural pruning, a heavy thinning is made which removes from 40 to 60 per cent. of the trees. This thinning takes out the suppressed, partially suppressed, and defective trees. Those left standing are the best dominant trees in the stand. Each tree is isolated, and will produce its greatest possible growth. Usually there is only one thinning, but if the trees all tend to be slender and subject to possible danger from windfall, two thinnings are made, the first a light one and the second establishing just the conditions desired. This thinning is made in pine stands at an age of from 40 to 50 years, in oak at from 50 to 60 years, and in larch at from 35 to 40 years.

The stand is then underplanted with some tolerant species like birch, hornbeam, spruce, or fir, according to the requirements of site. This constitutes an under-story which protects the soil from deterioration. The lower crop is of tolerant species, and is able to live under the open stand of the older trees. Usually the crowns of the upper story spread rapidly, and it is necessary, about once in ten years, to make a further thinning to sustain rapid growth and prevent excessive injury to the under-story by crowding. At the end of the rotation of the upper story, the whole stand is cleared, including the lower story, and restocked artificially to a stand of the species composing the upper story. If the rotation is 120 years, the trees of the upper story contain material of 
high grade and value, of a size which would be produced under other systems only in about 150 years. The understory may be about 60 years old, more or less crippled, and of small dimensions. It is used for cordwood. 


\section{CHAPTER V}

\section{THE COPPICE SYSTEMS}

\section{Simple Coppice}

UNDER this system a stand is cut clear, and reproduction takes place by sprouts from the stumps. It is applicable only to species which sprout vigorously after cutting, such as chestnut, oak, maple, hickory, ash, tulip, basswood, locust, birch, and certain other hardwoods. It is not applicable to conifers, since, with a few exceptions, these do not sprout from the stump at all.

The simple coppice system has for many years been used in a rough, haphazard way by the farmers of the hardwood region of the Northeast. Conspicuous illustrations of its use are found in southern New England, southern New York, and northern New Jersey. Formerly many iron mines were operated in this region, and consequently there was a demand for charcoal. The hardwood forests were cleared off. The stands which took their place were again cleared off as soon as large enough for use, reproduction taking place by sprouts. As the population increased, demand for fuel succeeded that for charcoal, after the mines were closed, so that in many sections it is still the custom to clear off the wood at intervals of from 25 to 40 years. 
It is a very simple system to practise, for there is no skill to be exercised in selecting trees for cutting, and reproduction takes place promptly and abundantly by natural means, and without expense. There are, however, certain principles governing sprout reproduction

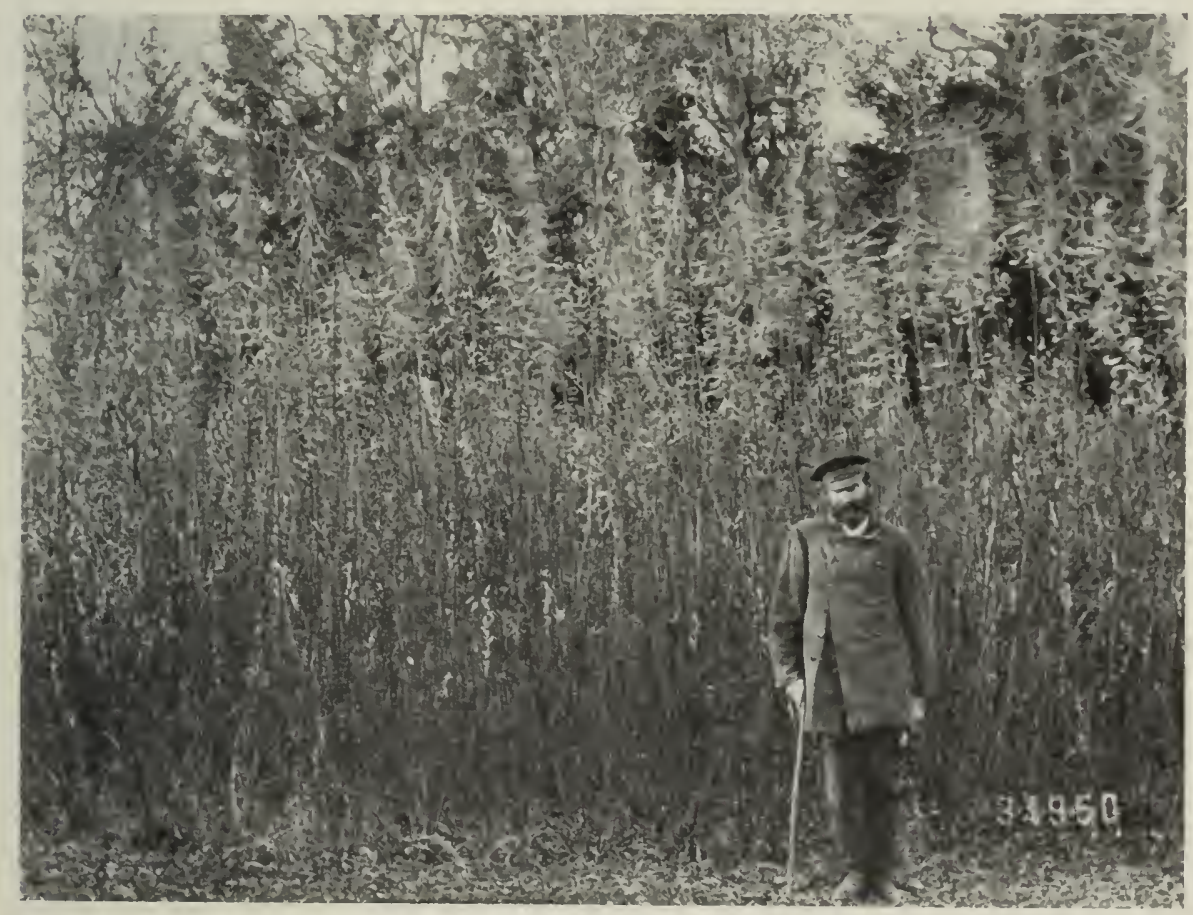

FIG. 36. - Simple Coppice on a very Short Rotation, Illustrated by Willow Culture.

which must be observed in the continued practise of the system. If these are ignored, the forests will deteriorate and their productiveness will steadily diminish. Exactly this has happened in New England. No attention has been paid to the condition of the forest when cut, the season of cutting, or the manner of cutting the stumps. Fires have run through the woods repeatedly and injured 
the trees, reducing their vitality and sprouting vigor. The result has been that many stumps fail to sprout, the density of stocking by good species is reduced, and the growth and final yield are greatly diminished.

Willow culture is an example of simple coppice, handled on a small scale and on a very short rotation.

Age of Cutting.-There is an age of maximum sprouting vigor, which varies with different species and under different conditions of site. It occurs in early life, and ordinarily under 25 years. There is also a maximum age limit of sprouting. This may, in individual cases, be over 100 years. It is later with trees from the seed than with trees that have originated from sprouts. There is a point in the life of a stand of sprouts when certain individuals become defective and weakened, and reach the limit of their power to send up vigorous shoots. If a stand is cut after this period, some stumps fail to sprout, and reproduction by this means is incomplete. This period is usually from 25 to 40 years of age.

In simple coppice management the stands must be cut young enough to insure sprouting from practically all stumps, and the cutting should take place as near the age of greatest sprouting vigor as practicable. In Europe, oak coppice is often cut on a rotation of from 10 to 15 years. Experiments have shown that oak at this age sprouts most vigorously and consistently, and that the coppice system of regular cropping can be maintained more successfully, and with less work of replacement and fewer failures, than with a longer rotation. In some 
cases the trees are allowed to grow to be 25 or 30 years old, but where larger timber is required one of the modified coppice methods is commonly used.

In this country the market is seldom good enough to cut trees below 25 years old. In certain places there is a market for small material at brick-yards and lime-kilns, and for domestic fuel. Under these conditions the trees are cut on a rotation of about 25 years. More often, it does not pay to cut the stand until at least ties and poles can be obtained from the largest trees. This means a rotation of 40 years or more. At so late an age the simple coppice method is uncertain of reproduction, and the pole-wood or system of holding over reserves is preferable.

Season of Cutting.- The trees should be cut during the season of vegetative rest. In general, in the climate of New England, any time from September 15th to April 1st is favorable. Cutting in April results in good reproduction, but at this time there is danger of injury to the stumps by the peeling of the bark and bruising in removing the wood.

Care in Cutting.-The best sprout reproduction is obtained by cutting low, smooth stumps. Where a very short rotation is used, as in Europe, the manner of surfacing the stump is even of greater importance than under the conditions in this country. The European forester takes care that a smooth cut is made on a slant, to shed off the water. A ragged or cup-shaped surface tends to hold water and hasten decay. A short rotation means the 
production of small trees and saplings. The stumps are so small that they are rapidly covered over by the new growth. If the stumps are cut properly they are covered before decay sets in. With larger trees, such as are cut in this country, it is often not possible for the new growth to cover the whole stump; but low stumps mean vigorous sprouting, little hindrance to individual development by the sprouts, and much less danger from decay than is apt to occur after careless cutting.

The Cutting.- It is important to remove the wood from the clearing as soon as possible. Where the wood is piled and left in place for a season, a good many stumps are inevitably covered by the stacks, and thereby prevented from sprouting. Moreover, when the wood is taken, it is usually done by driving on the area with a team and heavy wagon. Large numbers of one-year sprouts are broken off and otherwise damaged in this way.

One of the serious problems in this country is the disposal of the brush. Ordinarily the farmer throws the brush in windrows. They may actually cover about 25 per cent. of the whole area cut over. These piles cover a large number of stumps, and either prevent them from sprouting or cripple the sprouts enough to make them useless.

Maintenance of Density.-If the stand is in healthy condition when cut, the stumps sprout vigorously and a full stand is the result. It often happens that certain stumps have failed to sprout, or through previous abuse 
the stumps are too far apart. Sometimes new stock creeps in by natural seeding. But under the simple coppice method the rotation is short, and the trees do not bear much seed. Therefore such seeding as occurs comes largely from neighboring lots containing old seedbearing trees.

In Europe, where the rotation is very short, natural seeding is never relied on to fill gaps in the reproduction, but resort is had to artificial replacement. When a sprout stand is cleared, it is closely examined with reference to the condition and vigor of the trees. Spots where there are no stumps, and where stumps are likely to fail, are filled by planting. In oak coppice, for example, it is customary to plant in spaces as large as 15 feet square. The custom is to plant oak transplants which have stood two years in the nursery. Ordinarily these are cut back when planted. That is, the seedling is planted, and then cut off at the ground. It throws up a vigorous sprout and grows up with the remainder of the stand. Such a plan naturally presupposes a regular organization, with a nursery and with men in charge of the property who are trained in such work.

Arrangement of Cutting.- In this country owners of sprout forests cut al lot here and there as the trees come to marketable size. In Europe, the system is extensively used in the management of communal and government forests. In such conditions the forests are so organized that an approximately equal yield is secured each year. This is accomplished by dividing the forest into as many 
lots as there are years in the rotation. If the trees are to grow twenty years, there will then be twenty divisions, one of which is cut each year. After the work has been in operation one rotation, there are 20 ages represented, and one lot is coming to the rotation age each year. If the quality of site is about uniform over the whole for-

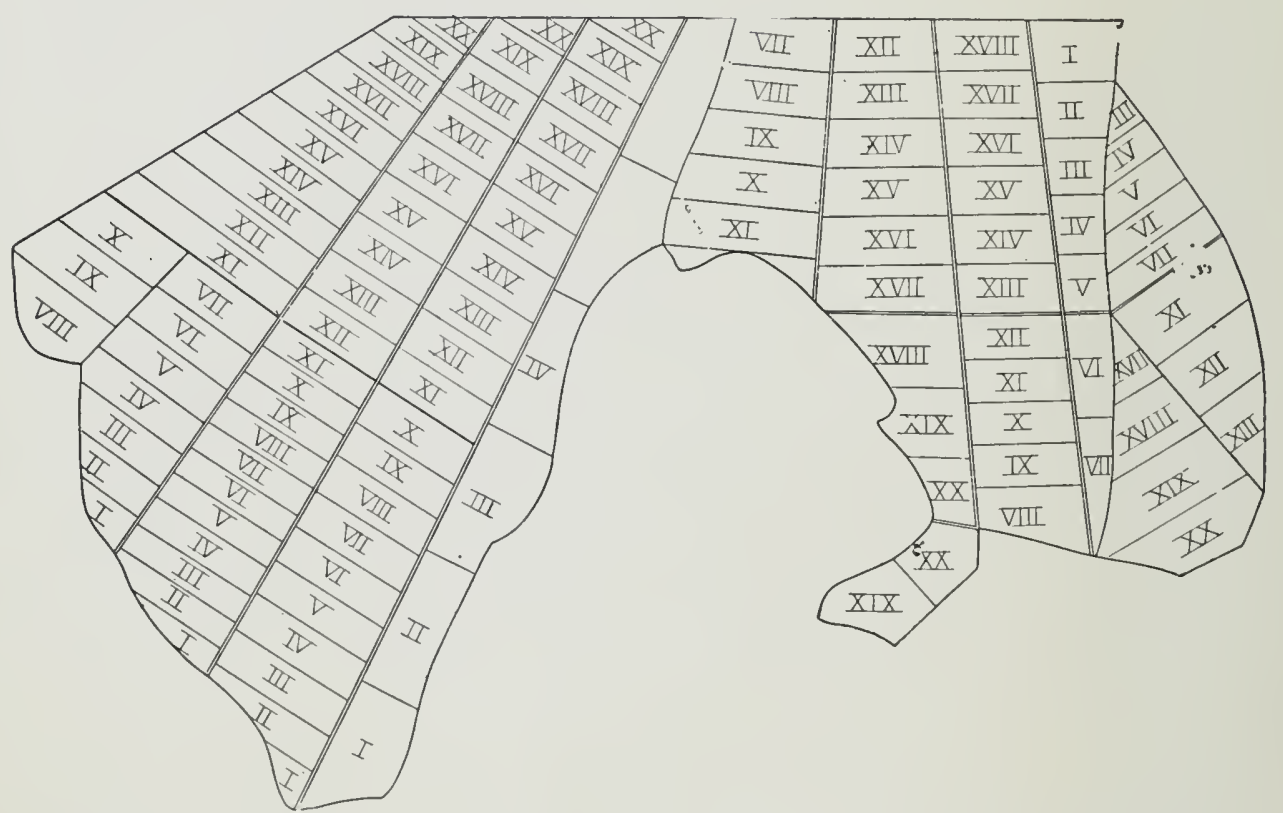

Fig. 37.-Distribution of Annual Cutting Areas in a Forest Managed under the Simple Coppice System on a Rotation of Twenty Years. A Communal Forest in Northern Germany.

est, these lots are made about equal in size. If there are different types of land, with different qualities of site, and hence with different yield capacities, the lots are made somewhat larger on the poor soil than on the good soil, so that the yield in material will be about the same each year. The diagram above shows a German communal forest divided into 20 annual cutting areas. 


\section{Holding Over Reserves}

Under this system all trees in a sprout stand are cut, except a certain number of selected individuals left scattered over the area to remain during a second rotation. Take, for example, a stand of oak, chestnut, hickory, and maple sprouts 25 years old. Certain straight, thrifty trees are designated to be left, and the remainder cut clear, as in the simple coppice method. At the end of the next rotation, the main stand will be composed of 25 year old sprouts with scattered individuals 50 years old.

The purpose of this system is to use the land chiefly for the production of small wood, and at the same time to obtain a certain amount of large timber. It is the same principle as the system of reserving thrifty standards, described on page 118, applied to sprout forests. The rotation is short, returns are frequent, and there is secured a measure of the higher and more valuable grades of timber.

When the stand is ready to cut, the forester marks the reserves. He aims to leave, regularly distributed over the area, as many trees as possible without interfering with the reproduction from the stumps of those cut. As sprouts do not thrive under cover, there must be no sem. blance of a canopy of reserves, but the individuals must be scattered. The number left depends on the tolerance of the coppiced trees, which necessarily varies with different species and under different conditions. This 
number varies, further, with the age at which the sprouts are cut. If 25 years is the rotation, more reserves can be left than with a 40-year rotation, because the trees have a much smaller spread of crown. As a general rule, the number of reserves varies from 20 to 40 per acre.

The trees chosen for reserves are well-formed, dominant trees with a moderate crown development. They must be sound, thrifty, and windfirm. Trees standing singly are better than those growing in clumps, though it is often necessary to leave some of the latter class.

Under this system the returns are greater than under the simple coppice. The total amount of wood produced would not differ materially in cubic volume. The volume of coppice would be somewhat less because of the space occupied by the reserves and the retarding of the growth of shoots affected by their shade. It is probable, however, that the loss of growth of the coppice would be fully counterbalanced by the yield of the reserves in cubic volume, and more than equalled in value. The reserves are isolated, and have a maximum growth. They reach a size in 50 years what it would take in a closed stand 60 or more years to secure.

\section{Pole-Wood Coppice}

In most hardwood forests the simple coppice system on a short rotation is not practicable, on account of the lack of market for small material. The rotation is then extended until the trees, or a portion of them, are large enough for piles, poles, ties, or lumber. The age of 
cutting in this case is considerably later than the period of best sprouting capacity. Reproduction by sprouts alone cannot, therefore, be relied upon, but this must be supplemented by establishing many seedlings, naturally or by planting. The production of the pole class of timber and the reproduction partly by sprouts and partly from the seed, may be called the Pole-Wood Coppice System.

Use in the Hardwood Region of the East.-This is the method by which farmers' woodlots in southern New England are often treated; there, however, it is practised without design and with a poor degree of success from the standpoint of forest production. It is customary to cut the forest clear when a profitable sale can be made. The large trees are used for lumber or ties, the straight trees for poles, piles, and posts. The small, defective, and crooked trees, and the tops, are used for cordwood.

The trees are cut when from 40 to 80 years old. Some of the stumps sprout vigorously, some throw up weak shoots, and some do not sprout at all. It usually happens that a stand of second-growth hardwoods over 40 years old does not have a complete canopy. This is especially true of stands originating largely from sprouts. The small, scattered breaks in the canopy admit light, heat, and a free circulation of air to the soil. As a result, there may be started some advance reproduction from the seed. If this advance reproduction is plentiful at the time of cutting, and there are no fires to destroy it, the reproduction by sprouts will be largely supple. 
mented by seedlings. In this way, many hardwood stands, which are cut at an age when sprout reproduction is uncertain, are followed by surprisingly good second growth. Usually, however, fires run over the ground at frequent intervals, or cattle are allowed to graze

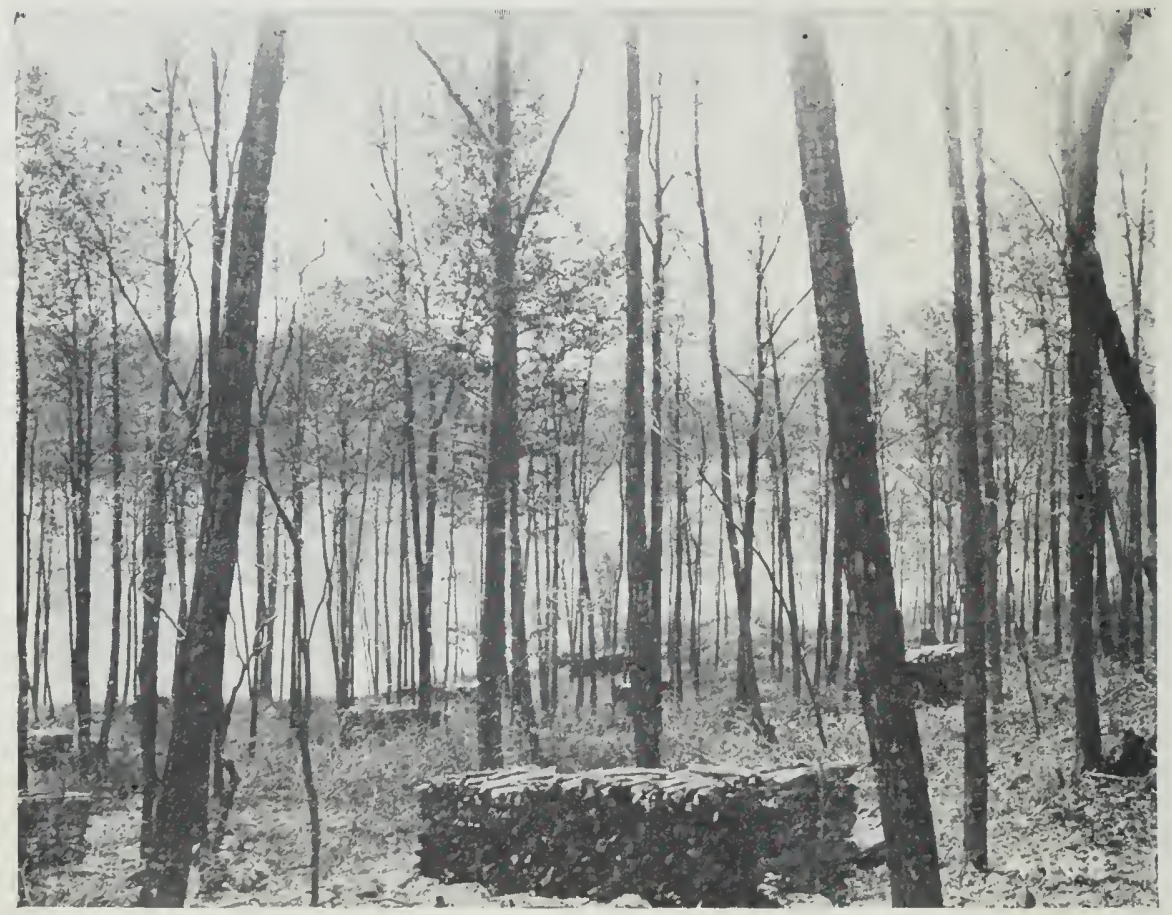

Fig. 38. - A Stand of Hardwoods, Composed of Trees of Sprout and Seedling Origin, after the First Cutting under the Polewood Coppice System. Southern New York.

through the woods; and at the time of cutting there are very few seedlings, or none at all, so that the succeeding stand is composed chiefly of the shoots from such stumps as may retain their sprouting capacity. There are wide gaps between the clumps of sprouts, and the stand is inferior in form, quality, and yield to the previous one. 
Continuance of such treatment results in steady deterioration of the forest.

The Reproduction Cuttings.-The poor results of this careless and haphazard way of treating second-growth stands are avoided by the systematic application of the pole-wood system. The aim of the method is to secure an advance reproduction of seedlings wherever there is a possibility that sprout reproduction will not be complete. This is accomplished by making a thinning to open the canopy sufficiently for natural reproduction. When the seedlings have become established, the rest of the timber is removed in one or more operations.

This system is in reality, therefore, the shelterwood system with a short rotation and the use of both seedling and sprout reproduction. Ordinarily there is no need of a preparatory cutting. Most of the hardwoods with which it will be used are intolerant of shade, and do not form a heavy canopy. Usually there is not a heavy layer of litter and humus. Since the trees are windfirm, a preparatory cutting as a precaution against windfall is not needed. The first cutting is, therefore, a seed-cutting.

The selection of the trees in this seed-cutting depends primarily on how far reproduction by sprouts can be counted on. If there is uncertainty as to the sprouting of most of the stumps, the effort should be to get a fairly general distribution of seed over the whole area. Thus, in the case of a mixed stand of oak and hickory from 60 to 70 years old, the period of greatest vigor of 
sprouting has already been passed, and it is difficult to tell which trees will and which will not sprout. The procedure, under these circumstances, is to make a uniform seed-cutting; that is, the stand is thinned throughout, instead of only in patches. The principles governing the cutting are the following:

1. The thinning removes about 35 per cent. of the volume.

2. The cutting takes the suppressed and defective trees, and those with large spreading crowns, especially any overgrown individuals which are older than the main crop.

3. In choosing between two trees, the least vigorous is cut, for the other will bear most seed, be most likely to sprout after the seed-cutting, and grow most rapidly before the final cutting.

4. In case of clumps of trees which have originated from sprouts, only defective and suppressed trees are taken. The dominant thrifty trees in a clump are traated as one tree. If, on account of defect, one or more large, dominant trees in a clump must be cut, the entire clump should be removed. If there is not space for a healthy development of sprouts the opening should be enlarged, so as to secure straight and vigorous sprouts.

5. All scattered individuals of undesired species are removed. Such sprouts as appear will be checked by the shade of the remaining trees.

6. If there are good groups of advance seedling or sprout reproduction, trees which are shading them should 
be cut, and in removing the trees, the groups should be carefully protected.

7. If for any reason the cutting takes healthy, dominant trees which are likely to sprout, the development of the sprouts is guaranteed by making an adequate opening in the canopy-cutting the neighboring trees if necessary.

As soon as there is a sufficient amount of seedling reproduction fully to supplement the sprout reproduction, the remainder of the stand is cut clear.

In many hardwood forests of the Northeast, there is a mixture of chestnut which sprouts vigorously even when the trees are 60 or 80 years old. Chestnut grows very rapidly, and usually has the largest yield of ties, poles, and lumber. The best results are obtained, in applying the pole-wood system, when the seed-cutting is confined chiefly to species which are less likely to sprout, like oak and hickory. It often happens that the chestnut occurs more or less in groups of from 5 to 10 clumps together, though individual clumps and trees occur scattered among the other species. The chestnut should be cut as little as possible at the seed-cutting, on the same principle that in an oak stand the individuals most likely to sprout well are left until the final cutting.

It may happen that an owner may wish to cut the chestnut, or a part of it, at the first cutting. In that event, whole clumps should be cut and not individuals from a clump, and in all cases openings should be made large enough for good sprout development. 
The presence of young chestnut sprouts here and there in the stand will necessitate care in taking out the wood at the second cutting, in order not to injure them.

The average well stocked stand of hardwoods 50 years old, in New England, yields from 25 to 30 cords per acre. The first cutting removes from 6 to 12 cords.

The Second Cutting. - The final cutting may be made after an interval of from 5 to 10 years. Usually, the second cutting is a clearing. This is the best plan, for if there were more than one final cutting, there would be a great deal of damage to the sprouts in felling and removing the trees left standing. In many cases, however, it may be desirable to leave scattered reserves to remain during a second rotation.

In making the seed-cutting the cost of cutting and piling the wood is 5 to 10 cents per cord more than if the stand were cleared. The cost of removing the wood is also increased 5 to 10 per cent. The cost of marking is about 3 cents per cord. The total added cost of the method, including the burning of the brush, over that of the old method of general clearing, is from 20 to 40 cents per cord for the wood taken out at the first or seed-cutting.

\section{Coppice with Standards}

The principles of the system of coppice with reserves described on page 177, may be extended still further in what is known as coppice with standards (also called stored, or storied, coppice). This differs from the sys- 


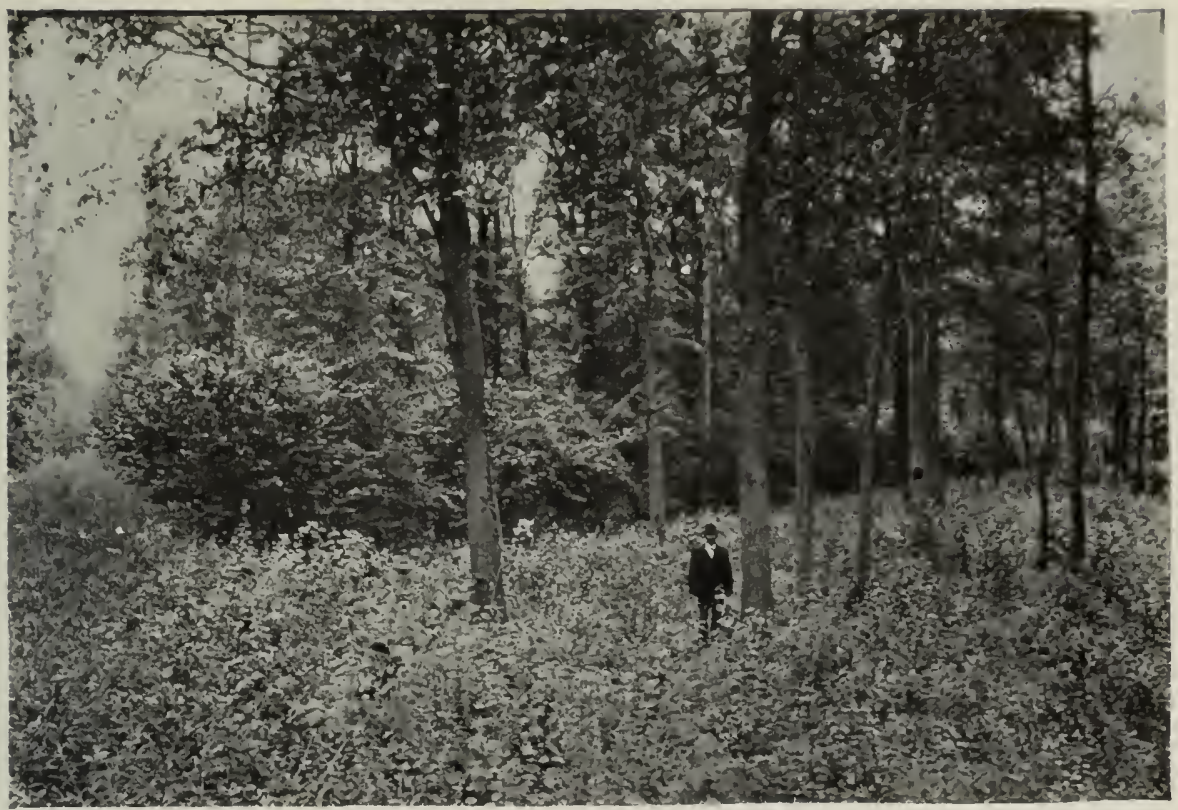

FIg. 39.-Coppice with Standards. Germany.

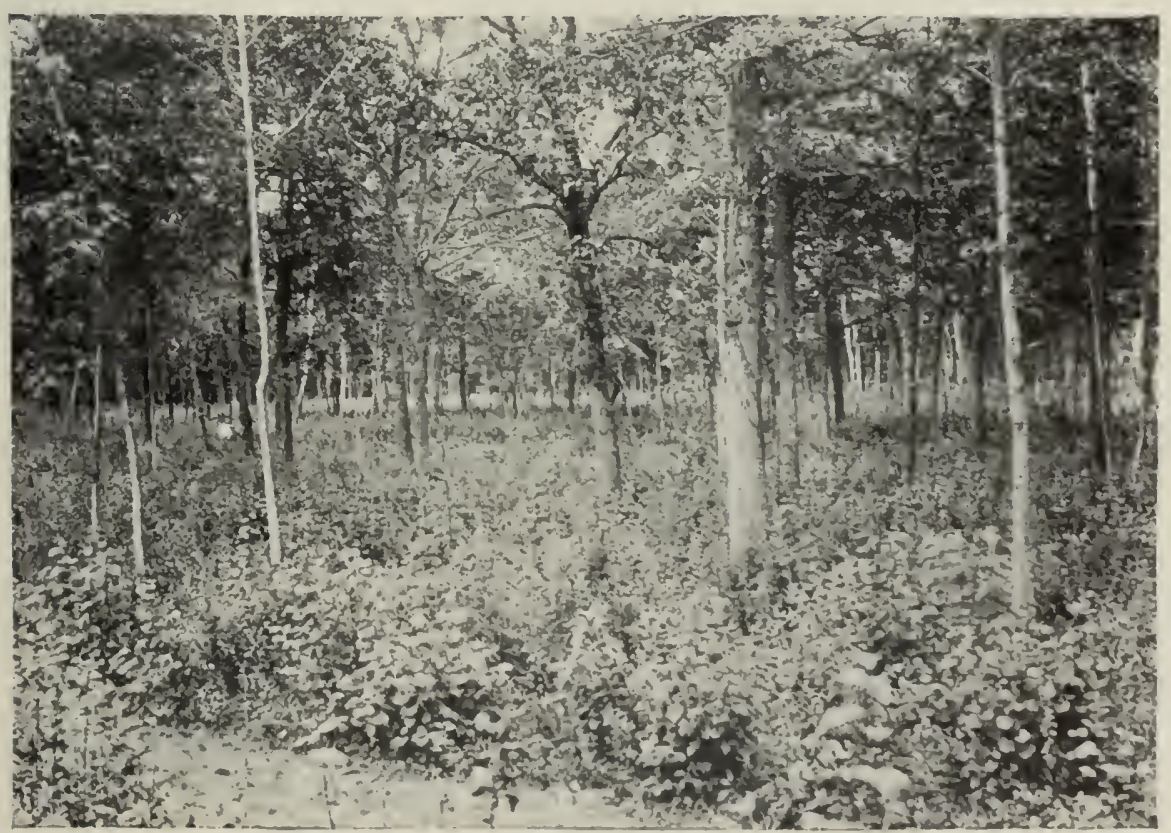

Fig. 40.- Another Example of Coppice with Standards. Germany. 
tem described on page 177 in two particulars; first, the reserves are left over several rotations for the production of very large trees, and second, the reserves are chiefly trees from the seed, and not sprouts.

This is a system long in vogue in Europe, and now practised there very extensively, especially on private and communal forests. As yet the method has not been used systematically in this country, but it will be undoubtedly as soon as there is a market for the products of coppice cut on a short rotation. The description given below necessarily applies to the practise in Europe.

This system is most simply understood by following its development from the simple coppice. Suppose that there is a simple coppice managed on a 20 -year rotation, and it is decided to develop a system of coppice with standards in which the latter will have a rotation of 100 years.

When the sprouts are cut, a certain number of reserves are chosen from among the best trees in the stand. Seedling trees are used if they occur; otherwise the best sprouts are used. If there are likely to be no seedlings in the reproduction, some are established by planting. Twenty years later, at the time the coppice is again cut, new reserves are chosen among the best trees, preferably seedling trees, of the 20 -year-old wood. After cutting there will then be standards 20 and 40 years old. After the following 20 years, the oldest standards are 60 years, the next 40 years old; and then some 20-year-old standards are chosen as before. This process is continued 
until the first standards reach the final age designed for them; in this case, 100 years. There will then be on the ground standards $100,80,60$, and 40 years old, in addition to the 20-year stand composed of sprouts and such seedlings as were established at the last cutting. The oldest standards are then cut, and new seedlings started in their place.

There is no rule regarding the number of standards. Sometimes in European practise the main stress is laid on the coppice production, and only a few standards are held over at each cutting. In this case the production of sprouts would be but little interfered with. In other cases the main stress is on the overwood. The system then approaches the selection system, combined with the production of a coppice crop. The form and condition of a compound coppice forest may be illustrated by the number of standards of different ages per acre. Drawing from a European stand in which the standards are oak, there might be the following at the time of cutting:

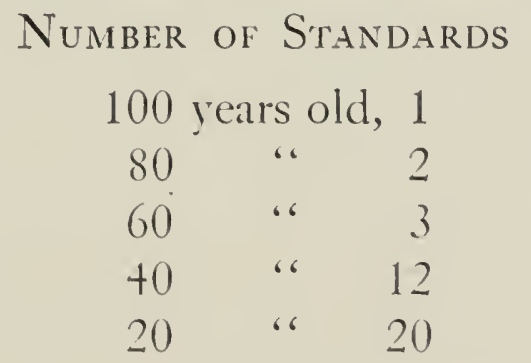

In this table it is seen that the number of standards is progressively smaller with increase of age. Theoretically, it is designed to have all classes of standards occupy equal areas. Enough standards are held over in the be- 
ginning to allow for loss through accident and for thinnings.

When a cutting is made, the spaces formerly occupied by the old standards are filled with seedlings by planting. The younger standards are inspected carefully, and thinnings are made when desirable, so as to benefit the best standards and to maintain the area occupied by each ageclass at about the normal.

The species used as standards are those which have a relatively light foliage, such as oak and ash. The underwood is best composed of comparatively tolerant species, such as (in Europe) alder, hornbeam, beech, elm, and maple.

The standards are crowded from the side only during the life of the sprouts, and consequently have only a comparatively short stem cleared of branches. Since they stand isolated for most of their life, they develop broad, spreading crowns. The diameter growth is at a maximum, and they produce one or two very large logs. 


\section{CHAPTER VI}

\section{IMPROVEMENT OF THE FOREST}

\section{Improvement Cuttings}

UNDER this head are comprised those cuttings which are made in immature stands to improve their character and growth. Their specific objects are:

1. To improve the composition of the stand.

2. To improve the form of the trees.

3. To increase the rate of growth of the trees.

4. To increase the yield and value of the final product.

Improvement cuttings are thinnings designed to give to the best trees the amount of light and growing space most favorable for their best development. Their purpose is entirely to benefit the existing stand. As far as possible, the openings are made small, with the expectation that in a few years the crowns of the surrounding trees will close together. 'They thus differ from reproduction cuttings, in which permanent openings in the canopy are made with the intention of establishing reproduction. 
Improvement cuttings may be classed in the following groups:

1. Cleanings.

2. Liberation cuttings.

3. Thinnings.

4. Damage cuttings.

\section{Cleanings}

This term is applied to cuttings in young, even-aged stands which remove the undesirable trees likely to overtop and injure those of greater promise. In nearly every young stand there are a certain number of individuals of poor species or of poor form which grow taller than the surrounding trees; and if these are allowed to stand, they will interfere with or actually kill trees of prospective value. These undesirable trees are removed by the cleanings while the stand is still very young, and before they have done any appreciable damage. The small openings made by their removal are quickly closed together.

The material which most commonly requires attention is advance growth of poor species or of poor form. A tree from 5 to 10 years older than the main stand may develop an open-grown form, overtop and injure the surroünding trees of good form, occupy a proportionately lárge space where a number of much better trees might be growing, and itself produce knotty, inferior wood. Often this advance growth is composed of inferior species. If, however, a stand is poorly stocked, and 
an advance tree is more or less isolated, it really constitutes an integral part of the crop, and is allowed to stand.

In reproducing a forest naturally, the species most desired often do not establish themselves as quickly as the poorer kinds, or, during early youth, the inferior species may be the more rapid growing. If the stand is left untouched, a large number of the most promising trees may thus be killed or crippled, and the value of the crop may be much reduced. A good illustration of this condition is found in New England. After a pine stand is cut, the first species to spring up are hardwoods. Later on, young pines creep in abundantly under the hardwoods, but many of the pines are killed in the com. petition. A cleaning would release the best pines, and thus maintain the species in the next crop.

The application of this method may be seen also in the mountains of Europe, where beech and spruce in mixture are reproduced naturally. The two species come up together in the reproduction, but the beech grows the more rapidly, overtopping and injuring the spruce. The latter is maintained in proper proportion only by cleanings in which those beeches which are likely to injure the spruce are cut back.

In hardwood regions one of the problems is to protect young seedling trees from sprouts. The latter grow very rapidly during early youth, and in some cases overtop seedling trees which are of special value. This is illustrated where pine is planted after the clear-cutting of hardwoods. There are inevitably a certain number of 


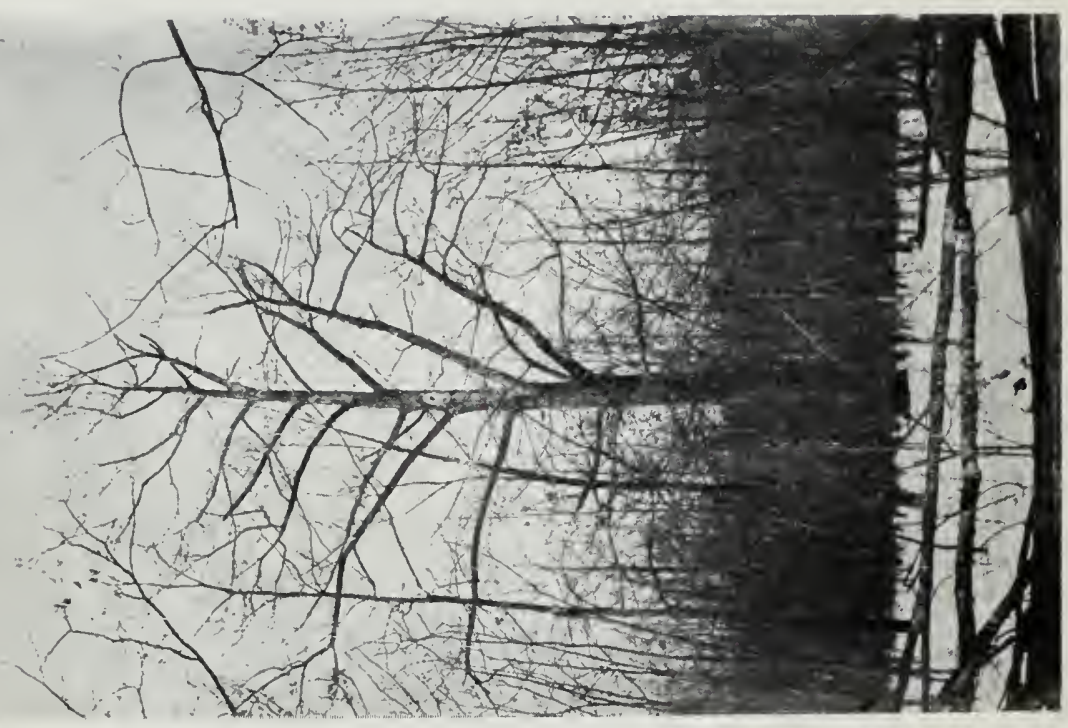

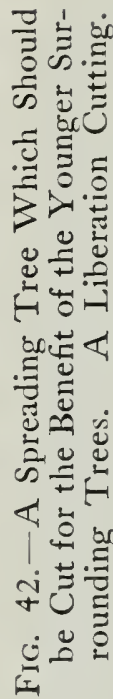

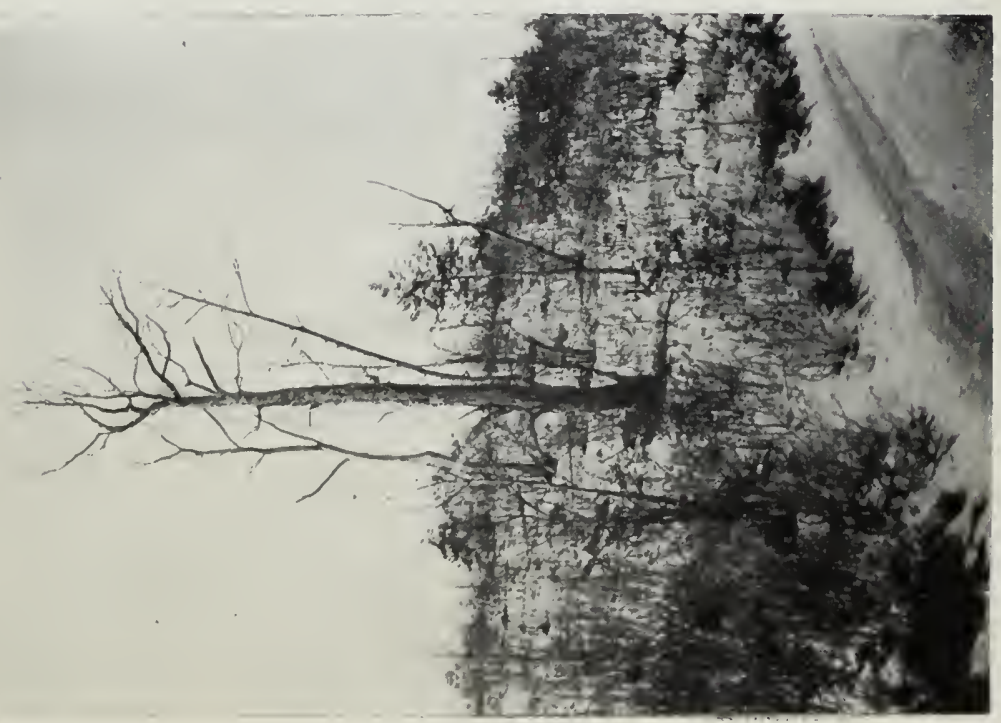

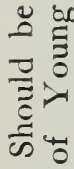

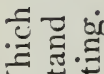

उ范艺

त 0

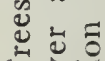

F十

.

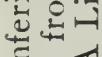

$\stackrel{\square}{\square}$

10

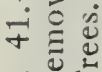

e्t. 
fast-growing sprouts which overtop and injure the pine trees. Unless the stand is cleaned in early life, there may be a very large percentage of loss to the pine. The author is familiar with one plantation of pine which was practically destroyed in this way.

There is often a considerable growth of brush which competes with valuable young trees. Thus, in Pennsylvania such shrubs as scrub oak, sweet-fern, blueberry, etc., injure an immense amount of valuable young tree growth. This damage can practically be eliminated by cleanings.

Cleanings are made in young stands as soon as the overtopping trees begin to be injurious. The first cutting is usually made within the first 10 years after the establishment of reproduction. The best plan is to make a cleaning within the first five years, and then go over the ground a second time within the next five years.

The trees are either cut down at the base or they are lopped. Sometimes the lopping of a single branch is sufficient to release a crowded tree permanently. It may occasionally be the best plan to lop off the head of a tree, leaving a high stub. This is done when there would be danger of rapid sprouting from low stumps and the overtopping of the released trees.

In making cleanings, the forester must make it a point to remove only that which is absolutely necessary for accomplishing the purpose of the operation, and in this way to hold down the expense of cutting. There is a temptation to cut more than is necessary, and hence to 
increase the cost beyond what is warrantable. The work does not require much skill, and can be conducted by an intelligent foreman after some instruction. The part requiring the greatest exercise of judgment is the decision as to how much should be cut in a given case.

In making cleanings one ordinarily uses a bill-hook or a heavy hunting knife. One of the most satisfactory tools is a plain straight Rogers steel hunting knife of the largest size, with a 10-inch blade and weighing about 2 pounds.

The cleaning is a cultural operation, and usually yields no immediate money return. The cost necessarily varies under different conditions. It is commonly between 25 cents and $\$ 2$ per acre, and averages about 50 cents. An outlay in cleanings may be distinctly profitable in the long run. An expenditure of 50 cents per acre may prevent the injury of 30 or 40 per cent. of the valuable trees in the stand.

\section{Liberation Cuttings}

It frequently happens that in immature stands there are scattered trees much older than the main crop which, by their wide-spreading crowns, overtop and retard the development of the younger trees. The removal of these trees may be called a liberation cutting. This operation should not be confused with a cleaning in which the trees removed comprise advance growth only a few years older than the average. In the liberation cuttings there is a wide difference between the age of the trees to be cut and of those in the main stand. 
There are two problems of liberation cuttings: first, in young stands where the crowns of the old trees are well above the young trees; and second, where the crowns of the young trees have reached the crowns of the scattered older trees.

The first problem is exactly analogous to the removal and final cuttings in the shelterwood system of natural reproduction. There has not yet been any material injury to the young growth, and the overtopping trees may have been a benefit from the standpoint of shelter. In removing the overtopping trees care is taken to do as little damage as possible to the young trees. If the young stand has a good density, the openings will be rapidly filled by the meeting of the crowns. If the opening is too large for this, it is often possible to plant some young trees, which will then grow up with and form a part of the main stand, even though a few years younger.

In the second problem the stand is older than in the case just described, and the scattered old trees have already retarded the development of the trees immediately under and near their crowns. This is the situation very frequently encountered in second-growth forests. Usually these trees are large, with short boles and broad, spreading crowns. 'They will not increase appreciably in value, and their continued presence in the stand means further injury to the trees near them. They are, therefore, cut for the benefit of the stand. It often happens, however, that the opening made by cutting one of 
these trees is too large to be filled by the closing of the crowns. In other words, a permanent opening is made, in which reproduction of trees, brush, or weeds will take place. Such reproduction as comes in will probably not be thrifty, because the opening is too small to permit normal development of the new growth. But even if it is not possible to secure in these openings reproduction that will thrive, the stragglers should be cut for the benefit of those trees which surround the opening.

Sometimes the scattered older trees are well formed, middle-aged, thrifty trees. These are not cut, but rather are treated as reserves, and allowed to stand for the production of large timber.

Usually the trees cut are large enough for the market. The operation yields a good return. The liberation cutting is frequently made at the same time as a thinning. The large size of the trees may sometimes increase the general grade of the product, and thus make possible a thinning where this would by itself bring so small a return that the owner would be unwilling to make it.

\section{Thinnings}

This term is applied to cuttings made in immature stands with the object of reducing the density of canopy, and of giving to the most vigorous trees that space and light needed to secure most quickly the product desired in the management.

The word thinning is an unfortunate term, because any cutting other than a clearing is in a sense a thinning. 


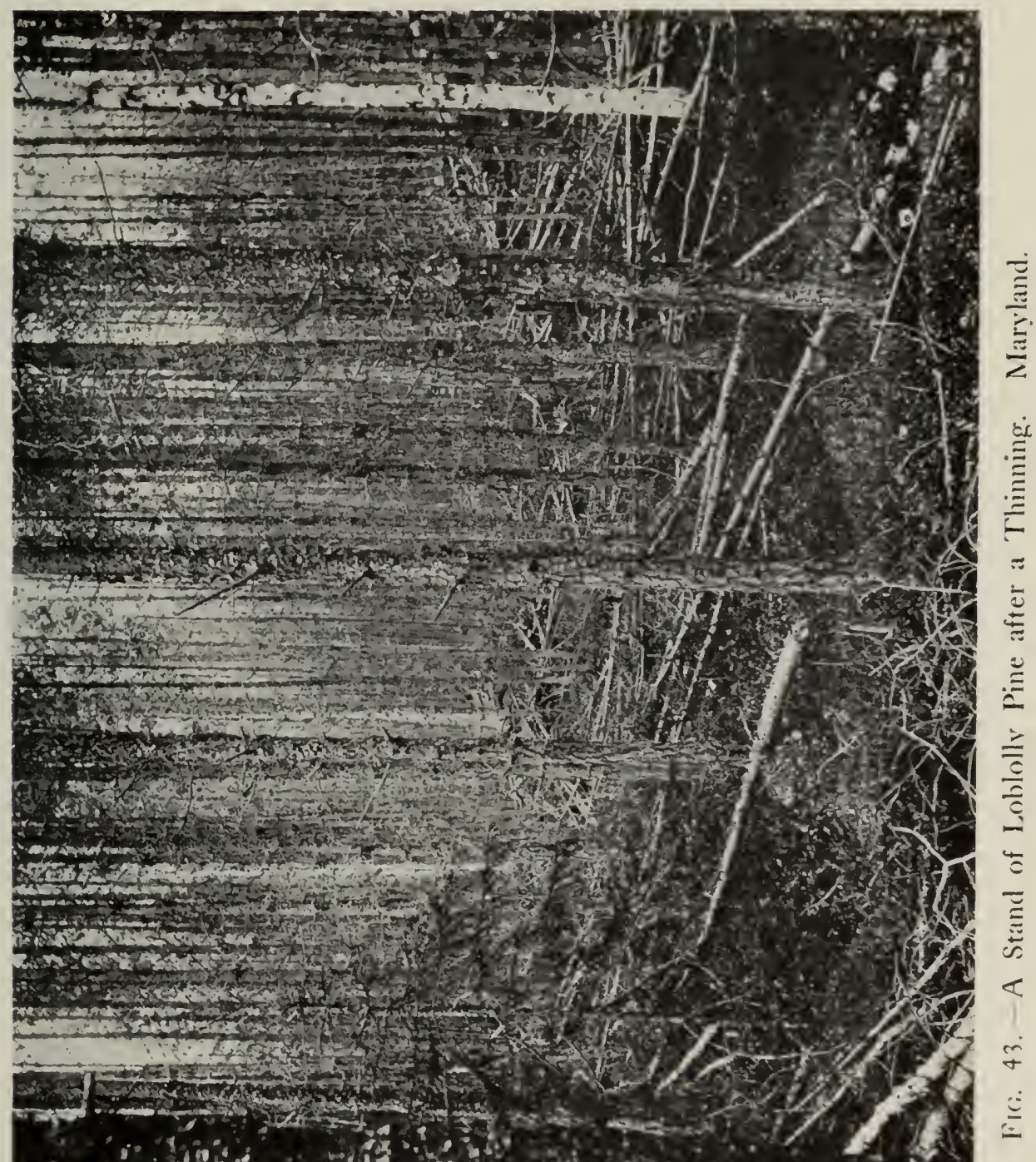

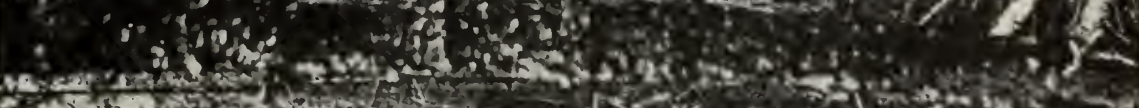

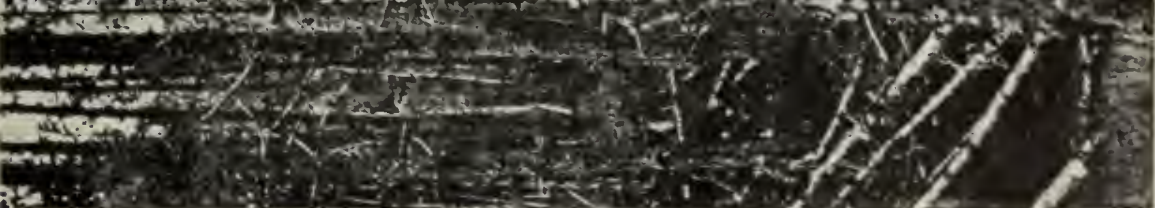


The term has, however, come to have a restricted technical meaning, both in British and American practise, and for that reason the author has chosen to retain it rather than to undertake the establishment of a new and unfamiliar expression.

Thinnings are made chiefly in even-aged stands. When used in even-aged groups in irregular stands, the principles are the same as where the whole stand is even-aged. Therefore the discussion in the following pages will be confined chiefly to the application of thinnings in stands which are even-aged or approximately so.

Need of Thinnings.-For the purposes of forestry it is desirable for trees to grow in crowded stands. The mutual crowding results in the natural pruning of the stems and the production of high-grade lumber. In planting forests the trees are set from 4 to 6 feet apart, or from 1,200 to 2,800 trees per acre, and successful natural reproduction often results in an even greater density of stocking. As soon as the crowns of the trees meet, and their growth is consequently restricted, the struggle for light, space, moisture, and nourishment begins. One of the first manifestations of this competition between the trees is their difference in crown development. Some trees forge ahead and take their place as leaders, with strong, dominant crowns; others fall behind, with crowded crowns, and take an intermediate place, while the weak trees are suppressed and overtopped. As the stand grows older and the trees must have more space 
for growth, the differences between the development of the individual trees are intensified. It is always the leaders which are best able to spread their crowns, so that many trees that are only partially crowded at first are later on suppressed, and those at first suppressed are at last actually killed. There is, therefore, a rapid reduction of the numbers of trees by the natural struggle for existence.

The development of a stand in this manner is attended with both advantages and disadvantages. The chief advantage is that the crowding results in the death of the lower branches and the production of clear stems. On the other hand, the restriction of the crowns, in both length and width, results in a reduction of the diameter and volume growth of the individuals. While the trees are young, the retarding of growth is relatively small, because only a small crown is required for growth and the natural vigor of the trees is at a maximum. Later on, there is a progressively greater relative difference between the actual and possible growth through the reduction of the crown. In some cases the crowns are so reduced that they do not occupy more than 15 per cent. of the total length of the stem. Such a tree is lanky, and exposed to damage by the wind; it is incapable of good seed production; it is weak and subject to insect attacks and to damage by excessive droughts; and its product, though of high quality, is quantitatively much less than it might be. The crowding of a stand is, therefore, beneficial in youth, as it contributes to the production 
of clear-boled trees; but excessive crowding in later life results in a great reduction of growth.

In a crowded stand left untouched, the struggle for space sometimes results in injury to the form of good trees. Most trees tend to grow straight, and the crook or sweep in a stem is often due to its bending and reaching for light, through being crowded on one side by another tree. This is particularly true in coppice stands, where a clump of sprouts all start straight, but through mutual crowding may all develop crooked stems.

Then, again, poor species will often take a dominant place and crowd those of more value.

Results of Thinnings.- The practical results of thinnings are as follows:

1. Rapid growth of individual trees. It is possible to bring a stand to merchantable condition 10 or 20 years sooner than without thinnings.

2. Increased total yield. In Europe, about 30 per cent. of the total aggregate yield of a stand during the rotation is from thinnings. This amount is really a surplus, because the final yield is not less, and is sometimes even more, than if there had been no thinnings.

3. Improved quality of product. The forester has the opportunity to develop trees of specially high quality, clear stems, and even grain. By timely thinnings he can prevent the distortion of valuable trees through side crowding, and thus reduce the percentage of crook.

4. If there is a cordwood market, decadent and defective material can be utilized. 
5. By the prompt removal of diseased and insectinfested trees further injury from these sources can be prevented.

6. The amount of inflammable débris on the ground is less than where there are no thinnings.

7. The trees are more windfirm.

Theory of Thinnings.-The objective point is the development of the dominant trees of good form. The aim is to give them the space required for their proper growth, with a view to a larger yield per acre, and the maintenance of a degree of density of cover which will maintain the soil in good condition.

In making thinnings, therefore, the forester studies the crowns of the trees and their position in the canopy. He does not consider the number of trees per acre, or the spacing between the trunks; his principal attention is directed to the requirements for crown space of the trees he seeks to develop. In order clearly to understand the principles of thinnings, the reader should keep in mind the distinctions between the different crown-classes, as outlined on page 28 , and illustratec in the diagram on page 29.

The methods of thinning most common in Europe are those developed in Germany and to-day most extensively practised in that country. The theory is to remove, first, the suppressed stand, and then such of the intermediate and co-dominant trees as are required by the local conditions and objects of management Dominant trees are not cut, except in the case of indi- 
viduals which are defective, injured, dying, or dead, or have exceptionally poor form.

The characteristic of the method is that the trees primarily chosen for cutting are in the subordinate part of the stand; and then such others are taken as are required by the special objects of management. Normally, the suppressed trees are not left standing at all, unless it is necessary to remove one of the larger trees because of some defect, and in that case subordinate trees are left as a ground cover.

The selection of the trees for cutting depends on how severe a thinning is required. For convenience in systematizing the work, thinnings are classified into the following grades, based on the severity of the cutting:

Grade A. Light, removing the dead and dying trees.

Grade B. Moderate, removing all suppressed and, in addition, the lower of the intermediate trees.

Grade C. Heavy, removing, in addition, the remaining intermediate trees.

Grade D. Very Heavy, removing, in addition, many of the co-dominant trees.

A heavier cutting than Grade $\mathrm{D}$ is called an accretion cutting. (See page 216.)

Principles Governing the Severity of Thinnings.The grade of thinnings to be used in any given case depends on a variety of circumstances, of which the following are the most important:

1. Purpose of management.

2. Condition of the stand. 
3. Tolerance of the species.

4. Danger from windfall.

5. Site.

Purpose of Managiment. - The character of the product depends on the density of the stand. If the aim is to secure rapid growth in diameter, the stand must be opened sufficiently to permit the development of a full crown. The long, full crown means, however, a shorter, clear-length and coarser logs from the upper stem. The largest trees and the greatest yield in log measure are obtained by the heavier grades of thinnings. On the other hand, for the production of trees of high quality moderate thinnings are made. In general, the best results are obtained by making the thinnings during the first half of a stand's life moderate, in order to secure good form of trees, and then, after the main height growth is reached, thinning heavily, in order to secure rapid growth in diameter and volume.

Condition of the Stand. - The considerations in the previous pages are necessarily subject to modification, if a stand is not regular or does not have a uniform density. In many stands-in this country, most of them-there are undesirable individuals in all crown classes. There are dominant trees of poor species, trees of poor form, defective trees, etc., which are cut whenever their removal will benefit the stand. In a thinning designed to be of the B grade, there might be taken out co-dominant or even dominant trees, of undesirable character. So, also, in a thimning designed to be of the $\mathrm{D}$ grade, there 
might be such a small density that intermediate or even suppressed trees should be left to fill gaps.

Tolerance of Species. - Tolerant species suffer from overcrowding less than intolerant species. To maintain a full crown and rapid growth, the latter must be thinned the more heavily. Conversely, to secure wood of high quality, the stand must be kept denser with the tolerant species.

Danger From WindFAll. - If there is danger from windfall, the stand is thinned early and heavily in order that there may be developed trees with strong roots. If an older stand is dense, and there is danger from windfall, the thinnings must be very moderate.

Site.-On good soil the trees are vigorous and the differentiation into crown-classes is more rapid and sharply defined than on poor soils. The trees respond quickly and energetically to thinnings, and fill very rapidly any gaps that have been made. Heavy thinnings may be made on good soils without danger of exposing the soil to drying influences. The poorer the soil, usually the greater is the need of thinnings to secure good growth, but the greater is also the danger of exposing the soil.

Time of First Thinning.- The best results are obtained if thinnings are begun early in the life of the stand. It would be a benefit if light thinnings were made as soon as the active crowding and sharp separation into crown-classes begin. This would ordinarily be when the trees are between 10 and 20 years old. In some 


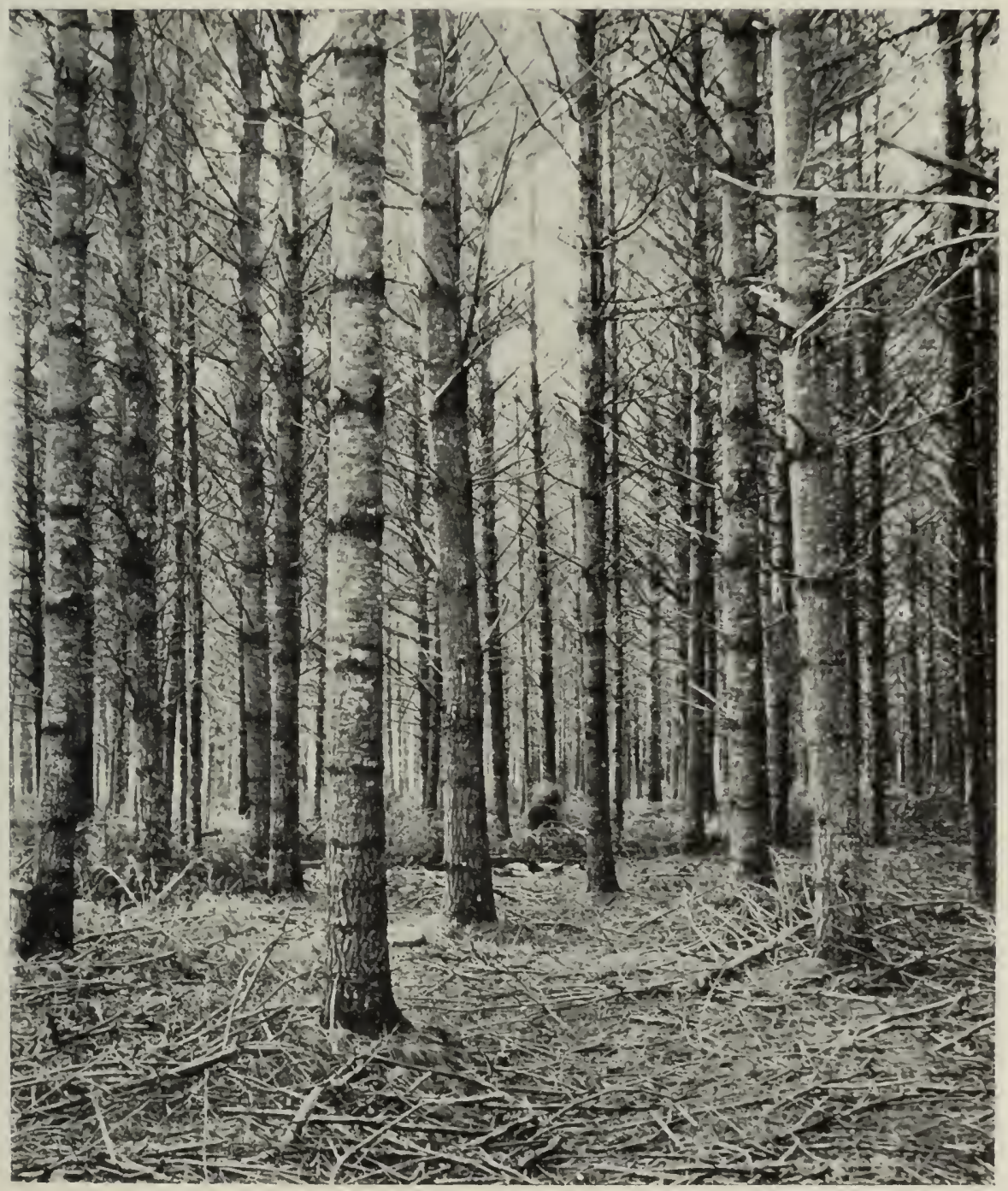

FIg. 44. - A Stand of White Pine after a Thiming. New Hampshire. 
instances in Germany, Scotch pine stands are thinned as early als at 12 years. Unless, however, there is a market for very small sapling wood for fuel, a very early thinning would bring no return whatever. The general rule is that thinnings should begin as soon as returns from the sale of the material covers the cost of the operation.

In most cases it will not pay to make thinnings involving an actual outlay. There are millions of acres of second-growth, even-aged timber in this country which need thinning, and need it badly, but are so situated with reference to the market that the product of the thinnings could not be disposed of at all. In the better populated districts, where there is a market for fuel, thinnings may often be made without loss, even at an early period in the stand's life.

Often a farmer is able to spend some of his own time or that of his regular employees in such work, without sacrifice to other work, and hence without a real loss. An owner may have in charge of his property a forest ranger who can devote part of his time to thinnings without interfering with his main work. Under such circumstances it certainly pays to make early thinnings, even before the product is salable. Therefore a rule based on market conditions does not answer the question as to when thinnings should be begun.

In some instances when the prospective value of the timber is large, it will pay to make thinnings, even if this entails an actual outlay of money. When such thinnings 
would mean the protection of the valuable trees against the crowding of less valuable ones, and the stimulation of growth in a stand which is stagnating from overcrowding, an investment in thinnings is warranted.

The owner of a forest is interested in knowing whether there is not a critical period before which thinnings should be made if they are to be of any real benefit. There is such a critical period, which differs with different species and with different conditions, and which depends also on the object of management. 'The forest should be thinned before the crowns of the dominant trees are so far reduced that the trees cannot respond to the improved conditions and accomplish the objects of management. If, for example, the purpose is to produce a maximum of large trees and a large volume of timber measured in board feet, the thinnings must be begun while the crown is relatively long. If the crown is permitted to become very small and short, occupying only 10 or 15 per cent. of the stem, the trees are not capable of much benefit from thinnings. In managing white pine for the production of box boards, the aim should be to begin the thinnings before the crowns of the dominant trees are on an average reduced below to per cent. of the total height of the trees. If for convenience the ratio between the crown length and that of the full stem is called the crown-ratio, the critical period in white pine managed for box boards is when further postponement of thinnings would be likely to reduce the crown-ratio to less than to per cent. 
The critical period would be later if the aim of management were the production of wood of high quality. In that case it might depend on a crown-ratio of 20 to 30 per cent., according to the species and site conditions.

The experience in thinnings in American species is so limited, and the markets are so poor for the products obtained from them, that no data can be given as to the time of beginning the work of thinnings with the various forest types.

Repetition of Thinnings.-Thinnings make small, temporary openings in the canopy which grow together in a few years. Theoretically, the thinning is repeated as soon as the crowns close over these openings. The interval between thinnings would depend, then, on the severity of the cutting and size of the openings. The old rule in Germany was to thin early, moderately, and often. Frequently in Europe thinnings are made at intervals of from 3 to 5 years. That is, of course, a very intensive application of thinnings. More often from 5 to 10 years represents the interval between thinnings. The interval is shorter in youth and middle life, when the growth of the crowns is rapid, than later, when it takes longer for the crowns to meet.

Application in Europe.-The principles outlined in the preceding pages may be illustrated by the policy of thinnings recommended by Dr. Heinrich Mayr, of $\mathrm{Mu}-$ nich, Germany, and by Dr. Flury, of Zurich, Switzerland. Dr. Mayr's program for the treatment of the average. even-aged stand in Germany is as follows: 
The cleanings are begun before the canopy is closed. From that point until it is from 30 to 40 years old, the stand is kept as dense as possible. During this period the death of the lower branches takes place over a satisfactory proportion of the stem. Then regular thinnings begin. The first thinning removes the dead and the suppressed trees. About 5 years later a second thinning removes suppressed trees, and also cuts into the lower intermediate class. Some 5 five years later a third thinning is made, comprising, in addition to the above, many of the intermediate and some of the co-dominant trees. This brings the stand up to about the 50 th year. The main object up to this point has been the development of form and quality. After this period the stand is thinned much more heavily for the production of volume. The design is then to give the crowns the advantage of full light. 'These cuttings occur every 5 years till the stand is about 80 years old. During this period the distance between the crowns is kept at about a meter. After the 80th year the cuttings are made every 10 years, and the crown distance is increased to about 2 meters. Dr. Mayr classifies these last cuttings-from 50 years on-as accretion cuttings, and assigns the term "thinnings" to those from the cleanings to the 50th year. The planting of an under-story, preferably of beech, as a ground cover during the period of accretion cuttings is recommended.

Dr. Mayr estimates that ordinarily there would be approximately 400 trees per hectar, or 160 per acre, at 
the end of the rotation. He estimates that the aggregate yield of the thinnings and the accretion cuttings will be about equal to the volume of the final cuttings, and that the latter will be fully equal to the final cuttings under other methods of treatment.

This program is somewhat more drastic than that recommended by some other European foresters. It may be compared with that of Dr. Flury, whose proposals are the result of a series of experiments in stands subjected to different grades of thinning.

Dr. Flury's conclusions for the management of spruce are that the thinnings should begin early and be conducted regularly. During youth and up to about middle age -50 to 60 years-they should be between grade $\mathrm{B}$ and $\mathrm{C}$, approaching $\mathrm{C}$. After middle age they are increased to a full $\mathrm{C}$ grade. At the beginning of the last third of the rotation, the stand is in a condition to require no more real thinnings. From that time further openings would be of the character of accretion cuttings. He recommends an early beginning of reproduction cuttings under the shelterwood system and a long period during which the trees would grow rapidly in an isolated position, with the ground protected by the young crop. This plan differs from that of Dr. Mayr chiefly in extending the period of real thinnings, and thus holding the stand dense for a longer time.

The French Method.-Somewhat in contrast to the principles just described, is a method of thinnings used very extensively in France. 
The objective point in this method is to assist trie growth and development of a certain number of the best individuals in the stand. The trees chosen are those most suited to form the final dominant stand, and the number is fully equal to what may stand on the area at maturity. 'These trees are given the right amount of light and space required for them to produce the class of timber desired. This is done by removing the upper intermediate, co-dominant, and, sometimes, even the dominant trees that are crowding them. The subordinate stand is not cut, except to remove dead and dying trees. Most of the lower intermediate and suppressed living trees are retained. Their removal would have practically no effect in helping the growth of the selected leaders, and they act as a soil cover, thus permitting greater freedom in cutting in the upper classes without fear of exposing the soil. The presence of the subordinate trees results in excellent natural pruning of the trees in the main stand, particularly by hastening the decay and fall of the dead branches.

Comparing this method with that used in Germany, it is in substance a thinning in the main stand of the grade $\mathrm{D}$, and a thinning in the subordinate stand of the grade A. From the standpoint of practical operation, the method has the advantage that the trees cut are almost all in the upper classes; their average size is larger than in the other method, and hence the returns are greater. This would sometimes warrant a thinning when market conditions are too poor for the German method. On the 
other hand, the presence of a great number of small trees increases the difficulty of felling the trees and making up the wood, and offers a distinct hindrance to removing the logs and wood.

\section{Practical Application of Thinnings in this Country.}

- The principles outlined in the preceding pages serve as a guide for practise. In actual application they are necessarily subject to considerable variation. The exact measures to be used and the details of selecting the trees must in every case depend on the requirements of the given stand. The forester must diagnose the stand and make the cuttings according to its peculiar needs. Knowing the specific life characteristics and requirements of the species and their capabilities under the given site conditions, he makes his thinning so as to accomplish in the highest measure the objects of management.

As regards the time at which to begin the real thinnings Dr. Mayr specifies from the 30th to the 40th years in the life of the stand. The statement means, however, that this is an average for a stand well established, in which the necessary work of cleaning in early youth has already been made. It means also that this is the period when thinnings ought ordinarily to begin. It often happens even in Europe that it will not pay to make thinnings even at 30 or 40 years of age, on account of poor market and logging conditions.

There are many instances of young mixed stands in which valuable species are being badly crowded and injured by those less valuable, and in the long run the 
YMPROVEMENT OF 'THE, FOREST

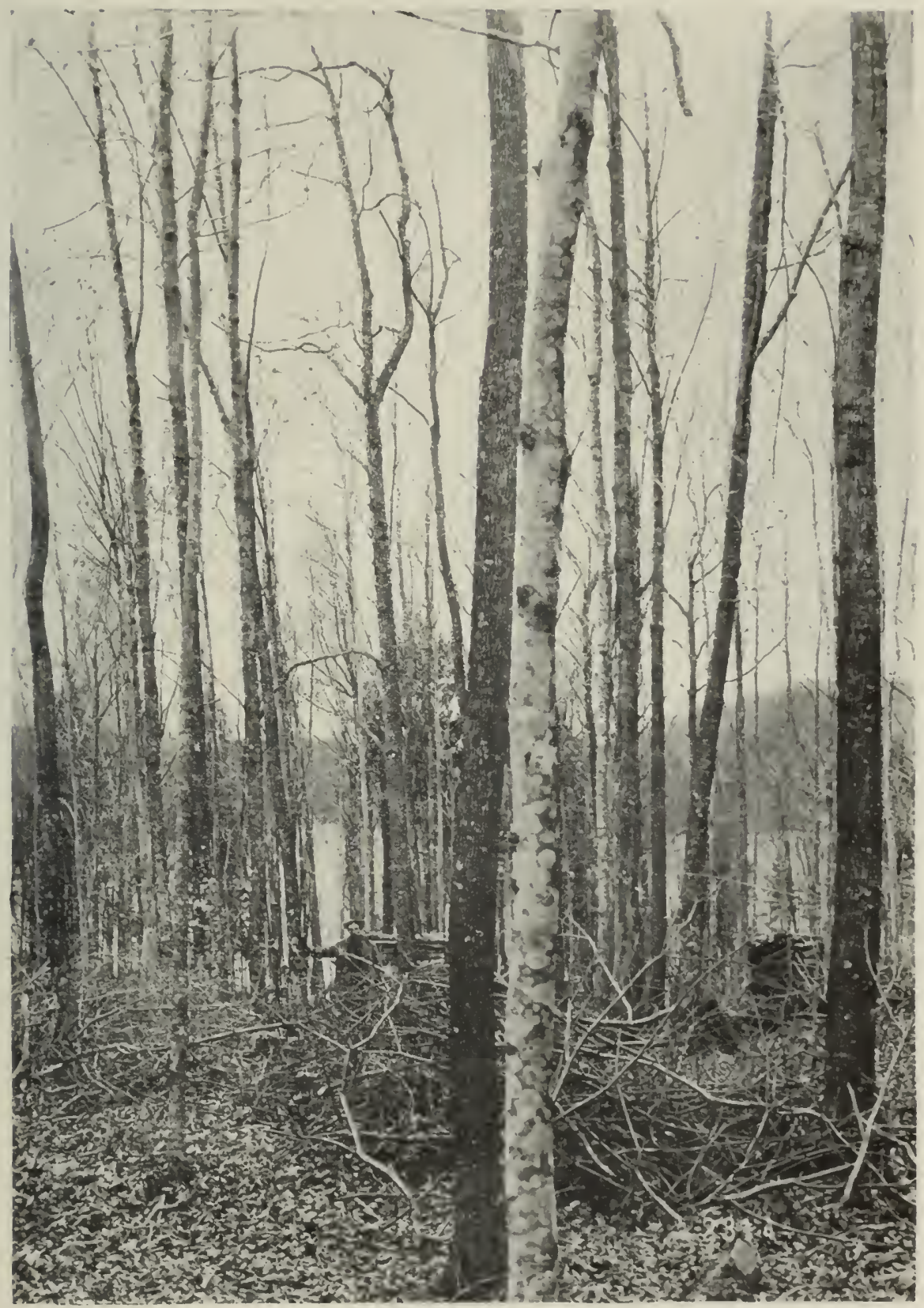

FIG. 45.-A Stand of Hardwoods after a Thimning. Massachusetts. 
prospective value of the stand and the final yield will be very much reduced. A thinning will save the trees of value, and there are certainly a great many instances in which an actual outlay will be not only fully justified but necessary if the purpose of management is to be accomplished.

In applying the principles relating to the grade of thinnings, the forester often finds it necessary to depart widely from the normal. This is particularly true in mixed forests, and those not perfectly regular. A stand which has been established under management, and cleaned at the right time, presents a quite different problem from a volunteer stand which has developed on an area cleared by fire or windfall and has never been treated at all. In the latter there are great irregularities. In spite of these irregularities the principles of thinnings may be applied in our even-aged stands.

In this country the forests in which thinnings are practised are now for the most part privately owned. Private forests will, in the main, be handled on a relatively short rotation. The object will be to raise as large trees as possible within a given time. Usually the grade of the trees will not be so important as the size. The general policy will be to keep the forest dense during the first half of the rotation so as to produce reasonably good form, and to thin rather heavily during the last half of the rotation.

In thinnings at all ages the forester should mark for removal all the dead, dying, and defective trees that can 
be disposed of. During the first half of the rotation the aim is to improve the form of the good trees, and to prevent a too great reduction of the crown. Trees of poor form, with spreading crowns, and those of poor species which are crowding better ones, are therefore cut. If no thinning is made until after middle life, the spreading trees will have done their principal damage. Such trees are cut only when the trees crowded by them are capable of prompt recovery and rapid growth.

During the first half of the rotation the aim should be to thin to about a $\mathrm{C}$ grade, and then to increase to a $\mathrm{D}$ grade, or sometimes even a heavier cutting. Thinnings are repeated when the crowns close together over the openings.

There are frequently overcrowded groups among the dominant trees. These are usually thinned by cutting the co-dominant trees, or such of the dominant trees as have the shortest crowns. Sometimes, however, the removal of one dominant tree will stimulate the growth of several co-dominant trees which, in the long run, would be overtopped and crowded out by the former. If these trees are released, their aggregate value will ultimately be greater than that of the single dominant tree. This principle is used in thinnings at all ages.

In a great deal of work in this country the thinnings will tend toward the French principle, and leave the subordinate classes standing. This will usually be because the small material is not merchantable, rather than because it is desirable to leave it for silvicultural 
reasons. Wherever there is danger from windfall, a stand must be opened gradually by moderate and frequent thinnings. In the same way, stands of trees with thin bark must be opened gradually to prevent sunscald, which frequently occurs, for instance, with secondgrowth white pine.

It is often necessary to make openings in the canopy which will be more or less permanent. This occurs when groups of damaged trees have to be removed.

\section{Accretion Cuttings}

It is a well-known fact that when stands are heavily thinned the trees usually show a marked increase in growth. This is due to the greater amount of light, and the stimulation this gives to the activity of assimilation. The increased growth may be called light growth. It takes place after thinnings when, by crowding, the crowns have been prevented from receiving as much light as they could utilize; when the trees are vigorous enough to respond to the new conditions; and when there is enough moisture and nourishment in the soil to meet the requirements of the increasingly active crowns.

The endeavor of modern forestry is to obtain the greatest possible light growth, particularly during the last half of a stand's rotation. Practically all foresters are agreed that during the first part of the rotation the forest must be kept dense to produce trees of good form. The principal difference in methods concerns the handling of the stand to secure the maximum light growth. 
The various methods developed to secure this object are called accretion methods, or methods of accretion cuttings.

The two-storied system of management is really an accretion method; but since it involves the reproduction of a stand to be grown with the main trees, it was described under the silvicultural systems. In like manner, the systems of reserves involve the same principle of giving individual trees full light.

One method of taking advantage of an accelerated growth is to make a long period of reproduction under the shelterwood system. The reproduction cuttings are begun earlier than usual. When the seed-cutting is made, the trees left standing are chosen primarily with reference to their ability to produce a more rapid growth. During the lengthened period of reproduction there is thus secured a large growth. This method is employed only where the rotation is relatively short, as, for example, in spruce 100 years of age or under. With old stands there would be little response to the changed light conditions, and hence very little or no light growth.

Probably the most common method used in Europe is that of underplanting. When the trees have reached their main height-growth and have developed the form desired, the stand is thinned very heavily and underplanted. The aim is to give to the best dominant trees in the stand just the amount of light they can fully utilize in making growth. In order that there may be as many 
trees per acre as possible, and hence a maximum total yield, no more space is given than is necessary to accomplish this purpose. The accretion cutting is made between the 50th and the 80th years.

The purpose of the underplanting is to protect the soil from deterioration. The rank growth of grass, weeds, blueberry-bushes, and the like, is a detriment rather than a benefit. An understory of a favorable tree species conserves and improves the quality of the soil.

Underplanting is most needed with intolerant species, which usually have a light foliage. The understory must be composed of a species capable of living in the shade of the old trees. Under a light canopy of Scotch pine, ash, or larch, trees of moderate tolerance can be planted. Under species with dense foliage, tolerant species must be used. Naturally, the species must be one adapted to the given site. In Europe, beech is regarded as the best tree for underplanting. Other species used are hornbeam, linden, maple, and sometimes tolerant conifers.

The function of the underwood is soil protection. It is not expected to produce a merchantable crop, except when the two-storied system is used. The cuttings in the overwood are made without regard to it. The aim is merely to keep it alive, regardless of its form. Crippled, spreading trees may make as good cover as straight ones.

'The underplanting is purely a cultural operation. 
The returns from it must be sought in the maintenance or improvement of the soil conditions and in the sustained rapid growth of the trees. Without underplanting the soil often suffers from loss of moisture and nourishment, and the growth of the tree drops off.

Underplanting is an intensive operation. So far as the author is informed, it has not yet been practised in this country. Such underplanting as has been undertaken here has been for advance reproduction or for esthetic purposes.

\section{Improvement Work in Irregular Stands}

In this country there are a great many second-growth stands which are uneven-aged and irregular. Some of these stands have resulted from very slow natural reproduction on old clearings. Others are the result of haphazard cutting and irregular reproduction. Competing with the best trees there are many trees of poor form and of poor species, and many defective trees. Such stands require thinnings to improve their composition and growth.

The stand is essentially immature. If there are old, straggling trees which interfere with the stand's development, they are cut. The thimning further remores defective trees of all classes, together with malformed trees and poor species, except when the density is so poor that they constitute an important part of the canopy. Crowded groups are thinned by cutting intermediate and co-dominant trees, and oftentimes a dominant tree is taken for 
the benefit of two or more co-dominant or intermediate trees.

Frequently the removal of an old straggler or of defective trees makes openings of a permanent character, in which natural reproduction takes place. Nevertheless, this is an improvement cutting, not a reproduction cutting. The whole aim is to improve the immature stand. If the defects and irregularity of the stand result in openings large enough for reproduction, this cannot be helped; and in that case the cutting is so made as to get as good natural reproduction as possible. In most of the thinnings only temporary openings are made.

\section{Improvement Work in Selection Forests}

In selection forests, thinnings are sometimes madeprovided there is a market for the product-for the benefit of the immature trees. Such thinnings are made at the time the mature trees are cut. In principle, they are of the same character as those just described for irregular second-growth stands. The good specimens of all ages are protected by removing undesirable crowding individuals. Seedling growth is aided by cutting away poor specimens over it, and sometimes even by cutting advance growth and brush, just as in a cleaning in an even-aged group. In such work, the principles of practically every kind of cutting are employed-cleanings in young groups, thinnings in even-aged patches, and damagecuttings in injured young groups. 


\section{Damage-Cuttings}

In nearly every forest there is some damage by wind, lightning, ice, snow, insects, disease, or fire. Good forestry calls for the removal of damaged material as soon as practicable, not only to utilize what is still fit before it deteriorates beyond usefulness, but also to prevent the spread of insects and disease.

If a mature forest is badly damaged, it is cut and reproduced as soon as practicable.

It frequently happens that an immature stand is damaged, and a large number of trees are so injured that they ought to be cut. Their removal involves a heavier opening of the stand than if the forest were thinned, and often makes permanent openings in the canopy. Such a heavy cutting in an immature stand, required by fire, windfall, or otherwise, may be called a damage-cutting.

When a stand has been so damaged, the forester must determine whether it will pay to leave the uninjured trees standing. If the stand is approaching maturity and a considerable portion is injured, it is usually reproduced, ahead of the normal time. If the damage is localized, that portion may be reproduced. If the damage is confined to only a few patches, the injured material is removed, and the openings are left to natural reproduction or, in the case of intensive practise, are filled by planting.

Sometimes a surface fire runs through an immature stand, killing from 40 to 60 per cent. of the trees. The remainder are rapid-growing, and the loss of growth 
222 THE PRINCIPLES OF HANDLING WOODLANDS

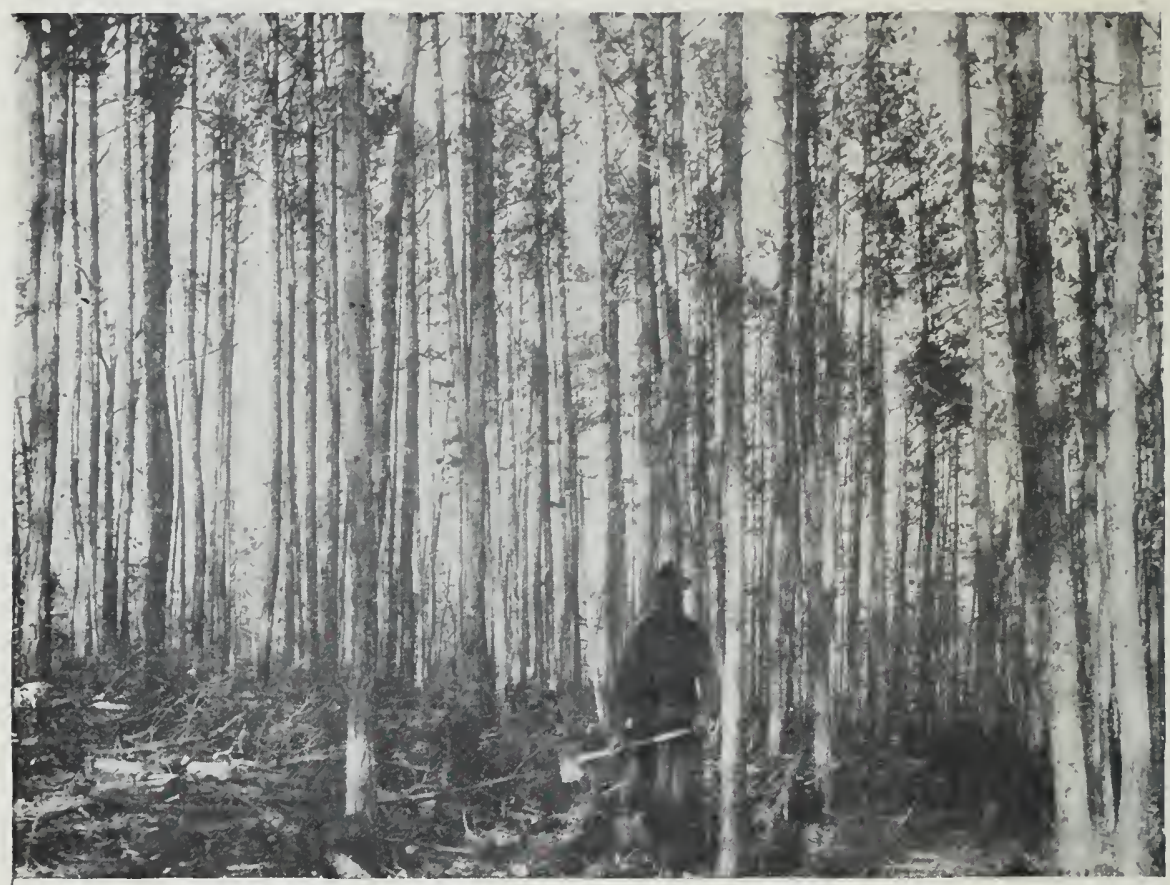

FIg. 46. - A Thinning in Progress in a Shortleaf Pine Stand. Biltmore, North Carolina.

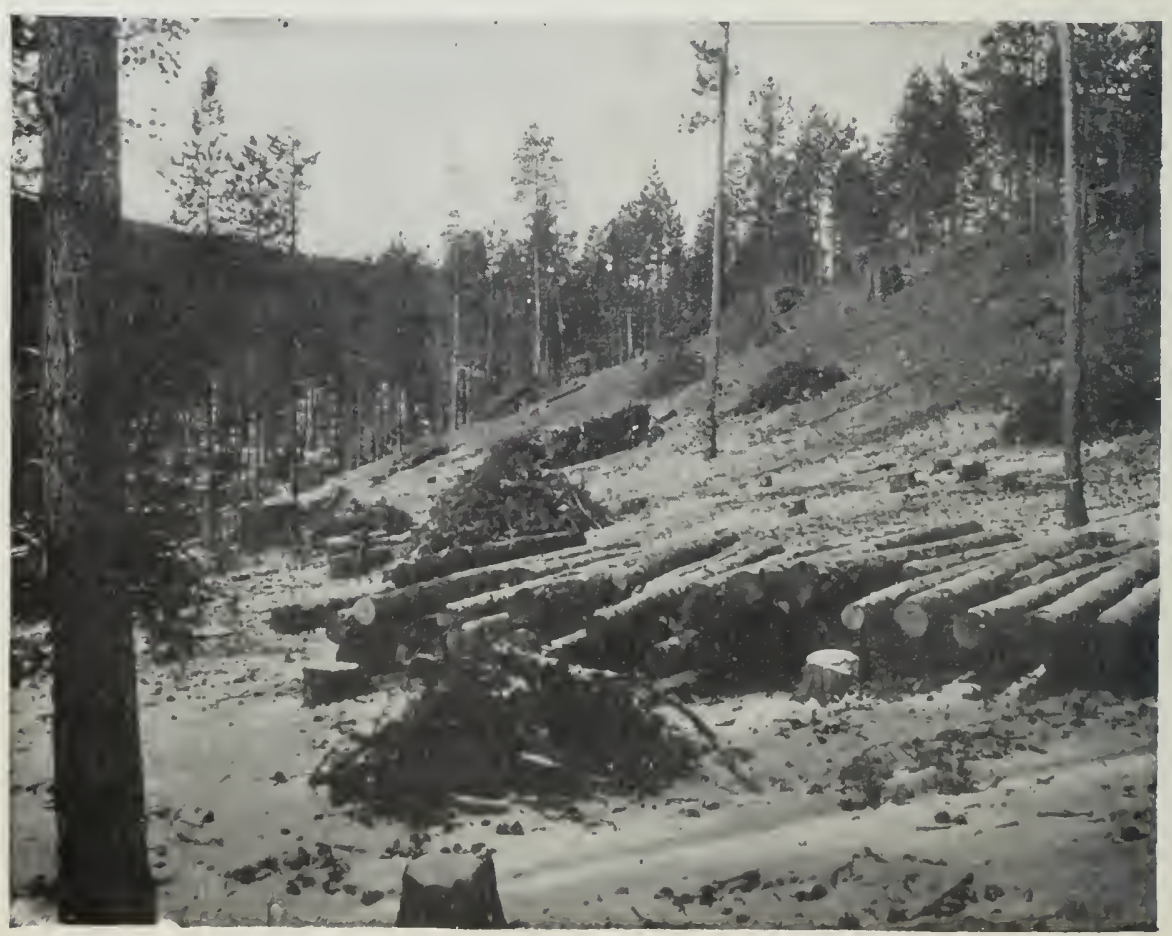

Fig. 47.-Example of a Damage-Cutting. Trees Removed Because Infected by Inects. Black Hills National Forest, South Dakota. 
through their removal would be large. When possible, the good trees are retained, either as reserves or as an upper-story, or brought to merciantable size as an incomplete stand.

\section{Pruning.}

The pruning of forest trees is confined chiefly to cutting off the lower branches, in order to have as much of the stem as possible clear of knots, and so raise the grade of the lumber produced. As a rule, forest trees are not pruned at all, but there is a natural cleaning of the stem, called natural pruning, by the loss of the lower branches als a result of the crowding of the trees. Often, however, natural pruning fails to give satisfactory results. With many species the branches remain on the tree long after they die, and their stubs produce loose knots in the lumber. The branches of white pine, even in crowded stands, persist for many years after their death; but after a time they drop off, and the wood subsequently made yields lumber clear of knots. Very old white pine-trees, therefore, yield a good proportion of clear lumber if they have grown in crowded stands. But if this species is managed on a short rotation very little clear material is ordinarily obtained, unless the trees are pruned. An unpruned stand, cut at from 50 to 60 years of age, yields but little clear lumber; whereas, if the trees had been pruned when from 20 to 30 years old the wood produced during the last half of the rotation would have been free from knots.

Pruning is a relatively expensive operation. It in- 
volves an investment whose return appears in the increased value of the final product. It is practised only when stands are intensively managed, and even then the work is confined to a limited number of the most valuable and promising trees in the stand. Usually not over 100 trees per acre are pruned, and these are selected individuals which are of good form, thrifty, and most likely to be the choicest trees in the final stand.

The aim is to clear off the branches for a distance of about 16 or 18 feet, enough to include one saw-log. This is about as high as it is practicable to prune, even with the help of ladders and long-handled saws and hooks.

The period for pruning is usually when the stand is from 20 to 40 years old. In most cases only dead branches are cut, though a live branch may be cut here and there. The work is not undertaken until the branches are dead for a distance of from 16 to 20 feet above the ground. Some of the limbs can be knocked off by a blow from a stick, or pulled off with a hook. The larger limbs have to be sawed off. Care is taken to make the cut close to the trunk.

The cost of pruning conifers from 20 to 40 years old is about 2 cents a tree.

Forest pruning will not be extensively practised in this country for some time. For the most part, it will be confined to comparatively small tracts which are intensively managed, and to valuable individual trees here and there in the forest. 


\section{CHAPTER VII}

\section{PROTECTION OF FORESTS FROM FIRE}

The first measure necessary for the successful practise of forestry is protection from forest fires. As long as there is any considerable risk from fire, forest owners have little incentive to make provision for natural reproduction, to plant trees, to make improvement cuttings, or to do other work looking to continued forest reproduction.

In many localities great progress has lately been made in forest protection. Organized fire protection has been established in the National Forests and in most of the State forest reservations. A number of States have begun to develop systematic fire protection on private lands, through the organization of State fire wardens. In some instances private owners have formed cooperative associations for fire protection and employ a regular force of rangers for patrol during the fire season. The most conspicuous and successful associations are those formed by certain lumber companies in Idaho and Washington. Throughout the country there are here and there instances of serious effort toward thorough fire protection by individual private owners. In spite of all that has been done, however, the fact remains that most of the forests of the country, particularly those privately owned, 
are inadequately protected from fire. It is probable that in fully 75 per cent. of the private forests there is no attempt whatever at systematic protection.

\section{Character of Forest Fires}

It is customary to distinguish three classes of forest fires, as follows:

1. Surface fires, which burn the surface layer of dry leaves and other litter, dry grass, brush, and small trees.

2. Ground fires, which occur where the mineral soil is covered with a deep accumulation of vegetable mold, and which, on account of the peaty character of the material, burn much more slowly than surface fires.

3. Crown fires, which burn through the crowns of the trees.

\section{Surface Fires}

Nearly all forest fires start as surface fires. The dry litter on the surface of the ground is ignited by a spark, perhaps from a locomotive or a camp-fire. At first the fire burns in a small circle, gradually eating out in all directions. If there is a wind, the fire burns with greatest intensity on the leeward side, and quickly assumes an oval form. If the wind is very strong, the fire may die out entirely on the windward side, but it burns intensely on the other side, soon developing a distinct front or head, with side wings running diagonally with the wind. At first the front of the fire is very narrow, but it gradually widens and takes the form of a broad, irregular line. The front may reach indefinite proportions, from a feiw 
hundred feet to a number of miles in width. Irregularities of topography and differences in the amount of inflammable material cause the fire to burn more rapidly in some spots than in others, so that the entire front becomes scalloped and irregular.

Ordinarily a surface fire simply burns along the ground and does not get into the tops of the trees. Sometimes, however, the flames reach up into the crowns and scorch them, or even ignite them here and there; but such a fire still has the character of a surface fire, unless it actually burns through the crowns.

The manner of burning, the form of the fire areal, the rapidity of burning, and the intensity of the fire depend upon the following conditions:

1. The character and quantity of inflammable material.

\section{The topography.}

3. The character of the soil.

4. The condition of the atmosphere.

Inflammable Material. - The severity of a surface fire depends largely on the quantity of dry material in the forest. If there is an accumulation of leaves representing the fall of a number of years the fire is much more severe than if the litter is the result of the fall of only a year or two. The quantity of accumulated litter is greatest with species having large leaves and large crowns. Maple and red oak, for example, make a heavier litter than ash or birch; white pine makes a heavier litter than pitch pine. The severity of a fire depends further on 


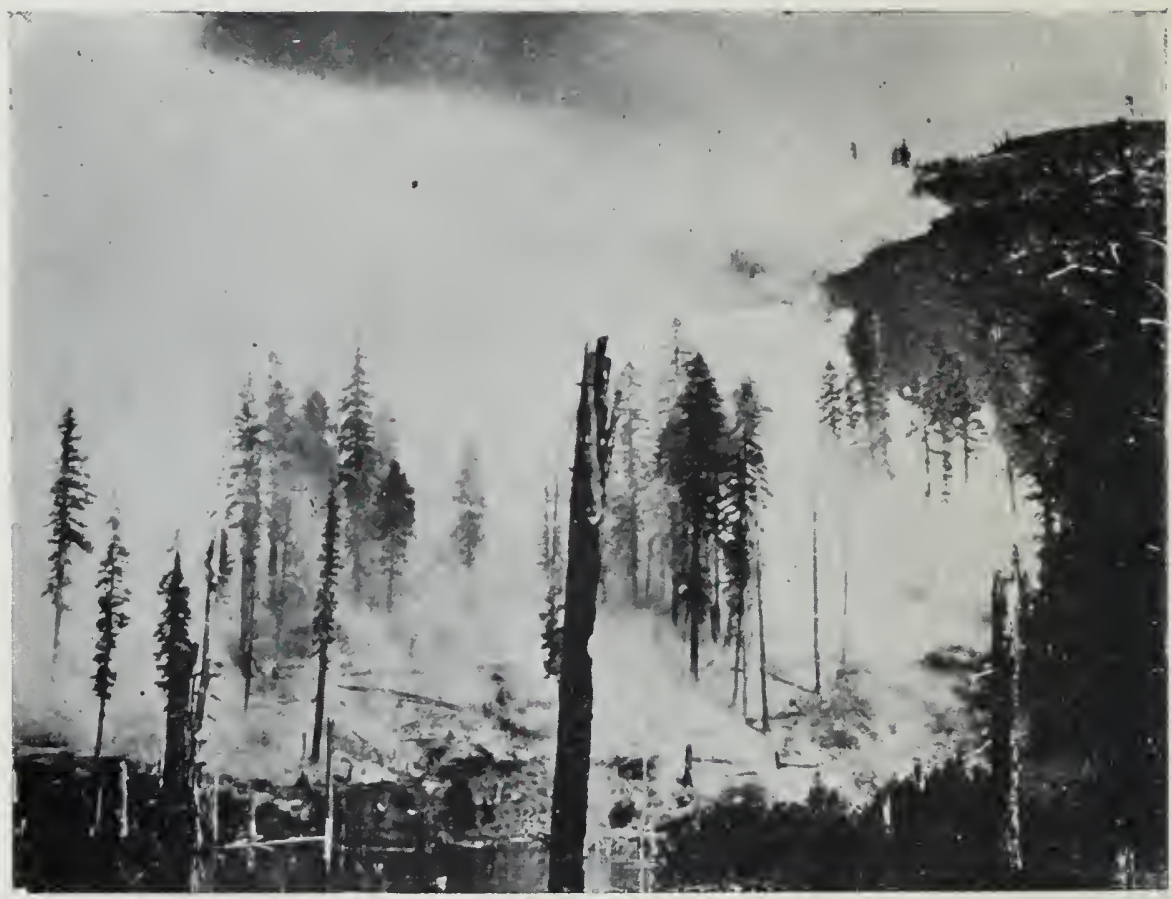

FIG. 48. - A Fire Burning in the Rocky Mountains.

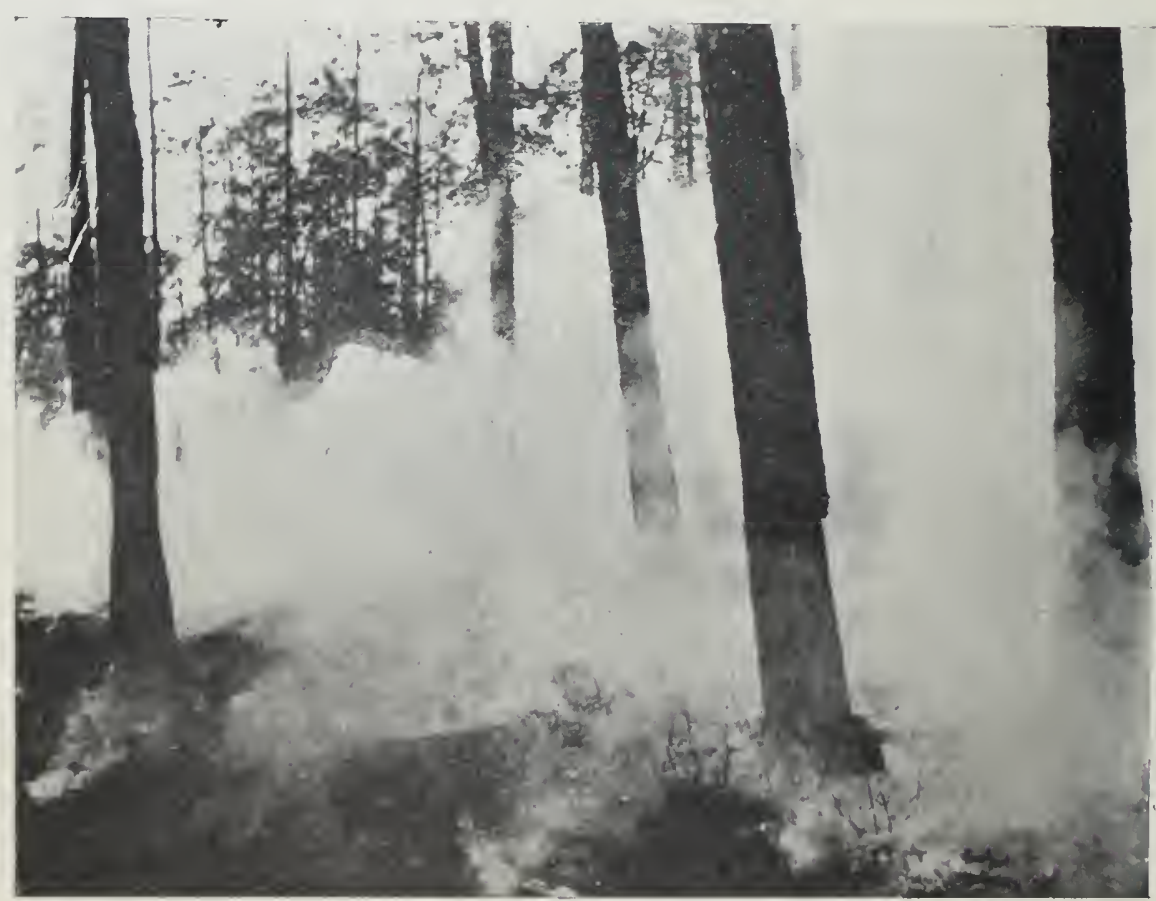

Fig. 49. - A Surface Fire in a Longleaf Pine Forest in the South. 
the character of the leaves. A layer of resinous softwood needles burns more rapidly and with a hotter fire than does a layer of hardwood leaves.

The amount of dry wood on the ground influences largely the severity of a fire. In some types of forest there are a great number of fallen dead trees, which litter the ground, and thus increase the fire danger. This is well illustrated in the lodgepole pine forests of the Rocky Mountains. In localities subject to windfall there is likely to be a large amount of fallen timber, while fires, disease, and insects leave standing dead trees and snags, which are easily ignited. After lumbering in the oldfashioned way, the ground is covered with a mass of tops and rejected logs, which soon become dry and highly inflammable.

Again, the condition of the litter and débris governs largely the character and severity of the fire. The most severe fires occur where the material is thoroughly dried to the mineral soil. When the material is only partially dry the fire is slow, and the litter is not completely burned.

Since the ground litter is, as a rule, unevenly distributed, a surface fire burns very irregularly. Still another cause of the irregularity of surface fires is the varying soil moisture.

Topography.-A fire runs uphill with great rapidity, because the heated air-currents draw the flames upward. If the litter is evenly distributed, the velocity with which a fire will run up a slope is in direct proportion to the 
steepness of the slope. After passing the crest, a fire travels more slowly in its descent on the other side.

Mechanical obstructions, such as abrupt walls, narrow ridges, outcropping ledges, and so on, tend to check a fire and to prevent its gathering volume. On extensive level ground, fires burn more uniformly, gather a greater volume, generally do more damage, and extend over a larger area than in rugged topography.

Character of the Soil.-Any influence which tends to dryness increases the intensity of a fire. Thus on sand and limestone soils, which warm up and dry out readily, fires are likely to be very severe. Southern and western slopes are apt to be more severely burned than others, because they are the warm and dry exposures.

Condition of the Atmosphere.-The character of a fire is influenced, further, by the condition of the atmosphere. Roughly, the greater the velocity of the wind, the more rapid is the progress of the fire. A fire burns more severely when the wind is constant than when it is gusty. It is the steady high wind which makes the most intense fire.

A fire burns most fiercely when the atmosphere is dry. Fires are, therefore, most severe during the hot part of the day, and when fanned by a dry wind. A moist atmosphere retards a forest fire. The well-known fact that the night is the best time to fight a fire is thus explained; for at night there is usually little or no wind, while the air is comparatively heavy and damp.

Rapidity of Surface Fires.-No reliable estimate of 
the rapidity of surface fires can be made, because it varies so greatly under different conditions. In the hardwood regions of the East a surface fire seldom travels more than 5 miles a day, but in the coniferous forests of the West instances are known where this rate of speed has been more than doubled.

Grass Fires.-In nearly all open forests there is a certain quantity of grass which, when dried, carries fire very rapidly. In many forests the presence of grass constitutes one of the important problems connected with surface fires. This is particularly true in the Southern pine forests.

A grass fire is more influenced by the density of the grass than by its height. Where the grass is in separated patches, with no leaves or other inflammable material between, it is difficult for a fire to spread. Uniformly dense grass burns with the greatest intensity. High grass burns with greater intensity than low grass, but the fire does not usually run so rapidly. Grass a foot high, if dense, may produce such a hot fire as to start a crown fire. In short grass, with an ordinary wind, a fire will run from 3 to 4 miles an hour; with a high wind, twice as fast. The chief factors affecting the burning of grass are its dryness and the force of the wind. Other factors have their influence, however, just as they do in the burning of litter.

Brush Fires.-Bushes and small trees frequently retain many dried leaves late into the fall, and in some cases even into the following spring. 'This is particular- 
ly true of some of the oaks. A fire will sometimes run through such brush and do an immense amount of damage. Such a fire is called a brush fire. It is carried along in part by the burning of the litter, but, wherever the opportunity offers, it runs up through the dried leaves, remaining on the brush. In the eastern United States a brush fire is most likely to run during the late fall. Under ordinary circumstances it has rather the character of a surface fire than that of a crown fire

Fires running through young stands of conifers consume the foliage and readily kill the trees. In a very young stand, in which the trees stand isolated and the crowns have not yet grown together, the fire has the nature of a surface fire, intensified by the burning crowns. If the crowns meet, and there is a more or less complete canopy, a true crown fire is developed.

A special class of brush fires are those in the chaparral of the Southwest. The brush is dense and there are many species with inflammable foliage. In many places a thick layer of litter and humus is formed on the ground, just as in a dense forest. Fires in this class of scrub forest are very fierce and destructive. They are analogous to fires in dense stands of young conifers.

\section{Ground Fires}

This term is applied to the slow fires that burn in the deep accumulations of vegetable matter common in many of our damp Northern forests. Here the fallen leaves, needles, and other offcastings of the trees decompose 
very slowly, and a deep layer of partially decalyed organic matter accumulates, often to a depth of from 2 to 3 feet. This material absorbs moisture with avidity and retains it tenaciously. Consequently, in moist seasons it is not readily ignited. In some seasons, however, it becomes thoroughly dry and will burn. A fire in this peaty substance burns slowly, but with very intense heat, and is exceedingly difficult to extinguish. Ground fires in the Adirondacks have been known to burn all winter, creeping along under a deep layer of snow.

Ordinarily a ground fire does not cover more than a few acres in a day. Frequently, however, there is upon the surface a large amount of dry débris or small coniferous trees so that there accompanies the ground fire a surface fire or a brush fire, or both, and occasionally a crown fire.

\section{Crown Fires.}

Crown fires are those which burn through the crowns of the trees. They almost invariably start from surface fires. Occasionally, however, they are started when lightning strikes and ignites a dry stub or resinous tree surrounded by a dense stand of conifers. If the crowns are of such a character that they will burn, they may be easily ignited by the flames which rise from a surface fire. Sometimes a crown fire is started by the flames from a burning clump of young growth, and where the trees have exuded resin or there is loose inflammable bark, a crown fire may be started by the flames running up the trunk. 
Crown fires occur when the woods are very dry, and when there is a high wind. Without a strong wind a crown fire is seldom started, and even if the crown of an individual tree is ignited, a fire does not usually spread and run through the crowns on a still day. Before a high wind, a crown fire spreads with great velocity, taking at once a V-shaped form with a distinct front or head. This head may be only from 50 to 100 feet wide, but in the case of the largest fires its width may be very great. In the case of the larger fires the front is generally carried forward by a series of heads. The head of the fire burns very rapidly through the crowns, and there follows closely a surface fire burning with the same rapidity. There are well-developed wings, where the fire runs through the crowns on each side of the head. These, in turn, are accompanied by surface fires, while spreading out on the skirts are wider surface fires, eating out diagonally with the wind and covering a broader area than the crown fire.

The strong draft of heated air arising from the fire carries up with it an immense quantity of burning cinders and pieces of bark. The wind, in turn, carries this material far in advance of the main fire-head, and thus innumerable new surface fires are started. This gives rise to the popular idea of a spontaneous starting of fires in advance of a crown fire.

An ordinary crown fire does not run more than 2 or 3 miles an hour, although undoubtedly the great conflagrations of the north woods, such as the famous Hinck- 
ley fire in Minnesota in 1894, are swept along at a much greater rate, particularly if the starting of new fires by burning cinders is taken into consideration. Even in extreme cases, however, it is questionable whether crown fires burn at a rate of more than from 6 to 10 miles an hour.

The behavior of a crown fire depends on the character of the crowns. Crown fires are mainly confined to coniferous forests, for the leaves of hardwoods are not easily ignited.

They may, however, run through forests of mixed hardwoods and conifers, and in such cases the heat generated is so great that the hardwood leaves are scorched or killed. The velocity of the fire depends, further, on the density of the stand, the thickness of the crowns, and the force and steadiness of the wind. Other influences affect the severity of crown fires in much the same way as they affect that of surface fires.

\section{Damage by Fires}

The damage done by forest fires may be discussed under the following heads:

1. Death of standing trees.

2. Injury to trees that are not killed.

3. Injury to the soil.

4. Reduction of the rate of growth of the stand.

5. Effect on reproduction.

Death of Standing Trees.-Crown fires usually kill outright all trees in their path. In a severe crown fire 
the foliage of coniferous trees is completely consumed. Hardwood trees in mixture are generally so badly scorched that the buds, leaves, and living tissues in other finer parts of the tree are killed, if not consumed, by the heat. Sometimes, however, where the fire burns somewhat irregularly - as, for example, where there are a good many hardwoods in mixture or the fire is broken by irregularities in topography-many single trees or groups of trees escape injury.

Ground fires, also, usually kill all trees in their way, for although they burn very slowly, they generate a great volume of heat and kill the living tissues of the roots. Sometimes the injury is not apparent above ground at all, but the trees die and, after a time, are blown over, because the roots have been killed and weakened.

Surface fires kill seedlings and young trees with tender bark, but in a great many cases do not kill outright the larger trees. Nevertheless, a very severe surface fire may kill everything in its path, and, not uncommonly, hardwood forests are entirely destroyed by fires which do not at any time assume the character and proportions of crown fires.

Some species have much greater power of resisting surface fire than have others. This is usually due to the character and thickness of the bark. 'Trees with delicate, thin bark are killed much more readily than those with thick, corky bark. Young trees are killed more readily than old ones, because the bark is thin, and there has not been developed the layer of cork, which increases in 
amount with age. According'y, some trees which are very resistant to fire when mature are exceedingly sensitive when young. Good examples are the Eastern and Western white pines, the red pine, the Western larch, and Douglas fir. The cork in the bark acts as a nonconductor, and protects the living tissues from overheating.

Some species exude from the baik a great deal of resin, which catches fire and increases the intensity of the heat. A good example is lodgepole pine, which often exudes resin over a considerable portion of the trunk, and increases the damage by fire. Other trees have soft, flaky bark, which catches fire readily. Like the resinous trees, these are killed at the point burned by the heat generated in this way. Shallow-rooted trees may be killed by surface fires when the heat of the burning humus is great enough to injure the insufficiently covered roots.

The living parts of a tree are more sensitive to intense heat at some periods of the year than at others. The most sensitive period is during the early part of the growing season, when active cell division is taking place and new cells are being formed, which are tender and naturally sensitive to abnormal conditions. This is very well shown by the damage of late spring fires. Thus, a surface fire in May or June may entirely kill hardwood trees which in the early fall would successfully resist a fire of equal severity.

Living tissue is killed when it is heated to $54^{\circ} \mathrm{C}$. 
$\left(129.2^{\circ} \mathrm{F}.\right){ }^{1}$ Very often the forester wishes to determine, after a fire, the extent of the injury. If the inner bark is brown or black, in contrast to the normal green color, this is an indication that the cambium is dead.

Injury to Trees.-Many surface fires do not kill trees outright, but seriously injure them by killing a portion of the roots or trunks. It is very common to find, after a fire, that nearly all the trees in the forest have been killed on one side. This is usually the leeward side, because here the flames have an opportunity to run in immediate contact with the tree long enough to injure it. If a fire is burning up a slope, even when there is no wind, the upper side of a tree is usually more damaged than the lower side, both because of the accumulation of leaves and other litter above the tree, and because fires are carried upward by the currents of hot air, just as a fire on level ground is swept along by the wind.

In the case of a well-established tree, the killing of one side may not result in its death for a long period; and if the wound is not large it may heal over. Very commonly, however, the killing of one side of the tree induces the attack of some fungous disease, which ultimately results in the tree's death. 'Trees injured and weakened by fire are subject to the attack of insects. In many cases the death of trees after a burn is the result of insects' work and not of the killing of the tissues by the fire. Damage by fire often follows damage by in- 
sects. Thus, in certain conifers insects injure the trunks, calusing a local accumulation of pitch. A surface fire later burns the tree at this point and kills one side. The defect called "cat-face" is often caused in this way. Insect attacks, moreover, by increasing the number of dead trees in the forest, increase the fire danger.

In the calse of large trees, which are very resistant to fire, a first fire may kill the tissues on one side, and subsequent fires may then burn into the dead wood until the trunk is nearly hollow. This result is very commonly seen in large white pines that have a large proportion of the butt gouged out by repeated fires and are still alive. Many of the large trees on the Pacific Coast, like red fir, yellow pine, sugar pine, and bigtree, stand for many years after injury of this character.

The damage to a tree by killing a part of the trunk or a part of the root depends on its resisting power and at variety of other circumstances. In some cases the tree is so weakened by the burning that it is afterward broken off at the butt. This is very common in long-leaf pine forests, where old turpentine "boxes" burn out and weaken the tree.

The injury to the tree usually results in a reduced rate of growth. It is obvious that if a portion of the tree is killed, the whole tree camnot perform its functions so effectively as before. The killing of a part of the crown, stem, or root system necessurily reduces the amount of nourishment which the tree can take in and furnish the growing parts. 
It is not only in shortening life and in reducing growth that fires injure trees; the quality of the product is also affected. Even where there is no injury by insects or fungous disease, a fire that has killed one side of a tree usually leaves its scar. In time the wound may entirely heal over, but there is nearly always a point of weakness which may ultimately cause a seam or wind shake, and unfit the butt $\log$ for lumber. If rot sets in, it may spread throughout the trunk and make the tree worthless, even if it does not kill it.

Injury to the Soil.-A surface fire burns the dry. leaves, and usually the humus which lies on the surface of the ground. If the trees are all killed by the fire, the crown cover, as well as the layer of litter and humus, is destroyed, and injury to the soil follows this exposure to the wind and sun. If the canopy is not seriously interrupted by the fire, and only the surface litter and humus are burned, the extent of the soil injury from one burning is not serious. A very light surface fire, that merely burns off the dry litter formed by one or two years' fall of leaves has little influence on the soil; and probably no single fire, even if it burned the entire humus and layer of litter would so injure the soil as seriously to affect the growth of well-established trees. Normally in every forest a certain amount of humus is mixed with the mineral soil. This is of value, both physically and chemically. If a forest is burned over repeatedly, however, the humus in mixture gradually disappears, and since the leaves which fall are destroyed, and no new humus is 
formed, the soil is injured. While the soil loses its supply of nitrogen and the physical benefits of humus, the mineral ashes are not lost, except as they are subsequently leached away. Nevertheless, repeated fires are very injurious to the forest.

Besides the direct injury to the soil through changes in its chemical content and physical quality, fires do further damage through opening the way to soil erosion. A leaf litter reinforces the forest canopy in protecting the soil against the impact of falling rain, and the network of roots which fills the ground holds the soil in place. The greater the humus content of the soil, the more absorptive the soil is. Fires leave the soil in condition to be easily borne away by running water, and increase the amount of water which runs over the surface instead of sinking in. If the slopes are steep and the soil easily borne away, erosion is sure to follow fires. In mountain country, if the rainfall is heary, thin soils may be so badly washed as to be no longer capable of supporting forest growth.

Reduction of Density.-Most fires kill a certain number of trees, or injure them so that they either die or deteriorate in value before the forest can be cut. This is particularly the case with immature forests. The result is a reduction in the number of trees which will come to maturity, and hence a reduction of the total increment and the final yield.

If a stand is mature and a part of the trees are injured or killed, it is sometimes possible to prevent loss by cut- 
ting directly after the fire. Often, however, it is not practicable to make a cutting in a given part of a forest just when desired.

When some of the trees in an immature stand are killed or injured, there is always a loss. If the stand is cut, there is a loss through cutting trees which are in full productive growth. If the stand is allowed to grow, the final yield is reduced nearly in proportion to the reduction in the number of trees killed in the dominant or leading class.

An owner is often confronted with the problem of dealing with an immature stand in which a part of the trees-say 30 to 60 per cent. - are killed or injured by fire. If the remaining trees are sound and thrifty, the best plan is usually to cut out the dead and damaged individuals, utilizing such as are marketable, and permit the remainder to mature, provided enough can be realized to cover substantially the cost of the work.

Influence on Reproduction.-Reproduction in the forests of this country has been more influenced by fire than by any other one factor. 'The present composition, form, density, and yield of a great many stands are due to the influence of fires on reproduction.

Repeated fires prevent reproduction by destroying the seed and killing the seedlings. This is well illustrated in certain areas of the South, where longleaf pine is not reproducing itself-not because there is a lack of seed or because the conditions for germination are unfavorable, but because the annual fires kill the young trees. 
Fires may influence reproduction through their effect on the soil and the soil cover. Frequently after fires the ground is occupied by heavy brush or by grass, which impedes or in some cases prevents the reproduction of valuable trees. Many of the grass parks in the Western mountains are the result of fire. A grass vegetation has replaced the forest. The rumning wild of burned areas to a heavy growth of brush is a common occurrence after fires in many of our Eastern forests, as, for example, in Pennsylvania.

Forest fires modify the composition of stands. The opening up of a forest may so change the conditions of germination that some species cannot develop even when seed is abundantly supplied. This is in some cases due to the drying of the soil. A species which requires protection against drought in early youth might be excluded from openings made by fire. In the same way the reproduction of a species sensitive to frost in early youth is often confined to areas protected by old trees.

Where the fire makes a large clearing, the succeeding forest usually differs in composition from the burned stand, except where there are only one or two species native to the region. The first species to spring up on the burn are those whose seed is readily and abundantly distributed to a distance from the seed-trees. Thus, in the north woods of the East, birch and aspen are among the first species, beciuse their seed is very light and is blown by the winds to great distances. Bird cherry comes up in abundance, because its seed is spreald widely 
by the birds, and probably much of it is already in the ground before the fire. The trees with heavier seed creep in gradually after a few years.

Fires may kill certain non-resistant species, and thus stop their supply of seed. The tendency of repeated fires is to reduce the number of species in a stand.

\section{The Prevention of Fires}

In some sections of the country forest fires have always been of such common occurrence that there is a popular notion that they cannot be prevented. The risk from fires can never be entirely eliminated, for in the forest there is always inflammable material which is very easily ignited. They may, however, be largely prevented, and under efficient organization their damage may be kept down to a very small amount. The problem is like that in cities, where fires can never be entirely eliminated, but where the risk of loss to property may be reduced almost to insignificance.

For the successful protection of a forest from fire there are necessary:

1. The elimination, so far as possible, of the causes of fires.

2. A proper organization of the forest, including the disposal of slash, the opening of roads, the construction of trails, etc.

3. An adequate supervision.

4. Facilities for fighting fires, including an adequate force of men, proper implements, etc. 
Elimination of the Causes of Fires. - The causes of fires may be grouped under the following heads:

(a) Sparks from locomotives; (b) sparks from sawmills, donkey engines, etc.; (c) camp-fires; $(d)$ clearing land and burning brush; (e) burning to improve pasturage; $(f)$ careless smokers; $(g)$ incendiarism; $(h)$ lightning.

Back of any practical plan of fire protection there must be State fire laws and a competent organization to enforce them. In many States to-day there are laws, some of them fully adequate, requiring the use of sparkarresters on engines, and punishing incendiarism, carelessness in clearing land, and in leaving camp-fires, etc. In most States, on the other hand, organizations to carry out the laws and an enlightened sentiment to support them are lacking. Education of the people to the value of forests and the need for their protection is necessary to overcome the carelessness and ignorance that cause fires to originate from camp-fires and clearing land. Vigorous application of the laws will accomplish this result, but the laws will not be vigorously enforced until there is a public opinion back of them.

For the most part, though probably not entirely, the starting of fires by sparks from locomotives may be prevented by the use of spark-arresters. If the right of way is properly cleared and patroled, such occasional fires as start may readily be extinguished. Railroad fires are therefore unnecessary. Railroads should be held responsible for damage from fires which they cause. 
In the same way there are excellent devices for arresting the throw of sparks from the stacks of donkey engines and sawmills. When fires start from these sources it is usually because such devices are not used at all or not properly used.

There will, of course, always be some accidental fires and an occasional incendiary fire, just as in a city. In certain districts also lightning will continue to be an unavoidable cause of fire. The management of the forest must, therefore, be so organized that such fires as do start may be extinguished as quickly as possible.

Organization of the Forest.-By organization of a forest for protection is meant the establishment of such conditions that the chances of a fire are reduced to a minimum, and that such fires as are started may be extinguished with the minimum of damage. Among measures variously used to accomplish this are:

1. The disposal of slash from logging operations.

2. The development of roads, trails, and firelines.

3. The establishment of lookout stations and telephone lines.

4. The organization of a protective supervisory and fire-fighting force.

5. The control of insects which kill trees and cause an accumulation of dead, inflammable timber.

No one measure is sufficient for adequate fire protection. 'The disposal of dry tops and brush reduces the danger from fire, but there always remains enough in- 
flammable material in a forest to make possible a damaging fire. There must also be roads, trails, or fire-lines giving ready access to the forest, so that fires may be located and reached. Nor are these together sufficient, for there must be a constant watching for fires in order that they may be discovered and attacked when they are small and easily controlled, and before they have done much injury. All the measures of fire protection are used together, and supplement each other.

Disposal of Slash.-The presence of dry tops and piles of brush in the forest constitutes the greatest menace from fires. The severity of a fire, and hence the damage done, is in direct proportion to the amount of dry débris on the ground. Still more serious is the fact that the presence of this material makes it exceedingly difficult to control and extinguish a fire. If there is no material on the ground other than the ordinary leaf litter, a surface fire may be easily extinguished. Old logs, dead and down trees, and snags lying about on the ground are also a great hindrance to fighting fires, for when once ignited they are apt to smolder for long periods, and so continue to threaten a further spread of the flames. In many of our forests the dead, standing snags constitute a very dangerous feature. If these are surrounded by a dense stand of conifers, they often carry the flames up into the canopy and make a crown fire; if isolated, they may burn for days, and finally fall, throwing sparks in all directions. The forester aims to reduce the amount of this inflammable débris in a forest as rapidlya as possible, since 


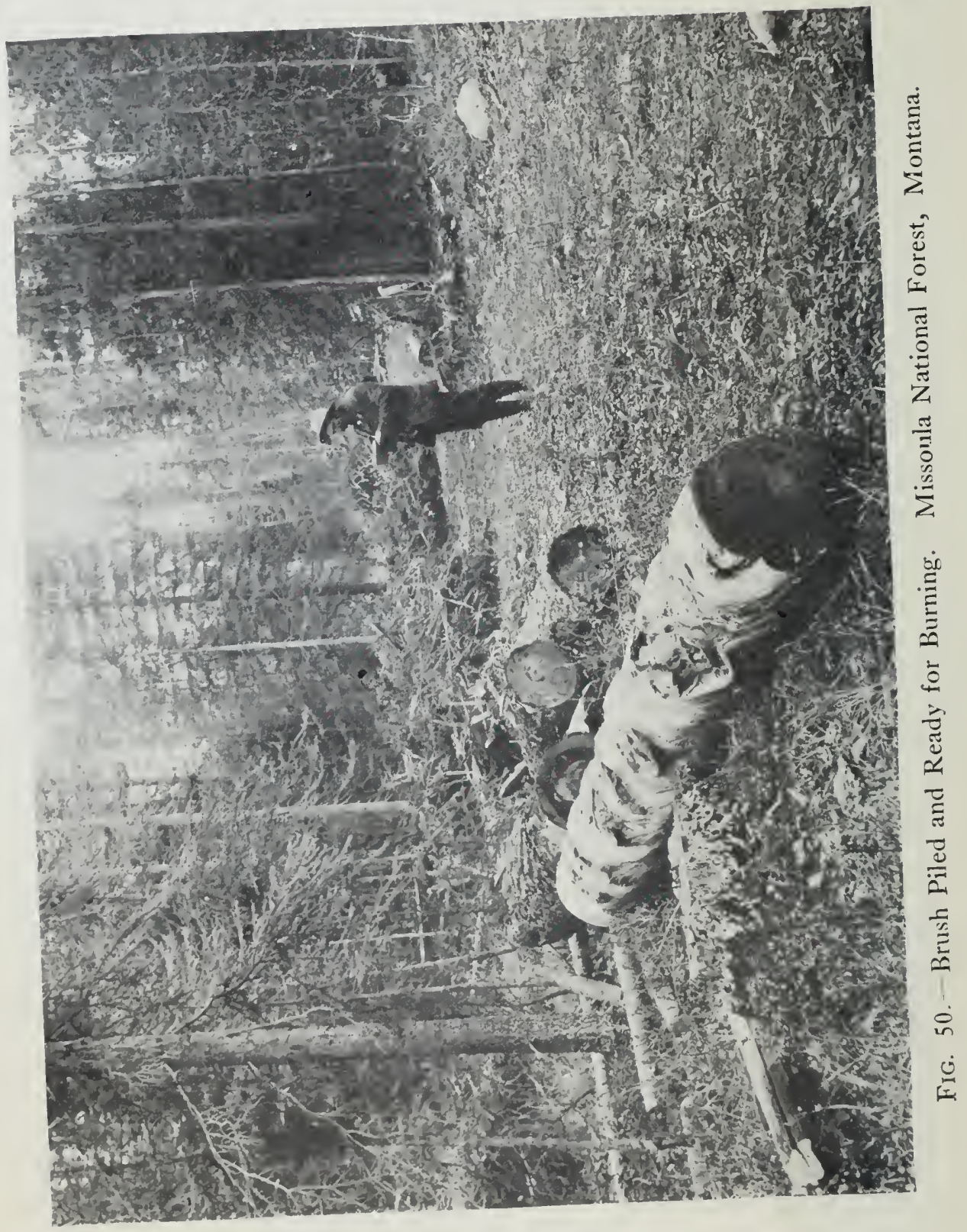


the "clean" stand is easy to protect in comparison with a stand that is littered with dry débris.

Disposal of Brush and Débris.-A first practical step is to prevent a further accumulation of débris in a forest by disposing of the slash from new cuttings. The ap. plication in all forests of a uniform method for disposing of this material would, however, be unwise. It should be clearly understood that no fixed rule of procedure and no single method could possibly fit all the different forest conditions in a country so large as the United States. The method used in any given case must be chosen after a careful study, and must rest upon a complete knowledge of the local conditions. Many methods have been tried in the disposal of brush, but those producing the best results are the following:

1. Piling and burning as logging proceeds.

2. Piling and burning in separate operations.

3. Lopping the tops.

4. Lopping the tops and scattering the brush.

5. Broadcast burning.

Piling and Burning Brush as Logging Proceeds.The most economical method of destroying brush and débris produced in lumbering is to burn it as the logging proceeds. This is possible when the ground is covered with snow or is so damp that fire will not spread. The work is done by the logging crew. As the trees are felled, convenient locations for burning the brush are selected, where no damage will be done to the trees and to young growth left standing, and where the fires will 
least interfere with skidding the logs. Small fires are started, and as the branches are cut off the trimmers throw them on the nearest fire. One reason why this method is cheaper than the others is because the branches need not be cut up so small, for the fire is already burning when they are thrown on. In coniferous forests the tops burn readily, even on the snow or in stormy weather. Sometimes when it is not practicable to start a fire near a given top, the trimming of the limbs is deferred until the skidders can haul it bodily near a fire. The branches are then lopped and the last cut made, enabling the skidders to go on with the top log, while the choppers throw the brush on the fire.

If the work is systematized, the brush is practically all disposed of as the logs are skidded, and the woods are cleaned up as the logging proceeds. There is a distinct advantage to the skidders through having open ground to work over. This method should be used only when there is no danger of a spread of fire. Its use on a large scale is confined to logging during the season of snow or rain.

The best method of calculating the cost of brush disposal is on the basis of the amount of timber cut, measured in board feet, $\log$ measure. A determination of cost per acre would be misleading, because of the great variation of yield in different forests.

The cost varies widely under different conditions. If trees have heavy crowns and large, heavy limbs, the cost is much greater than where the crowns are smaller. 
Thus, for example, the cost of destroying the brush produced in logging a stand of large hemlock would be greater per thousand feet of merchantable timber secured than in logging an equal amount in a small-crowned species like red pine. If the trees have a large volume, and the stand is heavy, the cost of disposing of their tops is less than it would be on an equal area for a sparse stand of trees that yielded only a small amount of merchantable timber per tree.

'The cost and efficiency of labor must, of course, enter into the cost of piling or burning brush, as it does in any other logging operation. If the men know just how to perform the work to the best advantage, and are industrious and energetic, the cost of piling the brush is much less than otherwise. In many cases the high cost of brush disposal has been simply due to the fact that the men who were doing the work were inefficient, unwilling, or unskilled. Still another factor influencing cost is the ease of the work as influenced by the density and amount of small growth and the irregularities of the ground.

The Forest Service, working in forests in the Iake States composed of mixed red and white pine, has disposed of brush in the manner described at a cost of 12 cents per thousand board feet.

\section{Piling and Burning Brush in Separate Opera-} tions. - Where the logging is done during the dry season, the brush is piled wherever convenient, but the burning of the piles is deferred until a farorable time, such ats during damp weather or after the first snow-fall. 
The best time for piling brush is during the cutting and skidding of the timber. As the branches are lopped from the stem they are immediately cut up and thrown on a pile. The work is done by the regular trimming crew, and, ordinarily, the extra work requires the addition of only one man to the regular number. The advantages of organizing the brush-piling work in this way are:

1. The brush is cleared at once for the skidding of the logs.

2. The work is done more cheaply than if the brush is piled by a separate crew after the logging is completed; besides, the trimmers have to throw aside the brush in any case to clear the way for skidding. Piling after the logging means a second handling of the brush, and is an expensive operation on account of the inevitable difficulties of picking up the branches from tangled piles.

3. The men work more efficiently and cheerfully when part of a trimming crew than when they do nothing but pile brush.

4. Supervision is more effective and less costly when the brush is piled with the logging than when it is a separate later operation.

Sometimes, when the logging is done in the winter, it is impracticable to burn brush at the time of logging, in the way described in the previous pages, or on account of the deep snow, to pile the brush for later burning. In this event the piling is done in the spring, as soon as the snow permits. 
In locating the piles it is necessary to take into consideration the convenience and cheapness in handling the brush, the clearance of way for skidding the logs, and the safety to standing trees and young growth when the piles are burned. Ordinarily they are placed at least 15 feet away from any trees or groups of young trees that may be injured. In forests like spruce, which have a great amount of branches, and where the trees stand so close that the piles cannot be placed at this safe distance, the brush is either piled and not burned, or is thoroughly lopped and left scattered evenly over the ground. When the brush is piled after the logging, the piles are located in the logging roads and skidding trails, and on spots where skidways were located.

The brush piles should be small and compact. (Fig. 51.) As a general rule, they should not be over 10 feet across or over 6 feet high. The very small branches are put in the bottom of the pile, with successively larger material laid on afterward. The ends of the branches are placed toward the center of the pile. Trimmed sticks may be leaned against the pile to hold it in shape, keep it from blowing over, and render it more compact for burning. Windrows and large piles make control of burning difficult, and are likely to make such a large fire that the crowns of trees are scorched and injured.

When the piles are loosely thrown together complete burning is very difficult and often impossible. To secure "clean burning" (so called), it is necessary to rebuild 


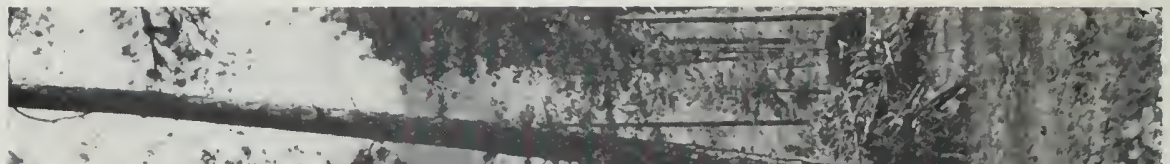
now $x c^{4}$

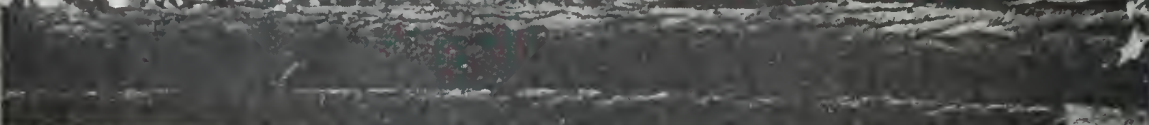

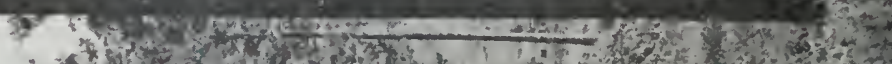

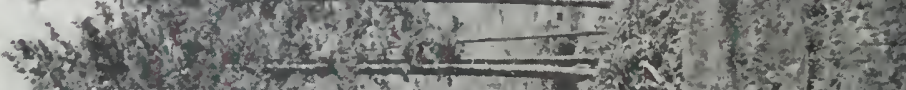

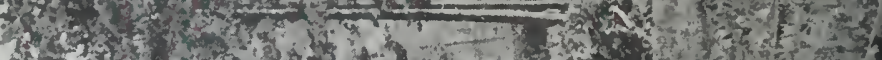

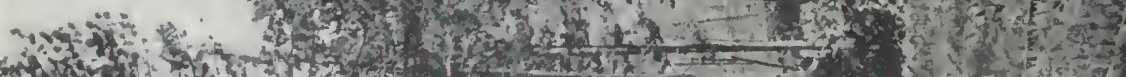

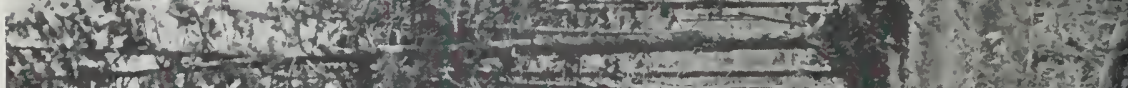

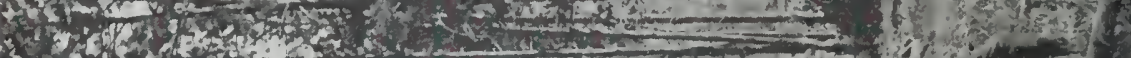

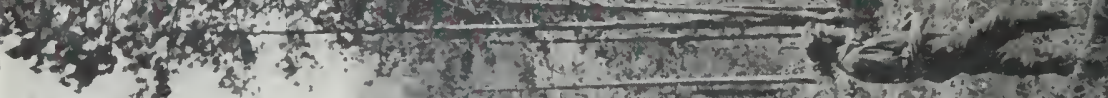

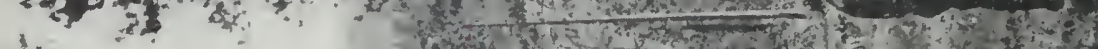

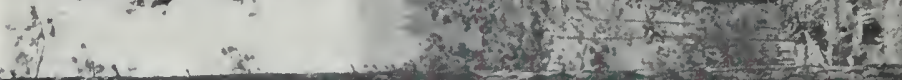
3.

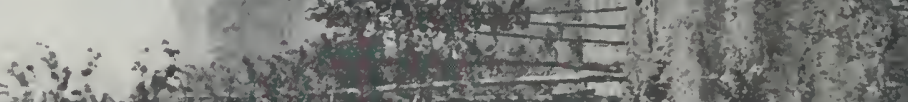

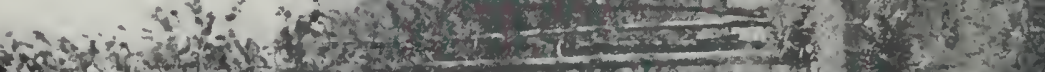

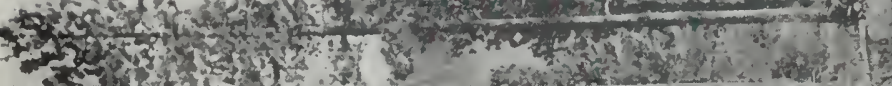


open and loose piles. 'This is called "chunking up" the piles. It is very expensive, for it costs as much as the first piling.

Brush should not be thrown on a top, at least until all branches are trimmed off. Ordinarily, they should be piled away from the top piece of the stem.

In some instances in the National Forests the practise has been to stake the piles. Sticks are driven into the ground 6 or 8 feet apart, and the limbs are ranked lengthwise between them, as shown in Fig. 52. The advantage of this method is that it insures thoroughness of work and a compact pile. It has been proved that it costs much less to burn a staked pile than the ordinary irreg ular pile, and the area of ground burned over is considerably less. 'This method has been found of especial value when the brush piling has followed the logging. The foreman of the piling crew selects the locations for the piles, drives the stakes, and supervises the work. Organized in this way, the work is done rapidly, and the expense is but little if any more than if the piles are irregular. Any extra expense of the staking is more than offset by saving in the cost of burning.

The cost of piling brush necessarily varies under different conditions. The first work undertaken in this country cost as high as $\$ 1$ per thousand feet, log run, of timber cut. 'This high cost was largely due to lack of knowledge of methods and to the inexperience of labor. With better organization and with trained workmen the cost of piling brush in coniferous forests has been reduced 
to from 10 to 50 cents per thousand. 'There is no reason why the piling alone in coniferous forests should cost more than 25 cents per thousand, except where the tops are unusually large and the physical difficulties unusual.

Burning the Piles. - An excellent time for burning brush piles is immediately after the first snow of winter. This is usually a light fall, and the snow does not penetrate the compact piles of brush sufficiently to prevent burning. There is no danger of the fire running on the ground, and the branches of the standing trees are so damp as to prevent injury by the rising flames. If the brush is burned before winter, it should be only during damp weather, when the ground is so wet that fire will not run easily.

When large areas of piled brush are to be burned the work should be organized with care. It should never be undertaken when there is a strong wind, and the best time is in calm weather. If there is any wind, the burning should begin with the piles on the lee side. Several piles may be fired at one tine, but they should be some distance apart, with one or more unburnt piles between them. When the first fires have burned down to coals, the intermediate piles may be ignited. This alternating method of burning the piles prevents the injury to trees and young growth between the piles that might result from the collective volume of heat of adjacent fires. Just as the brush on level ground is burned against the wind, so, on a hillside, the piles near the top are burned first, and the work progresses down the slope. 
Whenever large areas of piled brush are to be burned, a sufficient force of men, equipped with fire-fighting implements, should always be present to insure that the fire will not get beyond control. In some instances, when brush is piled in the winter during logging and left for later burning, the piles become very wet from the snow and rain and do not dry out till late spring or summer, a time when burning on a large scale is dangerous. If the brush of winter lumbering cannot be burned as the logging proceeds, the piles must ordinarily remain unburned till the first snow of the following winter, or till especially wet weather comes in late summer or fall.

The devices used in different localities for starting fires in piled brush are many. Some loggers use a torch of burning wood, as resinous pine; others carry live coals from one pile to another; others use a long-handled torch; others, again, pour a little oil on the brush and fire it with a match. The most satisfactory seems to be an ordinary tubular torch with wicking and a ferrule into which a rake-handle can be inserted. A good substitute, though a crude one, for the last is a piece of bagging or burlap wound around an iron rod or stick of wood and occasionally saturated with oil.

The cost of burning piled brush in the coniferous torests may vary from 1 to 30 cents per thousind, according to the manner in which the brush is piled, the condition of the brush, the size of the crew needed to prevent the running of fire, etc. Commonly, it ranges from 5 to 15 cents per thousand feet. Where the cost has been 
higher than this, it has been attributable either to poor work in piling or to inefficient management in the work of burning. The average cost of both piling and burning should range in coniferous forests between 10 and 50 cents, and as the lumbermen become more experienced in performing the work, the cost will be correspondingly reduced.

In a Montana logging operation shown in Fig. 52, where the brush was burned just after a slight snowfall under particularly favorable conditions, the actual cost of burning was only a fraction of 1 cent per thcusand feet. No watching of the piles to see that fire did not run was necessary; it was simply a case of walking from one pile to another and starting the fire.

In some coniferous forests careful records were kept at the area actually burned over. Where the stands per acre ran from 10,000 to 50,000 feet per acre, the aggregate area burned over by the brush fires was found to be approximately 7 per cent. of the toual area cut over in the logging operations. Where the brush is burned as the logging proceeds, the percentage of the area burned over is less.

Disposal of Hardwood Brush. - Most of the work of piling and burning brush has been in coniferous forests. Of late, however, there has been considerable discussion of burning the slash after logging in hardwood forests. So far as the author is informed, systematic brush burning after hardwood logging has not been conducted anywhere on a large scale or in a manner to justify 


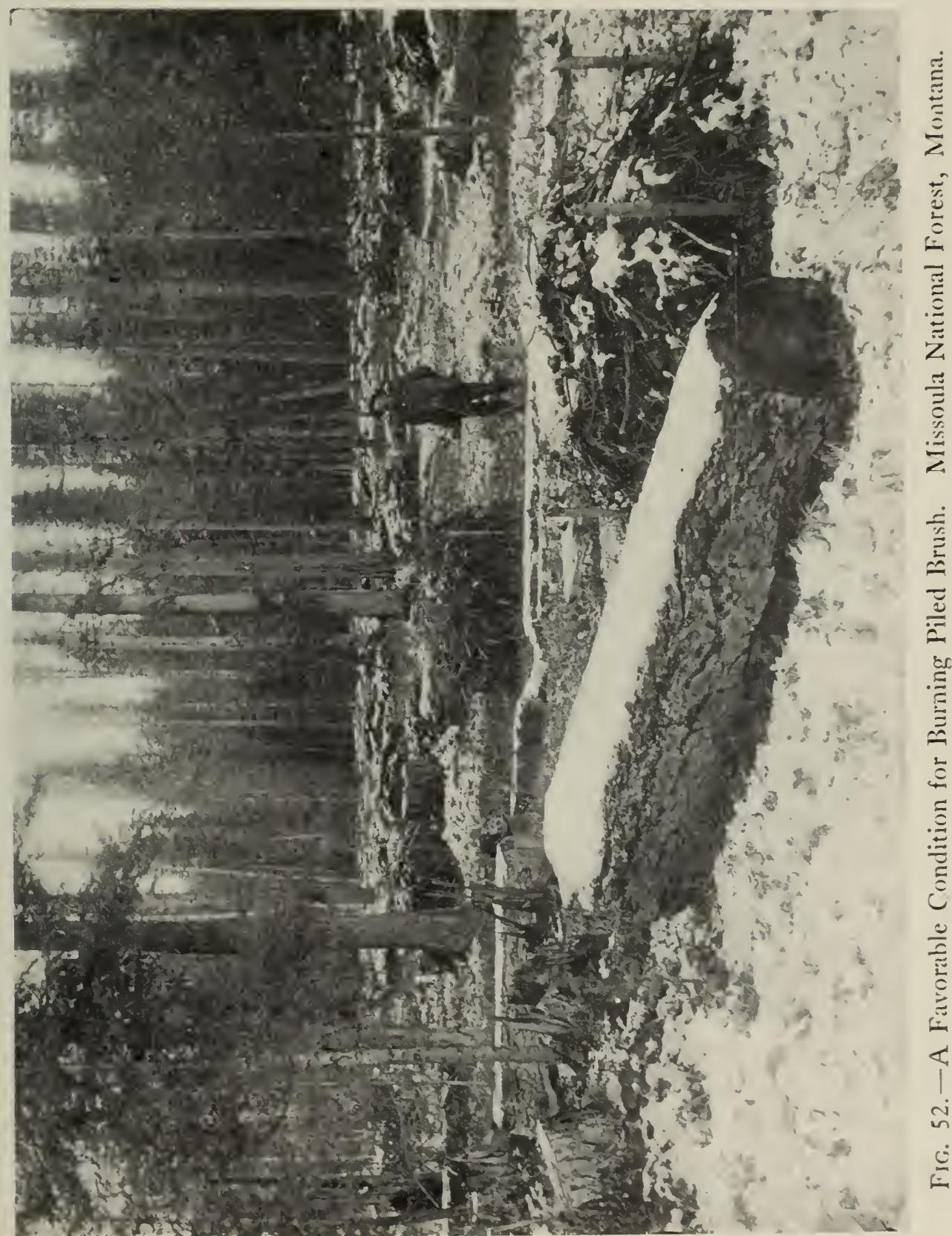


a judgment as to its practicability. Hardwood tops are necessarily large, heavy, and awkward to handle. The cost would be much greater than in coniferous forests. It is probable that lopping and scattering will be used rather than piling and burning.

The author has conducted some experiments in the burning of hardwood brush in the second-growth forests of New England, where the wood was utilized to about 3 or $t$ inches, so that the amount of brush to be disposed of was much less than would have remained from logging old timber in the ordinary manner. The results of these experiments showed the average cost of piling and burning to be between 10 and 25 cents per cord. In this class of material with good organization the cost would probably not exceed 10 to 15 cents per cord, though these figures furnish but scant basis upon which to make calculation of the cost of piling and burning the brush and débris from an ordinary hardwood logging operation, where the size and number of the limbs would be very much greater.

Lopping the Tops.-In some forests the burning of the brush maly be unnecessary or actually undesirable. A method of brush disposal applicallye in many forests is to lop off the branches from the tops and leave the material on the ground. 'The purpose is to bring all the brush in close contact with the ground, so that it will absorb moisture more readily, dry out less in summer, and decay more rapidly than when propped high above the ground. 
So far as the author is informed this method was first used on an extensive scale in the Adirondack Mountains in lumbering spruce and pine. At first the plan was to cut off only the upper branches of the top as it lity on the ground. This left the stem still propped above the ground, as shown in Fig. 53. The next step was to cut off the under branches and lower the whole mass to the ground. The heavy snows during the first winter after cutting flattened down the top and the branches. (Fig. 54.) In this condition the brush absorbs moisture so rapidly that after three years there is little risk of fire.

This method was first used in private shooting preserves, mainly to prevent the tops from obstructing the hunter's view. It also enables a freer movement over the ground and facilitates the fighting of fires.

A later development of the method is to cut up and scatter the branches about over the ground. This has been used in the cuttings on second-growth woodlands when the amount of material left after cutting the cordwood in the tops was small. It has also been extensively used in certain National Forests in the dry districts of the West, where the scattered branches serve as protection to the soil and aid reproduction.

The cost of lopping the tops of spruce in the Adirondacks was 12 cents per thousand feet of lumber cut.

Lopping is the most advisable method of brush disposal under the following conditions:

1. Where there is very little danger of fires starting. 
2. Where the region is moist and the branches will absorb moisture quickly.

3. Where the forest is so dense that piling and burning is impracticable.

4. Where the conditions of logging and of the market are such that the greater part of the tree is utilized and but little crown is left, while what is left will not be especially dangerous if thoroughly lopped and scattered.

5. Where the scattering of the branches is necessary or desirable to protect the soil and small seedlings from drought or frost.

Broadcast Burning.-For a number of years it has been the custom of certain lumbermen to burn their slashings, in order to protect valuable standing timber on neighboring areas. 'There is usually no attempt to regulate the fire within the area burned, and all living trees and young growth upon it are destroyed along with the brush and débris. From the standpoint of forest production such fires are very destructive.

'The principle of broadcast burning may, however, be used to advantage in making clear-cuttings, provided the fire can be confined to small areas and fully controlled. Thus, in making clearings in patches and strips in certain of the National Forests, the slashings are burned on the ground without piling. 'This method is now under trial in some of the clear-cuttings in the northwestern National Forests, where, in addition to the slash from the cuttings, there is a great accumulation of débris and 


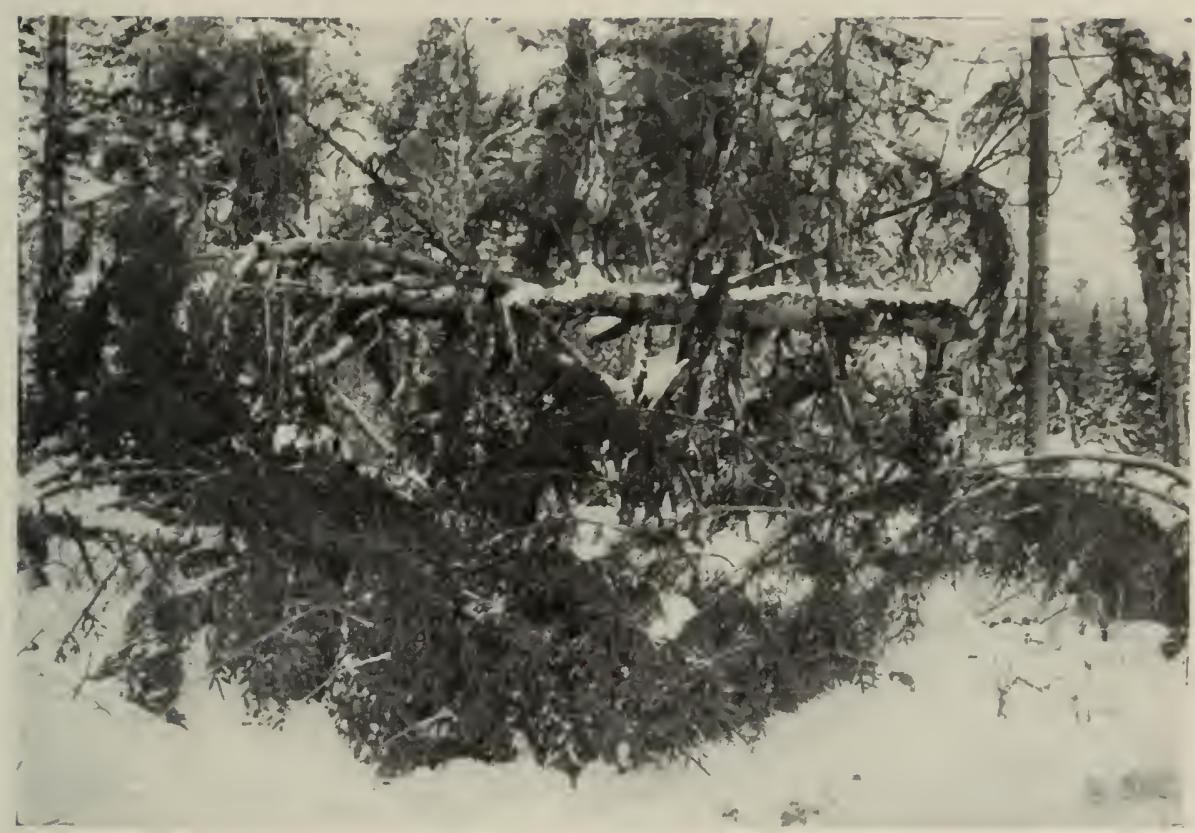

FIG. 53. - A Spruce Top Improperly Lopped.

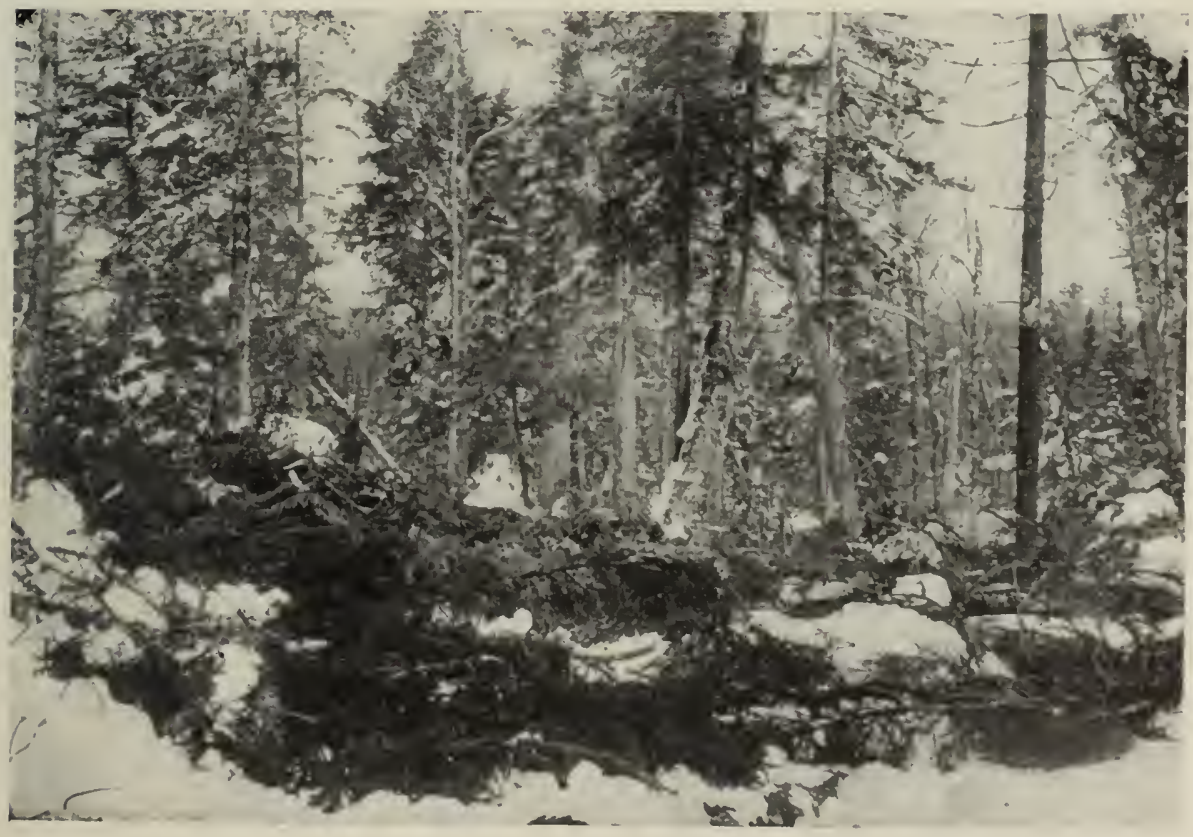

Fig. 54. - The Same Spruce Top Properly Lopped. 
the litter and humus is very heavy. In some instances this débris and litter is a hindrance to reproduction, as well as an invitation to fire, and its destruction is beneficial. 'The heavy loss of humus which must accompany so hot a fire may be more than counterbalanced by the improved conditions for reproduction of the species desired. The expense of piling all the slash and débris in the ordinary manner would, under these conditions, be very large, probably not less than from $\$ 1$ to $\$ 2$ per thousand feet of timber cut.

In order to control the fire in burning over the ground broadcast, ample fire-lines should be constructed around the outside of the areas to be burned. These should usually be not less than 1 rod wide, and should be entirely cleared of inflammable material. The material in the lines may often be thrown on the side of the cut-over area and burned with the other débris, but if this would make a dangerously large pile near the line, it is better to burn it in piles on the cleared space.

The burning should be done with great caution. A time should be selected when the slash is dry enough to burn well, but not so dry that it will be impossible to confine the fire within the fire-lines. The best time is usually when the slash in the open, cut-over area has just dried out sufficiently to burn, and while the contiguous forest is still too damp to burn freely. In the case of wide, cleared strips it may be advisable to construct a fireline through the middle, as well as along the edges. Very often the logging trails can be used for intermediate 
fire-lines for the control of the burning, and in this way the expense of making special lines may be partly saved.

In the work of burning it is usually advisable to have a crew of at least 10 men, properly equipped with firefighting implements, in order to control the fire. So far as possible only small portions of the area should be under fire at one time, especially when there is any possible danger of the fire spreading to the adjoining woods.

There is no question that this method is much more dangerous than burning brush in piles, and for this reason the latter method should be used whenever possible. A great objection to broadcast burning is that any remaining trees, reproduction, or young growth, already started on the cut-over area, are almost inevitably destroyed.

Annual or Periodic Burning of Litter.-In many places, notably in the pine districts of the South, it has been the custom to let surface fires run through the woods every year, usually in order to improve the range. This is defended on the theory that if the litter is allowed to accumulate for a number of years, a fire would be so severe as to kill all the timber, whereas an annual fire burns only the year's fall of leaves or needles, and does little damage to the standing trees. Where the trees are tapped for turpentine the litter is raked away from the boxed trees, so that the fire will not reach them.

There is no question that in the unprotected yellowpine forests this custom has resulted in saving a large 
amount of old timber, but it has also retarded the reproduction of the forest by killing off young growth and seedlings in their tender stage. Deliberate burning of the litter as a protective measure is justified only under special conditions and only on selected areas. The considerations bearing on the use of fire in this way are:

1. It should never be used except where absolute fire prevention cannot be assured, and there is real danger resulting from heavy leaf litter.

2. It should be used only in stands in which there is no reproduction that it is desired to conserve.

3. It should be used only where the benefit in fire protection more than offsets the injury to the soil, resulting from repeated burning.

4. It should be used only with very fire-resistant species.

5. It should be used only when the trees are old and large enough to have developed the corky bark necessary for resistance to the heat of the fires.

6. It should be used only when the fire can be controlled.

The burning is done best in early spring, when the loose litter is dry but the ground below is damp, the purpose being to burn only the upper litter.

In many places it is very difficult to control the burning without the use of fire-lines. A tract divided by roads and paths into small blocks presents a simple problem, for each block maty be burned separately, and there is no danger of the development of a fire too large to 
control. On large tracts without roads, ground-cleared fire-lines may be used to protect areas of young growth, or these may be developed at certain points to aid in the control of broadcast burning.

Annual burning for fire protection is never justified where it cannot be systematically controlled. The practise in many parts of the South and West, of setting out fires to burn off the litter and brush-usually for the sake of a better range-cannot be justified, for the fires are uncontrolled, and they destroy an immense amount of young growth and otherwise damage the forest. Merely setting fire to the woods without control is nothing less than forest destruction.

Fire-Lines.-Broadly speaking, a fire-line is a cleared strip in the forest used as an aid in the protection from fire. It may be a road, a trail, a river or stream, a line cleared especially for a fire-break, or a plowed furrow. The purpose of fire-lines is to check or stop fires, and to facilitate fighting them. A small surface fire may be stopped entirely by a road or even a path. Some surface fires are easily checked in their progress by narrow firelines; others can be stopped only by very wide lines. Crown fires and surface fires of unusual severity will readily leap across even very wide fire-lines. Fire-lines, therefore, should not be built with the idea that they will always stop fires. They are intended to serve primarily as an aid, and often are an indispensable aid, in controlling fires and preventing their spread. Even when they do not actually stop or check a fire they serve as vantage 
points from which the fighting crew may work. Their establishment usually makes the woods accessible, so that a crew can get to a fire or near it quickly with appliances for fighting it. If back firing is necessary, it can often be done best from the fire-line.

Fire-lines differ very greatly in construction and width, according to local conditions of fire danger and of special forest organization. They will be discussed under the following heads: (1) Roads; (2) trails; (3) special fire-lines.

Roads.-An ordinary dirt road ranks as one of the best of all fire-lines. The wider the road the more effective it is. A forest well cut up with roads is, therefore, much more easily protected than one with few or no roads. In Europe, every well-organized forest has a thoroughly planned network of roads. These are located primarily with reference to the problem of logging, but they serve also as a network of fire-lines, and special lines are cleared to supplement them where necessary. Every part of the forest is readily accessible, not only for patroling for fire during the danger season, but for the quick transportation of fire-fighting appliances. In case a fire should start in such a forest and be discovered within a reasonable time, it would be easy to confine it to a small area.

We cannot expect to have such a well-organized system of roads and fire-lines in our forests for a long time, but much can be done in the way of utilizing the more or less temporary roads that are used in logging and 


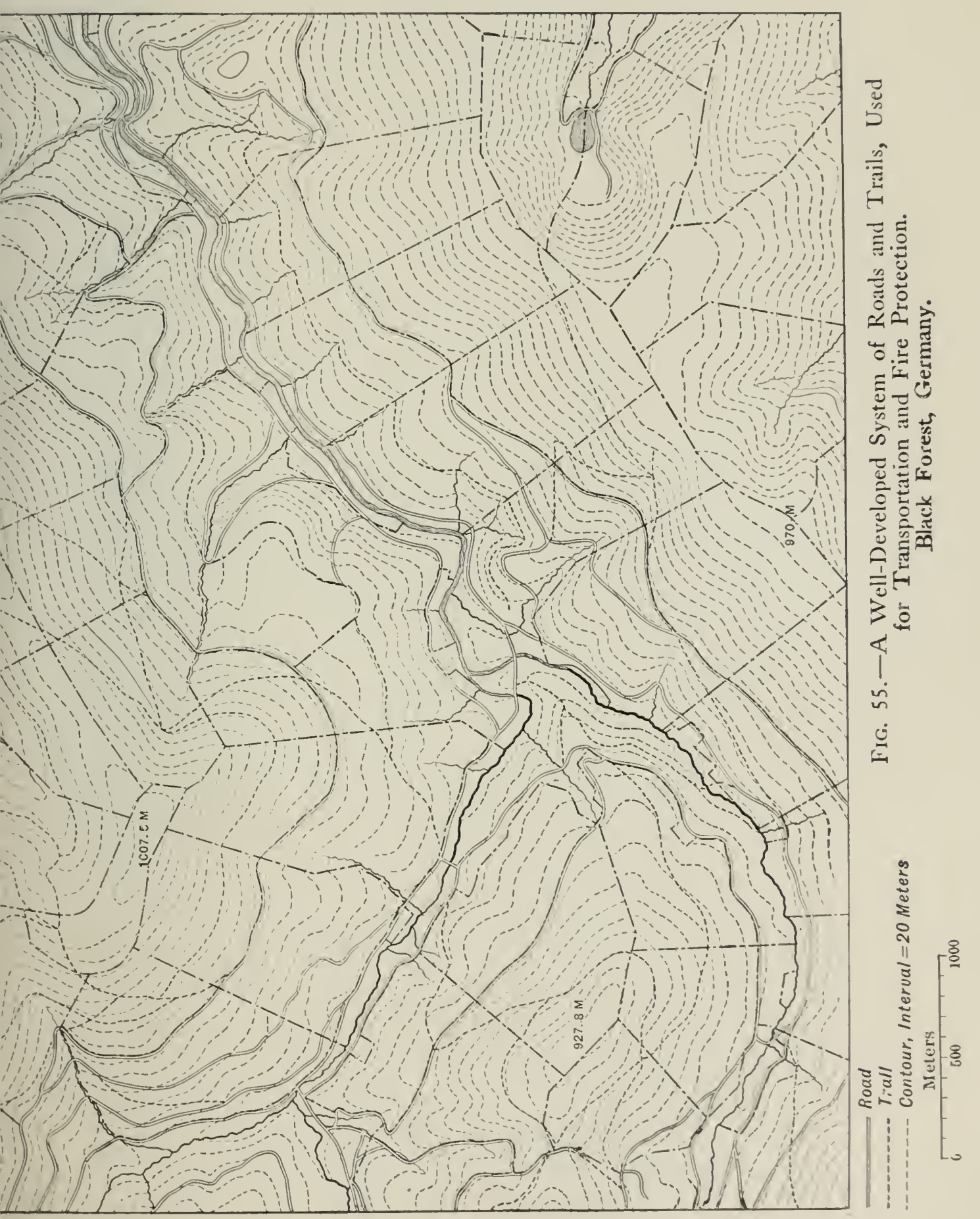


afterward abandoned. 'This is particularly true in the second-growth woodlots.

In most woodlots there are a great number of old wood roads, often badly overgrown with weeds, brush, or trees. If these are kept clear they are of great value in fire protection. They make the different parts of the woods accessible and offer points from which the fighting crews may work. The author has in mind a tract in Pennsylvania which was burned over in 1909 with great loss, but which might easily have been saved had the old roads been clear.

It is us:ally impracticable, on account of the expense entailed, to keep all the roads free of leaves, grass, etc., but they may be kept brushed out with very little cost. The author recently had some work of this sort done on a Pennsylvania tract, eight years after abandonment of the road, for less than $\$ 3$ per mile. It may not always pay to repair bridges and restore badly washed roads, but in almost every second-growth woodlot most of the overgrown roads may be reestablished sufficiently for fire-lines with very little cost.

Trails. - The first object of trails is to open up a forest and make it accessible for patrol and for fighting fires. In the National Forests, this work of trail construction constitutes the first step in organizing for fire protection. In undeveloped mountain regions it is impossible without good trails to get to a fire in a reasonable time and with means for fighting it. The trails in the National Forests are permanently constructed, and are 
designed for saddle and pack-horse travel. (Fig. 59.) While their first purpose is to facilitate patrol and access to a fire, they may be used as starting-points for backfiring, and will often check or actually stop a small surface fire.

Special Fire-Lines. - When there are no roads or trails which will answer the purpose, it may be advisalble to construct special fire-lines. Special fire-lines are necessarily expensive, and are used where the property to be protected is very valuable. 'They are most used in woodlands in the better settled portions of the country, where land values are relatively high. In many cases it is advisable in a valuable woodlot to construct here and there a special fire-line at points where it is not worth while or practicable to build a road or trail. 'Thus, special lines are frequently run along the boundaries or at strategic points connecting roads. It is a sound principle, however, that special fire-lines should never be built where a road or trail can be used for the same purpose.

In the less intensive forest conditions, such as occur in the lumber woods, special fire-lines have so far been constructed only under exceptional conditions. In a large forest, the first work is to open up the area for communication by the construction of trails, and, where possible, of roads. Like all other work in forestry involving an investment, the use of fire-lines must be based on sound business principles. They should be used only where necessary, and where their expense is justified by the returns. 
Special fire-lines may be classed under the following heads: (a) Fully cleared lines; (b) tree-cleared lines; (c) ground-cleared lines.

Fully Cleared Lines. - The ideal fire-line is a completely cleared strip, from which are removed not only the trees and brush, but also all ground débris down to the mineral soil.

Fully cleared lines are advisable when the risk of fire is very great and adequate protection can be secured only by having a clear break, which will either stop or check possible fires. Such lines are necessarily expensive to construct and maintain. They are, therefore, used only when the property is valuable and the damage from a fire would be very great, as, for example, to protect nurseries, plantations, or valuable blocks of timber.

They are especially necessary wherever fire will run swiftly and it may not be possible to reach the fire promptly with fighting appliances. A conspicuous example of the necessity of such fire-lines and of the service rendered by them is found in the chaparral forests of the mountains in southern California. (Fig. 58.) The preservation of the chaparral cover is of great importance in protecting the local watersheds. The area is large, the mountains are rough and difficult to travel, and fire runs with great rapidity. Fire-lines are very necessary in such localities to control any fires that may start, and they must be of a character to stop fires, or to check them to such an extent that they can be controlled. The Government is, therefore, building 
extensive trails for patrol to prevent fires, and supplementing them by wide, cleared fire-lines to stop any fires that may start.

Cleared fire-lines are also used in extensive pine forests on dry, sandy land. Fires start easily and run swiftly under such conditions, and fire-lines are easy to construct and comparatively cheap to maintain. Thus, in the pine forests of northern Germany and southern France, wide cleared lines are used to supplement the road systems.

The danger from fire is always very great in the regions of the Tropics that have a pronounced dry season. In India, for example, fire protection constitutes one of the greatest problems of management. The forest becomes very dry in the hot season, and there is a great abundance of grass, which ignites readily and carries fire swiftly. Under these conditions cleared fire-lines are absolutely necessary for efficient protection.

The width of fire-lines varies greatly under different conditions. In general, the following classes from the standpoint of width may be recognized: Normal, from 6 to 15 feet; wide, from 15 to 30 feet; very wide, from 30 to 60 feet. In Europe fire-lines are usually about 10 to 15 feet wide, but in the pine plains they are often as wide as 50 feet.

In this country such fire-lines as have been constructed are usually less than 1 rod in width. In the chaparral of California, however, broad lines, from to to 60 feet wide, have given the best results in stopping fires. 
$27+$ THE PRINCIPLES OF HANDLING WOODLANDS

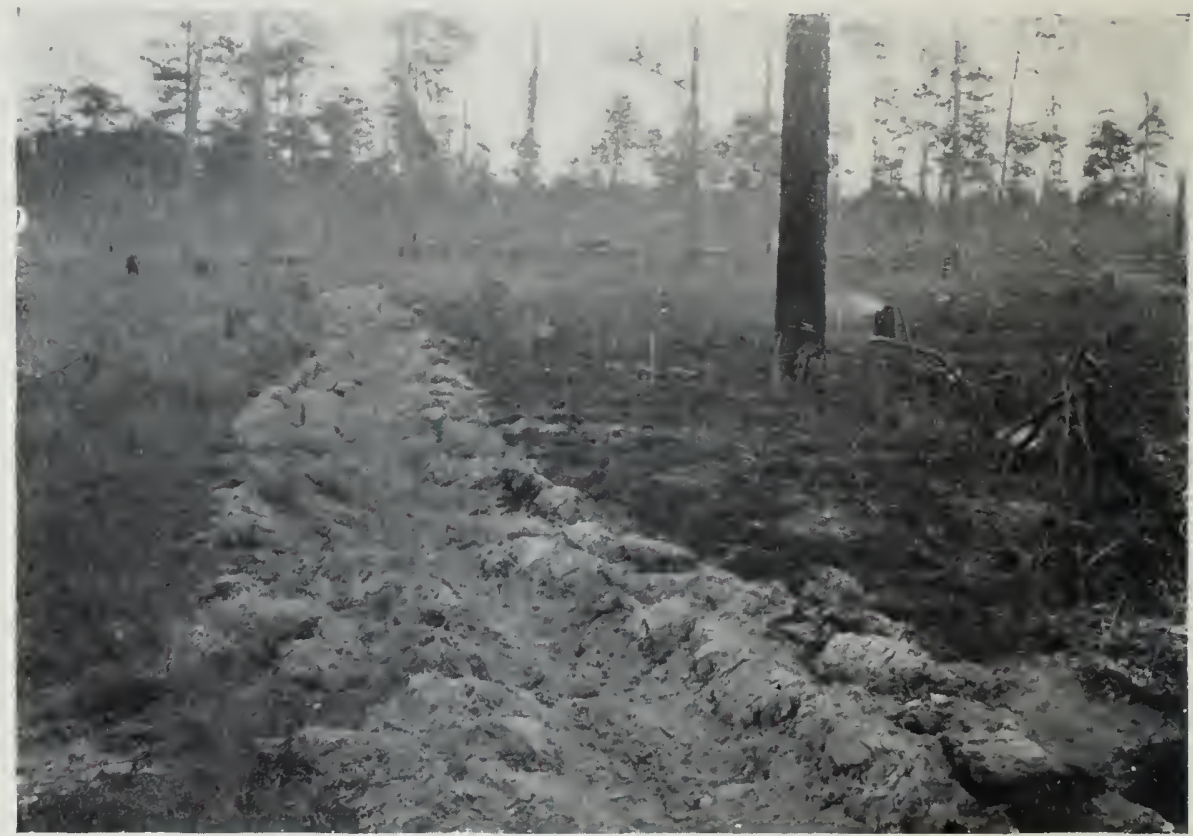

Fic. 56.-A Plowed Furrow that Stopped a Surface Fire.

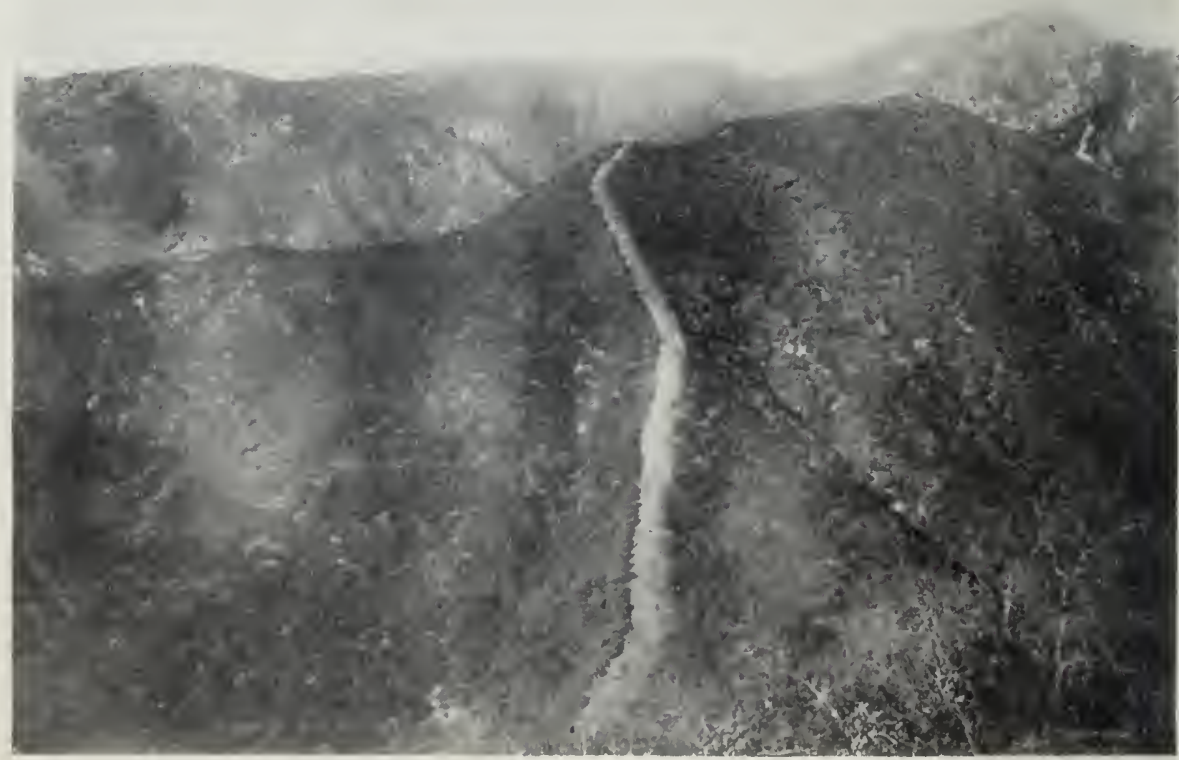

Fig. 57. - A Fu!ly Cleared Fire-I,ine in the San Gabriel Mountains, California. 
It is seldom necessary or practicable to make fire-lines over 60 feet wide. Usually it is more economical to make a number of narrow lines rather than a few very broad ones.

In constructing a fully cleared fire-line the timber and brush should all be removed or disposed of to the desired width. Where it is impossible to utilize the timber, the logs may be left along the side of the lines. The brush and other débris should be burned. Piling the brush along the edge of the line is a dangerous practise. As a rule, the best plan is to burn the brush in piles in the cleared area, and then burn the ground litter by a broadcast fire.

In the best permanent lines the stumps are all grubbed out and the soil is occasionally stirred by grubbing or harrowing. Sometimes only a part of the line is cleared to the soil. Thus, for example, the timber and brush may be cleared from a strip from 10 to 15 feet wide, and a narrow strip or trace about + feet wide ground-cleared. This cleared trace may be located in the middle of the line, or on one side. A good plan is to make two traces, one on each side of the fire-line. The advantage of the last plan is that it affords a very good protection when burning the débris on the line.

The method of constructing a narrow, ground-cleared trace, covering only a part of the fire-line, is very commonly used where there is a deep duff on the ground. It is then a question of protection against ground fires. Under such circumstances the trace amounts to a trench. 
In the north woods the duff is frequently 2 feet deep. A narrow trench, from 1 to 3 feet wide to the mineral soil, suffices to stop or check a ground fire. The trees and brush are cleared for a width of 6 to 15 feet, to facilitate work in fighting fire and in constructing and maintaining the trench.

Fully cleared fire-lines should be cleaned off every year or two. The leaves and other débris accumulating upon them should be removed by burning or otherwise, and in the case of grubbed lines the soil should be stirred over by raking or harrowing.

The work of burning over the fire-line can best be done in early spring. The leaves and other débris will become dry on the open fire-line sooner than in the adjoining forest or chaparral. The aim should be to do the burning at exactly the time when there will be the least danger of the fire spreading to the woods. It is, however, not always possible to organize the crew so as to have the work done at the most favorable period. In the case of an extensive tract the work may be begun exactly on time, but the whole woods may become dangerously dry before it can be finished. It is especially difficult to carry out this work of burning over the fireline in open pine woods on dry, sandy soil.

When the burning has to be deferred until the woods as well as the fire-line are dry, great care should be exer. cised in the work. If the ground cover consists of leaves or needles, the procedure is as follows:

Narrow, cleared traces are made on each side of the 
fire-line proper, by raking or brushing aside the leaves, or needles, and débris. Sometimes, in flat, level areas it is possible to make the trace by plowing one or two furrows. Usually these traces need be no more than a foot wide. A fire is set along the side of the fire-line. One or more men follow this up, constantly brushing the burning or smoldering embers toward the center of the fire-line, the idea being to keep the fires confined between the traces. Other men follow behind and watch the burning area to prevent a possible spread of fire. If there is a strong wind, no burning should be done. If there is a slight wind across the line, one trace may suffice on the lee side, and the burning should proceed against the wind. Under ordinary circumstances a crew of from four to six men suffices for burning over fire-lines, but if the weather is very dry a much larger crew may be required.

In very dry weather the burning is best done early in the morning or in the late afternoon and evening. The air is moister, and there is usually less wind at those times.

In California, several interesting experiments in keeping down the brush on the broad lines are being tried. One is to pasture on the line a flock of goats which eat down the new weeds and sprouts, and trample the ground. Another experiment is to establish on the line a dense growth of succulent, herbaceous plants which would keep out ordinary weeds and obviate annual or periodic grubbing. 
The cost of constructing fully cleared fire-lines varies enormously, just as does the construction of a road or trail. The cost of clearing the line depends on the width, character, and quantity of timber and brush to be cut, the quantity of tops to be disposed of, and the character and quantity of ground débris, as well as on the labor, the difficulties of work, the efficiency of organization, etc. If the ground is grubbed, the cost is affected by the character of the work done, the difficulties of working the ground, and the topography. In general, the first construction of an 8-foot fully cleared line costs anywhere from $\$ 10$ to $\$ 100$ per mile. An average for a secondgrowth woodlot would be from $\$ 30$ to $\$ 50$. If there is a good market for cordwood and other-material, the timber might return 50 or 60 per cent. of the whole cost. The wide fire-lines in southern California cost from \$100 to $\$ 200$ per mile. They are now cleared every two years at a cost of from $\$ 30$ to $\$ 75$ per mile. The cost of maintenance will be progressively smaller from year to year.

Tree-Cleared Lines.-By a tree-cleared line is meant one from which the trees and brush are removed, but from which no effort is made to clear the leaves or other small litter. 'The object of such lines is not to stop a fire, but to furnish a vantage ground for patrol and for fighting fires. 'The brushing out of all wood roads, already mentioned on page 270 , makes the best kind of tree-cleared lines.

Very frequently special tree-cleared lines are made 


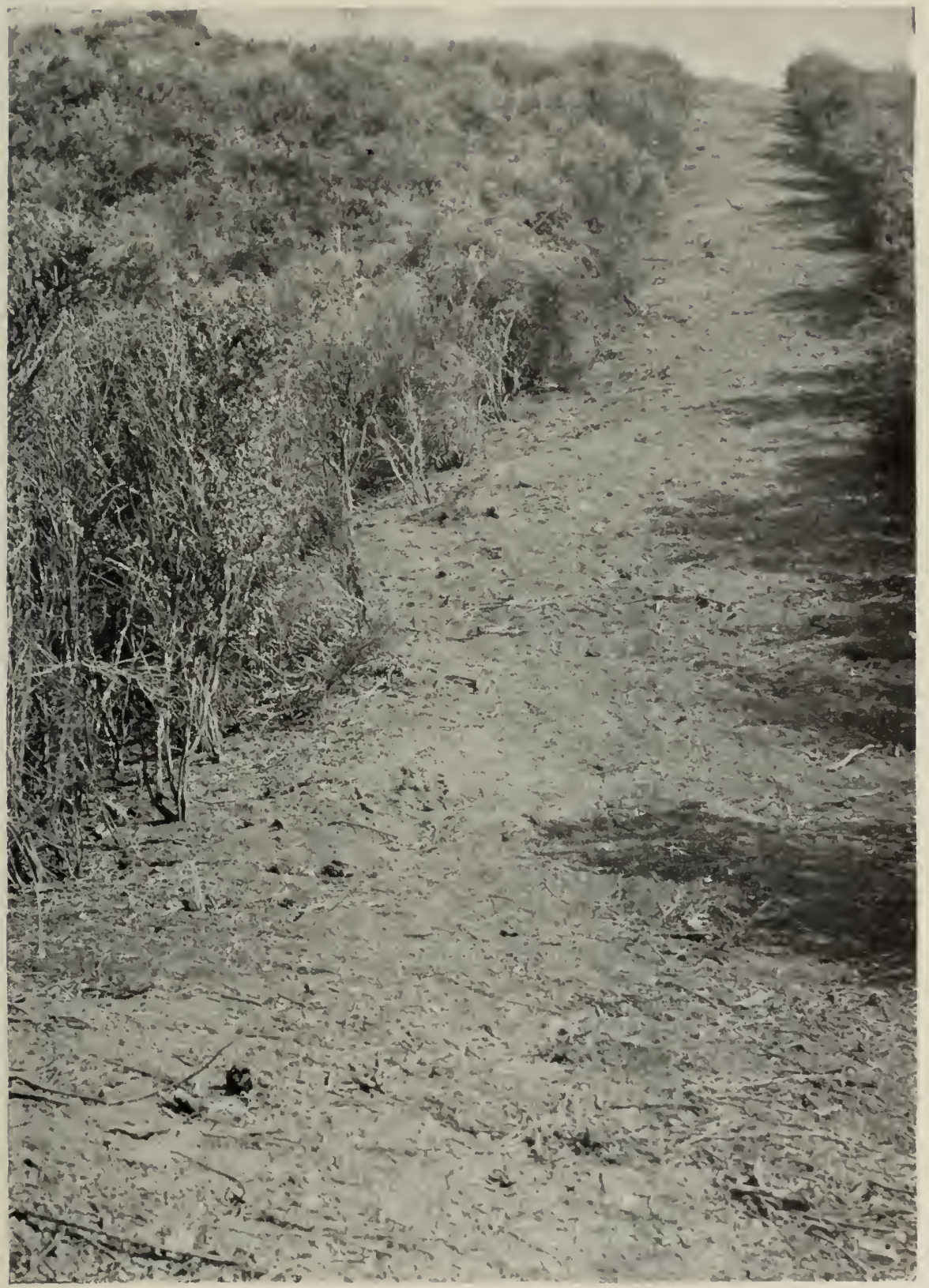

FIG. 58. - A Fire-Line in the Chaparral. Angeles National Forest, California. 
where there are no roads or trails, as, for example, along the boundary of a tract, about a recent clearing, around a body of young timber, etc. In Europe, such lines are often made between two compartments where there is no road or other permanent boundary.

The width of tree-cleared lines is usually from 6 to 15 feet. The European tree-cleared lines between compartments are usually about 6 or 8 feet. Often a line from 10 to 15 feet is cut, especially where a road may later be located. In a number of instances in this country very wide lines have been cut, 75 or 100 feet in width. Such great width is ordinarily unnecessary. Strips a rod wide are usually of fully as great value as the very wide lines, except in conifers, where there is danger of crown fires. The maintenance of these lines consists in brushing them out every year or two.

Ground-Cleared Lines.-By ground-cleared lines are meant strips on which the small brush and ground débris are destroyed, and the larger trees are left standing. Ground-cleared lines may be made in open woods, where there is little or no undergrowth to be injured or to interfere with the work of clearing the ground. 'The usual procedure is to burn a strip through the woods from 10 to 20 feet wide. This can be done only where the conditions are such that a surface fire may be controlled and restricted to the desired strip.

The open pine woods of the South present an ideal condition for the use of ground-cleared lines. In burning the lines, practically the same methods as those 
described on page 276 for burning over regular fire-lines should be used.

Location of Fire-Lines.-The existing roads usually constitute the base or framework of a system of firelines. Ordinary roads, old wood roads, skidding trails, and other open strips are used first, and special lines are constructed only when necessary. Special lines should always be located at the strategic points.

In any given forest the boundaries should first be protected. There must be protection from fires that may start on a neighboring tract. Often roads running along or near the boundary will give adequate protection. If not, and there is danger of fire entering from the outside, a fire-line is desirable, even if it is only a tree-cleared strip.

Fire-lines are often constructed around recent cuttings, where there is young growth established or on areas where there is still considerable slash.

One of the places where fire-lines are most needed is along railroads. It is the custom of certain railroads to keep their rights of way clear, usually by annual burning. In some States this is required by law. In spite of this precaution, innumerable fires are set on the right of way, and very commonly by sparks thrown into the woods beyond.

Many special fire-lines have been tried. In general, these are based on the principle that the right of way should be cleared, then a strip of woods left standing, and then a second cleared fire-line constructed back of 
this strip of timber. The theory is that the trees on the timbered strip will catch the sparks thrown beyond the right of way. Any fire set by these sparks on the timbered strip will be stopped by the second fire-line.

This principle has been used in a number of instances in this country. One good example is found in a hardwood forest in southern New York. A railroad runs through the tract, along a stream valley. The stream acts as a fire-line on the low side of the railroad, but the opposite side is exposed to frequent fires resulting from the sparks escaping from the locomotives. A stretch of several miles is on a steep grade, and the locomotives, under forced draft, throw out great showers of burning cinders, and no spark-arresters whatever are used. As a protection, a fire-line, varying in width from 8 to 15 feet, has been constructed on a bench at a distance of from 50 to 150 feet from the railroad. The strip between the line and the railroad is left untouched. A patrolman rides over the strip about the time the trains going up grade pass by. Ordinarily the smali fires are extinguished by beating. In case, however, a number of fires are started by a train, as often happens, one or two of them burn over the strip to the fire-line before the patrolman can reach them. The strip is so narrow, however, that they gain little headway, and are absolutely stopped by the fire-line.

In mountainous country, fire-lines are located with reference to the topography. Where roads are used, or fire-lines are made that are intended to be used later as 


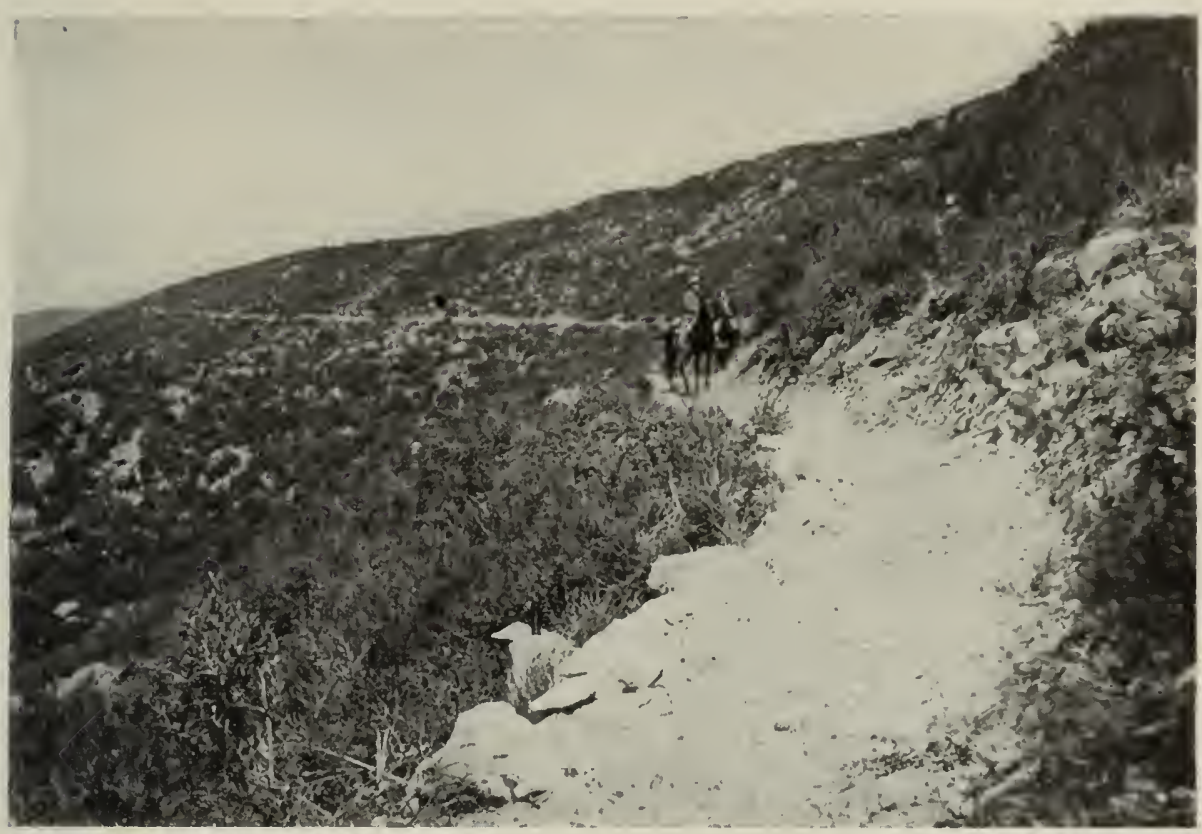

FIG. 59.-A Mountain Trail Built for Fire Patrol. Angeles National Forest, California.

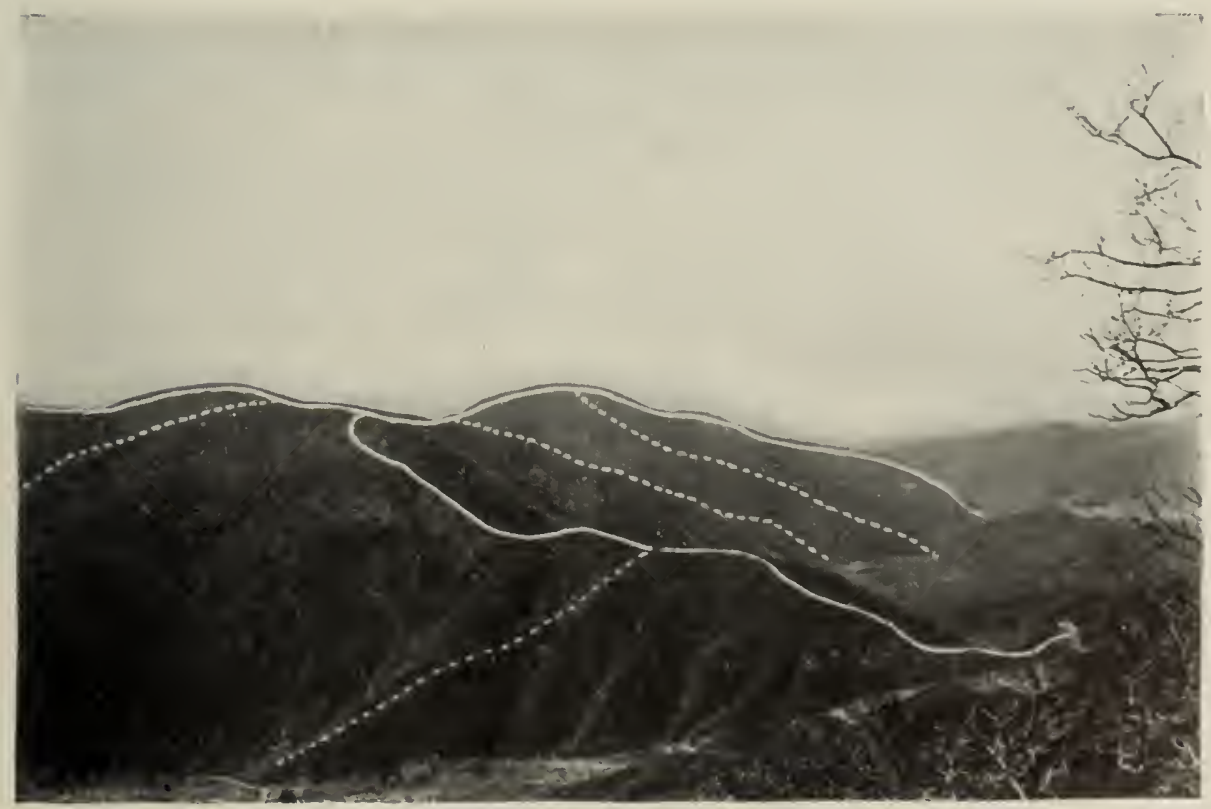

Fig. 60.--Location of Fire-Lines in the Angeles National Forest, California 
roads, the location is governed largely by the principles of road construction. Special fire-lines, however, constructed for protection alone, are built mainly on the crest of ridges. (Fig. 60.) For example, the wide lines in southern California, already mentioned, are on the various ridges. A fire runs up a slope very rapidly and works over a ridge slowly. If there is a wide, cleared fire-line on the ridge the fire may be stopped entirely by it alone. In the southern Appalachians and other mountains, the old mountain trails on the ridges may be developed into admirable fire-lines.

The question of when and where to construct special fire-lines must depend on local conditions, the danger from fire, the value of the forest, the organization of patrol and force available for fighting fire, the object of the owner in protecting the forest, and many other factors. As with other operations of management, the expense must be justified by the results which their construction is intended to accomplish.

Artificial Fire Obstructions.-It is well known that a small, creeping surface fire is stopped or checked by a stone wall or other similar obstruction. This principle may be used in fire protection, and other types of firelines may often be dispensed with where there are such obstructions. A well-known railroad has been experimenting with a specially constructed fire-wall.

Supervision and Patrol.-A careful supervision or patrol during the dry season is one of the most important measures in organized forest protection. Its purposes 
are: (1) To prevent fires from starting; (2) to detect fires as soon as possible after they start; (3) to fight fires.

The mere fact that a tract is carefully watched makes it safer, because campers, hunters, and others crossing it are less careless on that account. By an efficient oversight most of the unnecessary fires can be prevented, such as those arising from carelessness in clearing land, leaving camp-fires, and smoking; from improperly equipped sawmills, locomotives, donkey engines, etc.

One of the fundamental principles in fire protection is to detect and attack fires in their incipiency. In an unwatched forest a fire may burn for a long time and gain great headway before being discovered. In a forest under proper protection there is some one man or corps of men responsible for detecting fires and for attacking them before they have time to do much damage or to develop beyond control.

Aids to Supervision and Patrol. - Under the head of aids to supervision and patrol are included: (1) The posting of fire warnings; (2) lookout stations; (3) telephone systems; (4) signal systems.

The Posting of Fire Notices.-One of the first steps in organizing protection in a forest is to post it with fire warnings. These notices emphatically warn against carelessness in the use of fire, and often give instructions how to construct camp-fires and how to extinguish them when breaking camp. They usually contain also the prescribed penalties for infringement of the fire-laws. Notices are posted at frequent intervals along roads and 
trails, at camping grounds, near permanent camps and settlements, and in many cases along the boundaries of tracts. On private tracts the fire warning is combined with the trespass notice.

In the National Forests fire-warning notices are printed in English, Italian, French, and Spanish. Notices printed in Italian are posted where Italians are employed in railroad construction or section work. Spanish notices are used in New Mexico, southern Arizona, or other localities where there are many Spanish-speaking people. Near the northern boundary French notices are sometimes used. Beyond question many forest fires have been prevented by these warnings.

In the case of a forest owned by a non-resident it is a good plan to have on the notice the name of the responsible local agent, as well as the owner's name. 'This lends emphasis to the fact that there is a local man who is looking after the property.

Lookout Stations.-Lookout stations include watch towers, inountain lookouts, and other elevated stations used for overlooking tracts and watching for fires. On small tracts they consist usually of some simple structure which enables the person responsible for the property to overlook the forest to see if there are any fires, and, in calse he sees smoke, to locate the fire. Sometimes an arrangement on the roof of the house or barn serves as a watch-tower, or a lookout may be built in a tall tree, or it may be necessary to build a rough tower to see over the tree-tops. In a rugged country it is usually possible to 


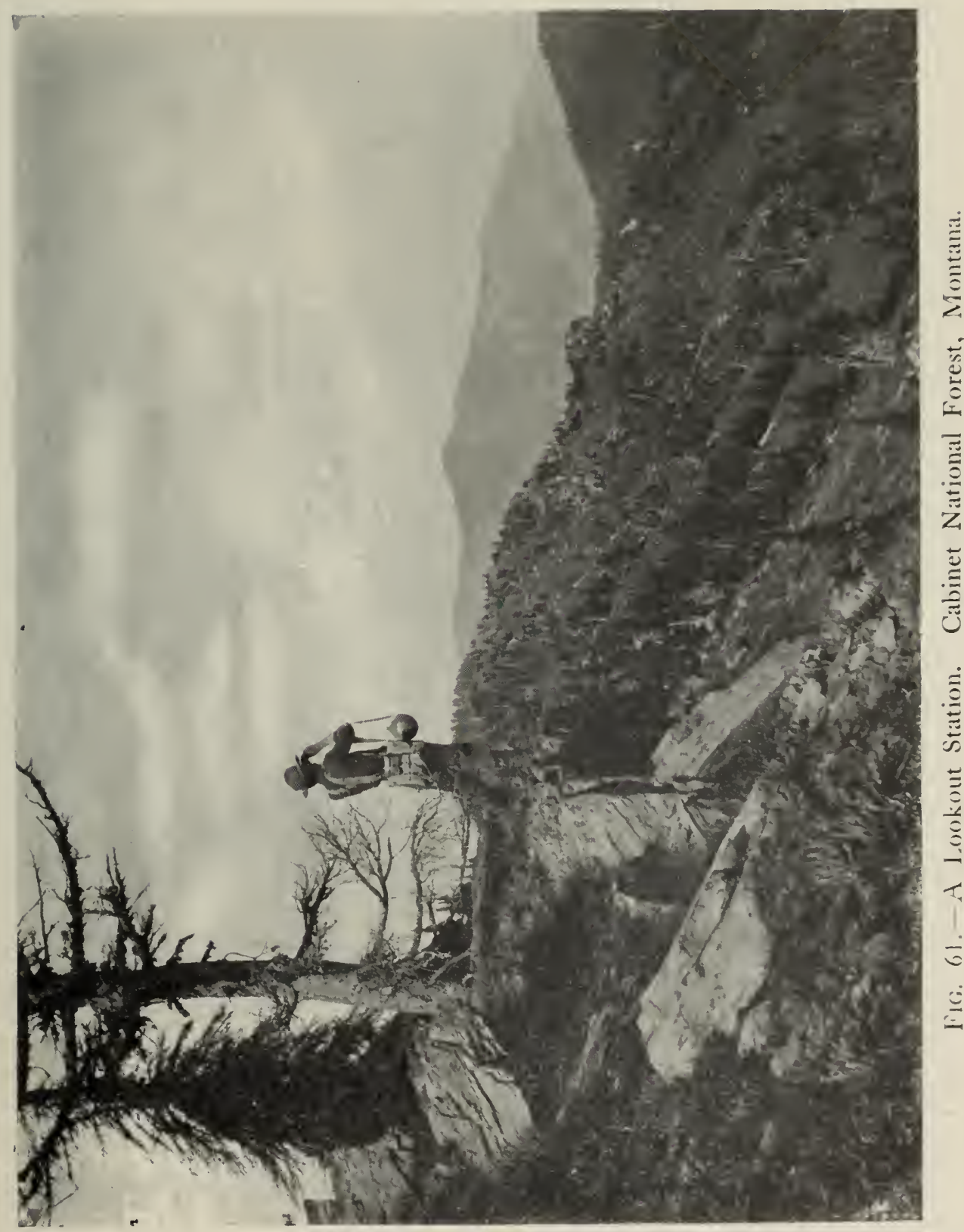


find some convenient peak from which a large area can be overlooked.

In the organization of large tracts in mountain regions special lookout stations are sometimes provided. These are located at high points from which a large area of the forest can be seen. A man is kept constantly at each station during the dry season. The various stations should be in communication by telephone or telegraph, or by some system of signals. Each is provided with range-finders or other equipment, by means of which any fires that may occur can be precisely located. They are also in communication with the forest ranger or superintendent at headquarters, so that a force of men may be called at once to the fire and put it out. In extensive mountain regions these lookout stations constitute an important part of organized fire supervision. They have been successfully operated in the National Forests.

Telephone System.-One of the great difficulties in extensive forest districts is to secure the necessary help in fighting fires. 'The telephone is the greatest aid in fire patrol. It enables the man who discovers a fire to call for help and to give directions as to the number of men and the equipment needed. By the use of the telephone on the National Forests millions of dollars have doubtless already been saved. The Forest Service has since 1905 built over 9,000 miles of telephone line, and it is extending the lines as rapidly as Congress furnishes the funds for the work.

Signal Systems. - When there is no telephone system 
and a regular lookout station is not feasible, a special system is used for signaling for help in fighting a fire. Some prominent peak is selected, from which, in case of fire, the location and size of the fire and the required help are signaled by a prearranged code. There are various systems of signals in use. The fire signal is one of the oldest methods. At a time when the signals are not needed small piles of wood, brush, or other inflammable material are gathered and placed in position at about equal distances, usually about 50 to 100 feet apart, ready for firing on short notice. The number of fires burning at the same time conveys the information required. Thus, one fire might mean that a forest fire is burning in a certain locality on one side of the mountain; two, in another locality; three, in anotner; and so on.

Another system that is sometimes employed is the smoke signal. This was once very commonly used by the Indians in ccmmunicating with each other from one distant peak to another. A small fire is built, and after it gets under good headway, damp moss or earth is used to deaden it and develop a heavy smoke. A blanket or other covering is thrown over the top of it to smother the smoke down for a few moments. The blanket is then raised, and a dense puff of smoke is released. The blanket is again thrown over the fire to check the smoke for a moment, then it is again removed, and another puff of smoke ascends. This system also requires a prearranged code. The smoke signal may be used in the same manner as the fire signal, by causing 
two or three separated columns of smoke from dampened fires to be steadily rising at the same time. This system of signaling may be used to good advantage on a still day for communicating long distances. The separated fire signal on top of prominent peaks can be used in the night as weil as in the day.

The heliograph is an instrument which may be used for flashing signals from the lookout stations. 'The Forest Service has recently conducted successful experiments with this instrument.

In some cases it might be possible to use flags and the code of the Army Signal Corps. Near settlements the fire bell, gong, or whistle is commonly used to bring together the men for fighting fires.

The organization of an efficient patrol varies under the following conditions: (1) Size of tract; (2) character of the forest; (3) condition of the forest with reference to the amount of inflammable material; ( 4 ) difficulties of communication; (5) difficulties of securing help in fighting fires; (6) the topography with reference to the amount of territory which can be overlooked; 7 special sources of fire, such as the presence of a railroad; (8) local sentiment.

Supervision of Small Tracts.-The supervision of a woodlot attached to a farm is exceedingly simple. If a farmer himself uses proper care in starting fires, in clearing out his roads, in disposing of brush, and in keeping a careful watch for fires, his woodlot is comparatively safe. Many woodlot fires are caused by the 
owner's own carelessness in clearing land, destroying brush, burning meadows, etc. 'The fact that the owner is careful in the matter of fires becomes known very quickly in the neighborhood, and that fact in itself is a great protection. It is not necessary for a farmer to patrol his woodlot at regular intervals, as would be necessary in the case of a large tract.

Many fires start on the property of non-resident owners, who themselves are unable to supervise it on the ground. Non-residents may secure protection by an arrangement with some farmer living near the forest. The usual course is to pay a small retaining fee for general supervision, with the understanding that the farmer goes over the tract every few days, thus giving the impression of constant patrol. In case fire starts, the agent has the responsibility of repairing to the fire and putting it out, and employing such help as is necessary. There is no reason why this plan should not provide adequate protection for tracts of from 100 to 500 acres at an annual cost of from 3 to 5 cents an acre.

One of the most essential measures in the protection of small tracts is to secure the cooperation of the owners of all the neighboring tracts in watching for fires and in mutual assistance in extinguishing fires, no matter-on whose land they start.

Supervision of Large Tracts. - In the protection of large tracts from fire a special organization for patrol is necessary. This organization can best be combined with that required for the management of the tract. In exery 
forest that is being developed there is necessary a certain force to supervise any work such as logging, the construction of roads, the protection of game, the prevention of trespass, etc. This organization is best illustrated in the National Forests. There is a permanent corps of trained rangers who live on the Forest, each in charge of a specified area. These men have executive charge of all the work in the woods. During the dry season this force may be supplemented by temporary forest guards for special fire patrol. Each guard is assigned to a specified part of the Forest, which he is required to patrol regularly; he prevents the start of fires as far as possible and watches for any fires which may start within his range. It has already been explained that one of the purposes of the construction of trails through the Forests is to enable the constant patrol and access to fires which may be started. The guards ride or walk over these trails under a systematic plan. There is usually a regular beat over which the guard travels at regular intervals. In some tracts it is possible to go over the beat once a day; in others it requires a much longer period. When not on patrol the guards are engaged in other general work on the Forest.

In the plan of patrol the guards keep in close touch with each other and with the ranger in charge of the whole work, in order that they may communicate in case of fire by signal from lookout stations, by telephone, or any other method of communication that may be established in the Forest. 
Most of the National Forests of the West are in rugged mountain regions, with comparatively few roads and trails. The guards usually travel on horseback over certain roads or trails, keeping track of the people who enter the Forest, and giving them special warning regarding carelessness with fire. In this way each person entering the Forest is impressed with the fact that his movements are watched, and the result is that he is more careful with camp-fires, smoking, etc.

On large tracts patrol is concentrated at critical points. The guards spend the most time where there is the greatest travel, frequently inspecting camp-grounds, sawmills, and other points where fires are most likely to start.

In some instances the actual patrol over trails is more or less dispensed with, and men are kept continuously at lookout stations, from which a large area can be overlooked. In case of fire, signals are sent to other lookout stations and to headquarters, with the necessary instructions regarding the location of the fire, the number of men needed to fight it, etc.

It is impossible to give a specific rule regarding the number of men required to protect tracts of different sizes. There is no question that the National Forests are very much undermanned. In some cases a single man has the responsibility of protecting more than 100,000 acres. This area is much too large even under the most favorable conditions. Even with proper facilities for communication, the fire protection force on the National Forests should be quadrupled. Very good 
results would be obtained if there were, during the dry season, one guard for each 15,000 or 20,000 acres. This will follow naturally as the increased receipts from the Forests justify a more intensive management.

In flat regions more men are required for patrol than in a rugged country, where large areas may be overlooked from prominent elevations. It has been the general view that in flat regions like the Lake States and the plateau portions of Maine and the Adirondacks there should be at least one guard for each 10,000 acres.

The required force of guards is governed by the risk of fire and the value of the property to be protected. In the case of a forest of very great value there is necessarily a correspondingly greater justification for expenditure in fire protection, just as one takes out fire insurance in proportion to the value of his property. As the value of our forests increases, there will be a correspondingly greater amount of money spent on protection. This principle is illustrated in Europe, where the forests are very valuable and where frequently there is one forest guard for each 1,000 acres. (Prussia, one for 1,700 acres; Baden, one for 750 acres.)

Patrol Along Rallroads. - Railroads in many cases are the most prolific source of fires. In some sections over 50 per cent. of the fires are from the sparks from locomotives. While most of these fires could be prevented if the railroads used proper appliances on the locomotives for arresting the sparks, nevertheless, in many cases, it is probably impossible to prevent sparks 


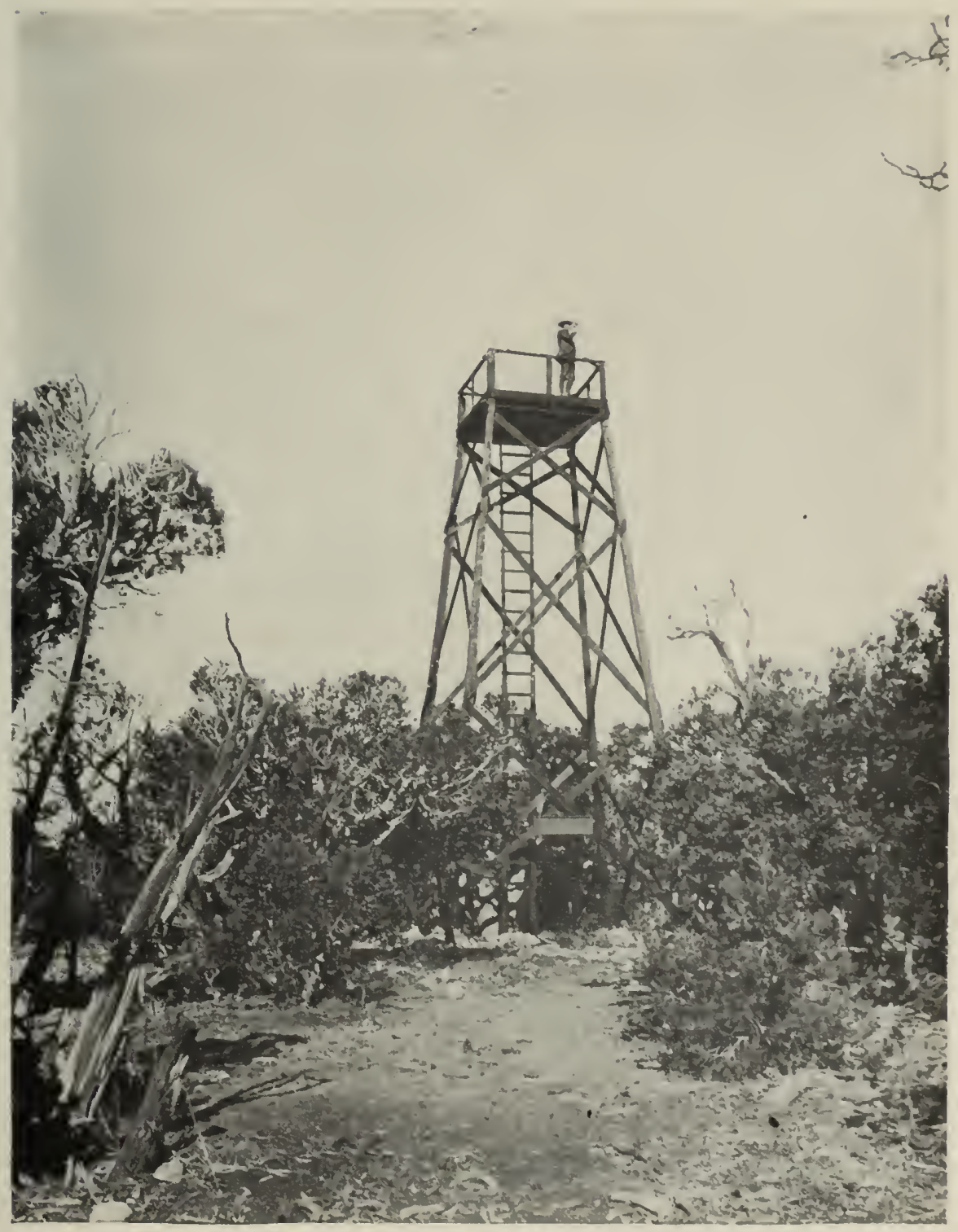

FIg. 62.-A Watch Tower in the Tusayan National Forest, Arizona. 
which will start fires in very dry weather. It is, therefore, necessary to supplement the use of spark-arresters by patrolling the right of way.

The most effective method of patrol is to follow every train with a speeder equipped with mattocks, shorels, pails, and other necessary equipment for fighting fires. A fire started by a spark from a locomotive may then be put out before it has an opportunity to gain any considerable headway or to do much damage.

It is not always practicable to follow every train over a long distance, and it may happen that there is danger from the sparks only at steep grades. In that event the patrol is concentrated at the dangerous points.

The plan of following every train by patrolmen may be practicable where the distance traversed by the road is not great, but it would not be feasible for a great mileage. Thus, for example, the problem of patrol is being considered by certain large railroads with the view of applying it over the entire system, wherever there is danger from fires. The purpose is to save the annual expense of fire damages. One system in the Northeast, covering not over 2,000 miles, is said to have an annual expense of over $\$ 50,000$ for forest-fire claims. It is probable that the most practical method of supervision of the right of way would be through the organization of the section men, with a special patrol at certain grades where the danger from fires is particularly great. There is no reason why the section men, if provided with proper speeders and other equipment, should not be trained to 
repair at once to fires which may start along the right of way and put them out, with a comparatively small loss of time.

In Mimnesota the law requires that railroad companies must put on patrolmen to patrol their tracks. 'The forest commissioner may compel the companies to put on as many as one man to each mile of track.

\section{The Methods of Fighting Fires}

The principles of fighting forest fires are essentially the same as those recognized in fighting fires in cities. The following are of first importance: (1) Quick arrival at the fire; (2) an adequate force; (3) proper equipment; (4) a thorough organization of the fighting crew, and (5) skill in attacking and fighting fires.

Quick Access to Fires.-Quick access to fires is accomplished through the work of supervision and patrol in discovering fires before they have gained much headway, and by a well-developed system of communication through the forest by roads and trails.

An Adequate Force of Fighters. - A small fire may be put out by one man, but in extensive forests several hours may pass before the fire can be reached. It is important to secure an adequate force of men and to get them to the fire quickly. In a well-organized system of patrol the guard who discovers a fire communicates quickly to other guards and to headquarters by telephone, signal, or other means, and indicates the number of men he needs. It is essential that there be definite arrange- 
ments for securing a force of men in case of fire. This may be accomplished by cooperation with lumber or sawmill operators who employ forces of men, and through cooperation with local residents, or, in case of small tracts, through the cooperation of neighboring owners, each of whom agrees to assist his neighbor in case of fires. In some States there is a system of fire wardens. In case of fire, the fire warden may call upon residents to assist in extinguishing it. They are required by law to repair to the fire in case of call, and there is a small statutory compensation for services. In case of extensive forests cooperative arrangements should be made with every resident within the forest and with every user of the forest to assist in fighting fires. In most cases where lumbering is going on the men who are employed in the logging operations, at sawmills, in road construction, etc., will furnish a large force on occasion. Through an efficient system of cooperation it is possible to secure quickly a large force of fighters, and through this same system all the residents soon take an active interest in preventing fires from starting.

The cooperative fire protective associations in the Northwest, following the example of the Forest Service, have organized systems of patrol and are doing highly important work in suppressing forest fires in the white pine regions of Idaho and Montana, and the fir forests of Washington. 'These associations now include practically all of the large timber owners in the Northwest, and many small owners as well. 'The expense of maintaining 
a patrol during the dry season, of fighting fires, and of building trails and telephone lines to assist in fire fighting, is apportioned among the members of the association on an acreage basis.

Proper Equipment for Fighting Fires.-Just as in a city the efficiency of a fire service depends in large part on the equipment, so also in forest work it is essential that fire fighters be furnished with the proper tools and other equipment. The implements needed for fighting fires differ under different conditions. Wherever dirt can be used the men should be provided with long-handled shovels. If water is available, buckets should be provided, and, where possible, bucket pumps. Under most conditions it is desirable to have mattocks and iron rakes, and there should always be axes to aid in clearing brush or cutting through down timber and old tops.

These implements should be kept in a convenient place for use in fighting fires. Proper organization for fire protection includes an adequate equipment for the fire-fighting force. No matter how numerous or skilled the crew, the men are helpless without proper implements. In the protection of woodlots in settled regions every farmer who repairs to a fire usually takes his own shovel, rake, ax, or other implement. In the more remote forests under organized protection, the implements are usually provided by the ranger. A very good plan is to have caches at convenient points on the trails or at the lookout stations, containing fire-fighting tools. In some cases in the mountain regions tools are kept in a 
special pack outfit ready to be thrown upon horses and taken at once to the fire. Such special outfits usually inciude shovels, collapsible pails, axes, mattocks, ropes, and in some cases fire-extinguishers, and a small quantity of provisions to enable fire fighters to camp out overnight if necessary. Where there are good roads, as in the woodlot regions, special fire wagons have been used to advantage. These consist of an ordinary wagon of the Concord type, furnished with a complete equipment of tools, bucket-pumps, fire-extinguishers, water-tanks, or barrels, etc. The author has used on his own tract in Pennsylvania a crude fire wagon consisting of a twoseated buckboard provided with a special galvanized-iron water-tank with a capacity of about $1 \frac{1}{2}$ barrels. The wagon is also equipped with two fire-extinguishers, two bucket-pumps, one-half dozen buckets, shovels, rakes, axes, and such other tools as are needed in fighting fires.

Organization of the Fighting Crew.-It is important that there be in charge of the fighting crew some one in authority to thoroughly organize the work. A small crew, well organized, can do much more effective work than a loosely organized large crew. One of the advantages of the fire-warden system adopted in a number of States is that the warden has authority not only to impress men to fight fire but to direct their work.

The efficiency of the fire-fighting crew depends very largely on their skill and experience, and particularly on the skill and experience of the man directing the work. It is not only a question of knowledge of how to assign 
each man where his work will be most effective, but judgment must be exercised in determining the general method of attack. The character of the fire, the character of the forest, the condition of the atmosphere, the strength and direction of the wind, the rapidity with which the fire is running, and many other points have to be taken into consideration.

Methods of Fighting Surface Fires.-Small surface fires may often be beaten out. 'This is possible when the fire is burning chiefly in a dry leaf litter or short grass. Where there are tops or piles of dry brush, or the fire is burning through thick brush or undergrowth, beating is very difficult.

There are various devices for beating. A blanket, coat, or riding slicker is often used. A gunny-sack or piece of canvas is a good implement for beating, particularly if it can be wet from time to time. A handful of green brush serves also very well for a beating device. In beating out a fire, one strikes the fire with a sideways sweep, driving the flames and burning material back upon the burned ground. A direct stroke scatters the fire.

The best way to extinguish running surface fires is to throw sand upon the flames. This method is, of course, practicable only when the soil is fairly clear of rocks and loose enough for ready digging. In the plains of the Atlantic Coast, for example, the sand is so loose that it can be dug up and thrown on a fire almost anywhere. The fighting crews are equipped with long-handled shovels, and the sand is thrown along the line of fire. 
When the fire is running in the open woods, in pine needles, a single shovelful of sand, properly thrown, will extinguish over 10 feet of fire.

Loose loam is also very good, but not so effective as sand. Heavy soil which clods is difficult to manipulate. Frequently sand or loose loam can be dug up in spots, but it is too stony to secure it all along the line of fire. The fighters must then supplement the use of sand or earth with beating or other methods.

Where, on account of the accumulated débris, the flames are intermittently too severe for beating, water is used if available. Water usually has to be brought from some distance; it must therefore be used very economically. The best way is to deaden the flames by a little water, and then beat them out with a gunny-sack or other device. Experience has shown that water may be most effectively applied by a hand-spray pump. This pump throws a stream 20 or 30 feet and makes it possible to apply the water exactly where it is most needed. The pump can be purchased at prices varying from $\$ 3$ to $\$ 4.50$. They are extensively used by farmers in the Northeast. Collapsible pails are excellent for carrying water, because of their lightness and compactness. Ordinary metal water pails are commonly used by farmers, and are much cheaper than collapsible pails.

When water must be brought over mountain trails special water sacks are used, which can be slung on a pack saddle. Water kegs, adapted to pack horses, have been tried in Pennsylvania. Where there are passable 
roads water is hauled in barrels or in specially constructed tanks.

Patent fire-extinguishers have also been used in fighting fires. These throw a stream of water from 15 to 20 feet. The stream is chemically charged, so that it is very effective in putting out flames which would be little affected by ordinary water. In practise a crew is provided with several extinguishers, a supply of water, and extra chemical charges. As soon as an extinguisher is emptied it is reloaded, so that there may be a continuous play along the line of fire. In case of an ordinary fire running through grass or leaf litter, one extinguisher will put out 200 feet of flame.

A very good method in fighting running surface fires, where there is not much slash, is to make a narrow trace in front of the fire by raking to one side the leaves and other litter. As soon as the fire reaches the trace it is checked and readily beaten out. Sometimes, on level land and in open woods, a furrow is plowed as an emergency fire-line. (Fig. 56.) This same principle may be used to check fires burning through young growth and brush, where it is difficult to get at the flames. A narrow lane is cut through the brush ahead of the fire. This gives a space where the crew can work without hindrance. As soon as the fire approaches, it is attacked by all the crew with the various fighting devices with which they may be provided.

Sometimes the front of the fire is so fierce that it is impossible to meet it directly. (One method under such 
circumstances is to direct the course of the fire. The attack is made on the sides near the front, separating the forward portion of the fire from the main wings. A part of the crew attacks the forward part and others run down

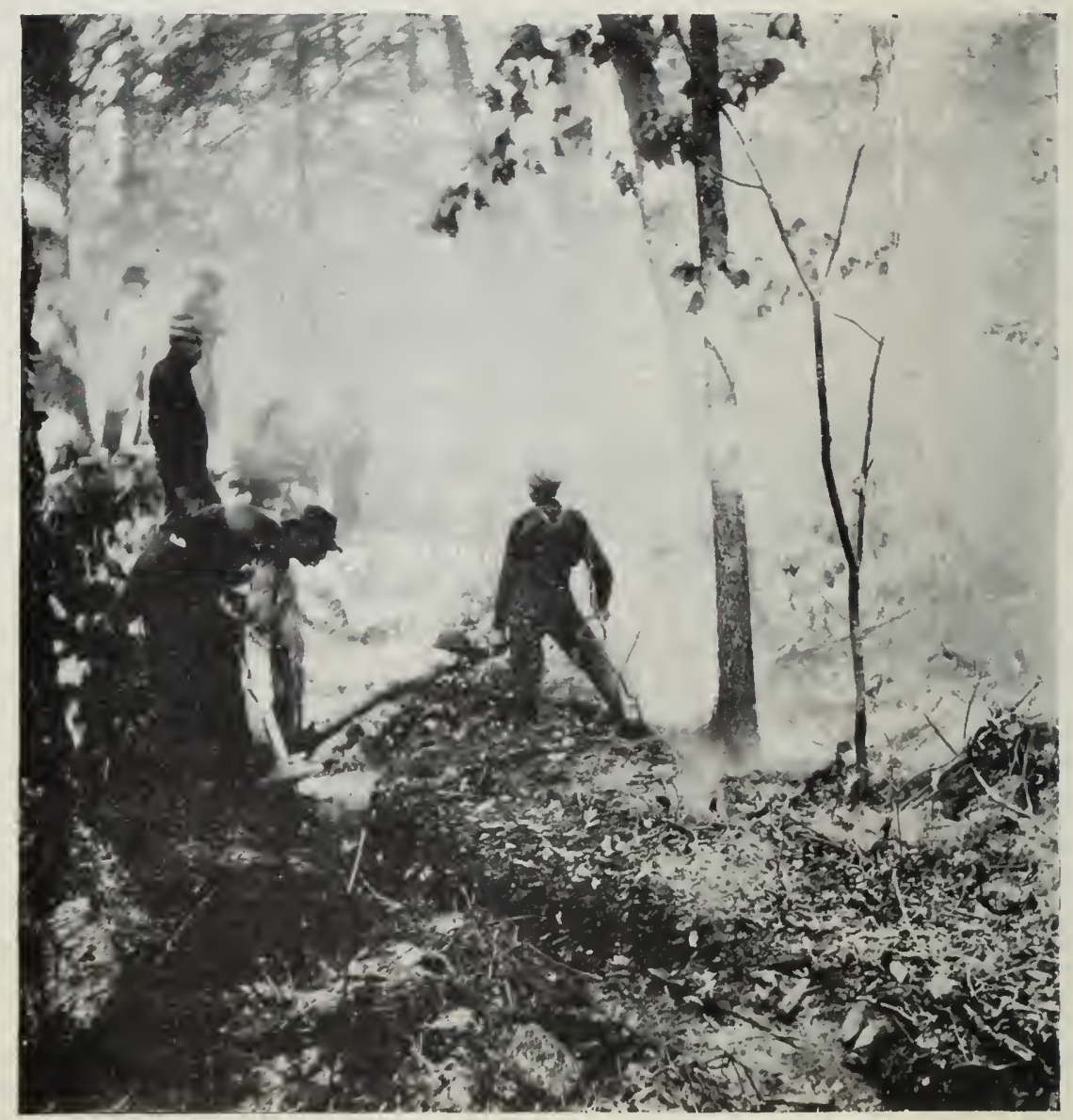

FIG. 63. - Fighting a Ground Fire by Trenching.

and extinguish the wings. 'The front of the fire, attacked from the sides, is forced gradually and constantly into a narrower path. Usually the front can be directed toward some cleared space, road, pond, stream, swamp, or fireline, when it will be checked enough to admit of a direct 
front attack. Sometimes, by this plan, the front may be rapidly narrowed by working from the sides, until it is at last entirely extinguished. The plan of giving direction to the course of the fire has often been successfully carried out when the fighting crew is too small for a direct attack.

Methods of Fighting Ground Fires.-Ground fires, burning in the deep layer of organic matter, are exceedingly difficult to extinguish. If the layer of vegetable matter is not very deep, it is sometimes possible to put out the flames by water or sand. If the layer is deep, trenching is the only practical method of stopping the progress of the fire. In using this method of fighting ground fires, one judges the rapidity with which the fire is burning and then, at a proper distance away, digs a trench through the vegetable layer down to the mineral soil, using axes, mattocks, and shovels, as the particular case may require. Such a trench, which has a width at the bottom of 1 foot, will enable the fighters to stop an ordinary ground fire, especially if the work can be supplemented by the use of water or sand at the trench.

Methods of Fighting Crown Fires.-Crown fires are always accompanied by surface fires. Crown fires stop when there are no longer inflammable crowns through which the fire will run, or when there is no longer any material on the ground to carry the surface fire. An ordinary crown fire will jump a wide fire-line, and many fires have been known to cross wide rivers, almost without check. In the mountains, a crown fire rumning up a slope is almost impossible to check. 
Back-Firing.-On level ground it is possible to stop crown fires by back-firing, when the conditions are such as to make back-firing possible at all. Thus in the pine forests of the Atlantic Coast crown fires are frequently checked by back-firing. 'The back-fire burns off the surface material, and thus in itself acts as a check to the crown fire, and, if the area burned by the back-fire is large enough, will stop it in this way. At other times, when the back-fire has been successfully started and is well under way, eating back against the wind, it is caught by the hot volume of air generated by the heat of the crown fire. The flames are then turned quickly toward the crown fire, and the meeting of the two lines of flame stops the advance of the fire.

When fires gain such headway that it is impossible to stop them by direct attack, no matter how numerous and efficient the crew or complete the equipment for fighting, back-firing becomes the only means of stopping the fire. It should, however, be used only when it is absolutely necessary. One of the commonest mistakes in fighting fires is to overestimate the rapidity of the fire and the difficulty of putting it out. A forest fire is always a frightening spectacle, particularly if it is sweeping in the direction of one's own property. Men often become excited and start back-fires when it is entirely unnecessary. Back-firing necessarily involves deliberately burning over property. When this belongs to another person and one's own forest seems to be in danger, there is a great temptation to sacrifice it. 
A second principle in back-firing is to burn over as small an areal as possible. 'The counter-fires are, therefore, set only as far ahead of the fire as is necessary to make them effective. Very often, however, there is only one point from which a back-fire can safely be started, so that the fighters have no choice.

If it is found that a back-fire is necessary, a favorable point is selected directly in front of the fire, from which to set the new fire. This must be a point where it is safe to start a back-fire, such as a road, fire-line, stream, or swamp. The leaves are ignited at points 5 feet to a rod apart for a distance not greater than the estimated width of the head of the fire. These small fires gradually meet and form a continuous line, eating back against the wind.

A part of the crew is stationed across the road, or other break from which the back-fire is started, and put out at once the small fires which may result from the sparks blown over from the back-fire.

The meeting of the two fires stops at once the head of the main fire. It is usually possible then to attack the wings with the ordinary methods of fighting. It is necessary to attack the wings at once, particularly if there is a strong wind, for otherwise each wing of the old fire would soon form an independent fire with a well-developed head. It is necessary, also, that a number of men be stationed where the original fire and the back-fire meet in order to extinguish smouldering fires in tops, logs, and other débris. 
Patrol After a Fire is Extinguished.-A fire is never out until the last spark is extinguished. Often a log or snag will smolder unnoticed after the flames have apparently been conquered, only to break out afresh with a rising wind. After the fire-fighting crew has left the ground it is always well to assign at least one man to patrol the edges of the burned area until it is certain that the fire is entirely out. This may not be for several days. 


\section{CHAPTER VIII}

\section{PROTECTION FROM OTHER INJURIOUS AGENCIES}

\section{Protection from Insects}

Next to fire the greatest damage to forests is done by insects. Sometimes the depredation by insects manifests itself in a wide-spread invasion in which a large percentage of the most valuable trees are killed over hundreds of square miles. Such outbreaks have unquestionably occurred from time immemorial. It is probable that in some cases insects are responsible for the practical destruction of whole forests. In recent years there have been numerous great invasions in different forest regions of the country, causing damage to the extent of millions of dollars. More often the work of insects is less conspicuous, and for this reason the importance of protecting forests from this source of damage has not been fully appreciated by the public, nor even by practising foreste. There are at all times throughout every forest hordes of insects at work on the trees. Some of these are relatively harmless, but there are nearly always some injurious species at work. It is very common to find trees dying here and there, individually or in groups, as a result of the work of insects. The aggregate loss from these scattered injuries is enormous. 
The subject of forest entomology is, therefore, of great importance in the practical handling of woodlands. It is just as essential to protect the forests from insect invasions as from fire. The protective measures which must be used depend entirely upon the nature of the attack, and hence upon the species of insect doing the work. It is necessary to understand the life history of the different insects and the manner in which they work under different conditions, in order to be able to prescribe measures for their control. The list of injurious insects is very large, and it would be entirely beyond the scope of this book to include an adequate description even of the more important genera. This information must be obtained from special works on forest insects. The purpose here is to call attention to the importance of the subject and to explain some of the general principles of the problem. Information regarding insects attacking the forests of the United States may be obtained from the publications of the Bureau of Entomology of the U. S. Department of Agriculture, especially the works of Dr. A. D. Hopkins, who has taken the lead in developing Forest Entomology in this country.

Death of Trees.-The most extensive damage is done by bark-beetles, which burrow in the inner bark of the trunk and girdle the trees. Coniferous forests in particular suffer from the attacks of various bark-beetles. It is very common in the coniferous forests to see here and there trees or groups of trees turning red and dying. A close examination usually reveals small perforations in 
the bark, numerous pitch tubes, and fine boring-dust at the base of the tree, all of them indications of the work of bark-beetles.

It was a species of bark-beetle that caused the socalled spruce blight which has appeared in the red spruce forests of the Northeast from time to time during the last century, and which in certain sections caused the death of most of the mature spruce. It was another species of bark-beetle which has been devastating the forests of the Black Hills in South Dakota.

Still another species of bark-beetle destroys annually an untold number of trees in the pine forests of the Southeast. To-day this insect constitutes one of the greatest menaces of the pine timber of the South, unless provision is made to prevent the development of an invasion.

One of the most serious present outbreaks is located in eastern Oregon in the Wallowa and Whitman National Forests. Previous to 1903 only a few isolated areas of less than a section each were infested. There was no check to the spread of the insects, and in 1910 the invilsion has spread over about one million acres, having already killed 35 per cent of the lodge-pole pine in addition to a large amount of yellow pine. Unless the invasion is checked the damage will amount to hundreds of thousands of dollars.

Extensive injury is also done by defoliating insects. When a tree is defoliated only once, it is not necessarily. killed. If it is thrifty, it may produce leaves again the 
following year. It is, however, weakened, and continued defoliations will ultimately kill it. The most conspicuous example of an invasion of defoliating insects is the present outbreak of the gipsy and brown tail moths in New England. Extensive wood-lots have been entirely killed. 'The States, the Government, and the various communities are spending hundreds of thousands of dollars to check the depredations.

Another illustration of the damage by defoliating insects is seen in the outbreak of the larch-worm, which has occurred in the Northeastern States within recent years. In many sections 50 to 100 per cent. of the mature larch has been killed by repeated defoliations of the trees.

Injury to Trees.-Certain classes of insects attack the wood of living trees, but do not kill them. These insects bore into the interior of the trees and seriously affect the value of the lumber cut from them, often rendering it useless.

The damage done by the chestnut timber worm is well known. In some sections practically every mature chestnut is more or less affected. Dr. Hopkins estimates that the reduction in value of the lumber of chestnut amounts to about 30 per cent on account of the attacks of this insect.

The locust suffers so constantly from the attacks of the locust borer that foresters hesitate to propagate the tree at all. Another example of damage by borers is seen in the defects of white and rock oak, beech, yellow poplar, and other hardwoods, resulting from the work of 
one of the ambrosia beetles. The injury in reducing the value of the lumber may amount in many localities to from 25 to 75 per cent.

Another class of injury is seen in the work of the white pine weevil. This insect repeatedly attacks the leading shoots of young white pine, causing a distorted growth. The trees develop a crooked stem, and their value is consequently very much reduced.

Dying and dead trees are especially subject to attacks by insects. The loss caused by them is principally in the reduction in value of the product of the trees. $\mathrm{In}$ some cases insects attack and kill trees weakened by fire or some other cause, which otherwise might have recovered and lived.

There is a very close relation between forest fires and damage by insects. It is believed that in some cases when the past destruction of forests has been attributed to fire, it has been primarily the work of insects. The timber was first killed by the insects. The dead trees furnished fuel for the later fires, which also killed all young growth and retarded reproduction. The presence of the dead trees which had been killed by insects, always increases the menace from fire, not only by the addeci amount of inflammable material, but also because of the chance of their being struck by lightning and starting at forest fire.

When a forest has been burned, the final death of the trees is often due to attacks by insects. The presence of fire-scorched trees may cause al rapid multiplication of 
insects injurious to trees. Ordinarily the effect is to extend an invasion rather than to be the primary cause of an outbreak.

There is also a close relation between insects and fungous diseases affecting trees. The burrows in the bark and wood often afford entrance for the fungi, and hasten the decay of the tree. 'Then, too, trees weakened by disease may be attacked the more readily by certain insects.

Injury to Reproduction.-Insects affect the reproduction of the forest chiefly by attacking seed. Undoubtedly natural reproduction is often retarded because a large proportion of the seed is destroyed by insects. Young seedlings are also subject to attack by certain insects.

Control of Insects. - In the systematic control of forest insects, provision must be made, first, for prevention of a possible outbreak, and, second, for attacking an invasion.

The principles are comparable to those used in fighting fires. In fire protection the first aim is to reduce the causes of fires and to prevent them from being started. In the same way in insect control, it is essential to prevent the multiplication of insects to a point where an invasion may be developed. If there is an invasion, then very drastic measures must be used to stamp it out, just as in the case of a dangerous forest fire.

The enemies of insects are very numerous. Birds, parasitic insects, parasitic fungi, and unfavorable seasons 
are constantly contributing to check the multiplication of insects. Very frequently, however, there is a combination of favorable conditions resulting in the rapid development of a given species of insect to a point where the natural enemies can no longer keep them in check, and an invasion is the result.

In preventive control work, it is necessary to watch the forest constantly for any indications of the spread of an injurious insect which may cause an invasion. Where the markets for wood and timber permit intensive silviculture, all trees found to be infested are promptly removed. The forest is kept clear of logs, tops, and other slashings, not only to reduce the danger from fire, but also to remove breeding-places for insects. In this way the loss by desultory attacks of insects is reduced to a minimum, and the chance for an outbreak is eliminated.

Unfortunately the conditions in most of our forests do not permit intensive forest management. In the extensive forests where forestry has not advanced much beyond the stage of mere protection, the first aim is not to attempt to prevent the entire loss caused by death of an occasional tree or group of trees, but to prevent a damaging invasion. Even under our present conditions it is entirely practicable to prevent large outbreaks of insects. It is necessary to keep careful watch of the forest for any general large development of insect work. As soon as it is apparent that there is danger of an invasion, it is necessary to apply immediately remedial measures, even if it is necessary to incur considerable expense. 
In attacking an insect invasion the attempt is not made to destroy all the insects. That would be impracticable, and fortunately it is not necessary. A destruction of a part of the insects checks their further multiplication, scatters the energy of the invasion, and subjects the remainder to check by their natural enemies. Oftentimes it is necessary to destroy only 50 to 75 per cent of the broods.

The most serious problem of insect control is in the great coniferous forests of the South and the IVest, where there is almost constantly a certain amount of damage by some species of bark beetle. As soon as there is danger of an invasion immediate steps should be taken to destroy enough of the insects to check their further multiplication. If there is a market for the timber, the trees containing the broods may be cut and removed with little or no extra expense. Frequently, however, the depredations occur in the remote forests, where there is no market for the timber, or only the largest and best trees can be sold. Under such circumstances the work of control must be largely an investment representing insurance, just as in the case of expending money to fight dangerous forest fires.

One method of destroying insects is to cut the trees down and destroy the bark on the main trunk. Another method is to peel the bark from the body of standing trees to a height of about 20 to 30 feet. If the work is done at the right season of the year it is necessary only to remove the bark, without burning it. 'This method 
was used in the attempt to control the invasion of the bark-beetle in the Black Hills. Special tools were developed for removing the bark of standing trees. IThere the trees cannot be utilized, the design is to cut or peel only such trees as are absolutely necessary to check the spread of the insects. Ordinarily it is necessary under such conditions to employ an expert, who is thoroughly familiar with the habits of the beetle, to select the trees, in order to secure the greatest possible economy in the work.

In the case of some insects, control work is conducted by the use of so-called trap-trees. Thus, in the case of insects which breed in fallen logs, tops, stumps, etc., trees may be felled here and there as traps. 'The insects are attracted to them as breeding-places. At the right season of the year the bark is removed and the broods destroyed.

Other meisures are used in the case of certain defoliating insects. At the present time drastic measures are being used to suppress the outbreak of gipsy and hrowntail moths in the Northeast. Various measures are used, including the destruction of egg masses where these can be reached, the wropping of trees with burlap or tanglefoot, and wholesale spraying with high-power spraying machines. 'This work is expensive, but it is necessiry to protect property which will inevitably be destroyed unless the insects are checked.

'The above illustrations show the general character of the work required in controlling an insect invasion. 'The! 
serve to emphasize the necessity of preventing an invasion from starting. Careful preventive measures save not only the loss of timber resulting from the work of insects, but also the expense of fighting an invasion.

\section{Protection from Fungous Diseases}

The protection of trees from attacks of parasitic fungi is of great importance in forestry. The most serious defects in timber are caused by fungi. Every woodsman is familiar with certain external indications of such defects, and is often able to distinguish trees which contain so large a proportion of unsound lumber as to render them unprofitable to cut. There is, however, an immense amount of hidden defect, resulting directly from fungous attacks. Fungous diseases enormously reduce the value of timber and the profits of lumbering. They contribute directly to the death of trees, sometimes working slowly, as in the case of those which attack the interior of the tree, and sometimes rapidly, as is illustrated by the chestnut-bark disease which may kill the trees within a few years after the first infection.

Fungous diseases are spread by minute spores which are carried by the wind, and which gain access to trees through wounds. 'Ihe wood is readily reached through fire scars, broken branches and tops, bruises, borings made by insects, etc. 'The rapid spread of injurious fungi is illustrated in many mature forests. Southern lumbermen appreciate the damage done by the so-called red rot, which in some localities affects the majority of 
the mature trees. There are many instances in the Western forests where nearly all trees of a given species are affected by disease, including not only the old but the middle-sized trees as well. An illustration is the hemlock in certain localities in northern Idaho.

It is one of the aims of forestry to maintain a forest in healthy condition, in order that the trees may be sound when ready for the market. In a forest under intensive management diseased trees are promptly removed as soon as their condition is discovered. In this way the spread of disease is checked. In operating virgin forests it is essential to make the first cuttings in those portions on which the trees are past maturity and are rapidly succumbing to disease.

The study of the diseases affecting American trees is in its infancy. It is of increasing importance to determine the facts regarding the habits of different fungi, in order to develop practical measures to protect our forests from their injurious effects.

\section{Protection Against 0ther Agencies}

Trees suffer damage from various other agencies. Mention has already been made, in the discussion of the silvicultural systems, of damage by windfall. While this cannot be altogether prevented, it can be very largely reduced through the proper location of cuttings and the application of careful silviculture.

In addition to the sources of injury already mentioned, trees are injured by certain animals, by ice, snow. 
and hail-storms, by inundation by water, by exposure to acid fumes from smelters, etc. For a full discussion of these various injuries and the methods of protection from them, the reader is referred to special works on forest protection, of which Dr. Schlich's "Manual of Forestry," Volume IV, is recommended. 


\section{INDEX}

Accretion cutting, 202, 209, 216

Adirondacks, $12,17,44,75,76$, $94,233,261,294$

Advance growth, 112, 135, 161, $165,182,190$

Age class, 28

Alder, European, 183

Alternate cleared strips, 123

Ambrosia beetles, 313

Angeles National Forest, 283

Annual burning of litter, 265

Arapahoe National Forest, 51, 66,73

Area of original forests, 1

Arizona, 254, 295

Artificial reproduction, 88,89 ,

Ash, 170 $98,103,126,135,158,175$

Ash, European, 188, 218

Aspen, 243

Associations, fire protective, 27, 225,298

Atmosphere, influence of, on fires, 230

Austria, 33, 160

Back-firing, 268, 305

Bark-beetles, 310, 316

Rasswood, 170

Beating out fires, 282, 301

Beech, 80, 312

European, 33, 98, 136, 159, 188, 191, 218

Big Horn National Forest, 139

Bigtree, 239

Birch, 80, 170, 227, 243

European, 168

Black Hills, 122, 147, 160, 222, 311,317

Blocks of trees, reserved, 36 , 103,127

Broad-cast burning, 202, 275

Brown-tail moth, 312, 317
Brush, disposal of, 246

piling, 248, 249, 251, 254, 275

Brush fire, 231

Bucket-pumps, 300

Burning brush, 249, 251, 255, 259, 275

Cabinet National Forest, 287

California, 4, 272, 274, 279, 283

Cedar, western red, 23, 86, 92, 102, 106

white, 134

Chaparral, 232, 272, 273, 279

Cherry, 243

Chestnut, 170, 177, 183, 312

Choice of species, 40

Classification of trees, 27

Cleanings, 190, 220

Clear-cutting, conditions requiring, 83

disadvantages of, 86

in strips, $36,37,97,130$

in patches, $36,37,97,135$

systems, $36,83,101$

the whole stand, 36, 95, 101

use in this country, 90

with artificial reproduction, 36

with natural reproduction, $36,89,98$

Coconino National Forest, 254

Co-dominant trees, defined, 29 , 30

Colorado, 51, 66, 73

Composite forest, 30,32

Composition of stand, 9

Connecticut, 10

Coppice, forms, 30,32

simple, 38,170

with standards, $32,38,184$, 185

Cornell tract, forestry on, 94

Cost of silviculture, 18, 24 
Crown class, 28, 29, 201

Crown fires, 226, 233

Crown-ratio, 207

Cutting cycle, 47

Cutting series, 133, 164

Damage cuttings, 190, 220, 222

Deer Lodge National Forest, 117, 130

Defoliating insects, 311

Density, of stand, 10 maintenance of, 174 reduced by fire, 240

Diameter limit, 53 application of, 56 determination of, 53,77 example of, 80

Diseases of trees, $112,220,240$, 314,318

Disposal of slash, 246

Distribution of seed, 101, 103, $106,110,120,123,129,138$, 157, 163

Dominant trees, defined, 29, 30

Drought, protection from, 87, $120,125,137,139,158,163$, 199, 262

Elm, European, 188

Erosion, 87, 125, 241

Europe, 35, 39, 70, 97, 98, 109, $121,130,136,151,158,166$, $172,175,176,185,191,208$, $217,273,280$

Even-aged form, 31

Exhaustion of supplies, 3, 22

Final cutting, 141, 145, 150, 153, 165

Financial returns, 19

Fir, balsam, 66

Douglas, 23, 86, 92, 103, 106, $116,121,125,237,239,298$

European, 136, 165, 168

white, 103, 106

Fires, causes of, 245

classification of, 226

damage by, $3,171,220,235$, 238,243

equipment for fighting, 299, 300,303

life history of, 227, 229, 230, 235
Fires, methods of fighting, 297, 301,305

prevention of, 244

protection from, 225

rapidity of, $230,231,233,234$

Fire-head, 234

Fire-lines, 246

fully-cleared, 272, 274

ground-cleared, 280

location of, 281, 282

maintenance of, 277

special, 271

tree-cleared, 278

width of, 277

Fire, notices, 285

obstructions, 284

patrol, 244, 246, 284, 290, 291, 294

protective associations, 27, 225,298

trace, 275

First cutting, 144, 149

Flury, Dr., 210

Forestry, defined, 6

Form of stand, 30

France, 210, 273

French method of thinning, 210

Front of a fire, 226, 234

Frost, $87,113,120,137,139,158$, 262

Fungi, 314, 318

Germany, 26, 33, 130, 141, 201, 208,273

Germination of seed, 108, 113, 124,159

Gipsy moth, 312, 317

Girdling hardwoods, 67

Grass fires, 231

Ground fires, 275

Groups, of seed-trees, reserved, 36,116

shelterwood cuttings in, 37 , 164

Growth, 12

Hardwoods, 95, 96, 114, 116, 170 , $178,183,191,213,312$

brush disposal, 528

thinnings in, 213

Hemlock, Eastern, 80, 103, 106, 251

Western, 23, 86, 92, 1C2, 106, 319 
Hickory, 170, 177, 181, 183

High forest, 30,31

Holding-over reserves, 177

Hornbeam, European, 168, 188, 218

Idaho, 27, 52, 105, 106, 298, 319

Improvement cuttings, 27, 64, 189 India, 273

Injuries to trees, by fire, 238 insects, 310

Insects, damage by, $3,87,125$, $199,220,238,239,240,246$, 309

control of, 314

enemies of, 314

invasions of, 309

Intensive forestry, $15,69,87,166$

Intermediate trees defined, 29, 30

Intolerant species, 63

Investments in forestry, 22, 24, 104,108

Irregular cleared strips, 128

Irregular form of stand, 31

Irregular stands, improvement of, 219

Kaniksu National Forest, 105

Larch, Eastern, 312

European, 168, 212

Western, 103, 106, 237

Liberation cuttings, 190, 194

Lightning, 245, 313

Limitation of cut, 48

Linden, 218

Location of seed-trees, 63

Locust, 170, 312

Logging conditions, influence of, 129,140

Lookout stations, 246, 286

Lopping brush, 260, 263

Maine, 5, 54, 294

Maple, 80, 116, 170, 177, 227

European, 188, 218

March of forest destruction, 2

Market conditions, influence of, $40,41,65,78,100,140$

Marking, 57

axe, 58

cost of, 59

Maryland, 197
Massachusetts, 115, 213

Maximum of production, 12

Mayr, Heinrich, 208

Measure of production, 12

Minimum of production, 13

Minnesota, effect of fire in, 11

Minnesota National Forest, 39, 109, 114

Missoula National Forest, 55, 248,259

Mixed stands, advantages of, 43 defined, 42

Montana, 55, 103, 117, 130, 248, $259,287,298$

National Forests, 15, 54, 90, 225, $255,261,270,286,288,292$

Natural pruning, 198

Natural reproduction, 88, 89, 98, $100,103,126,129,181$

New Hampshire, 115, 205

New Jersey, 134, 170

New York, 17, 74, 85, 170, 282

North Carolina, 222

Oak, 116, 170, 177, 181, 183, 227, 312

European, 98, 168, 172, 175, 188

Oregon, 23

Original forests, 1

Overwood, 187, 218

Owner, purpose of, 15

Patches, clear-cutting in, 36, 37, 97,135

Patrol, fire, 244, 246, 284, 290, 294,308

Pennsylvania, 8, 20, 193, 270, 302

Period of reproduction, 140,146 , $150,164,166,184$

Piling brush, 249, 251, 254, 275

Pine, loblolly, 116, 121, 197

lodgepole, 85, 117, 139, 229, 237,311

longleaf, 116, 121, 142, 228, $239,242,265,280,311$

pitch, 227

Scotch, 168, 206, 218

shortleaf, 222

sugar, 239

western yellow, 92, 93, 116, $121,147,160,167,311$ 
Pine, white, 26, 81, 94, 114, 121. 191, 205, 207, 223, 227, 237, 251, 261

western white, 103, 106, 237, 239, 298

Planting, 87, 89, 93, 95, 97, 98, $103,135,159,175$

Polewood coppice, 38, 178, 180

Preparation of soil, 112, 128, 159

Preparatory cuttings, 153, 163, 181

Primary cuttings, 165

Private forestry, 18, 20, 25

Progressive cleared strips, 133

Protection, from fire, 225

from insects, 309

of young growth, 68, 112, $146,150,161,174,183$

Pruning, 223

Public forestry, 15, 20

Pure stands, defined, 42

Railroad fires, 245, 281, 294

Red pine, 237, 251

Reduction of supplies, 3

Redwood, 4

Regular form of forest, 31

Removal cuttings, 151, 153, 161, $163,165,184$

Reproduction, cuttings, 27, 181

by sprouts, 179

effect of fire on, 242

effect of insects on, 314

method of, 87

Reserves in coppice, 177

Reserving, blocks of seed-trees, $36,103,105$

groups of seed-trees, 36, 116 , 117

scattered seed-trees, 36, 107 thrifty standards, 36, 118

Returns from public forests, 20

Rigid diameter limit, defects of, 60

Roads, use of, in fire protection, $244,246,268,269$

Rotation, defined, 18

Scattered seed-trees, reserved, 36, 107, 109

results from, 113

second cutting, 126, 132, 145,

$150,152,184$

system applied, 114
Second growth, 116, 179, 206, 261,270 secondary cutting, 165

Seed, destruction of, 63,314 distribution of, 103, 104, 110, $120,123,124,125,129$ germination of 113, 124

Seed-cutting, 141, 144, 147, 153, $156,163,165,181$

Seeding, 87, 89

Seed-trees, 63, 108 character of, 111 cost of, 114 location of, 108 left in groups, 116 number of, 120 selection of, 81

Selection, form, 31 stands, improvement of, 219

Selection system, 35 choice of, 72 cost of, 67 illustrated, 51, 55

intensive development of, 69 limitation of cut in, 48 origin of, 44 practical application of, 74 results of, 71 theory of, 45

Shelterwood system, 37, 137, 139, $148,160,167,181,195,217$ advantages of, 139

disadvantages of, 140

cuttings in groups, 37, 164

cuttings in strips, 37,162 cuttings, uniform, 37, 153 intensive application of, 152 primitive application of, 139, 141

progressive development of, 150

results of, 146

Signal systems, 288

Silvicultural systems, application of, 39

classification of, 34 combination of, 38 defined, 32

Silviculture, cost of, 18, 24 defined, 7 investments in, 18, 24 objects of, 8

Simple coppice, 38, 170, 171

Site, 204 
Size class, 28

Slash disposal, 246, 247, 249

Soil, drying of, $87,113,120,125$, 138

injury by fire, 240

preparation of, 112, 128

protection of, 138, 218, 262

South Dakota, 3, 122, 148, 160, 222,311

Spark arresters, 245, 246

Sprout forest, 30

Spruce, Engelmann, 51, 66

European, 33, 136, 153, 159, $165,168,191,210$

red, $74,85,95,103,261,263$, 311

Stand, defined, 30

form of, 30

origin of, 30

Standards, coppice with, 184, 185 number of, 120 reserving thrifty, 118 selection of, 119 .

State forestry, 15, 20, 27, 93, 245, 298

Stream flow, disturbance of, 5

Strips, alternate cleared, 123 clear cutting in, 36, 37, 97 irregular cleared, 128 location of, 123, 129 progressive, 132

shelterwood cuttings in, 37, 162

width of, 124, 164

Suppressed trees, defined, 29, 30

Surface fire, 226, 236

Telephone lines, use of, in fire protection, 246, 288

Thinnings, 190, 196

grade of, 202

need of, 198

practical application of, 212
Thinnings, repetition of, 208 results of, 200 theory of, 201 time to begin, 204

Tolerant species, 63

Towers, watch, 286, 295

Trace, fire, 275

Trails, use of, in fire protection, $244,246,269$

Trap-trees, 317

Trench, 275

Tulip-tree, 170, 312

Tusayan National Forest, 295

Two-storied form, 31

Two-storied system, 166, 217

Underplanting, 168, 218

Under-story, 168

Underwood, 188, 218

Uniform shelterwood cuttings, 37,153

Unregulated cutting, results of, 5

Upper-story, 168

Value of stand, 10

Virgin forest, 50

Wallowa National Forest, 311

Washington, 16, 27, 84, 86, 91, 298

Watch towers, 286, 295

Weevil, white pine, 313

Whitman National Forest, 311

Willow, 171, 172

Windfall, $56,64,81,85,104,118$, $126,128,132,140,155,163$, $204,216,319$

Wings of a fire, 226, 232, 304, 307

Woodlot, 96, 206, 270

Wyoming, 3, 139 






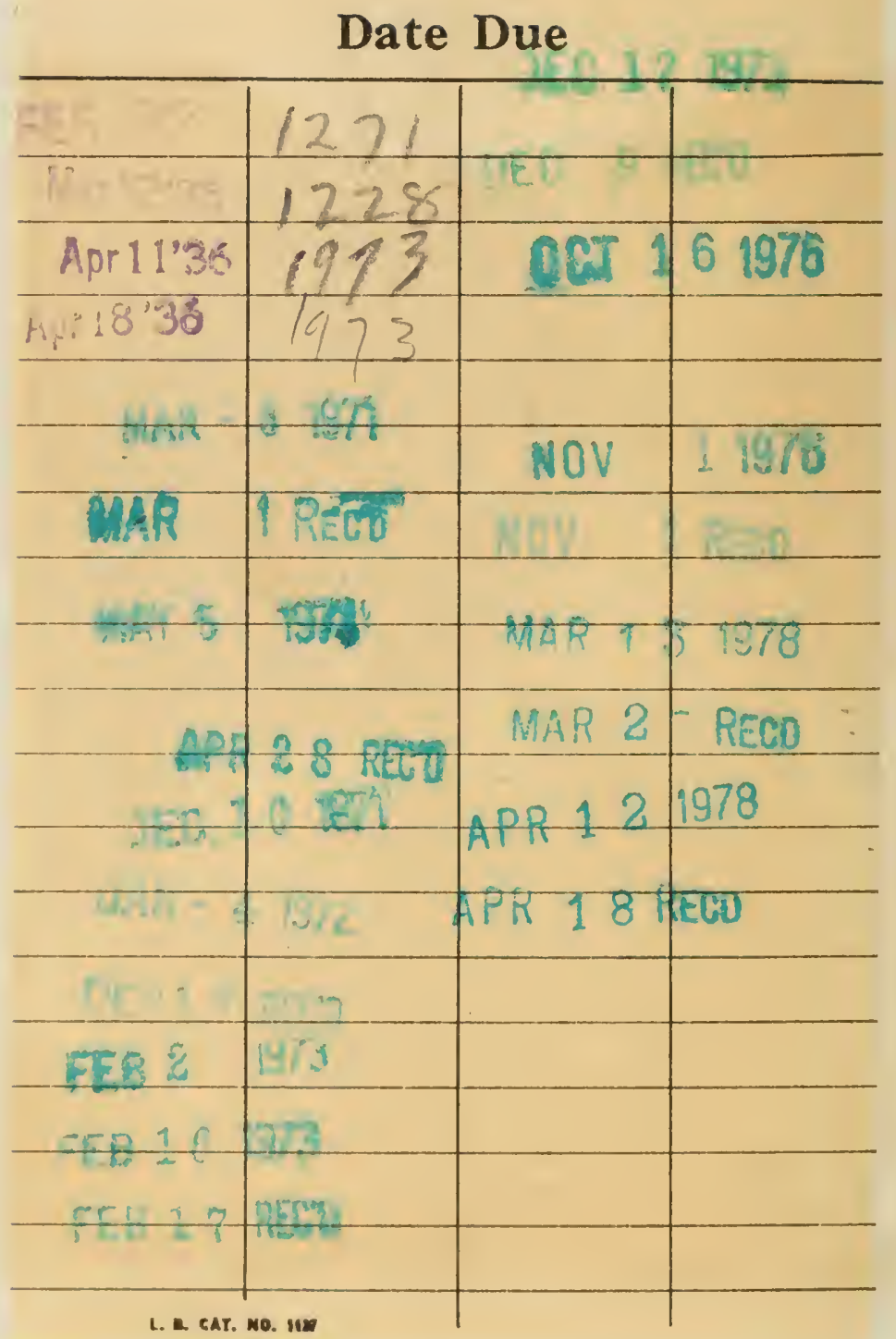


AGRICLITURE

FORECTRY

LIB?ARY , ?

I

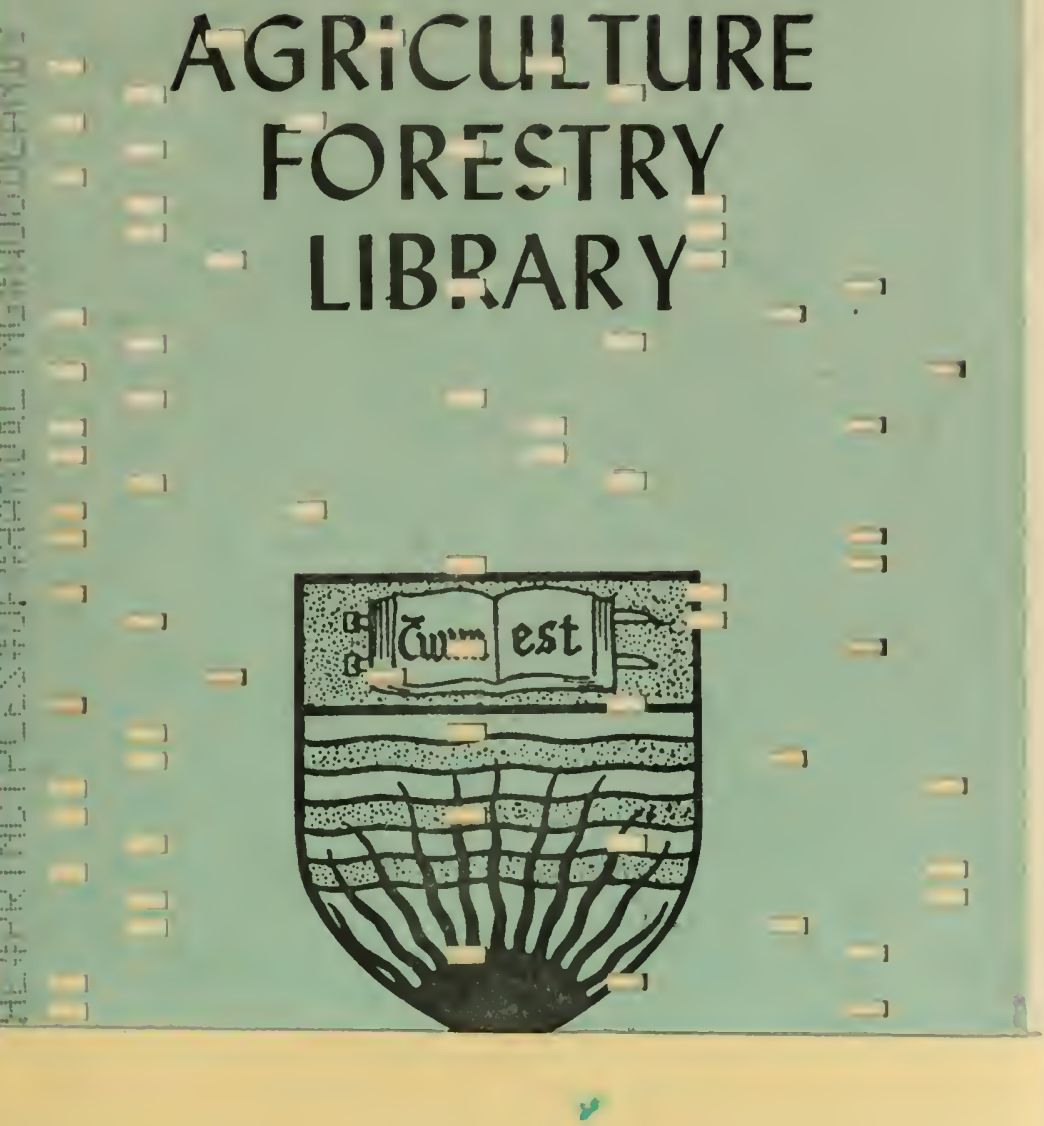


